\title{
Micro-environmental and macro-environmental improvement of joint quality in knee joint pathologies
}

Citation for published version (APA):

Timur, U. (2022). Micro-environmental and macro-environmental improvement of joint quality in knee joint pathologies. [Doctoral Thesis, Maastricht University]. Maastricht University.

https://doi.org/10.26481/dis.20220318ut

Document status and date:

Published: 01/01/2022

DOI:

10.26481/dis.20220318ut

Document Version:

Publisher's PDF, also known as Version of record

\section{Please check the document version of this publication:}

- A submitted manuscript is the version of the article upon submission and before peer-review. There can be important differences between the submitted version and the official published version of record.

People interested in the research are advised to contact the author for the final version of the publication, or visit the DOI to the publisher's website.

- The final author version and the galley proof are versions of the publication after peer review.

- The final published version features the final layout of the paper including the volume, issue and page numbers.

Link to publication

\footnotetext{
General rights rights.

- You may freely distribute the URL identifying the publication in the public portal. please follow below link for the End User Agreement:

www.umlib.nl/taverne-license

Take down policy

If you believe that this document breaches copyright please contact us at:

repository@maastrichtuniversity.nl

providing details and we will investigate your claim.
}

Copyright and moral rights for the publications made accessible in the public portal are retained by the authors and/or other copyright owners and it is a condition of accessing publications that users recognise and abide by the legal requirements associated with these

- Users may download and print one copy of any publication from the public portal for the purpose of private study or research.

- You may not further distribute the material or use it for any profit-making activity or commercial gain

If the publication is distributed under the terms of Article $25 \mathrm{fa}$ of the Dutch Copyright Act, indicated by the "Taverne" license above, 


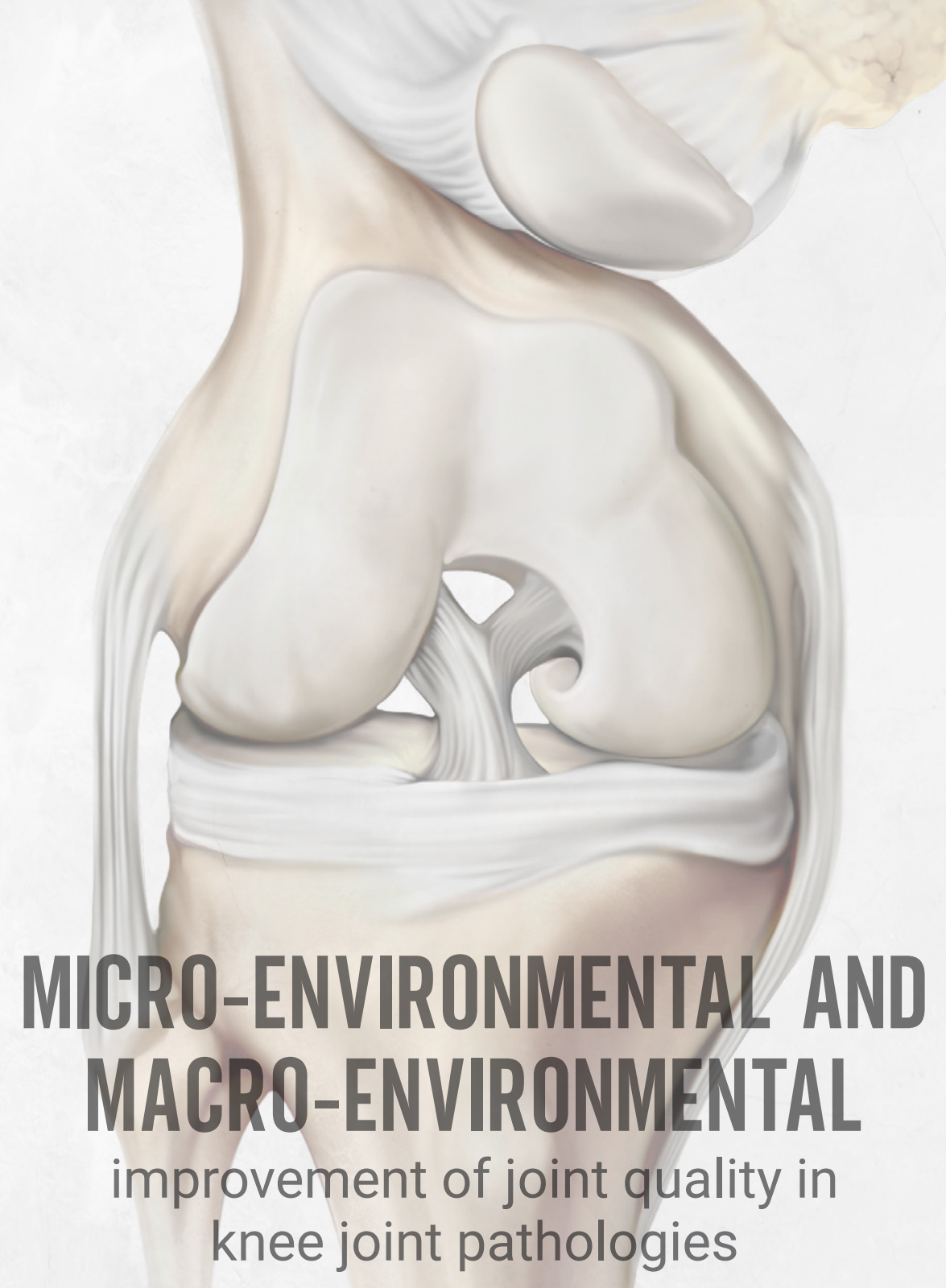

UFUK TAN TIMUR 
Micro-Environmental and Macro-Environmental Improvement of Joint Quality

in Knee Joint Pathologies

Ufuk Tan Timur 
Author: Ufuk Tan Timur

ISBN: 978-94-6421-640-0

Layout: Bobby Li

Printed by: Proefschriften.nl, Ede

Financial support for the publication of this thesis was provided by:

Maastricht University (UM, Caphri)

Maastricht University Medical Center (MUMC+)

Nederlandse Orthopaedische Vereniging (NOV)

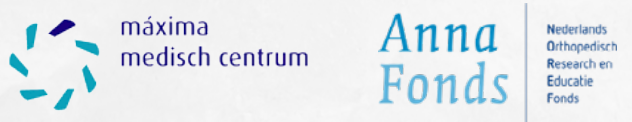

\section{Copyright $\odot$ U.T Timur, Maastricht 2022}

For all articles published, the copyright has been transferred to the respective publisher. No part of this thesis may be reproduced in any form or by any means without written permission from the author or, when appropriate, from the publisher.

Digital edition of this thesis can be downloaded using the QR code below:

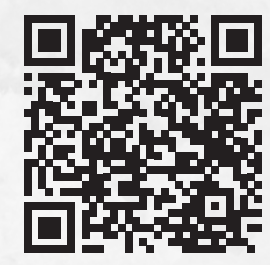




\title{
Micro-Environmental and Macro-Environmental Improvement of Joint Quality in Knee Joint Pathologies
}

\section{PROEFSCHRIFT}

\author{
Ter verkrijging van de graad van doctor aan de \\ Universiteit Maastricht, op gezag van de Rector \\ Magnificus, Prof. dr. Pamela Habibović volgens het \\ besluit van het College van Decanen, in het openbaar te \\ verdedigen op vrijdag 18 maart 2022 om 10.00 uur
}

door

\section{Ufuk Tan Timur}




\section{Promotoren:}

Prof. dr. L.W. van Rhijn

Prof. dr. T.J.M. Welting

\section{Copromotoren:}

Dr. P.J. Emans

Dr. H. Jahr (Uniklinik RWTH Aachen)

\section{Beoordelingscommissie:}

Prof. dr. M. van Griensven (Voorzitter)

Prof. dr. S.K. Bulstra (University of Groningen)

Prof. dr. H.B.J. Karperien (University of Twente)

Prof. dr. L.J.C. van Loon

Prof. dr. M. Poeze 
For my family, voor mijn familie, ailem için

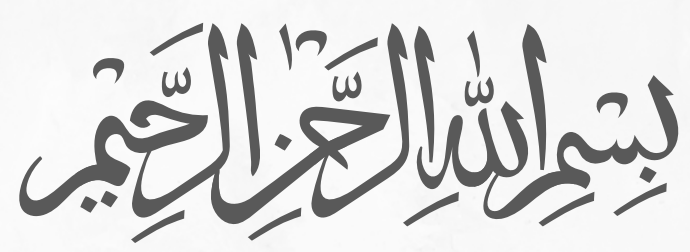

Bismillahirrahmanirrahim

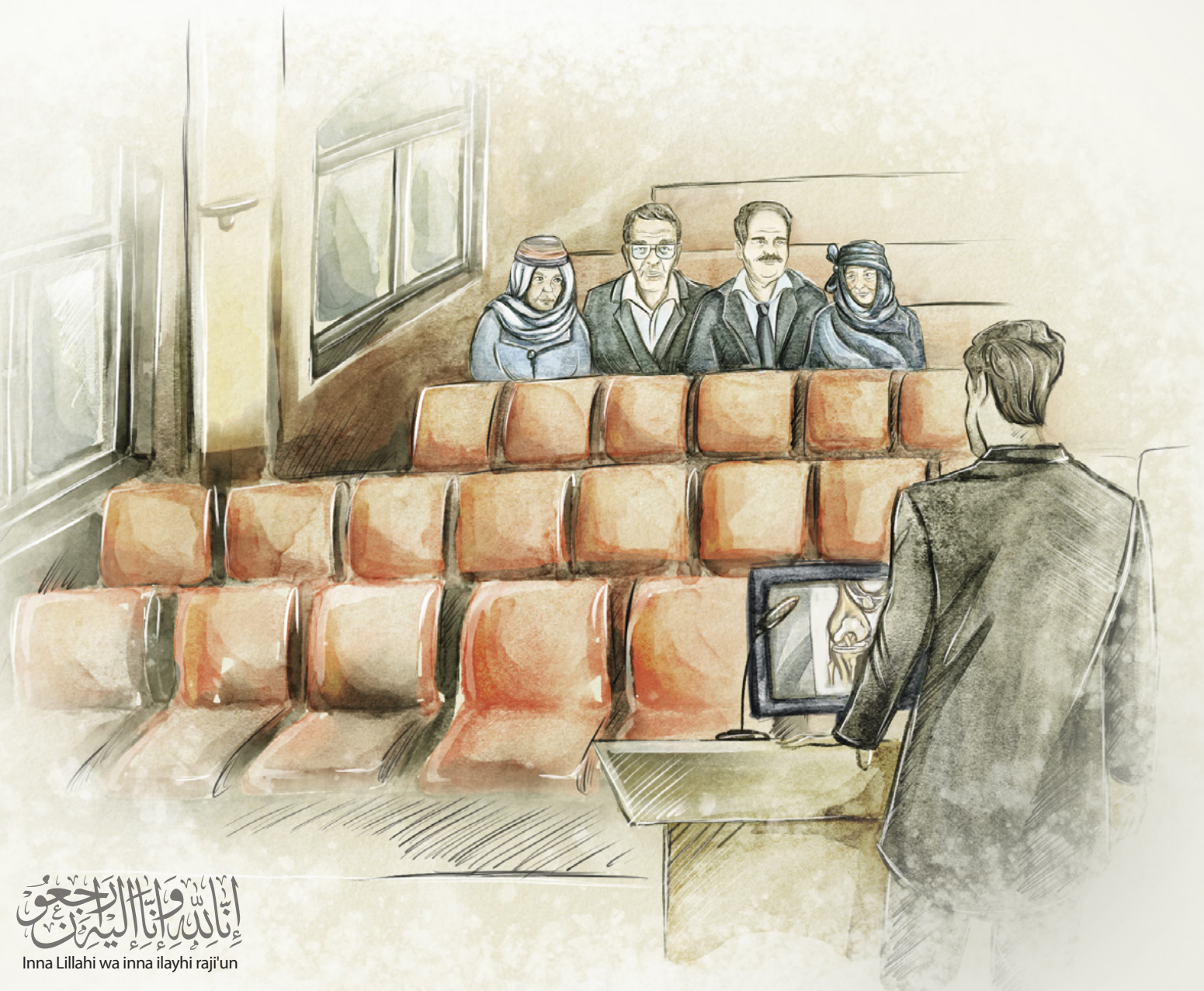




\section{Voorwoord}

Het was donderdag 7 november 2002. Ik herinner me het moment dat mijn leraar Latijn onderwijs gaf over de overtreffende trap, ofwel de comparativus in Latijn. Hij legde uit dat de comparativus wordt gevormd door achter de stam van het woord -ior te plaatsen. Een doctorandus was letterlijk vertaald 'hij die geleerder moet worden', en doctor was 'geleerder'. Je kon pas doctor worden als je een boek zou schrijven. Ik dacht bij mezelf, alsof al die proefwerken en verplichtingen al niet genoeg zijn, ook nog een boek schrijven? Ik keek zuchtend uit het raam, dwaalde af met mijn gedachten en ging aan leuke dingen denken, zoals de 6-0 overwinning van mijn jeugdliefde Fenerbahce op Galatasaray van gisterenavond. Wie had ooit gedacht dat ik precies 20 jaar later als zoon van gastarbeiders, opgegroeid in een flat in de Noordstraat, beter bekend als 'klein Turkije', daadwerkelijk dat boek zou schrijven? Lieve familie, vrienden en collega's, voor u ligt het boek wat ik heb geschreven en waar ik veel energie en tijd in heb gestoken. Het was een lange rit, met vallen en opstaan. Het laboratorium is een plek waar veel geduld voor nodig is. De resultaten beschreven in dit boek zijn misschien $10 \%$ van experimenten die succesvol zijn geweest, maar er zijn ook grotendeels experimenten die helaas minder succesvol zijn geweest. Experimenten waarvoor ik soms in de avonduren of in de nacht in het laboratorium heb moeten werken, experimenten waarvoor ik in de sneeuw op een trein met vertraging heb moeten wachten, experimenten waarvoor ik lange ritten heb moeten afleggen van Rotterdam naar Maastricht en Aachen.

'Het schrijven van dit boek heeft me geleerd dat wetenschap topsport is, geef nooit op en de overwinning is van degene die erin gelooft!

PS: Niet stiekem nu al naar mijn dankwoord bladeren hè! 


\section{Preface}

It was Thursday, November 7, 2002. I remember the moment my Latin teacher was teaching about the superlative, or comparativus in Latin. He explained that the comparative is formed by placing an -ior after the stem of the word. A doctorandus was literally translated 'he who must become a learned', and doctor was 'more learned'. You couldn't become a doctor until you wrote a book. I thought to myself, as if all those tests and obligations weren't enough, write a book too? I looked out the window with a sigh, lost my mind and started thinking about fun things, such as my childhood sweetheart Fenerbahce's 6-0 victory over Galatasaray of last night. Who would have ever thought that exactly 20 years later, me as the son of guest workers, raised in a flat in the Noordstraat, better known as 'small Turkey', would actually write that book? Dear family, friends and colleagues, this is the book that I have written and in which I have invested a lot of energy and time. It was a long ride, with trial and error. The laboratory is a place that requires a lot of patience. The results described in this book may be $10 \%$ of experiments that have been successful, but there have been a lot of experiments that have unfortunately been less successful. Experiments for which I sometimes had to work in the laboratory in the evenings or at night, experiments for which I had to wait in the snow for a train that was delayed, experiments for which I had to make long journeys from Rotterdam to Maastricht and Aachen.

'Writing this book has taught me that science is professional sport, never give up and the victory belongs to the one who believes in it!'

PS: Don't sneakily scroll to my acknowledgements! 


\section{Önsöz}

Bir perşembe günüydü, tarihlerden 7 Kasım 2002. Latince öğretmenimin Latince'de en üstün veya karşılaştırmalı sözcükleri öğrettiği anı hatırlıyorum. Latince'de karşılaşsırmanın -ior kelimesinin kökünden sonra yerleştirilerek oluşturulduğunu öğretti. Bir 'doktorandus', kelimenin tam anlamıyla 'bilgili olması gereken kişi' olarak tercüme edilir ve doktor 'daha bilgili' idi. Bir kitap yazana kadar doktor olamassınız. Bunca imtihan ve yükümlülükler yetmezmiş gibi birde kitap mi yazacağım diye düşündüm. Pencereden derin bir iç çekerek dışarı baktım, aklımı kaybettim ve çocukluk aşkım Fenerbahçe'nin dün gece Galatasaray'ı 6-0 yendiği gibi eğlenceli şeyler düşünmeye başladım. Tam 20 yıl sonra, Noordstraat'ta, daha çok 'küçük Türkiye' olarak bilinen bir apartman dairesinde büyümüş bir misafir işçinin oğlu olarak, o kitabı gerçekten yazacağım kimin aklına gelirdi?

Sevgili ailem, arkadaşlarım ve meslektaşlarım, yazdığım ve çok fazla enerji ve zaman harcadığım kitap önünüzde duruyor. Düşe kalka geçirdiğim uzun biryolculuktu. Laboratuvar çok sabır gerektiren bir yerdir. Bu kitapta açıklanan sonuçlar, başarılı olan deneylerin \%10'u olabilir, ancak ne yazık ki kariyerimde daha az başarılı olan deneyler çoğunluktadır. Bazen akşamları veya geceleri laboratuvarda çalışmak zorunda kaldığım deneyler, gecikmeli bir tren için karda beklemek zorunda kaldığım deneyler, Rotterdam'dan Maastricht ve Aachen'e uzun yolculuklar yapmak zorunda kaldığım deneyler.

'Bu kitabı yazmak bana bilimin profesyonel bir spor olduğunu öğretti, asla pes etme ve zafer inananlarındı!!

PS: Lütfen kitabi bastan okuyunuz ve simdiden gizlice teşekkür sözü bölümüne geçmeyiniz! 


\section{Table of Contents}

01 General Introduction and Aims of this Thesis

02 TGF- $\beta 2$ is Involved in the Preservation of the Chondrocyte Phenotype Under Hypoxic Conditions

Increased TGF- $\beta$ and BMP Levels and Improved

03 Chondrocyte-Specific Marker Expression In Vitro under

Cartilage-Specific Physiological Osmolarity

Celecoxib-Mediated Reduction of Prostanoid Release in

04 Hoffa's Fat Pad from Donors with Cartilage Pathology

Results in an Attenuated Inflammatory Phenotype

Chondroprotective Actions of Selective COX-2 Inhibitors In Vivo: A Systematic Review

Celecoxib-Loaded PEA Microspheres as an Auto Regulatory

Drug-Delivery System After Intra-Articular Injection

Identification of Tissue Type-Dependent Proteins in Knee

OA Synovial Fluid 
General Discussion, Conclusion and Clinical Perspectives for the Future

O9 Impact Paragraph

English Summary

Nederlandse Samenvatting

Türkçe Özet

List of Publications and Presentations

Dankwoord

About the Author 


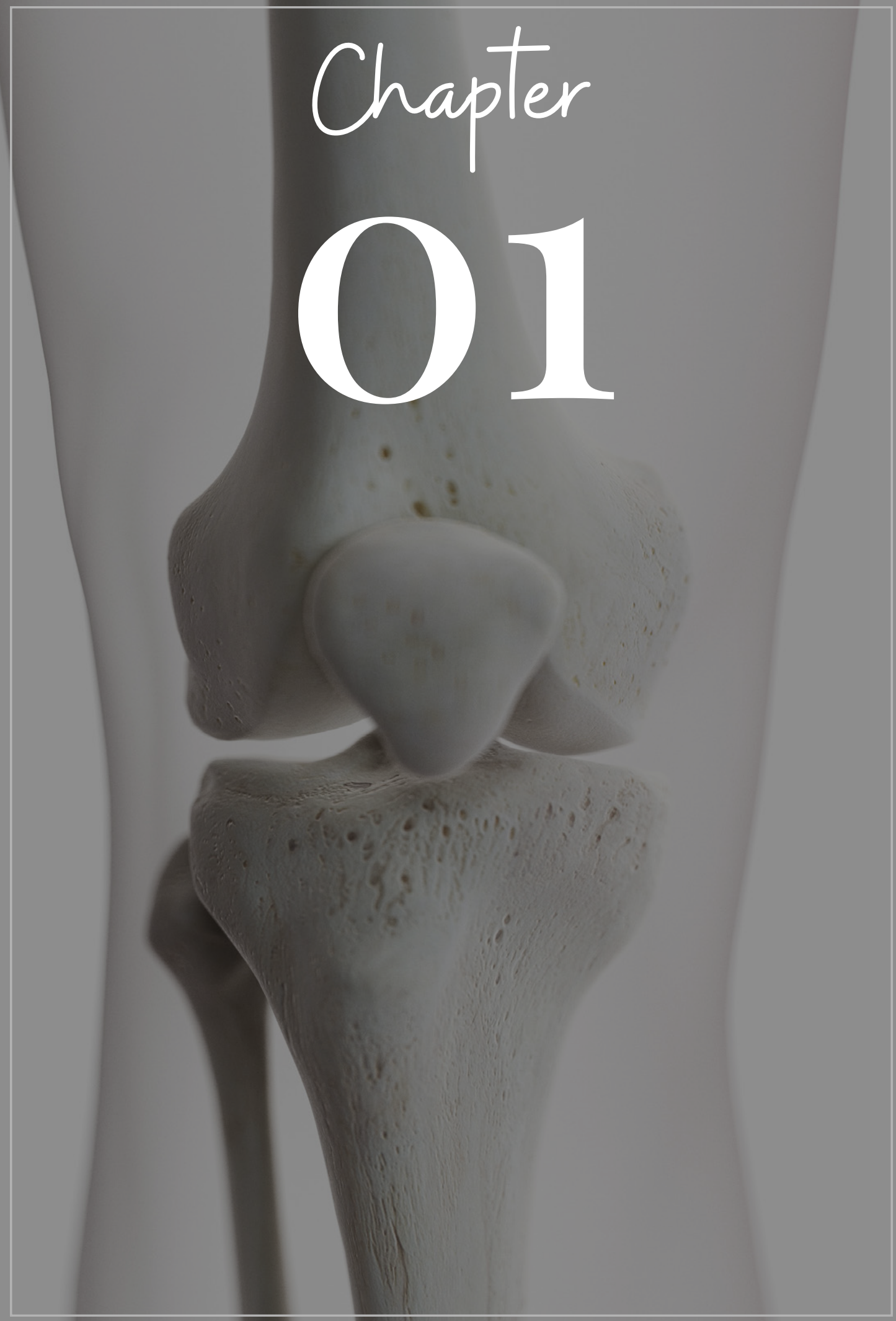


General Introduction and Aims of This Thesis 


\section{The Wisdom of the Knee Joint}

Humans are homeotherms which are capable of withstanding extreme temperatures'. Expose a healthy human being to high temperatures, his body temperature will not rise above normal. Expose an arctic mammal to cold as low as 25 degrees Centigrade below freezing, its body temperature will hardly show a noteworthy fall'. In 1929, it was Walter Bradford Cannon, coining in the concept of homeostasis²:

'The coordinated physiological processes which maintain most of the steady states in the organism are so complex and so peculiar to living beings - involving, as they may, the brain and nerves, the heart, lungs, kidneys and spleen, all working cooperatively - that I have suggested a special designation for these states, homeostasis. The word does not imply something set and immobile, a stagnation. It means a condition - a condition which may vary, but which is relatively constant'2.

The concept of homeostasis owes much to the endeavors made by ancient physicians such as Claudius Galenus from Bergama, Hippocrates, Paul of Aegina and Avicenna ${ }^{3}$. Claudius Galenus already described that health is a state which helps to maintain the functions of the human body through proper balance of its temperament and composition in a correct manner, while disease is contrary to the aforementioned state ${ }^{3}$. This concept has, amongst others, also been acknowledged by Ibn Sina (Avicenna), which was one of the pioneers of modern medicine ${ }^{4}$. The concept of homeostasis also holds true for the knee joint in the human body. The knee joint consists of two articulations formed by three bones: the tibia, femur and patella ${ }^{5}$. One articulation is present between the femur and patella (i.e. patellofemoral joint) and one between the femur and the tibia (i.e tibiofemoral joint). The knee joint is a synovial joint containing articular elements, enclosed in an articular capsule. These intra-articular elements are in close contact with each other and maintain 'joint homeostasis'. 


\section{Joint Homeostasis in the Healthy Knee Joint}

The specific anatomy of a human knee joint makes movement possible even under the most challenging circumstances such as marathon walking or heavy weight lifting. The knee joint comprises a closed cavity and different intra-articular structures can be identified. These different intra-articular tissues critically interact with each other to maintain 'joint homeostasis'. The articulating ends of each bone are covered by a thin layer of connective tissue, which is called articular cartilage. The principal function of articular cartilage is to provide a smooth, lubricated surface for the physical articulation and to facilitate the transmission of loads between bony skeletal elements with a low frictional coefficient. Articular cartilage is a hyaline cartilaginous connective tissue and is composed of water (65-80\%), collagens (12-21\%), proteoglycans (6-10\%) and other glycoproteins (2-3.5\%) The extracellular matrix (ECM) of hyaline articular cartilage is produced by the main cell type found in cartilage: the articular chondrocyte ${ }^{6}$. In healthy cartilage, a balance exists in anabolism and catabolism resulting in articular cartilage homeostasis ${ }^{7}$.

The intriguing characteristics of cartilage have already been recognized by Ogston and colleagues ${ }^{8}$ and date back to the $19^{\text {th }}$ century, underscoring the fact that it was hard to understand that cartilage is not worn away despite high forces the tissue has to resist, while on the other hand the enamel of teeth shows effects of friction in a short period of time. Reeves analyzed articular hyaline cartilage in 1876 and made horizontal thin sections of it, noting the appearance of straight bands running in various directions and planes ${ }^{9}$. Hence, reports in the $19^{\text {th }}$ century already described that based on chondrocyte shape, chondrocyte distribution, and collagen fiber orientation, different zones can be distinguished in articular cartilage.

Articular cartilage can be divided in the superficial zone, the transitional zone, the deep zone and the calcified zone. The calcified zone is separated from the deep zone by the 'tidemark'10. While chondrocytes in the superficial layer of articular cartilage have a flattened fibroblast-like morphology, chondrocytes become larger in size with a hypertrophic appearance towards the deeper layers of articular cartilage ${ }^{10}$. The superficial 


\section{Chapter 1}

zone comprises 10 to $20 \%$ of articular cartilage thickness and protects deeper layers from shear stresses ${ }^{10}$. Here, chondrocytes are flattened and collagen fibers are oriented parallel to the articular surface contributing to resistance to shear forces and to distribute load towards the subchondral bone ${ }^{10}$ (Figure 1). The transitional zone is the next layer, representing 40-60\% of articular cartilage thickness ${ }^{6}$. It contains proteoglycans and randomly organized thick collagen fibrils and has been thought to be the first zone to resist compressive forces imposed by articulation ${ }^{10}$. Closer to the bone than the transition zone is the deep zone, which contains the highest proteoglycan content and the lowest water concentration representing approximately $30 \%$ of the articular cartilage thickness. In this zone, chondrocytes are organized in column-like structures (Figure 1), while the collagen fibers are oriented perpendicular to the joint surface providing the greatest resistance to compressive forces ${ }^{10}$. The deep zone is separated from the next layer, the calcified cartilage zone, by the tidemark. This zone is scarcely populated by chondrocytes and chondrocytes present with a hypertrophic phenotype (Figure 1). The calcified cartilage plays an essential role in securing the layer of articular cartilage to the underlying subchondral bone by anchoring the collagen fibrils to the underlying subchondral bone tissue ${ }^{6}$.

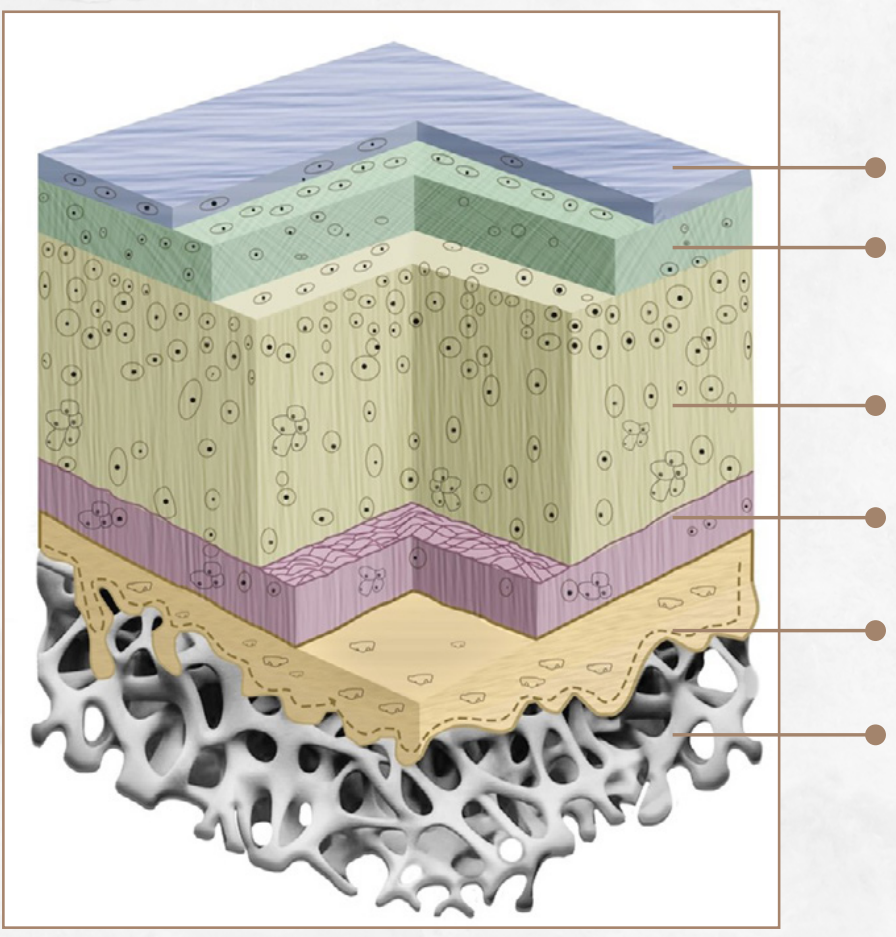

Superficial Zone

Transitional Zone

Deep Zone

Tidemark/Calcified

Cartilage

Subchondral Bone

Trabecular Bone 
Figure 1: Layers of Articular Cartilage.

Articular cartilage can be divided in to the superficial zone, transitional zone, the deep zone and the calcified cartilage, which is separated from the deep zone by the tidemark. While chondrocytes are flattened and parallel to the joint surface in the superficial zone, collagen fibers become tangential to the joint surface in deeper layers of cartilage providing resistance to compressive forces.

\section{Articular Cartilage: A Tissue with Unique Traits}

Functional adaptation is a concept that can be described as the ability of tissues to adjust structure in accordance with specific environmental requirements ${ }^{11}$. This concept has been established to occur in bone (Wolff's law) ${ }^{12}$. Given the unique architecture of cartilage and its intriguing ability to withstand compressive forces, this concept of 'functional adaptation' also may hold true for cartilage. Environmental factors such as mechanics aid in the specific structural architecture of cartilage. Indeed, several studies show that chondrocytes are responsive to mechanical stimuli ${ }^{13,14}$. Furthermore, the thickness of articular cartilage can change in response to mechanical stimuli, as evidenced by a study which showed reduced cartilage thickness in patients with reduced load bearing due to paraplegia ${ }^{15}$ or in a study showing reduced cartilage thickness in patients with reduced load bearing due to an ankle fracture ${ }^{16}$.

Articular chondrocytes are distinctively adapted to respond to biomechanical stress ${ }^{17}$. Compared to other cell types, articular chondrocytes have less negative resting membrane potential, which permits the chondrocyte to efflux positively charged potassium ions rapidly enough to limit cell-volume increase under conditions of reduced osmolarity ${ }^{17}$. This improved control of cell volume is crucial for the maintenance of optimal chondrocyte metabolism and matrix biosynthesis ${ }^{18}$.

Another unique feature for articular cartilage is that loading is needed for articular cartilage homeostasis. During loading, the displacement of water in and out of the articular cartilage increases the rate at which chondrocytes receive nutrients ${ }^{19}$. Moreover movement also assists in cartilage nutrition by increasing production of synovial fluid and aiding in the removal of waste products through the synovial membrane ${ }^{19}$. Furthermore, biomechanical 
stresses have been shown to activate latent TGF- $\beta$, a morphogen residing in the ECM of articular cartilage which plays a crucial role in articular cartilage homeostasis ${ }^{20}$. Importantly, it was shown that biomechanical forces can lead to activation of SMAD2/3 signaling, which is known to be protective for articular cartilage, again demonstrating the importance of movement for articular cartilage homeostasis ${ }^{21}$.

\section{Biophysiological Environment of Articular Cartilage}

Articular cartilage remains functional through life if not affected by pathology ${ }^{10}$. It differs from other cartilaginous tissues such as the growth plate or fracture callus, which undergo a process defined as endochondral ossification ${ }^{22,23}$. This process guides longitudinal skeletal growth and fracture repair and is characterized by chondrocytes that proliferate, become hypertrophic and that eventually are being replaced by bony tissue through the actions of invading osteoclasts and osteoblasts ${ }^{22,24,25}$. The differential behavior of chondrocytes in articular cartilage and chondrocytes in a growth plate or fracture callus may be related to their physiological environment ${ }^{25}$. Two biophysiological conditions are characteristic for articular cartilage: its lower oxygen tension levels and higher osmolarity in comparison to many other tissues. These biophysiological conditions are known to be active regulators of the chondrocyte and have been described to prevent the chondrocyte to undergo hypertrophic differentiation $26,27,28$.

Cartilage is not vascularized, and therefore oxygen supply occurs through diffusion from the synovial fluid, but also from the subchondral bone ${ }^{29,30}$. This causes relatively lower oxygen tension in cartilage in comparison to other tissue types ${ }^{31}$. It has been suggested that oxygen tension in cartilage ranges from $1 \%$ to $10 \%$ and oxygen tension decreases from the surface towards deeper regions of the cartilage $29,31,32,33,34,35$. Chondrocytes are well-adapted to this hypoxic environment and primarily employ anaerobic metabolism to generate ATP $^{36}$.

Next to the hypoxic environment in articular cartilage, another characteristic present in articular cartilage is the higher osmolarity in comparison to other tissues. Osmolarity in the 
interstitial fluid of cartilage ranges between 380 and $450 \mathrm{mOsm}$ in healthy cartilage (i.e. physiological osmolarity) $18,37,38,39,40,41,42$. The structure and composition of the ECM causes a high osmotic value in the interstitial fluid, which gives articular cartilage its unique essential biomechanical properties, able to withstand compressive forces which occur in the knee joint. The ECM of articular cartilage is mainly composed of proteoglycans (like aggrecan) entangled in a network of collagen fibers (mainly collagen type II) and large amounts of water ${ }^{43,44}$. Water and inorganic salts represent the bulk mass wet weight portion (65-80\%), with collagens representing the majority (i.e., 15-20\%) of the remaining fraction ${ }^{44}$. Cartilage requires a high osmotic value of the interstitial fluid to maintain its hydrostatic pressure and viscoelastic properties, for which negatively charged glycosaminoglycan side chains of the proteoglycans are crucial to attract mobile cations and water into the ECM environment resulting in a high osmotic value of the interstitial fluid. The intact collagen network, in contrast, restricts the inherent swelling force of the ECM and determines the relatively high osmolarity of this interstitial fluid ${ }^{18}$. Loading of the knee joint, for example during walking, causes water to squeeze out of the cartilage. In contrast to water, proteoglycans remain in the ECM, which causes water immediately to be osmotically attracted back into the ECM when compressive forces are reduced again. The perpetuation of hydrostatic pressure gives cartilage its unique ability to absorb forces up to $20 \mathrm{MPa}^{45}$.

\section{The Concept of Micro- and Macroenvironment}

Chondrocytes which reside in articular cartilage resemble a specific phenotype, responsible for the aforementioned unique properties of articular cartilage ${ }^{8}$. Unraveling the chondrocyte phenotype on a micro-environmental level will aid in understanding joint homeostasis. However, the chondrocyte is not the only cell type in the knee joint. The knee joint can be seen as an organ with a complex design, made up of smaller essential components, each exhibiting their own dynamic behavior. These smaller essential components combine into a large functioning unit, the knee joint macroenvironment, leading to the emergence of unique properties of the knee joint such as the ability to withstand biomechanical forces and support motion. The next paragraph will describe the smaller essential components which combine to form the knee joint macroenvironment. 


\section{Intra- and Extra-Articular Tissues in a Healthy Knee Joint}

The knee joint is surrounded by a joint capsule, which consists of an outer layer of fibrous connective tissue. This outer layer is lined on the inner side by the synovial membrane. The synovial membrane is composed of a thin layer of type A (macrophages) and type B (fibroblasts) synoviocytes ${ }^{46}$.The synoviocytes are important contributors to the biomolecular content found in synovial fluid, which contains compounds such as hyaluronic acid in order to lubricate the knee and to reduce wear and friction ${ }^{46}$. While cartilage is aneural and non-vascularized, the synovium is a highly vascularized, but also highly innervated tissue with sensory neurons ${ }^{47}$. Small molecules are able to diffuse through the synovium into the synovial fluid due to extensive vascularization of the synovium, providing cartilage with necessary nutrients, thereby maintaining joint homeostasis ${ }^{48}$.

Next to hyaline cartilage and synovial tissue, several other intra-articular tissues are present in the knee joint, each with their own function. Two menisci are situated between the femoral condyle and tibial plateau at both the medial and lateral aspects of the knee joint. These menisci withstand forces such as compression, shear and tension and play crucial roles in load transmission, shock absorption and load-bearing ${ }^{49}$. Another intra-articular tissue is Hoffa's fat pad (HFP). While four fat pads are present in the knee, the HFP is the largest in size ${ }^{50}$. Its position is posterior to the patellar tendon and inferior to the patella. The HFP is interposed between the capsular layer and the synovium and is thus located intra-articularly but extra-synovially, being in close proximity with the articular cartilage ${ }^{51}$. It is acknowledged that, besides acting as a reservoir for excess calories, adipose tissue can play a functional role in homeostatic processes. For instance, the omentum is well known as a visceral fat depot, but has also been described as 'the policeman of the abdomen' due to its ability to promote surgical wound healing and to attenuate peritoniti $5^{52}$. In fact, omental tissue has been described to possess angiogenic, fibrotic and immunologic activities which can promote vascularization, accelerate wound healing and limit infection ${ }^{53,54,55}$. Similarly, the HFP possesses angiogenic, fibrotic and immunologic activities which may play a role in maintaining knee joint homeostasis ${ }^{56,57,58}$. Besides its involvement in shock absorption in the anterior region of the knee $^{51}$, scientific evidence regarding its potential role in knee 
joint homeostasis is now accumulating ${ }^{51,56,57,58}$. Next to the aforementioned intra-articular tissues, also other intra- and extra-articular tissues such as the cruciate ligaments, collateral ligaments, other small fat pads, peri-articular muscles and subchondral bone all act in concert and combine into a large functioning joint unit.

\section{Articular Cartilage Defects}

One of the joint pathologies which can compromise joint homeostasis in a healthy knee joint are articular cartilage defects ${ }^{59}$. Articular cartilage can become damaged due to trauma, degeneration, osteonecrosis of subchondral bone, septic arthritis, aging and osteochondritis dissecans ${ }^{60}$. Damage to articular cartilage can be graded from mild to severe according to the ICRS cartilage grading system (Table 1$)^{61}$. 


\section{Chapter 1}

Table 1: The ICRS cartilage grading system for cartilage defects.

The International Cartilage Repair Society (ICRS) Cartilage Lesion Classification System. Published with permission from the ICRS Cartilage Injury Evaluation Package (http://www.cartilage.org/).

\section{GRADE 0}

Normal Cartilage

\section{GRADE 1}

Nearly Normal:

Soft indentation (A) and/or superficial fissures and cracks (B).

\section{GRADE 2}

Abnormal (lesions extending down to $<50 \%$ of cartilage depth) 


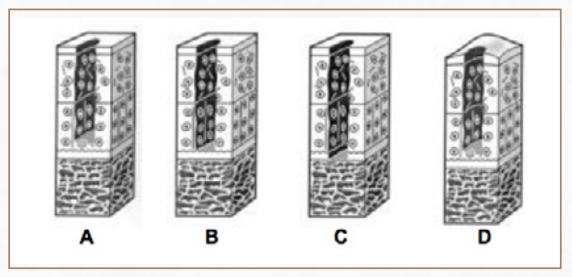

\section{GRADE 3}

Severely abnormal: cartilage defects $>50 \%$ of cartilage depth (A), as well as down to calcified layer (B) and down to but not through the subchondral bone (C). Blisters are included in this grade (D).

\section{GRADE 4}

Severely abnormal: Lesions through the subchondral bone

Cartilage is aneural and therefore superficial defects (ICRS grade $1+2$ ) do not result in pain ${ }^{62}$. However, defects that extend deeper in the cartilage may eventually become symptomatic ${ }^{59}$. Symptoms include pain, joint locking and functional impairment ${ }^{59}$. Cartilage has very limited self-repair capacity ${ }^{63}$ which was already well appreciated in 1743 by William Hunter who famously quoted:

'If we consult the standard chirurgical writers from Hippocrates down to the present age we shall find, that an ulcerated cartilage is universally allowed to be a very troublesome disease and that once destroyed it is never recovered".

Cartilage defects have been established to be an independent risk factor for osteoarthritis (OA) development ${ }^{64}$ and therefore it is essential to develop effective treatment strategies. Approaches in treatment of cartilage defects can be divided into several operative approaches (Table 2). A major disadvantage of microfracturing and subchondral drilling is that in the majority of cases fibrocartilage forms with inferior biomechanical properties 
compared to healthy hyaline cartilage ${ }^{65}$. Autologous chondrocyte implantation ${ }^{66}$ and Matrixinduced autologous chondrocyte implantation have superior clinical outcomes compared to microfracture ${ }^{67}$, but disadvantages of these techniques include the high economic burden, transplant failure and graft hypertrophy ${ }^{68}$. A limitation of the osteochondral autograft/allografting technique is that the size of the cartilage defect is a limit to use the technique and morbidity is induced to donor site when using autografts ${ }^{69}$. Non-biological resurfacing techniques rely on osseointegration rather than chondrogenesis and may be considered in the middle-aged patient ${ }^{70}$.

Table 2: Operative approaches in the treatment of cartilage defects.

\section{OPERATIVE APPROACHES}

\section{Regenerative Techniques}

Microfracture and subchondral drilling:

subchondral bone is penetrated with a drill to establish access of blood flow and influx of bone marrow stem cells into the defect which can initiate a repair response in the defect $^{71}$.

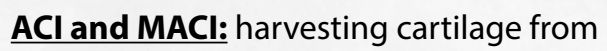
a non-weight bearing surface of the ipsilateral joint. Next, chondrocytes are isolated and expanded in a laboratory after which the expanded chondrocytes are placed either unseeded $(\mathrm{ACl})$ or pre-seeded into a matrix (MACl) into the defect during a second surgical procedure ${ }^{59}$.

\section{Resurfacing Techniques}

Osteochondral auto- and allografting ${ }^{60,72}$ :

harvesting osteochondral plugs from a nonweight bearing surface in the ipsilateral joint (autograft) or harvesting from another donor (allograft) and replacing it into the defect.

\section{Non-biological resurfacing techniques:}

focal knee resurfacing implants

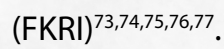

ACI: autologous chondrocyte implantation. MACI: matrix-induced autologous chondrocyte implantation 


\section{Homeostatic Failure of a Musculoskeletal Organ: Knee Osteoarthritis}

A disturbance in the balance between loading and load capacity may occur due to several reasons such as cartilage defects, an $\mathrm{ACL}$ rupture, varus or valgus leg malalignment, meniscus pathology, obesity, or an increasing age ${ }^{78}$. Various intra-articular joint preserving treatments such as cartilage repair surgery (Table 2), ACL reconstruction surgery or meniscal repair surgery may be performed to improve knee joint quality (Figure 2). Over time, these surgical strategies may fail or not suffice anymore leading to a disbalance in the knee joint between loading and load capacity. A disbalance between loading and load capacity will drive the knee joint into a catabolic condition leading to a compromised knee joint homeostasis with decreased knee joint quality ${ }^{79}$. When external and internal factors outpace physiological limits and the capacity for adaptive responses, 'joint homeostasis' is disturbed and knee osteoarthritis (OA) is prone to develop ${ }^{80,81}$. This development is a process of many years ${ }^{82}$. Early in the disease process (early-OA), extra-articular joint preserving treatments can be performed to delay progression of the disease (Figure 2). Examples of these treatments are an osteotomy, which is a surgical procedure realigning the knee joint thereby decreasing excessive forces on the medial or lateral side of the knee joint ${ }^{83}$. Another example is knee joint distraction, which is a technique that unloads the tibiofemoral joint using an external fixation frame ${ }^{84}$. Eventually, when joint preserving treatments fail and knee OA reaches an end-stage, total knee joint replacement surgery can be performed to relieve pain (Figure 2). 


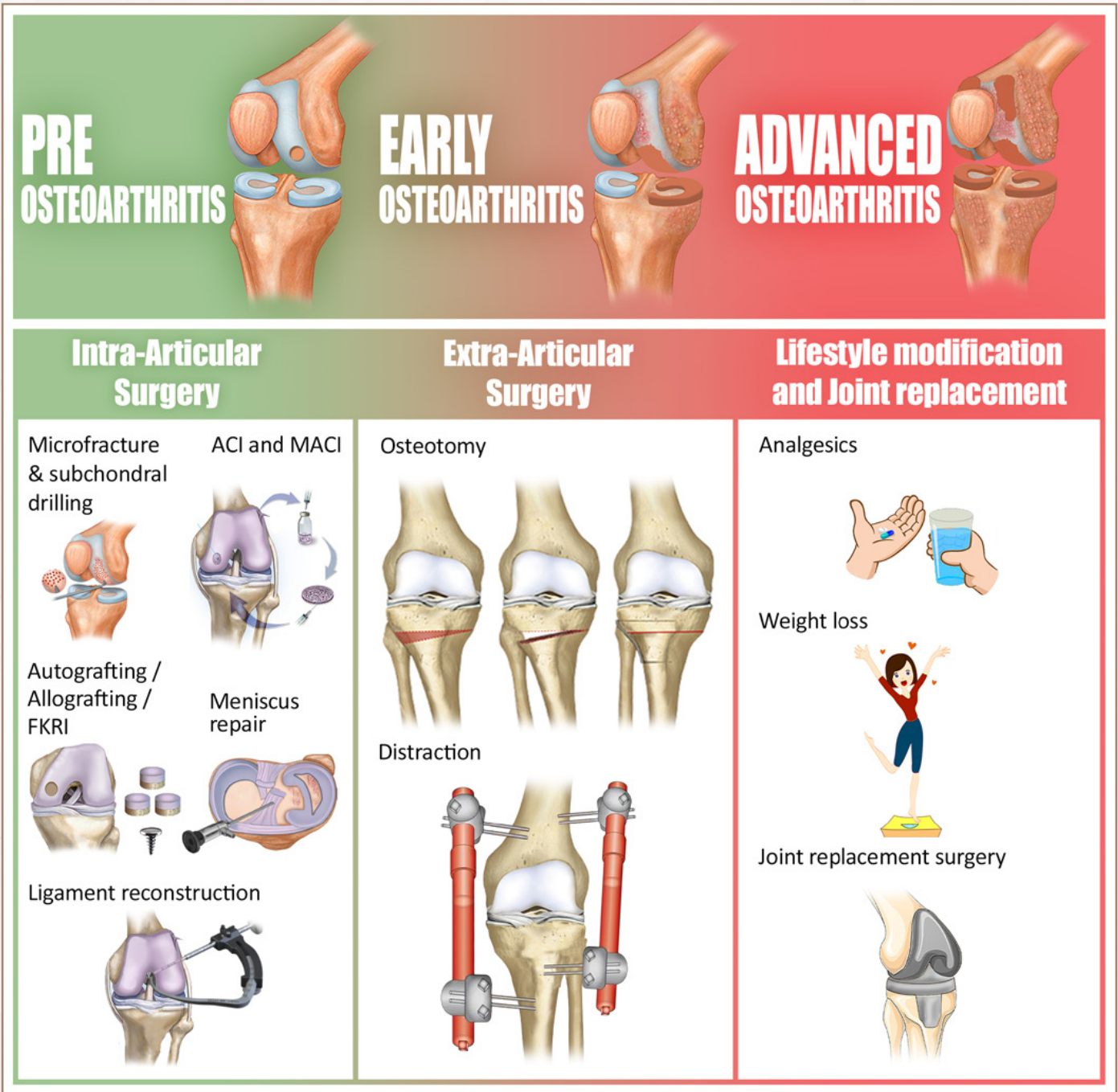

\section{Figure 2: Approaches in the treatment of decreased knee joint quality.}

Approaches in joint preserving treatment can be divided into different operative approaches. Joint trauma can lead to damage to intra-articular structures. When osteoarthritis is not present (pre$O A)$, this damage can be combatted by means of intra-articular surgery such as cartilage repair strategies, meniscus repair or ligament reconstruction surgery. Over time, these strategies may not suffice and osteoarthritis can develop. Early in the disease process (early-OA), extra-articular surgery such as a pressure relieving osteotomy or distraction surgery can be performed. These strategies may fail over time and osteoarthritis can proceed to a more advanced stage (advanced-OA). During this phase, conservative strategies such as weight loss and the use of analgesics can be used to combat pain. These strategies may also be used in earlier phases of the disease (pre-OA and early$O A)$. Eventually, when osteoarthritis progresses to an advanced stage, joint replacement surgery becomes inevitable. 
Knee $\mathrm{OA}$ is the most common joint disease of adults worldwide while the average age for developing knee OA is currently decreasing ${ }^{85,86}$. The most common symptoms are joint pain and joint stiffness. While the etiopathogenesis of knee OA remains obscure, it is now well appreciated that OA should not be considered as one disease, but rather as a final common pathway secondary to many predisposing factors. This 'final common pathway' is characterized by one of the most obvious features of OA: cartilage degeneration. Characteristic for the disease is the compromised balance in anabolic and catabolic activities in the cartilage tissue, with a shift towards catabolic activities, resulting in tissue degradation predominating over the capacity of tissue repair ${ }^{79}$. Clinically, joint cartilage degeneration is indirectly evaluated using the Kellgren \& Lawrence scoring system, which evaluates the presence of osteophytes and joint space narrowing (due to articular cartilage loss) on knee X-rays ${ }^{87}$. However, more sensitive imaging methods such as MRI are emerging ${ }^{88}$.

In the last decade, it became clear that, next to cartilage, other intra-articular tissues such as the subchondral bone, meniscus, synovium, Hoffa's fat pad and peri-articular muscles participate in the disease process leading to 'joint failure ${ }^{\prime 89}$. Thus, despite being considered as a cartilage problem, observations in these joint tissues are the impetus to consider OA as a total joint disease. Given the anatomical juxtaposition of intra-articular tissues such as articular cartilage, synovium, Hoffa's fat pad and meniscus, studying articular cartilage while taking the entire joint into account, is expected to aid in understanding cartilage pathology. Primarily focusing on the articular cartilage in joint pathologies would fail to notice the well-accepted phenomenon that living cells and tissues act in concert to maintain a constant milieu interne ${ }^{2}$. The following chapters will illustrate the pathological changes that occur in different intra-articular tissues in knee OA. 


\section{Pathological and Structural Changes in Osteoarthritic Cartilage}

While healthy articular cartilage has a smooth surface, in OA the articular cartilage tissue becomes disorganized. Typical features of osteoarthritic cartilage are surface fibrillation, fissures and erosion $\mathrm{s}^{90}$. In the healthy state, chondrocytes in normal adult cartilage display a quiescent phenotype with little turnover of their matrix ${ }^{91}$. When OA develops, chondrocytes turn from a quiescent state into an activated state ${ }^{92}$. Characteristic of this activation are chondrocyte proliferation, cluster formation and increased synthesis of matrix proteins but also matrix degrading enzymes ${ }^{90}$. It has been suggested that this activation may be regarded as an ectopic recapitulation of endochondral ossification, since the osteoarthritic chondrocyte displays features of hypertrophic chondrocytes also seen in the growth plate, and is typically characterized by collagen type $X$ expression ${ }^{25,93,94,95,96,97}$.

The activation of the chondrocyte and the consequent increase in synthesis of matrixdegrading enzymes results in a misbalance, shifted towards a catabolic phenotype. The osteoarthritic chondrocyte increases the synthesis of proteinases that are able to degrade the main cartilage ECM components, aggrecan and collagen. These proteinases include aggrecenases of the A Disintegrin and Metalloproteinase with Thrombospondin motifs (ADAMTS) family and metalloproteinases, but also other proteinases such as serine proteinases and cysteine proteinases ${ }^{98}$. Central roles have been attributed to metalloproteinase 13 (MMP-13) in degrading collagen type 2 and the aggrecanases ADAMTS4 and ADAMTS5 in degrading aggrecan ${ }^{98}$.

Next to the expression of matrix degrading proteinases, the osteoarthritic chondrocyte is characterized by activation of several pathways involved in metabolic and inflammatory processes, which can enhance catabolic events ${ }^{92}$. These include the mitogen-induced protein kinase pathways and canonical NF-KB (p65/p50) signaling pathway. Activation of these pathways can subsequently lead to expression of inflammatory molecules such as nitric oxide synthase (NOS) 2, cyclooxygenase (COX) 2 and interleukin-1 beta (IL-1 $\beta)^{92}$. Furthermore, breakdown products of cartilage matrix proteins (damage-associated 
molecular patterns (DAMPs) $)^{99}$ are generated in osteoarthritic cartilage ${ }^{100,101}$, which can subsequently stimulate the production of inflammatory cytokines and MMPs by articular chondrocytes resulting in a vicious circle loop ${ }^{100,102,103}$.

\section{Pathological and Structural Changes in Osteoarthritic Synovium}

Traditionally being classified as a non-inflammatory arthropathy, research in the last decades led to the currently held doctrine postulating that OA contains an inflammatory component ${ }^{104}$. A mild inflammatory infiltrate has been described in synovial samples of knee OA patients ${ }^{105}$. Typical histological observations related to the synovitis seen in knee OA include infiltration of lymphocytes and macrophages, villous hyperplasia and subintimal thickening ${ }^{106}$. Macrophage infiltration in the synovium is increased in early OA patients compared to more advanced disease ${ }^{107}$. It could be hypothesized that the inflammation in the synovium is a reaction to degraded cartilage debris, which leads to the production of inflammatory cytokines by the irritated synovial tissue, which will lead to more cartilage breakdown. On the other hand, the inflammation seen in the synovium might be the initiating etiological factor leading to cartilage breakdown. Several studies have been published supporting the role of an inflamed synovium in cartilage breakdown. Patients with progressive knee OA display higher CRP serum levels compared to patients without $\mathrm{OA}^{108}$ and semi-quantitative synovitis scoring on contrast-enhanced MRI was associated with OA disease severity as assessed by radiographs ${ }^{109}$. In addition, in a study with 422 knee OA patients enrolled, inflammatory changes observed by arthroscopy in perimeniscal synovium were associated with more severe worsening of medial chondropathy ${ }^{110}$. Further support comes from a study performed with patients without cartilage damage on MRI or without radiographic $\mathrm{OA}$ at baseline, in which a significant association was shown between baseline effusion synovitis and future cartilage damage ${ }^{111}$. Synovitis is not only found in late OA, but also in early OA patients. In 2002, Oehler et al. found synovial pathology in early OA patients, suggesting the synovium to be pathogenically involved in the OA disease process ${ }^{46}$. Pessler et al. showed increased infiltration of macrophages 
and T-cells in OA synovium compared to synovium of healthy subjects ${ }^{112}$ and Scanzello et al. reported increased levels of the inflammatory cytokine IL-15 in the synovial fluid of early OA patients ${ }^{113}$. Synovitis in OA has therapeutical implications from 2 points of view. As the synovium contains nerve fibers, the inflammation in the synovium itself can generate pain. Indeed, a correlation has been demonstrated between synovial inflammation and pain in knee $\mathrm{OA}^{114}$. On the other hand, synovial inflammation can lead to joint stiffness and more severe cartilage degeneration, which will cause denuded bony surfaces abutting each other causing pain. Next to associations found between synovitis and OA disease progression, several studies also reported correlations between synovitis and symptoms in knee OA patients ${ }^{115}$, indicating that treatments targeting the inflamed synovium in $\mathrm{OA}$ patients may have pain killing effects ${ }^{116}$.

\section{Pathological and Structural Changes in Hoffa's Fat Pad}

Adipose tissue has been described to possess more functions than solely acting to store energy from excess calories. Disturbances in the immunological functions of omental tissue may lead to an impairment in the defense against pathogens or mechanical damage ${ }^{117}$. Similarly, one can hypothesize that disturbances in intra-articular adipose tissues may lead to pathological joint diseases such as OA. The HFP is the largest sized adipose tissue in the knee joint and has long been believed to have a structural function without a metabolic role. Nevertheless, this fatty tissue could be an important participant in knee $\mathrm{OA}^{51}$. Besides adipocytes, this tissue also contains immune cells such as granulocytes, macrophages and lymphocytes ${ }^{50}$. The HFP contains a higher concentration of immune cells than subcutaneous adipose tissue, pointing to a possible inflammatory role of this tissue ${ }^{118}$.

Similar to synovium, inflammatory changes have been found in osteoarthritic HFP. Evidence is accumulating that inflammatory changes in the HFP itself may be involved in the OA disease process. For instance, superolateral edema in the HFP has been shown to be associated with future patellar cartilage loss ${ }^{119}$. Furthermore, Clockaerts et al. already showed that the HFP is capable of secreting large amounts of inflammatory cytokines such as IL-1 $\beta$ and Tumor Necrosis Factor- $\alpha$ (TNFa) ${ }^{120}$. These inflammatory cytokines are known 
to play key roles in degradation of the cartilage ECM. They are able to stimulate expression and release of proteinases such as collagenases and aggrecanases, which degrade collagen and aggrecan ${ }^{121}$. It was also shown that, when an inflammatory stimulus (IL-1 $1 \beta$ ) is applied to the HFP, it responds with an increased cytokine production ${ }^{120}$. It is likely that production and release of these inflammatory mediators by the HFP can lead to inflammatory and destructive responses in OA cartilage.

Signal intensity alterations in HFP have been detected on MRI, which may be related to inflammatory changes in the HFP tissue ${ }^{122}$. Given the presence of an extensive network of nerve fibers in the HFP ${ }^{123,124}$, the association of signal intensity alterations on MRI with clinical symptoms in patients with knee $O A^{125}$ is not surprising and points to another potential intra-articular source of pain in patients with knee OA.

In conclusion, next to cartilage and synovium, there is abundant evidence that the HFP is another intra-articular tissue that actively participates in the OA disease process and should be considered when developing treatment strategies to improve knee joint homeostasis and slow down knee OA progression.

\section{Pathological and Structural Changes in the Meniscus}

While it has been well established that damage to the meniscus increases the risk of developing knee $\mathrm{OA}^{126}$, it is now recognized that the meniscus itself shows pathologic changes which resemble the pathologic changes seen in osteoarthritic cartilage. Like in osteoarthritic cartilage, the meniscus displays changes such as matrix fibrillation, calcification, cell clusters and cell death ${ }^{127,128}$. In view of the essential biomechanical role of menisci in preserving adequate knee function, pathological changes in meniscus structure indeed may contribute to knee OA progression from a biomechanical point of view. In addition, it is also essential to realize that the meniscus has been shown to display molecular and cellular alterations, which could, via secreting catabolic mediators in the synovial fluid compromise knee joint homeostasis ${ }^{129}$. 


\section{Improving Knee Joint Macro-Environment: A Role for Targeting Inflammatory Pathways}

Reduction in load bearing capacity of the knee joint, due to cartilage damage, meniscal damage or any other factor, will lead to joint inflammation ${ }^{130}$ and drive the knee joint into a catabolic direction, making it prone for knee $\mathrm{OA}^{131}$. Knee $\mathrm{OA}$ is not yet a curable disease. With the aging of the world population, preventive measures and treatment strategies that can slow down the progression of knee OA are warranted. Since knee OA has an inflammatory component, targeting inflammatory stimuli that lead to catabolic responses in $\mathrm{OA}$ is a potential approach to provide effective treatments to slow down progression of the disease. It is now well established that some signaling pathways are specifically induced in an inflammatory environment. In this context, cyclooxygenase-2 (COX-2) has been demonstrated to be involved in inflammation ${ }^{132}$. Cyclooxygenases (COXs) are enzymes responsible for the oxidation of arachidonic acid (AA), a poly unsaturated omega- 6 fatty acid, which results in the conversion to prostaglandin $G_{2}\left(P G G_{2}\right)^{133}$. Next, the peroxidase activity of the COX enzyme drives the reduction of $\mathrm{PGG}_{2}$ to $\mathrm{PGH}_{2}$ (Figure 3). Specific synthases then convert $P G H_{2}$ to the main prostaglandin subgroups: $P G E_{2^{\prime}} P G D_{2^{\prime}} P G 2_{2^{\prime}}$ $\mathrm{PGF}_{2 a}$ and Thromboxane $\mathrm{A}_{2}\left(\mathrm{TXA}_{2}\right)^{134}$. These prostaglandins act as autocrine and paracrine lipid mediators to maintain local homeostasis in the body ${ }^{135,136}$. Three COX isoforms have been described: COX-1, COX-2 and COX-3 ${ }^{137,138}$. COX-1 is constitutively expressed by most mammalian cells and regarded as the 'housekeeping' cyclooxygenase, responsible for the production of basal prostaglandin levels which maintain local homeostasis. COX-3 is a splice variant of COX-1 and virtually nothing is known about its role in musculoskeletal tissues $^{138}$. COX-2 is considered a pro-inflammatory enzyme, a main target for the treatment of inflammatory diseases and it is encoded by the gene PTGS2 ${ }^{122,139}$. While the COX-1 gene contains cis-regulatory elements contributing to the constitutive expression of COX$1^{139}$, the promotor of the COX-2 gene contains several inducible enhancer elements ${ }^{132}$. COX-2 expression is upregulated in inflamed joint tissues ${ }^{140,141,142}$ and its expression is induced in cartilage, synovium and also in the HFP upon stimulation with inflammatory mediators ${ }^{143,144,145}$. The main reason for considering COX-2 as a pathological enzyme 
is that it can be induced by inflammation-associated factors pointing to a possible role in knee $\mathrm{OA}^{146}$.

\section{PHOSPHOLIPIDS}

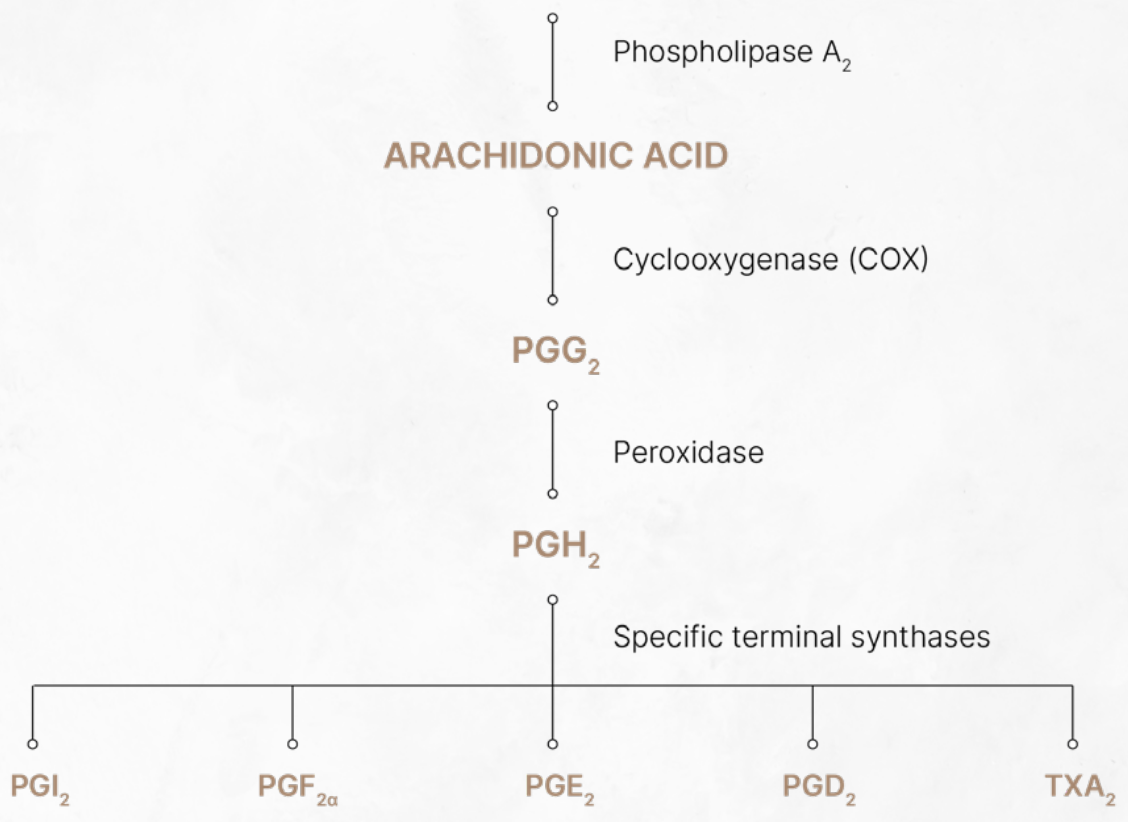

\section{PROSTAGLANDINS (PGs)}

Figure 3: Biosynthesis of Prostaglandins.

Membrane-bound phospholipids are converted into Arachidonic Acid (AA) by phospholipase $A_{2}$ $\left(P L A_{2}\right)$. COX first converts $A A$ to $P G G_{2}$ and then to $P G H_{2}$. Distinct terminal synthases convert $P G H_{2}$ to $T X A_{z^{\prime}} P G F_{2 \alpha^{\prime}} P G D_{z^{\prime}} P G E_{z^{\prime}}$ or prostacyclin $\left(P G I_{2}\right)$. 


\section{Chapter 1}

Given the inflammatory component in knee OA and considering the fact that COX-2 has been described as an inflammatory enzyme, it has been suggested that COX-2 inhibitors may be used as a therapeutic agent in OA. Traditionally, COX-inhibitors (belonging to a class of drugs called non-steroidal anti-inflammatory drugs (NSAID)) have been used to provide anti-analgesic effects. Inhibition of COX enzymes results in reduced production of prostaglandins, which besides having physiological functions, are important mediators of inflammation and pain ${ }^{147}$. However, side effects, such as gastrointestinal ulceration and bleeding, were accepted as inevitable consequences of the inhibition of the activity of not only the inflammatory COX-2 but also COX-1. Because COX-2 is clearly associated with inflammation, and COX-1 is considered to fulfill a physiological role, selective COX-2 inhibitors have been designed ${ }^{148}$. Celecoxib is a selective COX-2 inhibitor which is currently used as an analgesic by patients with inflammatory arthritic diseases such as rheumatoid arthritis and $\mathrm{OA}^{149}$.

Taken together, there is a growing body of evidence showing that once joint homeostasis is disturbed, joint pathologies such as OA can develop. OA should be considered as a total joint disease in which joint homeostasis is compromised and in which different intra-articular tissues are involved, which will lead to impaired knee joint quality. Since experimental evidence clearly shows the association between inflammation and cartilage degeneration, developing therapies for joint pathologies such as cartilage defects and OA should focus on inflammation in the joint as a whole. Insights into modulating inflammation in different intra-articular tissues will further contribute to developing new treatment strategies that can aid in cartilage repair strategies and slow down progression of knee OA. 


\section{Aims and Outline of This Thesis}

\section{To Investigate the Molecular Mechanisms Involved in the Micro-Environmental Improvement of the Chondrocyte Phenotype}

Cartilage defects are a major risk factor for knee $O A$ and in vitro expansion of human articular chondrocytes can be utilized for regenerative medicine purposes to restore cartilage tissue ${ }^{59}$. For tissue engineering purposes, it is of utmost importance that after in vitro expansion, the chondrocyte is reimplanted in the knee joint in a cellular phenotype that resembles the native chondrocyte as good as possible. In Chapter $\mathbf{2}$ and Chapter $\mathbf{3}$ we have evaluated methods to improve knee joint quality on the cellular level. In Chapter $\mathbf{2}$ we aimed to elucidate the molecular mechanisms involved in the improvement of the chondrocyte phenotype after in vitro expansion using an oxygen tension closely resembling the tension in cartilage in vivo environment, i.e. $1 \% \mathrm{pO}_{2}$. We have evaluated the effects of oxygen tension on TGF- $\beta$ signaling, which is known to play a key role in regulating the chondrocyte phenotype ${ }^{150}$. Next to oxygen tension, osmolarity is another factor that has been demonstrated to improve the chondrocyte phenotype in vitro ${ }^{151}$. In Chapter 3, we investigated the molecular mechanisms involved in the improvement of the chondrocyte phenotype after in vitro expansion under osmolarity closely resembling values found in the in vivo environment, i.e. $380 \mathrm{mOsm}$.

\section{To Investigate and to Modulate the Macro-Environment in the Knee Joint}

While the chondrocyte phenotype is important when cells are reimplanted into a knee joint, it is also essential to reimplant chondrocytes in a suitable 'macro-environment', because disturbance of this macro-environment has been shown to lead to cartilage degradation ${ }^{152}$. This disturbance of the joint macro-environment may be caused by a disturbed equilibrium in knee joint loading and knee joint load capacity due to for instance cartilage or meniscal pathology. Such a biomechanical mismatch can lead to inflammation in the entire knee joint ${ }^{130}$, eventually leading to a self-perpetuating inflammatory vicious circle resulting in 'total organ failure ${ }^{\prime 90}$. After our research in Chapter $\mathbf{2}$ and Chapter 3, which focused on 
methods to improve knee joint quality on the cellular level, we continued to investigate methods to improve knee joint quality on the tissue level. One of the intra-articular tissues which has been suggested to be a contributor to a self-perpetuating inflammatory vicious cycle participating in the knee OA process is the HFP50. In Chapter 4, we hypothesized that the HFP from OA patients releases higher amounts of prostanoids than the HFP from nonOA patients. Prostanoids are important factors involved in inflammation, and we evaluated whether we could modulate the prostanoid release profile by the OA HFP with the antiinflammatory COX-2 selective drug celecoxib.

We finally continued to investigate methods to improve knee joint quality on the total joint level. In Chapter 5, we have conducted a systematic review to investigate the ability of selective COX-2 inhibitors to act chondroprotective in vivo, depending on their route of administration. We reviewed whether compared to systemic oral administration, the intra-articular administration of selective COX-2 inhibitors is more potent in modulating knee joint pathological changes. To target the inflamed knee joint, thereby potentially improving knee joint macro-environment, a drug-delivery system (DDS) is an effective means to support an intra-articular therapy. In comparison to bolus drug injections, a DDS offers the advantage of minimizing systemic toxicity, avoiding the need for frequent intra-articular injections and allowing for prolonged drug residence time for long-term treatment in a chronic disease such as knee OA. We therefore investigated release behavior, biocompatibility and degradation of polyester amide (PEA) microspheres loaded with celecoxib in Chapter $\mathbf{6}$ in order to evaluate the potential of this DDS to be used for antiinflammatory treatment in knee OA.

Because the diagnosis of knee $O A$ is made when the disease has reached an end-stage stadium, early intervention in order to slow down knee OA disease progression is currently not possible. In a total joint disease such as knee $O A$, identification of intra-articular tissue type-dependent and OA-associated protein species in the synovial fluid is expected to fuel the development of synovial fluid-based diagnostic approaches. This would enable the grading and typing of knee OA on a molecular basis, and can potentially improve efficacy of treatment strategies. In Chapter 7, we therefore analyzed the protein secretome of different intra-articular tissues by means of mass-spectrometry analysis and subsequently 
evaluated whether tissue-dependent secreted proteins were OA-specific by comparing their abundance in OA versus non-OA synovial fluid.

Finally, Chapter 8 and Chapter 9 present the general discussion, the conclusion and the impact paragraph in which the results of this thesis are discussed and summarized and in which potential clinical applications are highlighted.

In Figure 4 a schematic overview can be found demonstrating the specific aims of this thesis per chapter.

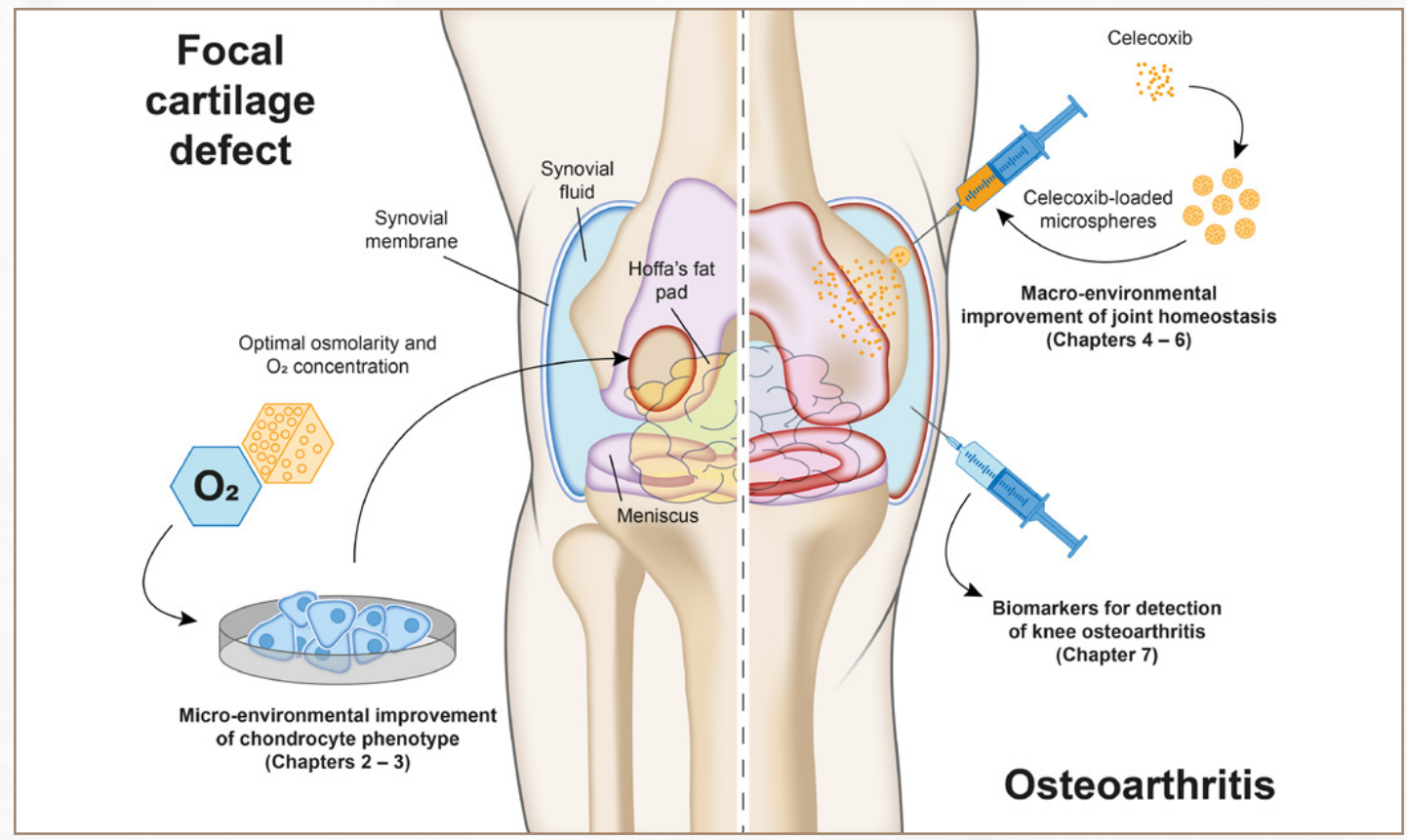

Figure 4: Schematic overview of the specific aims per chapter.

Chapter 2 and 3 focuses on improving knee joint homeostasis on the cellular level. Actions of microenvironmental influences such as hypoxia and hyperosmolarity on the chondrocyte phenotype were investigated. Chapter 4 focuses on improving knee joint homeostasis on the tissue level by treating HFP of OA and cartilage defect patients with celecoxib. Chapters 5 and 6 focused on improving knee joint homeostasis on a total joint level by means of intra-articular treatment with celecoxib. Finally, Chapter 7 investigated possible identification of intra-articular tissue type-dependent and OA-associated protein species in the synovial fluid. 


\section{References}

1 J.A. A. Homeostatic Processes for Thermoregulation. Nature Education Knowledge. 2011;3(10):7.

2 Cannon WB. The wisdom of the body. New York,: W.W. Norton \& Company; 1939. xviii, 19-333 p. p.

3 Anderson EM. The Prince of Medicine: Galen in the Roman Empire. Library Journal. 2013;138(11):98.

4 Sina I. Al-Qanun fi al-Tibb. 1025.

5 Gray H, Warwick R, Williams PL. Gray's anatomy. 35th ed. London: Longman; 1973. xvi, 1471 p. p.

6 Hunziker EB, Quinn TM, Hauselmann HJ. Quantitative structural organization of normal adult human articular cartilage. Osteoarthritis Cartilage. 2002;10(7):56472.

7 Hunter W. Of the structure and disease of articulating cartilages. 1743. Clin Orthop Relat Res. 1995(317):3-6.

8 Ogston A. On Articular Cartilage. J Anat Physiol. 1875;10(Pt 1):48 1-74.

9 Reeves HA. On the Structure of the Matrix of Human Articular Cartilage. Br Med J. 1876;2(828):616.
10 Buckwalter JA, Mankin HJ. Articular cartilage: tissue design and chondrocytematrix interactions. Instr Course Lect. 1998;47:477-86.

11 Frost HM. The regional acceleratory phenomenon: a review. Henry Ford Hosp Med J. 1983;31(1):3-9.

12 Wolff J. Das gesetz der transformation der knochen. A Hirshwald. 1892;1:1-152.

13 Kim YJ, Bonassar LJ, Grodzinsky AJ. The role of cartilage streaming potential, fluid flow and pressure in the stimulation of chondrocyte biosynthesis during dynamic compression. J Biomech. 1995;28(9):105566.

14 Waldman SD, Spiteri CG, Grynpas $M D$, Pilliar RM, Kandel RA. Long-term intermittent shear deformation improves the quality of cartilaginous tissue formed in vitro. J Orthop Res. 2003;21(4):590-6.

15 Vanwanseele B, Eckstein F, Knecht H, Spaepen A, Stussi E. Longitudinal analysis of cartilage atrophy in the knees of patients with spinal cord injury. Arthritis Rheum. 2003;48(12):3377-81.

16 Hinterwimmer S, Krammer M, Krotz M, Glaser C, Baumgart R, Reiser M, et al. Cartilage atrophy in the knees of patients 
after seven weeks of partial load bearing.

Arthritis Rheum. 2004;50(8):2516-20.

17 Lewis R, Asplin KE, Bruce G, Dart C, Mobasheri A, Barrett-Jolley R. The role of the membrane potential in chondrocyte volume regulation. J Cell Physiol. 2011;226(11):2979-86.

18 Urban JP, Hall AC, Gehl KA. Regulation of matrix synthesis rates by the ionic and osmotic environment of articular chondrocytes. J Cell Physiol. 1993;154(2):262-70.

19 O'Hara BP, Urban JP, Maroudas A. Influence of cyclic loading on the nutrition of articular cartilage. Ann Rheum Dis. 1990;49(7):536-9.

20 Morales TI, Joyce ME, Sobel ME, Danielpour D, Roberts AB. Transforming growth factor-beta in calf articular cartilage organ cultures: synthesis and distribution. Arch Biochem Biophys. 1991;288(2):397-405.

21 Madej W, van Caam A, Blaney

Davidson EN, van der Kraan PM,

Buma P. Physiological and excessive mechanical compression of articular cartilage activates Smad2/3P signaling. Osteoarthritis Cartilage. 2014;22(7):101825.

22 White A, Wallis G. Endochondral ossification: a delicate balance between growth and mineralisation. Curr Biol.
2001;11(15):R589-91.

23 Ford JL, Robinson DE, Scammell BE. Endochondral ossification in fracture callus during long bone repair: the localisation of 'cavity-lining cells' within the cartilage. J Orthop Res. 2004;22(2):368-75.

Mackie EJ, Ahmed YA, Tatarczuch L, Chen KS, Mirams M. Endochondral ossification: how cartilage is converted into bone in the developing skeleton. Int J Biochem Cell Biol. 2008;40(1):46-62.

Ripmeester EGJ, Timur UT, Caron MMJ, Welting TJM. Recent Insights into the Contribution of the Changing Hypertrophic Chondrocyte Phenotype in the Development and Progression of Osteoarthritis. Front Bioeng Biotechnol. 2018;6:18.

26 Murphy CL, Sambanis A. Effect of oxygen tension and alginate encapsulation on restoration of the differentiated phenotype of passaged chondrocytes. Tissue Eng. 2001;7(6):791-803.

27 Leijten JC, Moreira Teixeira LS, Landman $E B$, van Blitterswijk CA, Karperien M. Hypoxia inhibits hypertrophic differentiation and endochondral ossification in explanted tibiae. PLoS One. 2012;7(11):e49896.

28 van der Windt AE, Haak E, Das RH, Kops N, Welting TJ, Caron MM, et al. Physiological 
tonicity improves human chondrogenic marker expression through nuclear factor of activated T-cells 5 in vitro. Arthritis Res Ther. 2010;12(3):R100.

29 Zhou S, Cui Z, Urban JP. Factors influencing the oxygen concentration gradient from the synovial surface of articular cartilage to the cartilage-bone interface: a modeling study. Arthritis Rheum. 2004;50(12):3915-24.

30 Hodge JA, McKibbin B. The nutrition of mature and immature cartilage in rabbits. An autoradiographic study. J Bone Joint Surg Br. 1969;51(1):140-7.

31 Silver IA. Measurement of $\mathrm{pH}$ and ionic composition of pericellular sites. Philos Trans R Soc Lond B Biol Sci. 1975;271(912):261-72.

32 Anderson DE, Markway BD, Weekes KJ, McCarthy HE, Johnstone B. Physioxia Promotes the Articular Chondrocyte-Like Phenotype in Human ChondroprogenitorDerived Self-Organized Tissue. Tissue Eng Part A. 2017.

33 Kellner K, Liebsch G, Klimant I, Wolfbeis OS, Blunk T, Schulz MB, et al. Determination of oxygen gradients in engineered tissue using a fluorescent sensor. Biotechnol Bioeng. 2002;80(1):7383.

34 Lund-Olesen K. Oxygen tension in synovial fluids. Arthritis Rheum. 1970;13(6):769-76.
35 Brighton CT, Heppenstall RB. Oxygen tension in zones of the epiphyseal plate, the metaphysis and diaphysis. An in vitro and in vivo study in rats and rabbits. J Bone Joint Surg Am. 1971;53(4):719-28.

36 Grimshaw MJ, Mason RM. Bovine articular chondrocyte function in vitro depends upon oxygen tension. Osteoarthritis Cartilage. 2000;8(5):386-92.

37 Maroudas A, Venn M. Chemical composition and swelling of normal and osteoarthrotic femoral head cartilage. II. Swelling. Ann Rheum Dis. 1977;36(5):399406.

38 Buckwalter JA, Mankin HJ, Grodzinsky AJ. Articular cartilage and osteoarthritis. Instr Course Lect. 2005;54:465-80.

39 Bhalla A, Sankaralingam S, Dundas R, Swaminathan $R$, Wolfe $C D$, Rudd AG. Influence of raised plasma osmolality on clinical outcome after acute stroke. Stroke. 2000;31(9):2043-8.

40 Charkoudian N, Eisenach JH, Joyner MJ, Roberts SK, Wick DE. Interactions of plasma osmolality with arterial and central venous pressures in control of sympathetic activity and heart rate in humans. Am J Physiol Heart Circ Physiol. 2005;289(6):H2456-60.

41 Urban JP. The chondrocyte: a cell under pressure. Br J Rheumatol. 1994;33(10):9018. 
42 Urban JP, Hall AC, Gehl KA. Regulation

of matrix synthesis rates by the ionic and osmotic environment of articular chondrocytes. J Cell Physiol. 1993;154(2):262-70.

43 Lesperance LM, Gray ML, Burstein D. Determination of fixed charge density in cartilage using nuclear magnetic resonance. J Orthop Res. 1992;10(1):1-13.

44 Venn M, Maroudas A. Chemical composition and swelling of normal and osteoarthrotic femoral head cartilage. I. Chemical composition. Ann Rheum Dis. 1977;36(2):121-9.

45 Adams MA. The mechanical environment of chondrocytes in articular cartilage. Biorheology. 2006;43(3-4):537-45.

46 Oehler S, Neureiter D, Meyer-Scholten C, Aigner T. Subtyping of osteoarthritic synoviopathy. Clin Exp Rheumatol. 2002;20(5):633-40.

47 Smith MD. The normal synovium. Open Rheumatol J. 2011;5:100-6.

48 Smith MD. Immunohistochemistry of normal synovium. Ann Rheum Dis. 2004;63(11):1532-3; author reply 3.

49 Makris EA, Hadidi P, Athanasiou $\mathrm{KA}$. The knee meniscus: structurefunction, pathophysiology, current repair techniques, and prospects for regeneration. Biomaterials.
2011;32(30):7411-31.

50 Clockaerts S, Bastiaansen-Jenniskens YM, Runhaar J, Van Osch GJ, Van Offel JF, Verhaar JA, et al. The infrapatellar fat pad should be considered as an active osteoarthritic joint tissue: a narrative review. Osteoarthritis Cartilage. 2010;18(7):876-82.

51 Clockaerts S, Bastiaansen-Jenniskens YM, Runhaar J, Van Osch GJ, Van Offel JF, Verhaar JA, et al. The infrapatellar fat pad should be considered as an active osteoarthritic joint tissue: a narrative review. Osteoarthritis Cartilage. 2010;18(7):876-82.

52 Morrison R. On the functional aspects of the greater omentum. BMJ. 1906;1:76-8.

53 Rangel-Moreno J, Moyron-Quiroz JE, Carragher DM, Kusser K, Hartson L, Moquin A, et al. Omental milky spots develop in the absence of lymphoid tissue-inducer cells and support B and $T$ cell responses to peritoneal antigens. Immunity. 2009;30(5):731-43.

54 Garcia-Gomez I, Goldsmith HS, Angulo J, Prados A, Lopez-Hervas P, Cuevas B, et al. Angiogenic capacity of human omental stem cells. Neurol Res. 2005;27(8):807-11.

55 Divoux A, Tordjman J, Lacasa D, Veyrie N, Hugol D, Aissat A, et al. Fibrosis in human adipose tissue: composition, distribution, and link with lipid metabolism and fat 
mass loss. Diabetes. 2010;59(11):2817-25.

56 do Amaral R, Almeida HV, Kelly DJ, O'Brien FJ, Kearney CJ. Infrapatellar Fat Pad Stem Cells: From Developmental Biology to Cell Therapy. Stem Cells Int. 2017;2017:6843727.

57 Klein-Wieringa IR, Kloppenburg M, Bastiaansen-Jenniskens YM, Yusuf E, Kwekkeboom JC, El-Bannoudi $\mathrm{H}$, et al. The infrapatellar fat pad of patients with osteoarthritis has an inflammatory phenotype. Ann Rheum Dis. 2011;70(5):851-7.

58 Bastiaansen-Jenniskens YM, Wei W, Feijt C, Waarsing JH, Verhaar JA, Zuurmond $\mathrm{AM}$, et al. Stimulation of fibrotic processes by the infrapatellar fat pad in cultured synoviocytes from patients with osteoarthritis: a possible role for prostaglandin f2alpha. Arthritis Rheum. 2013;65(8):2070-80.

59 Brittberg $M$, Lindahl A, Nilsson A, Ohlsson $C$, Isaksson O, Peterson L. Treatment of deep cartilage defects in the knee with autologous chondrocyte transplantation. N Engl J Med. 1994;331(14):889-95.

60 Falah M, Nierenberg G, Soudry M, Hayden $M$, Volpin G. Treatment of articular cartilage lesions of the knee. Int Orthop. 2010;34(5):621-30.

61 van den Borne MP, Raijmakers NJ, Vanlauwe J, Victor J, de Jong SN,
Bellemans J, et al. International Cartilage Repair Society (ICRS) and Oswestry macroscopic cartilage evaluation scores validated for use in Autologous Chondrocyte Implantation ( $\mathrm{ACl}$ ) and microfracture. Osteoarthritis Cartilage. 2007;15(12):1397-402.

62 Buckwalter JA, Mankin HJ. Articular cartilage repair and transplantation. Arthritis Rheum. 1998;41(8):1331-42.

63 Haldeman KO, Soto-Hall R. The Response of Articular Cartilage to Trauma: With Special Reference to the Knee Joint. Calif Med. 1948;69(3):179-82.

64 Crema MD, Nevitt MC, Guermazi A, Felson DT, Wang K, Lynch JA, et al. Progression of cartilage damage and meniscal pathology over 30 months is associated with an increase in radiographic tibiofemoral joint space narrowing in persons with knee OA-the MOST study. Osteoarthritis Cartilage. 2014;22(10):1743-7.

65 Steinwachs MR, Guggi T, Kreuz PC. Marrow stimulation techniques. Injury. 2008;39 Suppl 1:S26-31.

66 Ritter SY, Subbaiah R, Bebek G, Crish J, Scanzello CR, Krastins B, et al. Proteomic analysis of synovial fluid from the osteoarthritic knee: comparison with transcriptome analyses of joint tissues. Arthritis Rheum. 2013;65(4):981-92.

67 Brittberg M, Recker D, llgenfritz J, 
Saris DBF, Group SES. Matrix-Applied

Characterized Autologous Cultured Chondrocytes Versus Microfracture:

Five-Year Follow-up of a Prospective Randomized Trial. Am J Sports Med. 2018;46(6):1343-51.

68 Harris JD, Siston RA, Brophy RH, Lattermann C, Carey JL, Flanigan DC. Failures, re-operations, and complications after autologous chondrocyte implantation--a systematic review. Osteoarthritis Cartilage. 2011;19(7):77991.

69 Hangody L, Rathonyi GK, Duska Z, Vasarhelyi G, Fules P, Modis L. Autologous osteochondral mosaicplasty. Surgical technique. J Bone Joint Surg Am. 2004;86A Suppl 1:65-72.

70 Jeuken RM, van Hugten PPW, Roth AK, Timur UT et al. A Systematic Review of Focal Cartilage Defect Treatments in Middle-Aged Versus Younger Patients. Orthopaedic Journal of Sports Medicine. October 2021. doi:10.1177/23259671211031244

71 Passler $\mathrm{HH}$. [Microfracture for treatment of cartilage detects]. Zentralbl Chir. 2000;125(6):500-4.

72 Jeuken RM, Roth AK, Peters R, Van Donkelaar CC, Thies JC, Van Rhijn LW, et al. Polymers in Cartilage Defect Repair of the Knee: Current Status and Future Prospects.
Polymers (Basel). 2016;8(6).

73 Becher C, Cantiller EB. Focal articular prosthetic resurfacing for the treatment of full-thickness articular cartilage defects in the knee: 12-year follow-up of two cases and review of the literature. Arch Orthop Trauma Surg. 2017;137(9):1307-17.

74 Nathwani D, McNicholas M, Hart A, Miles J, Bobic V. Partial Resurfacing of the Knee with the BioPoly Implant: Interim Report at 2 Years. JB JS Open Access. 2017;2(2):e0011.

75 Martinez-Carranza N, Hultenby K, Lagerstedt AS, Schupbach P, Berg HE. Cartilage Health in Knees Treated with Metal Resurfacing Implants or Untreated Focal Cartilage Lesions: A Preclinical Study in Sheep. Cartilage. 2019;10(1):120-8.

76 Cole BJ, Pascual-Garrido C, Grumet RC. Surgical management of articular cartilage defects in the knee. Instr Course Lect. 2010;59:181-204.

77 Pascual-Garrido C, Daley E, Verma NN, Cole BJ. A Comparison of the Outcomes for Cartilage Defects of the Knee Treated With Biologic Resurfacing Versus Focal Metallic Implants. Arthroscopy. 2017;33(2):364-73.

78 Loeser RF, Goldring SR, Scanzello CR, Goldring MB. Osteoarthritis: a disease of the joint as an organ. Arthritis Rheum. 2012;64(6):1697-707. 
79 Hunter DJ, Felson DT. Osteoarthritis. BMJ. 2006;332(7542):639-42.

80 Saris DB, Dhert WJ, Verbout AJ. Joint homeostasis. The discrepancy between old and fresh defects in cartilage repair. J Bone Joint Surg Br. 2003;85(7):1067-76.

81 Samuels J, Krasnokutsky S, Abramson SB. Osteoarthritis: a tale of three tissues. Bull NYU Hosp Jt Dis. 2008;66(3):244-50.

82 Ryd L, Brittberg M, Eriksson K, Jurvelin JS, Lindahl A, Marlovits S, et al. PreOsteoarthritis: Definition and Diagnosis of an Elusive Clinical Entity. Cartilage. 2015;6(3):156-65.

83 Insall JN. High tibial osteotomy in the treatment of osteoarthritis of the knee. Surg Annu. 1975;7:347-59.

84 van der Woude JA, Nair SC, Custers RJ, van Laar JM, Kuchuck NO, Lafeber FP, et al. Knee Joint Distraction Compared to Total Knee Arthroplasty for Treatment of End Stage Osteoarthritis: Simulating LongTerm Outcomes and Cost-Effectiveness. PLoS One. 2016;11(5):e0155524.

85 Zhang Y, Jordan JM. Epidemiology of osteoarthritis. Clinics in geriatric medicine. 2010;26(3):355-69.

86 van der Kraan PM, Blaney Davidson EN, Blom A, van den Berg WB. TGFbeta signaling in chondrocyte terminal differentiation and osteoarthritis: modulation and integration of signaling pathways through receptor-Smads. Osteoarthritis Cartilage. 2009;17(12):153945.

87 Kellgren JH, Lawrence JS. Radiological assessment of osteo-arthrosis. Ann Rheum Dis. 1957;16(4):494-502.

88 Oei EHG, Wick MC, Muller-Lutz A, Schleich $C$, Miese FR. Cartilage Imaging: Techniques and Developments. Semin Musculoskelet Radiol. 2018;22(2):245-60.

89 Felson DT. Developments in the clinical understanding of osteoarthritis. Arthritis Res Ther. 2009;11(1):203.

90 Loeser RF, Goldring SR, Scanzello CR, Goldring MB. Osteoarthritis: a disease of the joint as an organ. Arthritis Rheum. 2012;64(6):1697-707.

91 Repo RU, Mitchell N. Collagen synthesis in mature articular cartilage of the rabbit. J Bone Joint Surg Br. 1971;53(3):541-8.

92 Goldring MB, Marcu KB. Cartilage homeostasis in health and rheumatic diseases. Arthritis Res Ther. 2009;11(3):224.

93 Hoyland JA, Thomas JT, Donn R, Marriott A, Ayad S, Boot-Handford RP, et al. Distribution of type $X$ collagen mRNA in normal and osteoarthritic human cartilage. Bone Miner. 1991;15(2):151-63.

94 Aigner T, Frischholz S, Dertinger S, Beier F, Girkontaite I, von der Mark K. Type X 
collagen expression and hypertrophic

differentiation in chondrogenic neoplasias. Histochem Cell Biol. 1997;107(6):435-40.

95 Aigner T, Reichenberger E, Bertling W, Kirsch T, Stoss H, von der Mark K. Type X collagen expression in osteoarthritic and rheumatoid articular cartilage. Virchows Arch B Cell Pathol Incl Mol Pathol. 1993;63(4):205-11.

96 von der Mark K, Frischholz S, Aigner T, Beier F, Belke J, Erdmann S, et al. Upregulation of type $\mathrm{X}$ collagen expression in osteoarthritic cartilage. Acta Orthop Scand Suppl. 1995;266:125-9.

97 von der Mark K, Kirsch T, Nerlich A, Kuss A, Weseloh G, Gluckert K, et al. Type X collagen synthesis in human osteoarthritic cartilage. Indication of chondrocyte hypertrophy. Arthritis Rheum. 1992;35(7):806-11.

Troeberg L, Nagase H. Proteases involved in cartilage matrix degradation in osteoarthritis. Biochim Biophys Acta. 2012;1824(1):133-45.

99 Rosenberg JH, Rai V, Dilisio MF, Agrawal DK. Damage-associated molecular patterns in the pathogenesis of osteoarthritis: potentially novel therapeutic targets. Mol Cell Biochem. 2017;434(1-2):171-9.

100 Homandberg GA, Wen C, Hui F. Cartilage damaging activities of fibronectin fragments derived from cartilage and synovial fluid. Osteoarthr Cartilage. 1998;6(4):231-44.

101 Zack MD, Arner EC, Anglin CP, Alston JT, Malfait AM, Tortorella MD. Identification of fibronectin neoepitopes present in human osteoarthritic cartilage. Arthritis Rheum. 2006;54(9):2912-22.

102 Pulai Jl, Chen H, Im HJ, Kumar S, Hanning C, Hegde PS, et al. NF-kappa B mediates the stimulation of cytokine and chemokine expression by human articular chondrocytes in response to fibronectin fragments. J Immunol. 2005;174(9):5781-8.

103 Fichter M, Korner U, Schomburg J, Jennings L, Cole AA, Mollenhauer J. Collagen degradation products modulate matrix metalloproteinase expression in cultured articular chondrocytes. J Orthop Res. 2006;24(1):63-70.

104 Berenbaum F, van den Berg WB. Inflammation in osteoarthritis: changing views. Osteoarthritis Cartilage. 2015;23(11):1823-4.

105 Pessler F, Dai L, Diaz-Torne C, GomezVaquero C, Paessler ME, Zheng DH, et al. The synovitis of "non-inflammatory" orthopaedic arthropathies: a quantitative histological and immunohistochemical analysis. Ann Rheum Dis. 2008;67(8):11847. 
106 Pearle AD, Scanzello CR, George S, Mandl LA, DiCarlo EF, Peterson $M$, et al. Elevated high-sensitivity C-reactive protein levels are associated with local inflammatory findings in patients with osteoarthritis. Osteoarthr Cartilage. 2007;15(5):516-23.

107 Benito MJ, Veale DJ, FitzGerald O, van den Berg WB, Bresnihan B. Synovial tissue inflammation in early and late osteoarthritis. Ann Rheum Dis. 2005;64(9):1263-7.

108 Spector TD, Hart DJ, Nandra D, Doyle DV, Mackillop N, Gallimore JR, et al. Low-level increases in serum $\mathrm{C}$-reactive protein are present in early osteoarthritis of the knee and predict progressive disease. Arthritis Rheum. 1997;40(4):723-7.

109 Krasnokutsky S, Belitskaya-Levy I, Bencardino J, Samuels J, Attur M, Regatte $\mathrm{R}$, et al. Quantitative magnetic resonance imaging evidence of synovial proliferation is associated with radiographic severity of knee osteoarthritis. Arthritis Rheum. 2011;63(10):2983-91.

110 Ayral X, Pickering EH, Woodworth TG, Mackillop N, Dougados M. Synovitis: a potential predictive factor of structural progression of medial tibiofemoral knee osteoarthritis -- results of a 1 year longitudinal arthroscopic study in 422 patients. Osteoarthr Cartilage. 2005;13(5):361-7.
111 Roemer FW, Guermazi A, Felson DT, Niu J, Nevitt MC, Crema MD, et al. Presence of MRI-detected joint effusion and synovitis increases the risk of cartilage loss in knees without osteoarthritis at 30-month followup: the MOST study. Ann Rheum Dis. 2011;70(10):1804-9.

112 Pessler F, Chen LX, Dai L, Gomez-Vaquero C, Diaz-Torne C, Paessler ME, et al. A histomorphometric analysis of synovial biopsies from individuals with Gulf War Veterans' IIIness and joint pain compared to normal and osteoarthritis synovium. Clin Rheumatol. 2008;27(9):1127-34.

113 Scanzello CR, Umoh E, Pessler F, DiazTorne C, Miles T, Dicarlo E, et al. Local cytokine profiles in knee osteoarthritis: elevated synovial fluid interleukin-15 differentiates early from end-stage disease. Osteoarthritis Cartilage. 2009;17(8):1040-8.

114 Torres L, Dunlop DD, Peterfy C, Guermazi A, Prasad P, Hayes KW, et al. The relationship between specific tissue lesions and pain severity in persons with knee osteoarthritis. Osteoarthritis Cartilage. 2006;14(10):1033-40.

115 Hill CL, Hunter DJ, Niu J, Clancy M, Guermazi A, Genant H, et al. Synovitis detected on magnetic resonance imaging and its relation to pain and cartilage loss in knee osteoarthritis. Ann Rheum Dis. 2007;66(12):1599-603. 
116 Torres L, Dunlop DD, Peterfy C, Guermazi

A, Prasad P, Hayes KW, et al. The relationship between specific tissue lesions and pain severity in persons with knee osteoarthritis. Osteoarthr Cartilage. 2006;14(10):1033-40.

117 Liu M, Silva-Sanchez A, Randall TD, MezaPerez S. Specialized immune responses in the peritoneal cavity and omentum. J Leukoc Biol. 2020.

118 Klein-Wieringa IR, Kloppenburg M, Bastiaansen-Jenniskens YM, Yusuf E, Kwekkeboom JC, El-Bannoudi $\mathrm{H}$, et al. The infrapatellar fat pad of patients with osteoarthritis has an inflammatory phenotype. Ann Rheum Dis. 2011;70(5):851-7.

119 Haj-Mirzaian A, Guermazi A, HafeziNejad N, Sereni C, Hakky M, Hunter DJ, et al. Superolateral Hoffa's fat pad (SHFP) oedema and patellar cartilage volume loss: quantitative analysis using longitudinal data from the Foundation for the National Institute of Health (FNIH) Osteoarthritis Biomarkers Consortium. Eur Radiol. 2018;28(10):4134-45.

120 Clockaerts S, Bastiaansen-Jenniskens YM, Feijt C, De Clerck L, Verhaar JA, Zuurmond AM, et al. Cytokine production by infrapatellar fat pad can be stimulated by interleukin 1 beta and inhibited by peroxisome proliferator activated receptor alpha agonist. Ann Rheum Dis.
2012;71(6):1012-8

121 Bondeson J, Wainwright SD, Lauder S, Amos N, Hughes CE. The role of synovial macrophages and macrophage-produced cytokines in driving aggrecanases, matrix metalloproteinases, and other destructive and inflammatory responses in osteoarthritis. Arthritis Res Ther. 2006;8(6):R187.

122 Bondeson J, Wainwright SD, Lauder S, Amos N, Hughes CE. The role of synovial macrophages and macrophage-produced cytokines in driving aggrecanases, matrix metalloproteinases, and other destructive and inflammatory responses in osteoarthritis. Arthritis Res Ther. 2006;8(6):R187.

123 Bondeson J, Wainwright SD, Lauder S, Amos N, Hughes CE. The role of synovial macrophages and macrophage-produced cytokines in driving aggrecanases, matrix metalloproteinases, and other destructive and inflammatory responses in osteoarthritis. Arthritis Res Ther. 2006;8(6):R187.

124 Bondeson J, Wainwright SD, Lauder S, Amos N, Hughes CE. The role of synovial macrophages and macrophage-produced cytokines in driving aggrecanases, matrix metalloproteinases, and other destructive and inflammatory responses in osteoarthritis. Arthritis Res Ther. 2006;8(6):R187. 
125 Han W, Aitken D, Zhu Z, Halliday A, Wang X, Antony B, et al. Signal intensity alteration in the infrapatellar fat pad at baseline for the prediction of knee symptoms and structure in older adults: a cohort study. Ann Rheum Dis. 2016;75(10):1783-8.

126 Felson DT, Lawrence RC, Dieppe PA, Hirsch R, Helmick CG, Jordan JM, et al. Osteoarthritis: new insights. Part 1: the disease and its risk factors. Ann Intern Med. 2000;133(8):635-46.

127 Katsuragawa Y, Saitoh K, Tanaka N, Wake M, Ikeda Y, Furukawa H, et al. Changes of human menisci in osteoarthritic knee joints. Osteoarthr Cartilage. 2010;18(9):1133-43.

128 Pauli C, Grogan SP, Patil S, Otsuki S, Hasegawa A, Koziol J, et al. Macroscopic and histopathologic analysis of human knee menisci in aging and osteoarthritis. Osteoarthr Cartilage. 2011;19(9):1132-41.

129 Lopez-Franco M, Gomez-Barrena E. Cellular and molecular meniscal changes in the degenerative knee: a review. J Exp Orthop. 2018;5(1):11.

130 Cambre I, Gaublomme D, Burssens A, Jacques $P$, Schryvers $N$, De Muynck A, et al. Mechanical strain determines the sitespecific localization of inflammation and tissue damage in arthritis. Nat Commun. 2018;9(1):4613.
131 Glyn-Jones S, Palmer AJ, Agricola $R$, Price AJ, Vincent $T L$, Weinans $\mathrm{H}$, et al. Osteoarthritis. Lancet. 2015;386(9991):376-87.

132 Martel-Pelletier J, Pelletier JP, Fahmi H. Cyclooxygenase-2 and prostaglandins in articular tissues. Semin Arthritis Rheum. 2003;33(3):155-67.

133 Needleman P, Turk J, Jakschik BA, Morrison AR, Lefkowith JB. Arachidonic acid metabolism. Annu Rev Biochem. 1986;55:69-102.

134 Samuelsson B, Goldyne M, Granstrom E, Hamberg M, Hammarstrom S, Malmsten C. Prostaglandins and thromboxanes. Annu Rev Biochem. 1978;47:997-1029.

135 Vane JR, Bakhle YS, Botting RM. Cyclooxygenases 1 and 2. Annu Rev Pharmacol Toxicol. 1998;38:97-120.

136 Varga J, Diaz-Perez A, Rosenbloom J, Jimenez SA. PGE2 causes a coordinate decrease in the steady state levels of fibronectin and types I and III procollagen mRNAs in normal human dermal fibroblasts. Biochem Biophys Res Commun. 1987;147(3):1282-8.

137 Toussirot E, Streit G, Wendling D. The contribution of adipose tissue and adipokines to inflammation in joint diseases. Curr Med Chem. 2007;14(10):1095-100. 
138 Chandrasekharan NV, Dai H, Roos KL, Evanson NK, Tomsik J, Elton TS, et al. COX-

3, a cyclooxygenase-1 variant inhibited by acetaminophen and other analgesic/ antipyretic drugs: cloning, structure, and expression. Proc Natl Acad Sci U S A. 2002;99(21):13926-31.

139 Xu XM, Tang JL, Chen X, Wang LH, Wu KK. Involvement of two Sp1 elements in basal endothelial prostaglandin $\mathrm{H}$ synthase-1 promoter activity. J Biol Chem. 1997;272(11):6943-50.

140 Anderson GD, Hauser SD, McGarity KL, Bremer ME, Isakson PC, Gregory SA. Selective inhibition of cyclooxygenase (COX)-2 reverses inflammation and expression of COX-2 and interleukin 6 in rat adjuvant arthritis. J Clin Invest. 1996;97(11):2672-9.

141 Portanova JP, Zhang Y, Anderson GD, Hauser SD, Masferrer JL, Seibert K, et al. Selective neutralization of prostaglandin E2 blocks inflammation, hyperalgesia, and interleukin 6 production in vivo. J Exp Med. 1996;184(3):883-91.

142 Siegle I, Klein T, Backman JT, Saal JG, Nusing RM, Fritz P. Expression of cyclooxygenase 1 and cyclooxygenase 2 in human synovial tissue: differential elevation of cyclooxygenase 2 in inflammatory joint diseases. Arthritis Rheum. 1998;41(1):122-9.
143 Clockaerts S, Bastiaansen-Jenniskens YM, Feijt C, De Clerck L, Verhaar JA, Zuurmond AM, et al. Cytokine production by infrapatellar fat pad can be stimulated by interleukin 1 beta and inhibited by peroxisome proliferator activated receptor alpha agonist. Ann Rheum Dis. 2012;71(6):1012-8.

144 Amin AR, Attur M, Patel RN, Thakker GD, Marshall PJ, Rediske J, et al. Superinduction of cyclooxygenase-2 activity in human osteoarthritis-affected cartilage. Influence of nitric oxide. J Clin Invest. 1997;99(6):1231-7.

145 Pelletier JP, Mineau F, Fernandes JC, Duval N, Martel-Pelletier J. Diacerhein and rhein reduce the interleukin 1 beta stimulated inducible nitric oxide synthesis level and activity while stimulating cyclooxygenase-2 synthesis in human osteoarthritic chondrocytes. J Rheumatol. 1998;25(12):2417-24.

146 Seibert K, Masferrer JL. Role of inducible cyclooxygenase (COX-2) in inflammation. Receptor. 1994;4(1):17-23.

147 Ricciotti E, FitzGerald GA. Prostaglandins and inflammation. Arterioscler Thromb Vasc Biol. 2011;31(5):986-1000.

148 Lipsky PE. The clinical potential of cyclooxygenase-2-specific inhibitors. Am J Med. 1999;106(5B):51S-7S.

149 Clemett D, Goa KL. Celecoxib: a review 
of its use in osteoarthritis, rheumatoid arthritis and acute pain. Drugs. 2000;59(4):957-80.

150 Finnson KW, Parker WL, ten Dijke P, Thorikay M, Philip A. ALK1 opposes ALK5/Smad3 signaling and expression of extracellular matrix components in human chondrocytes. J Bone Miner Res. 2008;23(6):896-906.

151 van der Windt AE, Haak E, Das RH, Kops N, Welting TJ, Caron MM, et al. Physiological tonicity improves human chondrogenic marker expression through nuclear factor of activated T-cells 5 in vitro. Arthritis Res Ther. 2010;12(3):R100.

152 Saris DB, Dhert WJ, Verbout AJ. Joint homeostasis. The discrepancy between old and fresh defects in cartilage repair. J Bone Joint Surg Br. 2003;85(7):1067-76. 


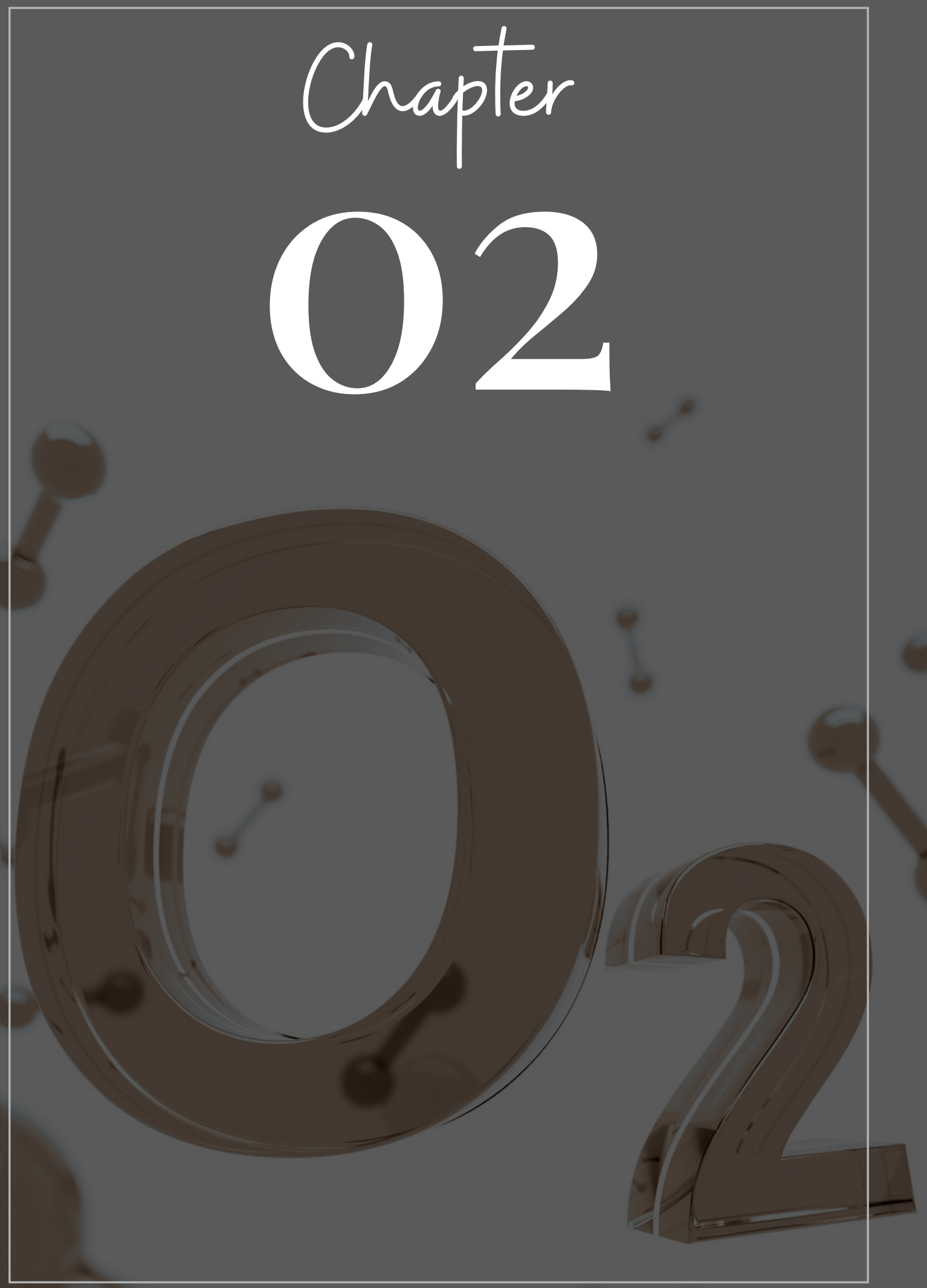




\section{TGF- $\beta 2$ is Involved in the Preservation of the Chondrocyte Phenotype Under Hypoxic Conditions.}

Das, R.; Timur, UT.; Edip, S.; Haak, E.; Wruck, C.; Weinans, H.; Jahr, H. (2015) Annals of Anatomy, volume 198, pp. 1 - 10 


\section{Abstract}

\section{Objective:}

Culturing chondrocytes under oxygen tension closely resembling their in vivo environment has been shown to have positive effects on matrix synthesis. In redifferentiation of expanded chondrocytes, hypoxia increased collagen type II expression. However, the mechanism by which hypoxia enhances redifferentiation is still unknown. We employed novel bioreactor technology to investigate the role of TGF- $\beta$, a growth factor heavily implicated in matrix production, in chondrocytes under hypoxia.

\section{Material \& Methods:}

Dedifferentiated chondrocytes in alginate were cultured for $48 \mathrm{~h}$ under hypoxic $\left(1 \% \mathrm{pO}_{2}\right)$ or normoxic (20\%) conditions, using specialized bioreactor technology. Hypoxia induced gene expression (GDF1-, PHD3, HAS2, VEGF, COX2), chondrocyte markers (SOX9, COL2, COL1, AGC1 and MMP13), as well as components of the TGF- $\beta$ signaling pathway (TGF- $\beta$ isoforms, receptors, and downstream effectors) were analyzed by qPCR after $48 \mathrm{~h}$. In addition, protein expression of COL2 and TGF- $\beta 2$ were evaluated. To further elucidate the involvement of the TGF- $\beta 2$, we used siRNA and ALK5 inhibition.

\section{Results:}

Hypoxic culture showed robust upregulation of hypoxic markers as well as upregulation of SOX9 and COL2 expression. Of all TGF- $\beta$ isoforms, only TGF- $\beta 2$ was upregulated under hypoxia on both gene and protein level. In addition, both type I receptors (ALK1 and ALK5) were upregulated under hypoxia, but type II and III receptors were not. TGF- $\beta 2$ downregulation via siRNA abrogated the hypoxia-induced COL2 expression, as did ALK5 inhibition, giving a strong indication that this pathway is involved in chondrocyte redifferentiation under low oxygen tension. 


\section{Conclusion:}

Hypoxic culture is a common approach for cartilage tissue engineering, but its underlying mechanisms are still poorly understood. Here, we show that increased TGF- $\beta 2$ signaling through ALK5 plays a role in hypoxia-induced redifferentiation of chondrocytes.

\section{Introduction}

Articular cartilage covers the surface of all diarthrodial joints in the body, where it provides frictionless articulation and resistance to compressive forces. Due to the avascularity of this tissue, chondrocytes rely on diffusion primarily from the surrounding synovial fluid for their supply of oxygen and nutrients. Consequently, articular chondrocytes reside in an environment that is naturally hypoxic compared to other tissues. $\mathrm{A} \mathrm{pO}_{2}$ of $7-10 \%$ is estimated for the pericellular regions in the superficial zone of articular cartilage, while the $\mathrm{pO}_{2}$ might be as low as $1 \%$ in the deeper zones near the calcified cartilage ${ }^{1,2,3,4}$. Chondrocytes are well adapted for survival in this hypoxic environment. For example, they mainly use anaerobic metabolism for the generation of ATP, thereby minimizing consumption of oxygen ${ }^{5}$. However, chondrocyte isolation and subsequent expansion exposes these cells to oxygen tension that far exceed physiological values. Culturing chondrocytes under oxygen tensions that more closely resemble their in vivoenvironment (i.e. "hypoxic") has been shown to have positive effects on matrix synthesis. Increased proteoglycans (PG) and collagen synthesis has been found in several studies, although findings are not always conclusive. In fact, effects appear to depend on cell source, species and exact oxygen tension ${ }^{6}$. In healthy bovine chondrocytes, hypoxia showed increased mRNA expression of aggrecan (AGC1) and TIMP-1, but a slight decrease in collagen type II (COL2) mRNA at near anoxic condition in one study ${ }^{7}$. On the other hand, increased proteoglycan deposition and COL2 synthesis was found in another study ${ }^{8}$. During redifferentiation of expanded chondrocytes, low oxygen tension also appears to increase collagen type II immunostaining?

TGF- $\beta$ appears to play a major role in cartilage repair and multiple micro-environmental factors potentially regulate the chondrocytes phenotype directly or indirectly by modulating TGF- $\beta$ signaling. TGF- $\beta$ is the prototypic member of the TGF- $\beta$ superfamily 
of growth factors, which further includes, among others, activins and inhibins, nodal, myostatin and bone morphogenetic proteins (BMPs) ${ }^{10}$. Three mammalian isoforms of TGF- $\beta^{1,2,3}$ exist and while their active forms mostly have similar actions on cells in vitro, they also have non-redundant functions in vivo ${ }^{11,12}$. This highly pleiotropic growth factor plays a key role in various cellular processes, including inhibition of cell growth, induction of apoptosis and production of extracellular matrix proteins.

In endothelial cells, hypoxia ( $\left.1 \% \mathrm{pO}_{2}\right)$ was shown to upregulate TGF- $\beta 2$ at the transcriptional level, peaking after $48 \mathrm{~h}^{13}$, while, in dermal fibroblasts, hypoxia upregulates the synthesis of the $\beta 1$ isoform ${ }^{14}$. In redifferentiating bovine chondrocytes, complete anoxia appeared to slightly affect TGF- $\beta$ expression ${ }^{7}$, but this study did not distinguish between the different isoforms, nor did it investigate oxygen tensions between $0 \%$ and $5 \% \mathrm{pO}_{2}$. Martin et al. showed that, in fresh bovine chondrocytes, short term hypoxia $\left(5 \% \mathrm{pO}_{2}\right)$ had a modulatory effect on TGF- $\beta$ expression, but no long-term effects were investigated, nor did the authors examine effects in human $\mathrm{OA}$ chondrocytes ${ }^{15}$. Other extracellular parameters also affect TGF- $\beta$ signaling; while low $\mathrm{pH}$ can facilitate TGF- $\beta$ signaling by activating its latent form $^{16,17}$. Other parameters, such as plasmin-mediated proteolysis ${ }^{18}$, can also influence this signaling pathway ${ }^{19}$. The controversy about ambivalent effects of TGF- $\beta$ on articular chondrocytes has been recently reviewed ${ }^{20,21}$ and appears to depend on the context of the culture: the presence of cytokines, the culture method (monolayer versus $3 \mathrm{D}$ culture) ${ }^{22}$ or even the phase of the cell cycle ${ }^{23}$. In chondrocytes, TGF- $\beta$ has been mainly implicated in the production of $\mathrm{COL} 2^{21,24,25}$. TGF- $\beta 2$ has been described as the more potent stimulatory isoform (compared to TGF- $\beta 1$ ) for chondrogenesis, proteoglycan synthesis and cell proliferation in rabbit chondrocytes ${ }^{26}$. TGF- $\beta 2$ is also unique among the three isoforms in that it lacks a RGD integrin-binding sequence in its precursor and is the only isoform with multiple CRE elements immediately upstream of its $\mathrm{P} 1$ promoter $^{11}$. Of note, the CREB family of transcription factors has recently been shown to be activated by hypoxia ${ }^{27}$.

Canonically, TGF- $\beta$ ligands bind to the TGF- $\beta$ type II receptor (TGFBRII) which, in most cells, then recruits the type I receptor activin-like kinase 5 (ALK5). The tetrameric receptor complex subsequently phosphorylates the intracellular effector molecules Smad-2 and -3, which, after translocation to the nucleus, regulate transcriptional activity in the target cell ${ }^{28}$. 
However, recently it was shown that in some cells (e.g. endothelial cells and chondrocytes) TGF- $\beta$ can also signal through an alternative receptor, ALK1 ${ }^{29}$. Signaling via this receptor leads to phosphorylation of Smad1/5/8 rather than Smad2/3. It was postulated that the ratio of ALK5 and ALK1 signaling is responsible for the seemingly contradictory effects of TGF- $\beta$ in chondrocytes ${ }^{30}$. In addition, Smad-independent pathways may fine-tune the response to TGF- $\beta$ in different contexts ${ }^{21}$.

In this study we hypothesize that hypoxia affects TGF- $\beta$ signaling in redifferentiating human chondrocytes. Moreover, we postulate that the positive effects on COL2 expression in hypoxic culture of redifferentiating chondrocytes are caused by upregulation of components of the TGF- $\beta$ signaling pathway. The different TGF- $\beta$ isoforms as well as their receptors are investigated at the gene expression and protein levels, employing pharmacologic receptor inhibition and TGF- $\beta 2$ RNAi to shed light on the underlying molecular effects.

\section{Materials \& Methods}

\subsection{Cell Culture}

Cartilage biopsies of 8 patients undergoing total knee replacement surgery (after approval by the local ethics committee; MEC2004-322) were used for this study. Full thickness cartilage was harvested, treated with $7 \mathrm{U} / \mathrm{mL}$ protease in physiological saline solution (SigmaAldrich, Zwijndrecht, Netherlands) for $90 \mathrm{~min}$ and subsequently digested overnight in basal medium (DMEM, $4.5 \mathrm{~g} / \mathrm{L}$ glucose with 10\% Fetal Calf Serum (FCS), $50 \mu \mathrm{g} / \mathrm{ml}$ gentamicin and $1.5 \mu \mathrm{g} / \mathrm{ml}$ fungizone (all Invitrogen, Scotland, UK)) supplemented with $15 \mathrm{U} / \mathrm{mL}$ collagenase B (Roche Diagnostics, Mannheim, Germany). The following day, the harvested cell number was determined using a haemocytometer. The primary chondrocytes were then seeded at a density of $7500 \mathrm{cell} / \mathrm{cm}^{2}$ in $\mathrm{T} 175$ culture flasks for expansion culture. The cells plated for expansion were cultured for three passages. Alginate beads were created with second passage chondrocytes in $1.2 \%$ low viscosity alginate (Keltone LV, Kelco, Surrey, UK) by dripping a $1.2 \%$ alginate suspension with 4 million cells per $\mathrm{ml}$ though a $23 \bigotimes$ gauge needle into a $\mathrm{CaCl}_{2}$ solution. After $10 \mathrm{~min}$, the beads were washed twice with physiological saline 


\section{Chapter 2}

and once with basal medium and transferred a T175 culture flask with $150 \mathrm{ml}$ basal medium with $25 \mathrm{mM}$ I-ascorbic acid. After five days of pre-culture, beads were transferred to a $\mu 24$ bioreactor (Applikon Biotechnology, Schiedam, The Netherlands). Chondrocytes were also stimulated with $10 \mathrm{ng} / \mathrm{ml} \mathrm{TGF}-\beta 2$ for $48 \mathrm{~h}$ and 7 days under $1 \%$ or $20 \% \mathrm{pO}_{2}$ and expression levels of key chondrocyte marker COL2 were compared to unstimulated controls.

\subsection{Bioreactor Culture}

The bioreactor system used for hypoxic culture has been previously described by our group ${ }^{31}$. Briefly, 30 beads were transferred to every well of a specific 24 well cassette, designed for use with the $\mu 24$ bioreactor. Four milliliter of redifferentiation medium (DMEM,

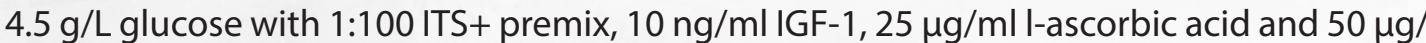
$\mathrm{ml}$ gentamicin and $1.5 \mu \mathrm{g} / \mathrm{ml}$ fungizone) was added to every well. Oxygen tension was lowered by continuous sparging with nitrogen. Oxygen tension was maintained the desired set-point (either $1 \%, 5 \%$ or $20 \% \mathrm{pO}_{2}$ ) by using air as a counter gas. Medium pH was maintained at 7.2 using $\mathrm{CO}_{2}$.

\subsection{RNA Isolation and Quantitative RT-PCR}

Alginate beads were produced as described earlier by our group ${ }^{32,33}$ and after dissolution, cells were resuspended in $350 \mu \mathrm{L}$ RNABee (TEL-TEST Inc., Friendswood, TX, USA). After addition of $60 \mu \mathrm{L}$ chloroform, samples were spun down for $20 \mathrm{~min}$ at $13,000 \times \mathrm{g}$. Total RNA was isolated from the supernatant using the Qiagen RNA Micro Kit according to the manufacturer's instructions (Qiagen $\mathrm{GmbH}$, Hilden, Germany) and nucleic acid content was determined spectrophotometrically (NanoDrop ${ }^{\circledR}$ ND1000, Isogen Life Science, IJsselstein, The Netherlands). In compliance with MIQE guidelines ${ }^{34}$, good RNA integrity (RIN $\geq 8.8$; BioAnalyezr 2100, Agilent Technologies, Amstelveen, Netherlands) and absence of PCR inhibitors (data not shown) was ensured. Reverse transcription was performed using the RevertAid First Strand cDNA Synthesis Kit (Thermo Fisher Scientific Inc., Rockford, IL) with mixed priming (oligo-d(T):random hexamers, 3:1, v/v) according to the supplier's instructions. Both cDNA synthesis (0.5-1 $\mu \mathrm{g}$ total RNA/reaction) and real-time quantitative PCR (10-15 ng cDNA/reaction) method, with specificity and efficiency controls, as well as 
data normalization to a reference gene index were described in detail elsewhere ${ }^{35}$. Briefly, the geometric mean of CT-values of pre-evaluated endogenous calibrators 18SrRNA, ubiquitin (UBC), beta-actin (ACTB), hypoxanthine phosphoribosyltransferase 1 (HPRT1) and beta-2 microglobulin (B2M) ${ }^{36}$ was used to normalize expression data. To choose the "best housekeeper index", the BestKeeper macro was used as established tool ${ }^{37}$. GAPDH, UBC and HPRT1 were chosen for the index for their stable expression across experimental conditions. The relative fold-change in gene expression was then calculated according to the $2-\Delta \mathrm{Ct}$ method as reported by Livak and Schmittgen ${ }^{38}$. Individual differences were first averaged and replicates then used to calculate the relative expression, normalized to the internal control, as described previously by $\mathrm{us}^{35}$. RT-PCR primers of extracellular matrix (ECM) components (aggrecan, collagen type I and type II (COL1(A1) and COL2(A1) resp.), sex determining region Y-box 9 (SOX9), matrix metalloproteinase-13 (MMP13), markers of hypoxia (prolyl hydroxylase 3 (PHD3), vascular endothelial growth factor (VEGF), growth differentiation factor 10 (GDF10), hyaluronan synthase 2 (HAS2) and cyclooxygenase 2 (COX2)), TGF- $\beta$ isoforms (TGF- $\beta 1,-\beta 2$ and $\beta 3$ ), TGF- $\beta$ receptors (activin-like receptor kinases (ALK1 and ALK5), TGF- $\beta$ receptor 2 (TGFBR2), betaglycan (BGCAN) and endoglin (EGN)) and targets of TGF- $\beta$ signaling (plasminogen activator inhibitor-1 (PAI-1) and inhibitor of DNA binding 1 (ID1)) were also previously described $35,39,40,41$. Cycling was performed on an ABI7000 (Applied Biosystems) with $60^{\circ} \mathrm{C}$ annealing and a standard two-step protocol.

\section{$2.4 \quad$ Immunoblotting}

After RNA isolation, polypeptides were purified from the phenol-ethanol supernatant layer left over by dialysis. Briefly, upon 1:4 dilution, pooled phenol layers from three independent bioreactor experiments were dialyzed against $0.2 \%(\mathrm{w} / \mathrm{v})$ SDS for 16,4 , and 2 h, respectively, using Spectra/Por 3 (Carl Roth GmbH \& Co.KG, Schoemperlenstr., Karlsruhe, Germany). Subsequently, dialysates were centrifuged $\left(10,000 \times \mathrm{g}, 10 \mathrm{~min}, 4{ }^{\circ} \mathrm{C}\right)$ and supernatants concentrated using Centriprep YM-3 (Millipore, Billerica, MA) according to the manufacturer's instructions. Polypeptide concentration was determined using routine bicinchoninic acid (BCA) protein assay reagent (Thermo Fisher Scientific Inc., Rockford, IL) as described earlier ${ }^{42}$ and immunoblotting was performed as described elsewhere by our group $^{43}$. Concisely, equal amounts of polypeptides were separated by routine SDS-PAGE, 


\section{Chapter 2}

subsequently transferred by electro-blotting and detected on an Odyssey infrared imaging system (Li-Cor Biosciences) as described earlier ${ }^{44}$, but using primary polyclonal goat antiCOL2A1, polyclonal rabbit anti-Sox9 $9^{45}$ and mouse monoclonal anti- $\beta$-tubulin (G-8; Santa Cruz Biotechnology Inc., Santa (ruz, CA) antibodies. For dot blot analyses, the pooled polypeptide fractions were spotted onto $0.45 \mu \mathrm{m}$ nitrocellulose membranes using a BioDot ${ }^{\circledast}$ Apparatus (both: Bio-Rad, München, Germany) and processed as described above for Western blots, except that an anti-human TGF- 32 -specific antibody (Proteintech, Chicago, IL; 1:1000) was used. Densiometric quantification data (ImageJ software, version 1.47) were normalized to $\beta$-tubulin and displayed relative to controls, as reported by Caron et al. ${ }^{45}$.

\subsection{ALK5 Inhibition}

ALK5 activity was inhibited using a novel, specific ALK5 inhibitor (SB-525334, SigmaAldrich; $10 \mu \mathrm{M})^{46}$ added $2 \mathrm{~h}$ prior to induction of hypoxia $\left(1 \% \mathrm{pO}_{2}\right.$ ). Ten beads were harvested after $48 \mathrm{~h}$ of hypoxia for RNA isolation as described above. Specificity of the inhibitor was confirmed using qRT-PCR analysis on ALK5 and ALK1 specific target genes PAI-147,48 and ID $1^{49,50}$, respectively.

\subsection{RNA Interference (RNAi)}

We used our established lentiviral vector technology for nontransient shRNA-mediated gene silencing in primary chondrocytes ${ }^{35}$, employing commercially available, pre-validated shRNA clones (Sigma-Aldrich, MISSION shRNA library). Briefly, BamHI/Munl restriction fragments of the parental pLKO.1-puro vector containing one out of five different, sequenceverified anti-human TGF- $\beta 2$ shDNAs were subcloned into corresponding restriction sites of recipient vector pRRL.PPT.PGK.GFPpre. Lentiviral particles were produced in HEK293T cells by transient transfection using a calcium phosphate protocol. Cells transduced with a lentiviral vector lacking the TGF $\beta 2$-specific shRNA expression cassette (CTRL) and a nontargeting scrambled shRNA sequence $(\mathrm{SCR})$, which did not significantly differ from CTRL (not shown) ${ }^{35}$, served as controls. Quantitative RT-PCR was subsequently used to determine the knockdown efficacies: TRCN0000033425 (RNAi-1) and TRCN0000033427 (RNAi-2) were selected as best performing shDNA clones, reaching 75-80\% of NM_003238 mean knock- 
down efficacy at a MOI of 1.5 in HEK29T cells (data not shown). In subsequent experiments, P1 OAHACs from three donors were seeded and transduced at a MOI of 2 with RNAi-1 and RNAi- 2 for $\pm 18 \mathrm{~h}$ as described earlier ${ }^{35}$. Cells were then used as passage 2 cells in monolayer culture $\left(10,000\right.$ cells $\left./ \mathrm{cm}^{2}\right)$ and cultured under hypoxia or normoxia for $48 \mathrm{~h}$.

\section{Results}

\subsection{Hypoxia and Chondrocyte Marker Expression}

To validate our culture system, we first confirmed the expression of accepted marker genes that have been shown to be hypoxia-responsive in different species and in vitro

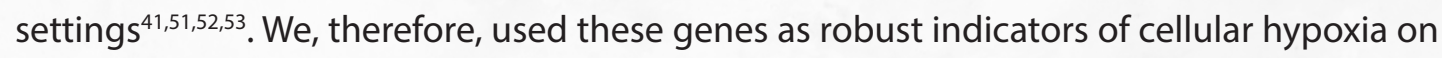
mRNA level: a highly significant upregulation was found for four out of five of these markers under $1 \% \mathrm{pO}_{2}$ (Figure $1 \mathrm{~A}$ ). When compared to the $20 \% \mathrm{pO}_{2}$ "normoxic" controls, PHD3 and VEGF were the most hypoxia responsive, displaying a more than 20 -fold upregulation under $1 \% \mathrm{pO}_{2}$, while GDF10 and COX2 were upregulated almost 7-fold. Expression of HAS2 was not significantly affected by hypoxia, although data suggested its responsiveness to hypoxia in chondrocytes ${ }^{41,54}$.
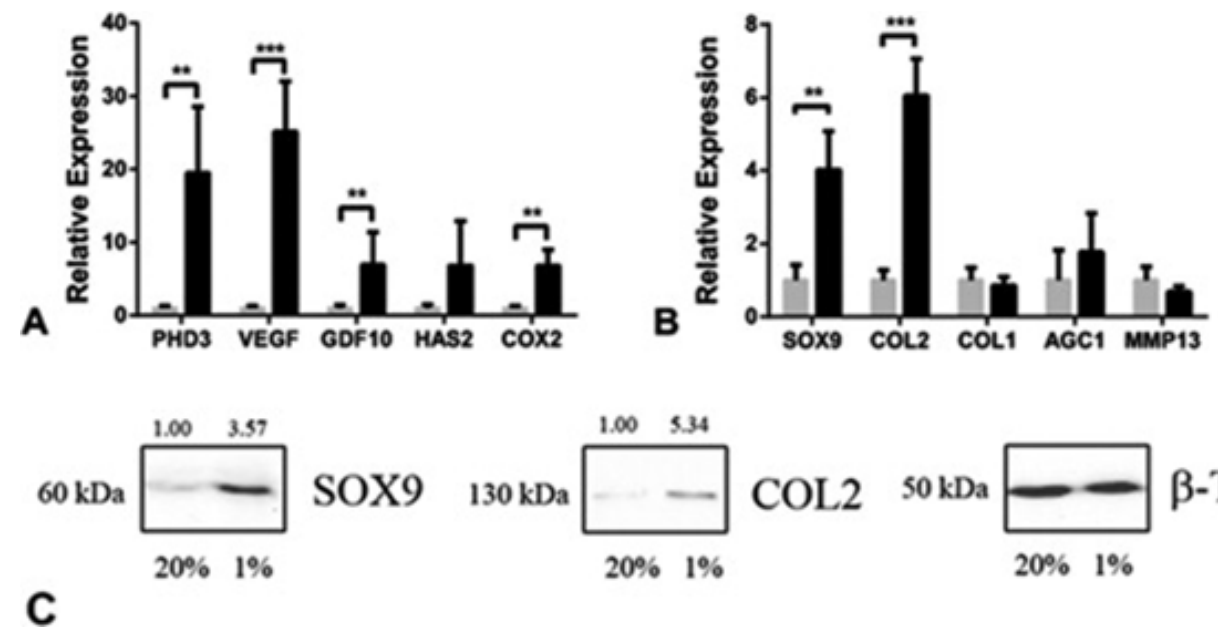

COL2 $50 \mathrm{kDa}$

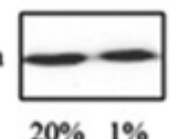

$\beta$-Tubulin

$20 \% 1 \%$ 


\section{Chapter 2}

Figure 1: Relative gene expression of hypoxia- and chondrocyte-specific markers.

Expression of accepted indicators of hypoxia in chondrocytes (A) next to that of chondrocyte differentiation-specific markers (B) after $48 \mathrm{~h}$ in bioreactor culture. Representative protein expression of SOX9, collagen type II (COL2A1) and $\beta$-tubulin (loading control) (C). Hypoxia ( $1 \% \mathrm{pO} \mathrm{z}^{\prime}$ black bars) and normoxia (20\% $\mathrm{pO}_{2^{\prime}}$ gray bars). Molecular weight markers $(\mathrm{kDa})$ are indicated on the left and normalized quantitative data above respective bands. ${ }^{* *} p<0.01,{ }^{* * *} p<0.001$.

Next, we studied the expression levels of selected chondrocyte differentiation stage specific markers: hypoxia induced COL2-specific transcription factor SOX955,56,57 significantly (4fold), along with that of COL2 (6-fold) itself. In contrast, collagen type I (COL1) expression was downregulated under the same condition (Figure 1B), leading to an improved COL2/ COL1 ratio (data not shown). Interestingly, we could only detect a non-significant trend toward upregulation of the core protein of key proteoglycan (PG) aggrecan (AGC1) after $48 \mathrm{~h}$ of low oxygen pressure. Of note, the key chondrocyte hypertrophy marker matrix metalloproteinase $13(M M P 13)^{58}$ showed a non-significant trend toward downregulation under these conditions. We further verified the expression of key chondrocyte phenotype markers, SOX9 and COL2, at protein level by Western blot analysis and confirmed a significant, more than 3-fold, upregulation of both (Figure 1C).

\subsection{Hypoxia Mediated TGF- $\beta$ Isoform Expression}

Since the TGF- $\beta$ system plays a crucial role in cartilage homeostasis and repair, we investigated its oxygen pressure-dependent regulation in articular chondrocytes. Of all three human isoforms, hypoxia specifically induced TGF- $\beta 2$ expression in human articular chondrocytes: Following $48 \mathrm{~h}$ of $1 \% \mathrm{pO}_{2}$ TGF- $\beta 2$ mRNA was significantly up-regulated by $60 \%$ as compared to the normoxic control $\left(20 \% \mathrm{pO}_{2}\right)$. Expression of the other two isoforms (TGF- $\beta 1$ and $-\beta 3$ ) was not altered under these conditions (Figure $2 A$ ). Subjecting human chondrocytes to $5 \% \mathrm{pO}_{2}$ also did not significantly alter the expression of TGF- $\beta$ isoforms (data not shown). Consequently, we further focused on comparing $1 \% \mathrm{pO}_{2}$ to $20 \% \mathrm{pO}_{2}$. To verify whether the detected changes on mRNA level could be biologically meaningful, we also performed TGF- $\beta 2$ immunoblots to demonstrate a similar magnitude of regulation at the protein level (Figure 2B). 
A
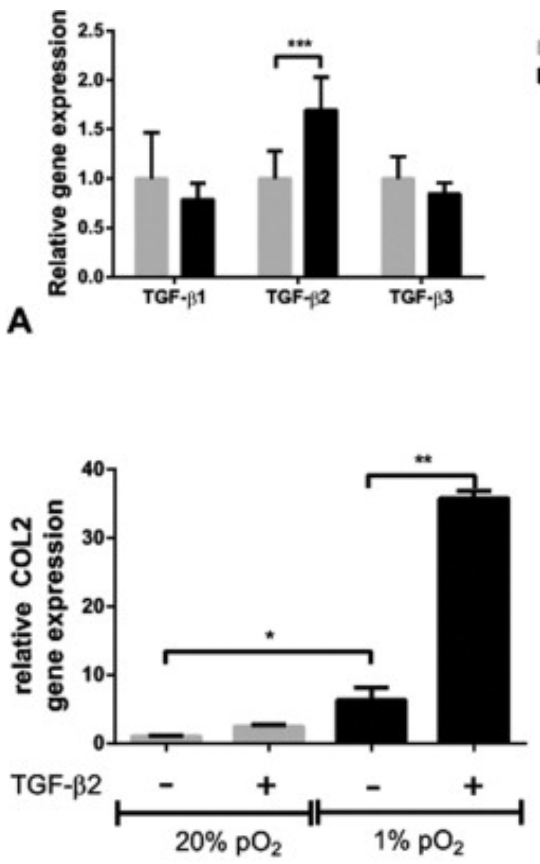

C

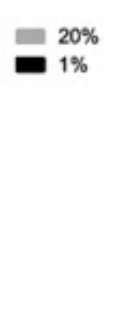

B
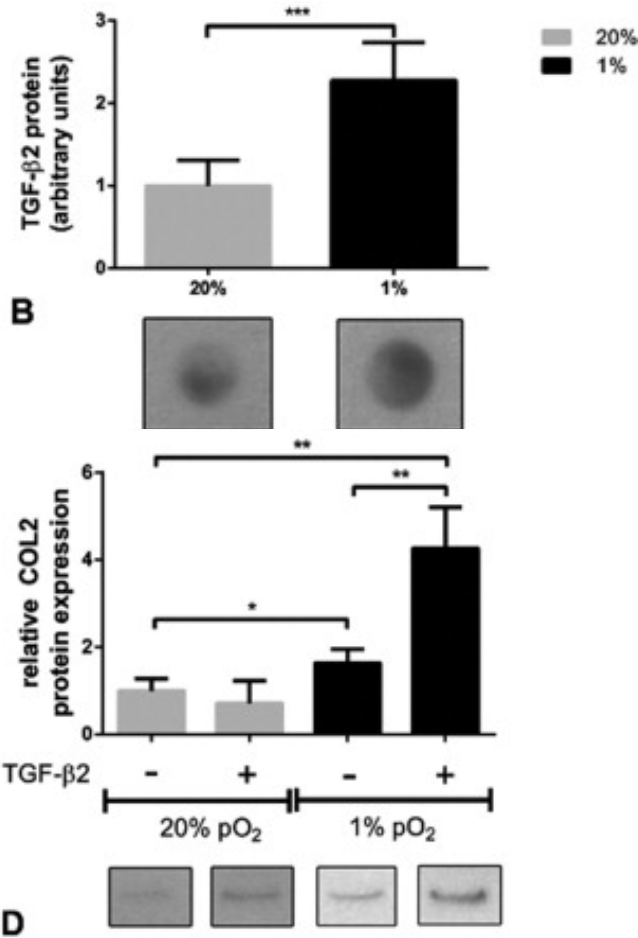

Figure 2: Oxygen tension dependent changes in gene expression of TGF- $\beta$ and collagen.

Relative mRNA abundance of the three mammalian TGF- $\beta$ isoforms after $48 h(A)$. Expression of TGF- $\beta 2$ protein under hypoxia and normoxia with representative blots below (B). Effects of hypoxia and stimulation with exogenous TGF- $\beta 2(10 \mathrm{ng} / \mathrm{ml})$ on the induction of COL2A1 mRNA (C) and COL2 protein expression (D). Representative immunoblot signals are shown below their respective quantification chart. Hypoxia (1\% $\mathrm{pO}_{2^{\prime}}$ black bars) and normoxia (20\% $p \mathrm{O}_{2^{\prime}}$ gray bars). ${ }^{*} p<0.05,{ }^{* *} p$ $<0.01,{ }^{* *} p<0.001$.

Exogenously appliedTGF- $\beta 2$ is known to induce COL2 expression in rabbit perichondrial cells cultured in alginate beads ${ }^{59}$, but little is known about its effects under hypoxic conditions. Therefore, we tested whether this isoform would also be able to induce COL2 expression in human articular chondrocytes. Under normoxic conditions $\left(20 \% \mathrm{pO}_{2}\right)$ exogenous TGF- $\beta 2$ did not significantly upregulate COL2 mRNA expression (Figure $2 \mathrm{C}$ ). In contrast, as shown previously (Figure 1B), hypoxia itself was able to induce COL2 expression to some extent. However, there was a prominent synergistic induction once exogenous TGF- $\beta 2$ was applied 
under hypoxic conditions: COL2 mRNA was significantly induced 5.7-fold. At the protein level, a similar trend was confirmed, resulting in a synergistic 4-fold induction of collagen type II under low oxygen pressure in the presence of TGF- $\beta 2$ (Figure 2D).

\subsection{Hypoxia and TGF- $\beta$ Receptor Expression}

To further shed light on the hypoxia-mediated TGF- $\beta$ signaling, we looked into the expression of relevant TGF- $\beta$ receptors. Hypoxic culture led to a significant upregulation of the expression of both type-1 receptors, ALK1 and ALK5 (Figure 3A), which more than doubled (approximately $120 \%$ increase) compared to the normoxic condition. In contrast, expression of the type II (TGFBR2) and type III receptors (BGCAN and EGN) was unaffected by changes in oxygenation levels (Figure 3B and C).

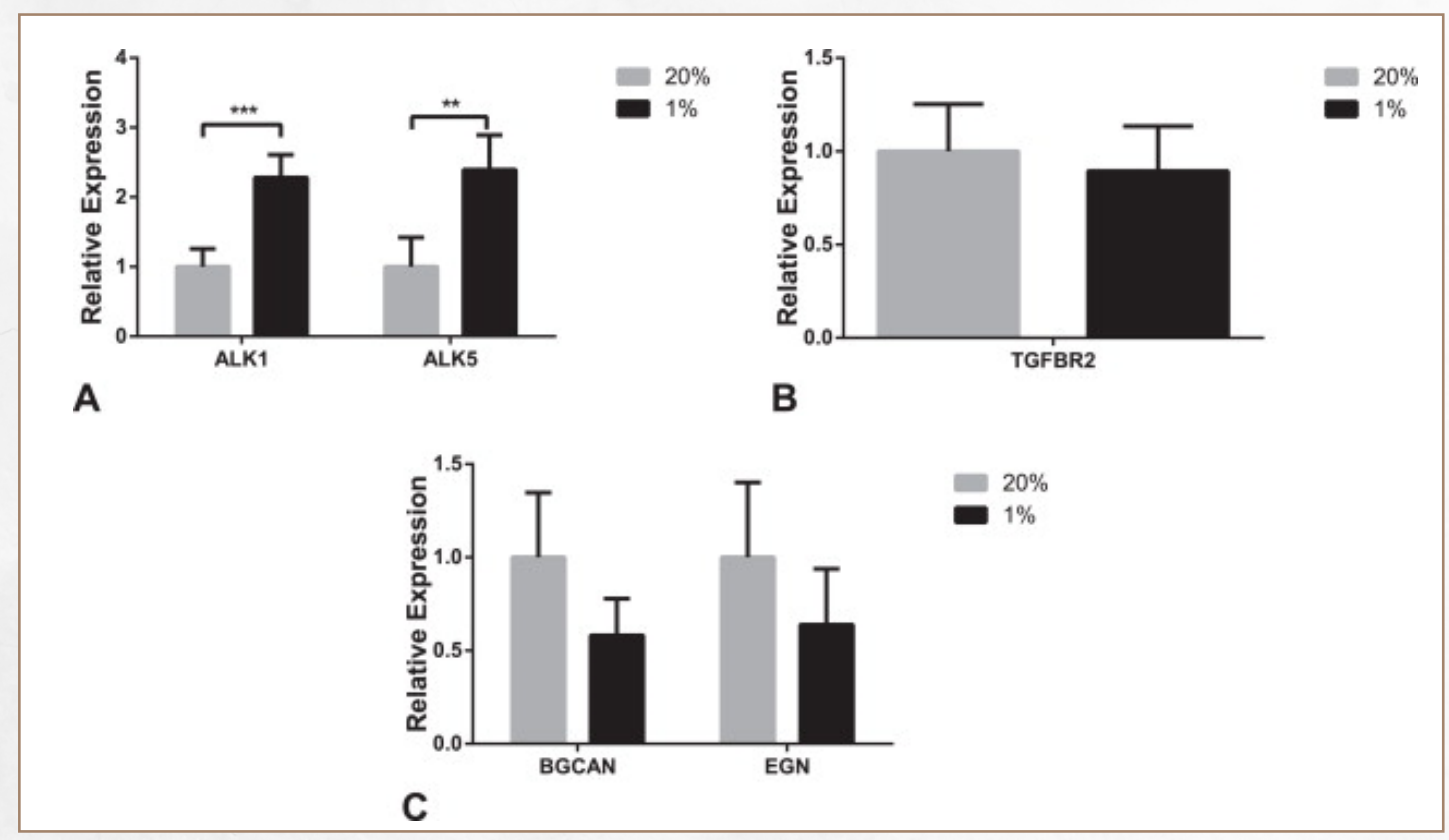

Figure 3: Oxygenation-dependent expression of TGF- $\beta$ receptors.

Type I receptors $A L K 1$ and ALK5 (A) next to type II receptor (B) and type III receptors (C). Hypoxia (1\% $\mathrm{pO}_{z^{\prime}}$ black bars) and normoxia (20\% $\mathrm{pO}_{z^{\prime}}$ gray bars). ${ }^{* *} p<0.01,{ }^{* * *} p<0.001$. 


\subsection{TGF- $\beta$ Signaling Interference}

Hypoxia induced COL2 expression in human articular chondrocytes in vitro and TGF- $\beta 2$ was the only isoform of this cytokine that was also induced upon oxygen deprivation in these cells. In addition, applying exogenous TGF- $\beta 2(10 \mathrm{ng} / \mathrm{ml})$ to these cells synergistically induced collagen type II expression at the mRNA and protein levels (Figure $2 \mathrm{C}$ and D) exclusively under hypoxic conditions. Therefore, we used isoform-specific shRNAs to investigate whether a specific knockdown of TGF- $\beta 2$ could selectively suppress COL2 levels under hypoxic conditions.

First, we evaluated the knockdown efficacy of five commercially available shRNA sequences by screening residual TGF- $\beta 2$ expression levels in HEK293 cells as reported earlier ${ }^{35}$. In our study, only two constructs (RNAi-1 and -2) reached at least $70 \%$ knockdown efficacy (data not shown) and were chosen for further experiments using primary human articular chondrocytes. In primary chondrocytes we first verified the TGF- $\beta$ isoform specificity and knockdown efficacy of the two most efficient shDNAs constructs 48 and $96 \mathrm{~h}$, respectively, after lentiviral transduction (Figure $4 \mathrm{~A}$, only RNAi-1 is shown). RNAi selectively suppressed only TGF- $\beta 2$ expression without negatively affecting the other two mammalian TGF- $\beta$ isoforms. The shRNA expression was shown to result in a stable, about 70\% (as compared to non-targeting controls, normalized to 1 ), efficient knockdown in cells $48 \mathrm{~h}$ after transduction and $48 \mathrm{~h}$ later $(96 \mathrm{~h}$ ) in alginate beads.

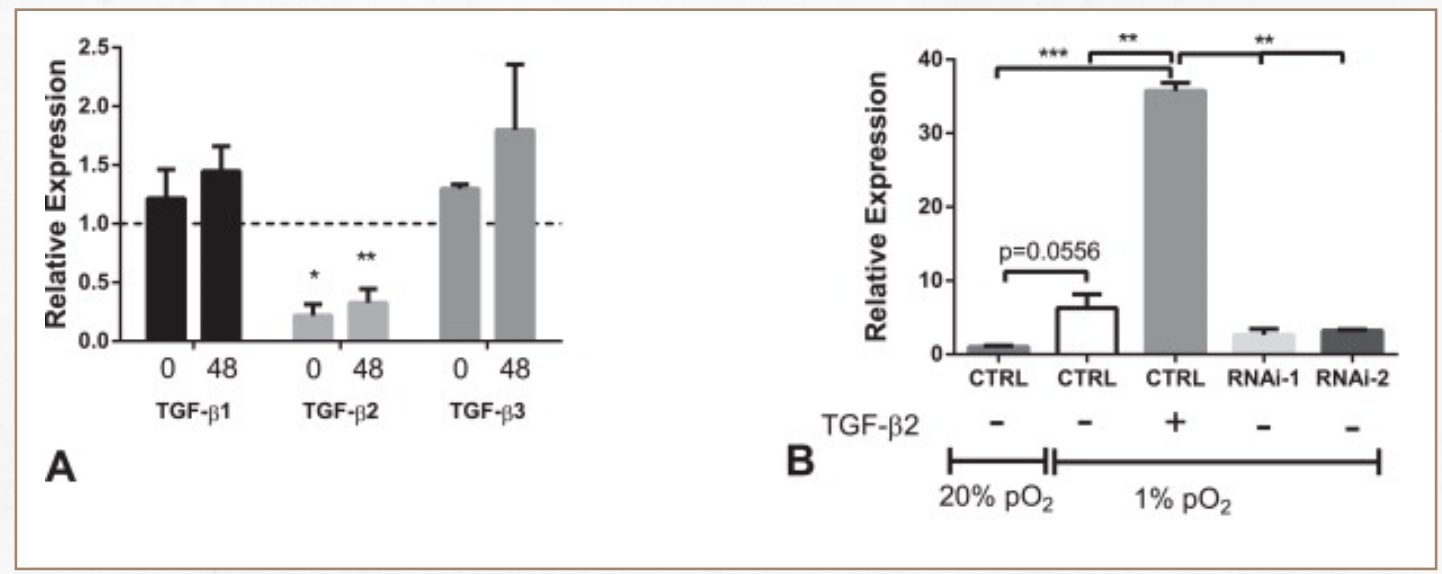




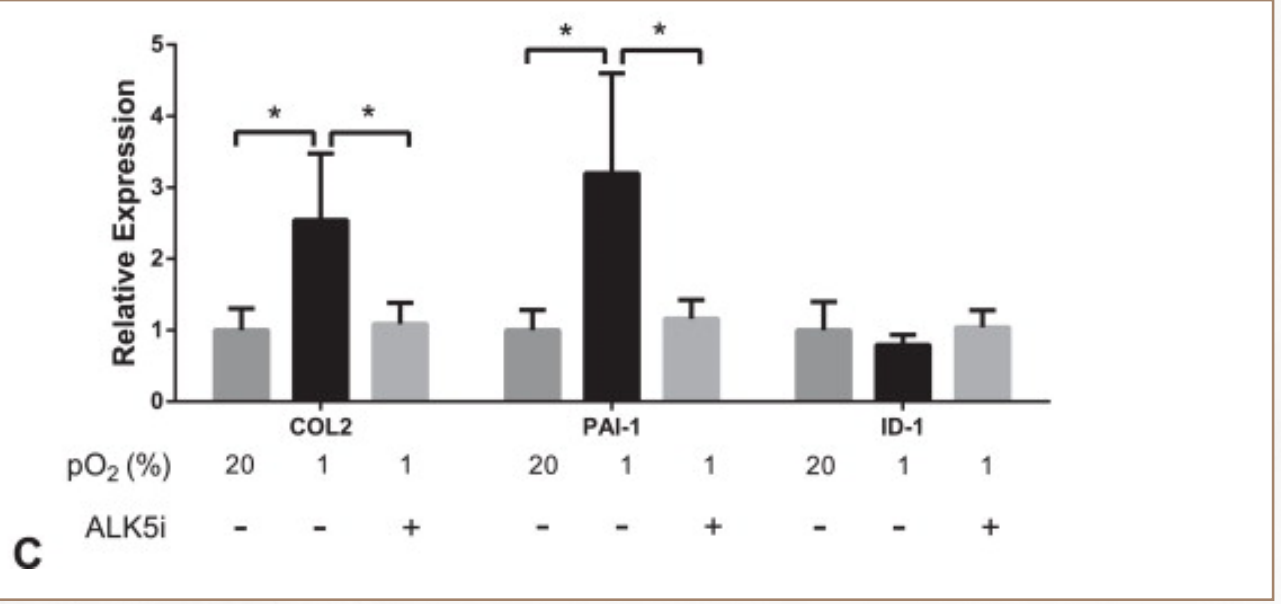

Figure 4: Specificity and efficacy of TGF- $\beta 2$ RNAi and TGF- $\beta$ receptor inhibition.

Confirmation of the isoform specificity and knockdown efficacy of the lentiviral shRNA vectors in primary chondrocytes (A). Suppression of hypoxia-induced TGF- $\beta$ mediated COL2 expression in primary chondrocytes by TGF- $\beta 2$ RNAi (B). A specific small molecular receptor antagonist (SB-525334, ALK5i) was used to confirm ALK5 participation in the TGF- $\beta 2$ mediated downstream signaling. PAI-1 and ID-1 served as established TGF- $\beta$ inducible, but strictly ALK5- and ALK1 dependent, controls (C). Hypoxia (1\% pO $\mathrm{2}^{\prime}$ black bars) and normoxia (20\% $\mathrm{pO}_{2^{\prime}}$ gray bars). ${ }^{*} p<0.05,{ }^{* *} p<0.01,{ }^{* * *} p<0.001$.

In primary human chondrocytes in alginate beads in a bioreactor culture system, hypoxic conditions alone non-significantly $(p=0.0556)$ upregulated COL2 mRNA expression in the non-targeting controls (CTRL). Addition of exogenous TGF- $\beta 2(10 \mathrm{ng} / \mathrm{ml})$ to these hypoxic cells prominently and synergistically increased COL2 expression even further (Figure 4B). In contrast, effective TGF- $\beta 2$ RNAi by means of non-transient lentiviral shRNA expression (RNAi-1 and -2) significantly suppressed this induction in COL2 expression. The TGF- $\beta 2$ RNAi suppressed the COL2 expression to below that of the non-targeting control (Figure 4B).

Finally, we aimed to identify the receptor that mediates this TGF- $\beta 2$-dependent upregulation of COL2 expression under hypoxic conditions. To this end, we used a highly ALK5-specific, novel type I receptor inhibitor under the same experimental conditions. While hypoxia, again, reproducibly induced COL2 expression under hypoxic conditions, the presence of the small molecular ALK5 antagonist SB-525334 (ALK5i) fully abrogated this effect (Figure 4C): COL2 induction was suppressed to control levels. Interestingly, in contrast to blocking 
TGF- $\beta 2$ itself, COL2 mRNA levels were indistinguishable between normoxic controls and the hypoxic condition with ALK5i. The established TGF- $\beta$-inducible and ALK5-dependent expression of PAI- ${ }^{49,60}$ revealed a very similar pattern to that of $C O L 2$. The expression of ID1 , which is reported to be TGF- $\beta$-inducible but in chondrocytes ALK1-dependent ${ }^{48}$, was not induced by hypoxia nor affected by ALK5i (Figure 4C).

\section{Discussion}

In the present study, we used a sophisticated bioreactor system to stringently feedbackcontrol the dissolved oxygen concentration in culture media of 3D-cultured chondrocytes to show that hypoxia $\left(1 \% \mathrm{pO}_{2}\right)$ induces $\mathrm{COL} 2$ expression. We further hypothesized that hypoxia facilitates TGF- $\beta$ signaling, which via ALK5, synergistically contributes to an improved phenotype by inducing the expression of key chondrocyte marker COL2A1 in redifferentiating human chondrocytes.

We first validated our culture system and confirmed the robust expression of well established hypoxia-responsive marker genes (Figure 1A). Hypoxia inducible factor, HIF, expression and transcriptional activity are regulated by oxygen-sensitive prolyl hydroxylases (PHD1-3), of which PHD3 was shown to be most prominently regulated by sustained hypoxic culture in other cells ${ }^{61}$. We confirmed its strong, 20-fold, induction in hypoxic chondrocytes. Others reported VEGF, GDF10, HAS2 and COX-2 (PTGS2) as hypoxia responsive genes ${ }^{41,51,52,53,62}$. Expression of vascular endothelial growth factor, VEGF, is hypoxia-inducible in cartilage cells $s^{63}$, but the magnitude of its induction (20-fold, Figure 1B) was unexpected. Lafont et al. ${ }^{41}$ earlier reported a rather moderate, approximately 3-fold induction, of this gene, which may be an underestimation due to their microarray-based analysis or result from the fact that these authors analyzed healthy human chondrocytes from osteosarcomas, since VEGF expression is known to be higher in $\mathrm{OA}^{64}$. The fold-change of GDF10 and COX-2 expression in the present study is in nice agreement with earlier reported QPCR data ${ }^{41}$.

Hyaluronan, a key component of the chondrocytes' ECM, is synthesized by a family of hyaluronic acid synthetases (HAS). HAS2, which is a particularly important isoform, was 
upregulated by hypoxia in our cultures, but just not significantly due to a large standard deviation. Others ${ }^{41,54}$ have also reported its positive hypoxia-dependency, although the fold change of hypoxia-induced HAS2 regulation was moderate $(<3$-fold). We further evaluated the hypoxia-dependency of selected other components of the chondrocytes' ECM, like SOX9, collagens, key proteoglycan aggrecan and hypertrophy marker MMP13 (Figure 1B). COL1 expression was not-significantly regulated in our study, but slightly, about $50 \%$, suppressed in another study using human chondrocytes in hypoxic 3D-culture ${ }^{54}$. The trend toward upregulation of $A G C 1$ under $1 \% \mathrm{pO}_{2}$ in our study was not significant. This may be a timing issue as $A G C 1$ expression seems to respond early ${ }^{41}$. Overall, $A G C 1$ seems to be only moderately induced by hypoxia ${ }^{41,54}$, which is apparently sufficient to double the sGAG content in cultured human chondrocyte pellets ${ }^{54}$ and the trend in our data may thus still be biologically meaningful. The magnitude of hypoxia-induced fold changes in SOX9 and COL2A 1 expression in human chondrocytes seem to be rather robust and there are similarities between our data and earlier studies ${ }^{41,54}$. Therefore, we propose that these genes can be viewed as robust indicators of cellular hypoxia at the mRNA level. A plethora of data suggests that, for tissue engineering, being able to improve $C O L 2 A 1$ expression may be more relevant than controlling $A G C 1$. Since $C O L 2 A 1$ can be regarded as the prime marker for redifferentiation, with SOX9 driving its expression, we verified the induction of both key factors at the protein level.

TGF- $\beta$ ligands have already been described as secreted polypeptides capable of inducing collagen production in general ${ }^{65}$ and in cartilage in particular ${ }^{24,25}$. We found a significant and selective upregulation of specifically the TGF- $\beta 2$ isoform, which was verified at protein expression level (Figure $2 A$ and $B$ ). This led us to postulate that the endogenously produced TGF- $\beta 2$ isoform is critically involved in the hypoxia-driven induction of COL2. Exogenous TGF- $\beta 2$ is known to upregulate $\mathrm{CO} 22$ in redifferentiating chondrocytes ${ }^{24,25}$ and its expression has also been shown to be hypoxia-driven in other cells ${ }^{13}$. Subjecting human chondrocytes to $5 \% \mathrm{pO}_{2^{\prime}}$ instead of $1 \% \mathrm{pO}_{2^{\prime}}$ did not significantly alter the expression of TGF- $\beta 2$ (data not shown), which suggests a potential contribution of hypoxia inducible factors (HIF) to hypoxic COL2a 1 production. The promoter regions of the TGF- $\beta$ isoforms are appreciably different from each other and characterization of the $5 \square$ UTR of the human TGF- $\beta$ genes 
also revealed that TGF- $\beta 2$ has the longest regulatory region of all isoforms to regulate its transcription and translation ${ }^{11}$. TGF- $\beta 2$ was shown to auto-induce its own mRNA after only $3 \mathrm{~h}^{66}$. Of note, blocking HIF-1a can also reduce TGF- $\beta$ stimulated collagen production ${ }^{67}$. TGF- $\beta 2$ is also different from the other two isoforms in that it needs betaglycan for signaling. TGF- $\beta$ /Smad3 signaling is then able to inhibit terminal hypertrophic differentiation of chondrocytes ${ }^{68}$. Even low concentrations of $1 \mathrm{ng} / \mathrm{ml}$ of TGF- $\beta$ can quickly upregulate its own receptors. In our study, protein levels of TGF- $\beta 2$ were also increased under hypoxia over two-fold (Figure 2B). Since low concentrations already have biological relevance, this increase can cause further downstream effects.

To further shed light on the hypoxia-mediated TGF- $\beta$ signaling, we also screened the expression of relevant TGF- $\beta$ receptors. Hypoxic culture significantly increased expression levels of both type I receptors that are involved in TGF- $\beta$ signaling in chondrocytes (ALK1 and $A L K 5^{49,60}$ ), but did not alter the expression of TGFBR2 or BGCAN and EGN (Figure 3). We cannot exclude that post-transcriptional regulation affected receptor protein levels differently as we were not able to investigate this aspect; this will be addressed in future studies. A previous study also reported upregulation of one type I receptor under short term hypoxia $\left(5 \% \mathrm{pO}_{2}{ }^{15}\right.$ ), but only looked at ALK5. While BGCAN favors TGF- $\beta 2$-mediated signaling, EGN regulates TGF- $\beta$ receptor endocytosis and inhibits TGF- $\beta$ signaling ${ }^{69}$. TGFBR2B (TbetaRII-B), a splice variant of TGFBR2, is also prominently expressed by osteoarthritic human chondrocytes and can form heteromeric complexes with all type I, II and III receptors and can thereby enhance TGF- $\beta$ signaling in chondrocytes when being overexpressed ${ }^{70}$. However, expression of this variant is another unexplored aspect that may have contributed to the upregulation of COL2 levels under hypoxia. Interestingly, it is the ratio between the two type I receptors that is suggested to dictate the TGF- $\beta$ response in chondrocytes ${ }^{29,49}$. Although hypoxia upregulated both ALK1 and ALK5, post transcriptional effects of hypoxia on either type I receptor might shift that balance at the cell signaling level. Additionally, EGN, which binds TGF- $\beta 1$ and $-\beta 3$, but not TGF- $\beta 2^{71,72}$, can inhibit the ALK5-mediated Smad2 phosphorylation (Smad2-P) in human chondrocytes ${ }^{73}$. Interestingly, hypoxia non-significantly decreased EGN expression, which would be in line with an ALK5Smad2-P dominance between these two signaling routes. Future experiments should 


\section{Chapter 2}

look into phosphorylation of Smads in this model to elucidate the active signaling routes involved.

Next, we employed RNAi to confirm a crucial contribution of TGF- $\beta 2$ to the hypoxiainduced COL2 production. Upon confirmation of the isoform specificity of the anti-TGF- $\beta 2$ shRNAs (Figure 4A), we showed that, in primary human chondrocytes, severely hypoxic conditions $\left(1 \% \mathrm{pO}_{2}\right)$ alone only just non-significantly upregulated COL2 mRNA expression in non-targeting controls (CTRL, Figure 4B). The addition of exogenous TGF- $\beta 2$ to these hypoxic cells, again prominently and synergistically increased COL2 expression. Nontransient lentiviral anti-TGF- $\beta 2$ shRNA expression significantly suppressed this induction in COL2 expression to below that of the non-targeting control. This is in line with a cell signaling model in which hypoxic conditions induce TGF- $\beta 2$ synthesis in order to maintain an autoregulatory loop that induces COL2 expression in these cells. However, in cells which actively express anti-TGF- $\beta 2$ shRNAs, the hypoxia-induced nascent TGF- $\beta 2$ mRNAs will be readily degraded. In these cells any positive contribution of TGF- $\beta 2$ signaling to the COL2 expression is inhibited and cannot reach the same level as in the untreated hypoxic cells. On the other hand, as the knockdown is never $100 \%$ efficient, the residual TGF- $\beta 2$ mRNAs in these cells may be sufficient to induce COL2 expression to just above normoxic control levels (Figure 4B).

We further inhibited ALK5 to elucidate its role during the TGF- $\beta 2$-mediated hypoxic induction of COL2 synthesis in human chondrocytes: while hypoxia induced COL2, ALK5i suppressed it (Figure 4C). In chondrocytes, TGF- $\beta$ signaling promotes HIF1a stabilization via ALK5 ${ }^{74}$, which would establish a positive feedback loop between hypoxia and TGF- $\beta$ signaling.

When demonstrating the hypoxia- and TGF- $\beta 2$-dependency of COL2 expression, we further used PAI-1 as an internal control: its expression was recently shown to depend on both, TGF- $\beta$ and HIF1A, in other cells ${ }^{75}$. Also, induction of PAI-1 crucially depends on SMAD3 and SMAD4 binding ${ }^{76}$. Exposure of HUVEC cells to $1 \% \mathrm{pO}_{2}$ resulted in SMAD binding to the -77 to -40 bp region ("CAGA box") in the TGF- $\beta 2$ promoter and increased TGF- $\beta 2$ mRNA levels as compared to normoxic controls $\left(20 \% \mathrm{pO}_{2}\right)$. These authors used a 3TP-lux reporter, 
a Smad2/3-responsive construct ${ }^{77}$ similar to the Smad3-responsive CAGA $_{12}$-lux reporter construct ${ }^{78}$, which is basically derived from the minimal SREs of the PAl-1 promoter, to show the SMAD-dependency of TGF- $\beta 2$ signaling in their system. Also here, TGF- $\beta 2$ mRNA was the only specifically induced TGF- $\beta$ isoform ${ }^{13}$. Finnson et al. ${ }^{60}$ showed that COL2 and PAI-1 is stimulated by exogenous TGF- $\beta 1$ in chondrocytes. It has also been shown in hepatocytes that the HRE site in the PAI-1 promoter could be a target for CREB binding to mediate PAI-1 gene induction ${ }^{79,80}$. Interestingly, TGF- $\beta 2$ is also the only isoform with multiple, hypoxiasensitive, CRE elements within 400 nucleotides upstream of its $\mathrm{P} 1$ promoter $^{11}$. Although TGF- $\beta 2$ is structurally similar to TGF- $\beta 1$, their biological responses may differ dependent upon cell type dependently. Interestingly, initial data suggest that cartilaginous effects of TGF- $\beta$ at low concentration $(1 \mathrm{ng} / \mathrm{ml}$ ) are especially dependent on low oxygenation levels below $5 \%{ }^{56}$.

Recently, Finnson et al..$^{60}$ also showed that endoglin enhanced TGF- $\beta 1$-induced Smad1/5 phosphorylation, but inhibits TGF- $\beta$-induced Smad2 phosphorylation, and Smad3-driven transcriptional COL2 and PAI-1 activation in chondrocytes. Our data support the notion that hypoxia induces the ALK5-SMAD2/3 pathway rather than ALK1-Smad1/5 signaling. We further used suppression of inhibitor of differentiation 1 (Id1), a downstream target of the BMPR2 pathway ${ }^{81}$ to show that the specificity of ALK5i: ID1 expression is not induced by hypoxia and not affected by ALK5i. ID-1 has been shown to be an ALK1 downstream target in endothelial cell $5^{50}$. It is interesting that ALK1 also stimulates MMP13 expression and we found a (non-significant) trend toward down regulation at MMP13 mRNA levels. The ID-1/ PAI-1 ratio also increases with OA progression (i.e. cartilage degradation) and that this is in line with a shift from ALK5 to predominant ALK1 signaling ${ }^{49}$. From Figure $4 C$ it is apparent that hypoxia increases the PAI-1/ID-1 ratio. We propose that this indicates a hypoxia-mediated shift in TGF $\beta$ signaling in favor of anabolic ALK5 signaling and ECM production. In addition, the $\mathrm{Sp} 1 / \mathrm{Sp} 3$ ratio is important for COL2 expression by chondrocytes, but was not studied by us. The levels of both transcription factors decrease with dedifferentiation ${ }^{82}$ and $\mathrm{Sp} 1$ overexpression increases $C O L 2$ expression. TGF- $\beta / S m a d 3$ signals are essential for repressing articular chondrocyte differentiation. Without these inhibition signals, chondrocytes leave the quiescent state and undergo terminal differentiation ${ }^{83}$. It is interesting that Sp1 has 


\section{Chapter 2}

been reported to be down-regulated by TGF- $\beta 1^{39}$; it would be interesting to see if this also holds for TGF- $\beta 2$ as our data would suggest the opposite.

In summary, our findings strongly suggest that the hypoxia-induced TGF- $\beta 2$ expression in human articular chondrocytes in vitro is responsible for the subsequent induction of type II collagen by these cells. We further provide data supporting the notion that ALK5 is critically involved in this process. This study suggests that hypoxic culture conditions for cartilage tissue engineering may benefit from an auto-regulatory TGF- $\beta$ signaling loop by the chondrocytes.

\section{Acknowledgements}

This research was funded by the Dutch Program Tissue Engineering (DPTE, Project No. RGT.6738) and the START initiative of the RWTH Aachen.

\section{Supplementary data}

Supplementary data associated with this article can be found, in the online version, at http://dx.doi.org/10.1016/j.aanat.2014.11.003. 


\section{References}

1 Falchuk KH, Goetzl EJ, Kulka JP. Respiratory gases of synovial fluids. An approach to synovial tissue circulatory-metabolic imbalance in rheumatoid arthritis. Am J Med. 1970;49(2):223-31.

2 Lund-Olesen K. Oxygen tension in synovial fluids. Arthritis Rheum. 1970;13(6):769-76.

3 Silver IA. Measurement of $\mathrm{pH}$ and ionic composition of pericellular sites. Philos Trans R Soc Lond B Biol Sci. 1975;271(912):261-72.

4 Treuhaft PS, DJ MC. Synovial fluid $\mathrm{pH}$, lactate, oxygen and carbon dioxide partial pressure in various joint diseases. Arthritis Rheum. 1971;14(4):475-84.

5 Grimshaw MJ, Mason RM. Bovine articular chondrocyte function in vitro depends upon oxygen tension. Osteoarthritis Cartilage. 2000;8(5):386-92.

6 Malda J, Martens DE, Tramper J, van Blitterswijk CA, Riesle J. Cartilage tissue engineering: controversy in the effect of oxygen. Crit Rev Biotechnol. 2003;23(3):175-94.

7 Grimshaw MJ, Mason RM. Modulation of bovine articular chondrocyte gene expression in vitro by oxygen tension. Osteoarthritis Cartilage. 2001;9(4):357-64.
8 Coyle CH, Izzo NJ, Chu CR. Sustained hypoxia enhances chondrocyte matrix synthesis. J Orthop Res. 2009;27(6):793-9.

9 Domm C, Schunke M, Steinhagen J, Freitag S, Kurz B. Influence of various alginate brands on the redifferentiation of dedifferentiated bovine articular chondrocytes in alginate bead culture under high and low oxygen tension. Tissue Eng. 2004;10(11-12):1796-805.

10 Miyazawa K, Shinozaki M, Hara T, Furuya T, Miyazono K. Two major Smad pathways in TGF-beta superfamily signalling. Genes Cells. 2002;7(12):1191-204.

11 Roberts AB, Sporn MB. Differential expression of the TGF-beta isoforms in embryogenesis suggests specific roles in developing and adult tissues. Mol Reprod Dev. 1992;32(2):91-8.

12 Sanford LP, Ormsby I, Gittenberger-de Groot AC, Sariola H, Friedman R, Boivin GP, et al. TGFbeta2 knockout mice have multiple developmental defects that are non-overlapping with other TGFbeta knockout phenotypes. Development. 1997;124(13):2659-70.

13 Akman $\mathrm{HO}$, Zhang $\mathrm{H}$, Siddiqui MA, Solomon W, Smith EL, Batuman 
$\mathrm{OA}$. Response to hypoxia involves transforming growth factor-beta2 and Smad proteins in human endothelial cells. Blood. 2001;98(12):3324-31.

14 Falanga V, Qian SW, Danielpour D, Katz $M H$, Roberts AB, Sporn MB. Hypoxia upregulates the synthesis of TGF-beta 1 by human dermal fibroblasts. J Invest Dermatol. 1991;97(4):634-7.

15 Martin G, Andriamanalijaona R, Grassel S, Dreier R, Mathy-Hartert M, Bogdanowicz P, et al. Effect of hypoxia and reoxygenation on gene expression and response to interleukin-1 in cultured articular chondrocytes. Arthritis Rheum. 2004;50(11):3549-60.

16 Jullien P, Berg TM, Lawrence DA. Acidic cellular environments: activation of latent TGF-beta and sensitization of cellular responses to TGF-beta and EGF. Int J Cancer. 1989;43(5):886-91.

17 Lyons RM, Keski-Oja J, Moses HL. Proteolytic activation of latent transforming growth factor-beta from fibroblast-conditioned medium. J Cell Biol. 1988;106(5):1659-65.

18 Yee JA, Yan L, Dominguez JC, Allan EH, Martin TJ. Plasminogen-dependent activation of latent transforming growth factor beta (TGF beta) by growing cultures of osteoblast-like cells. J Cell Physiol. 1993;157(3):528-34.
19 Annes JP, Munger JS, Rifkin DB. Making sense of latent TGFbeta activation. J Cell Sci. 2003;116(Pt 2):217-24.

20 O'Connor WJ, Botti T, Khan SN, Lane $J M$. The use of growth factors in cartilage repair. Orthop Clin North Am. 2000;31(3):399-410.

21 van der Kraan PM, Buma P, van Kuppevelt $T$, van den Berg WB. Interaction of chondrocytes, extracellular matrix and growth factors: relevance for articular cartilage tissue engineering. Osteoarthritis Cartilage. 2002;10(8):631-7.

22 Demoor-Fossard M, Boittin M, Redini F, Pujol JP. Differential effects of interleukin-1 and transforming growth factor beta on the synthesis of small proteoglycans by rabbit articular chondrocytes cultured in alginate beads as compared to monolayers. Mol Cell Biochem. 1999;199(1-2):69-80.

23 Vivien D, Galera P, Lebrun E, Loyau G, Pujol $J P$. Differential effects of transforming growth factor-beta and epidermal growth factor on the cell cycle of cultured rabbit articular chondrocytes. J Cell Physiol. 1990;143(3):534-45.

24 van Osch GJ, Mandl EW, Marijnissen WJ, van der Veen SW, Verwoerd-Verhoef HL, Verhaar JA. Growth factors in cartilage tissue engineering. Biorheology. 2002;39(1-2):215-20. 
25 Yaeger PC, Masi TL, de Ortiz JL, Binette F, Tubo R, McPherson JM. Synergistic action of transforming growth factorbeta and insulin-like growth factor-I induces expression of type II collagen and aggrecan genes in adult human articular chondrocytes. Exp Cell Res. 1997;237(2):318-25.

26 Okazaki R, Sakai A, Nakamura T, Kunugita $\mathrm{N}$, Norimura T, Suzuki K. Effects of transforming growth factor beta $s$ and basic fibroblast growth factor on articular chondrocytes obtained from immobilised rabbit knees. Ann Rheum Dis. 1996;55(3):181-6.

27 Leonard MO, Howell K, Madden SF, Costello CM, Higgins DG, Taylor CT, et al. Hypoxia selectively activates the CREB family of transcription factors in the in vivo lung. Am J Respir Crit Care Med. 2008;178(9):977-83.

28 Heldin CH, Miyazono K, ten Dijke P. TGFbeta signalling from cell membrane to nucleus through SMAD proteins. Nature. 1997;390(6659):465-71.

29 Finnson KW, Parker WL, ten Dijke $\mathrm{P}$, Thorikay M, Philip A. ALK1 opposes ALK5/Smad3 signaling and expression of extracellular matrix components in human chondrocytes. J Bone Miner Res. 2008;23(6):896-906.

30 Blaney Davidson EN, Remst DF, Vitters EL, van Beuningen $\mathrm{HM}$, Blom $\mathrm{AB}$, Goumans MJ, et al. Increase in ALK1/ALK5 ratio as a cause for elevated MMP-13 expression in osteoarthritis in humans and mice. J Immunol. 2009;182(12):7937-45.

31 Das RH, van Osch GJ, Kreukniet M, Oostra $J$, Weinans $\mathrm{H}$, Jahr $\mathrm{H}$. Effects of individual control of $\mathrm{pH}$ and hypoxia in chondrocyte culture. J Orthop Res. 2010;28(4):537-45.

32 Uitterlinden EJ, Jahr H, Koevoet JL, Jenniskens YM, Bierma-Zeinstra SM, Degroot J, et al. Glucosamine decreases expression of anabolic and catabolic genes in human osteoarthritic cartilage explants. Osteoarthritis Cartilage.

2006;14(3):250-7.

33 Uitterlinden EJ, Jahr H, Koevoet JL, Bierma-Zeinstra SM, Verhaar JA, Weinans $\mathrm{H}$, et al. Glucosamine reduces anabolic as well as catabolic processes in bovine chondrocytes cultured in alginate.

Osteoarthritis Cartilage. 2007;15(11):126774.

34 Bustin SA, Benes V, Garson JA, Hellemans J, Huggett J, Kubista M, et al. The MIQE guidelines: minimum information for publication of quantitative real-time PCR experiments. Clin Chem. 2009;55(4):61122.

35 van der Windt AE, Haak E, Das RH, Kops N, Welting TJ, Caron MM, et al. Physiological tonicity improves human chondrogenic 
marker expression through nuclear factor of activated T-cells 5 in vitro. Arthritis Res Ther. 2010;12(3):R100.

36 Foldager CB, Munir S, Ulrik-Vinther M, Soballe K, Bunger C, Lind M. Validation of suitable house keeping genes for hypoxiacultured human chondrocytes. BMC Mol Biol. 2009;10:94.

37 Pfaffl MW, Tichopad A, Prgomet C, Neuvians TP. Determination of stable housekeeping genes, differentially regulated target genes and sample integrity: BestKeeper--Excel-based tool using pair-wise correlations. Biotechnol Lett. 2004;26(6):509-15.

38 Livak KJ, Schmittgen TD. Analysis of relative gene expression data using real-time quantitative $P C R$ and the 2(-Delta Delta $C(T)$ ) Method. Methods. 2001;25(4):402-8.

39 Bauge C, Cauvard O, Leclercq S, Galera $\mathrm{P}$, Boumediene K. Modulation of transforming growth factor beta signalling pathway genes by transforming growth factor beta in human osteoarthritic chondrocytes: involvement of Sp1 in both early and late response cells to transforming growth factor beta. Arthritis Res Ther. 2011;13(1):R23.

40 Das $\mathrm{RH}$, Jahr $\mathrm{H}$, Verhaar JA, van der Linden JC, van Osch GJ, Weinans H. In vitro expansion affects the response of chondrocytes to mechanical stimulation. Osteoarthritis Cartilage. 2008;16(3):38591.

41 Lafont JE, Talma S, Hopfgarten C, Murphy $\mathrm{CL}$. Hypoxia promotes the differentiated human articular chondrocyte phenotype through SOX9-dependent and -independent pathways. J Biol Chem. 2008;283(8):4778-86.

42 van der Windt AE, Haak E, Kops N, Verhaar JA, Weinans $\mathrm{H}$, Jahr H. Inhibiting calcineurin activity under physiologic tonicity elevates anabolic but suppresses catabolic chondrocyte markers. Arthritis Rheum. 2012;64(6):1929-39.

43 Caron MM, Emans PJ, Coolsen MM, Voss L, Surtel DA, Cremers A, et al. Redifferentiation of dedifferentiated human articular chondrocytes: comparison of $2 \mathrm{D}$ and $3 \mathrm{D}$ cultures. Osteoarthritis and cartilage / OARS, Osteoarthritis Research Society. 2012;20(10):1170-8.

44 Siebelt M, Jahr H, Groen HC, Sandker $\mathrm{M}$, Waarsing JH, Kops N, et al. Hsp90 inhibition protects against biomechanically induced osteoarthritis in rats. Arthritis Rheum. 2013;65(8):2102-12.

45 Caron MM, van der Windt AE, Emans PJ, van Rhijn LW, Jahr H, Welting TJ. Osmolarity determines the in vitro chondrogenic differentiation capacity 
of progenitor cells via nuclear factor of activated T-cells 5. Bone. 2013;53(1):94102.

46 Grygielko ET, Martin WM, Tweed C, Thornton P, Harling J, Brooks DP, et al. Inhibition of gene markers of fibrosis with a novel inhibitor of transforming growth factor-beta type I receptor kinase in puromycin-induced nephritis. J Pharmacol Exp Ther. 2005;313(3):943-51.

47 Dennler S, Itoh S, Vivien D, ten Dijke P, Huet $S$, Gauthier JM. Direct binding of Smad 3 and Smad4 to critical TGF betainducible elements in the promoter of human plasminogen activator inhibitortype 1 gene. Embo J. 1998;17(11):3091100.

48 Goumans MJ, Valdimarsdottir G, Itoh S, Rosendahl A, Sideras P, ten Dijke P. Balancing the activation state of the endothelium via two distinct TGF-beta type I receptors. Embo J. 2002;21(7):174353.

49 Blaney Davidson EN, Remst DF, Vitters EL, van Beuningen $H M$, Blom $A B$, Goumans MJ, et al. Increase in ALK1/ALK5 ratio as a cause for elevated MMP-13 expression in osteoarthritis in humans and mice. J Immunol. 2009;182(12):7937-45.

50 Lebrin F, Goumans MJ, Jonker L, Carvalho $\mathrm{RL}$, Valdimarsdottir G, Thorikay M, et al. Endoglin promotes endothelial cell proliferation and TGF-beta/ALK1 signal transduction. Embo J. 2004;23(20):401828.

51 Fujita N, Markova D, Anderson DG, Chiba K, Toyama Y, Shapiro IM, et al. Expression of prolyl hydroxylases (PHDs) is selectively controlled by HIF-1 and HIF-2 proteins in nucleus pulposus cells of the intervertebral disc: distinct roles of PHD2 and PHD3 proteins in controlling HIF1alpha activity in hypoxia. J Biol Chem. 2012;287(20):16975-86.

52 Hashimoto K, Fukuda K, Yamazaki K, Yamamoto N, Matsushita T, Hayakawa S, et al. Hypoxia-induced hyaluronan synthesis by articular chondrocytes: the role of nitric oxide. Inflamm Res. 2006;55(2):72-7.

53 Lee JJ, Natsuizaka M, Ohashi S, Wong GS, Takaoka M, Michaylira CZ, et al. Hypoxia activates the cyclooxygenase2-prostaglandin E synthase axis. Carcinogenesis. 2010;31(3):427-34.

54 Markway BD, Cho H, Johnstone B. Hypoxia promotes redifferentiation and suppresses markers of hypertrophy and degeneration in both healthy and osteoarthritic chondrocytes. Arthritis Res Ther. 2013;15(4):R92.

55 Lefebvre V, Huang W, Harley VR, Goodfellow PN, de Crombrugghe B. SOX9 is a potent activator of the chondrocyte-specific enhancer of the pro 
alpha1(II) collagen gene. Mol Cell Biol. 1997;17(4):2336-46.

56 Murphy $\mathrm{CL}$, Thoms BL, Vaghjiani RJ, Lafont JE. Hypoxia. HIF-mediated articular chondrocyte function: prospects for cartilage repair. Arthritis Res Ther. 2009;11(1):213.

57 Stokes DG, Liu G, Dharmavaram R, Hawkins D, Piera-Velazquez S, Jimenez SA. Regulation of type-II collagen gene expression during human chondrocyte de-differentiation and recovery of chondrocyte-specific phenotype in culture involves Sry-type high-mobilitygroup box (SOX) transcription factors. Biochem J. 2001;360(Pt 2):461-70.

58 D'Angelo M, Yan Z, Nooreyazdan $M$, Pacifici M, Sarment DS, Billings PC, et al. MMP-13 is induced during chondrocyte hypertrophy. J Cell Biochem. 2000;77(4):678-93.

59 Van Osch GJ, Van Der Veen SW, Burger EH, Verwoerd-Verhoef HL. Chondrogenic potential of in vitro multiplied rabbit perichondrium cells cultured in alginate beads in defined medium. Tissue Eng. 2000;6(4):321-30.

60 Finnson KW, Parker WL, ten Dijke P, Thorikay M, Philip A. ALK1 opposes ALK5/Smad3 signaling and expression of extracellular matrix components in human chondrocytes. J Bone Miner Res.
2008;23(6):896-906.

61 Walmsley SR, Chilvers ER, Thompson AA, Vaughan K, Marriott HM, Parker LC, et al. Prolyl hydroxylase 3 (PHD3) is essential for hypoxic regulation of neutrophilic inflammation in humans and mice. J Clin Invest. 2011;121(3):1053-63.

62 Marxsen JH, Schmitt O, Metzen E, Jelkmann W, Hellwig-Burgel T. Vascular endothelial growth factor gene expression in the human breast cancer cell line MX-1 is controlled by $\mathrm{O} 2$ availability in vitro and in vivo. Ann Anat. 2001;183(3):243-9.

63 Zhang C, Li Y, Cornelia R, Swisher S, Kim $H$. Regulation of VEGF expression by HIF-1alpha in the femoral head cartilage following ischemia osteonecrosis. Sci Rep. 2012;2:650.

64 Jansen $\mathrm{H}$, Meffert RH, Birkenfeld F, Petersen W, Pufe T. Detection of vascular endothelial growth factor (VEGF) in moderate osteoarthritis in a rabbit model. Ann Anat. 2012;194(5):452-6.

65 Roberts AB, Sporn MB, Assoian RK, Smith JM, Roche NS, Wakefield LM, et al. Transforming growth factor type beta: rapid induction of fibrosis and angiogenesis in vivo and stimulation of collagen formation in vitro. Proc Natl Acad Sci U S A. 1986;83(12):4167-71.

66 Miura T, Shiota K. TGFbeta2 acts as an "activator" molecule in reaction-diffusion 
model and is involved in cell sorting phenomenon in mouse limb micromass culture. Dev Dyn. 2000;217(3):241-9.

67 Basu RK, Hubchak S, Hayashida T, Runyan CE, Schumacker PT, Schnaper HW. Interdependence of HIF-1alpha and TGF-beta/Smad3 signaling in normoxic and hypoxic renal epithelial cell collagen expression. Am J Physiol Renal Physiol. 2011;300(4):F898-905.

68 Grimaud E, Heymann D, Redini F. Recent advances in TGF-beta effects on chondrocyte metabolism. Potential therapeutic roles of TGF-beta in cartilage disorders. Cytokine Growth Factor Rev. 2002;13(3):241-57.

69 Bizet AA, Liu K, Tran-Khanh N, Saksena A, Vorstenbosch J, Finnson KW, et al. The TGF-beta co-receptor, CD109, promotes internalization and degradation of TGFbeta receptors. Biochim Biophys Acta. 2011;1813(5):742-53.

70 Parker WL, Finnson KW, Soe-Lin H, Knaus $P$, Philip A. Expression and function of TbetaRII-B, a variant of the type II TGFbeta receptor, in human chondrocytes. Osteoarthritis Cartilage. 2007;15(4):44253.

71 Brown CB, Boyer AS, Runyan RB, Barnett JV. Requirement of type III TGF-beta receptor for endocardial cell transformation in the heart. Science.
1999;283(5410):2080-2.

72 Sankar S, Mahooti-Brooks N, Centrella M, McCarthy TL, Madri JA. Expression of transforming growth factor type III receptor in vascular endothelial cells increases their responsiveness to transforming growth factor beta 2. J Biol Chem. 1995;270(22):13567-72.

73 Finnson KW, Parker WL, Chi Y, Hoemann $\mathrm{CD}$, Goldring MB, Antoniou J, et al. Endoglin differentially regulates TGFbeta-induced Smad2/3 and Smad1/5 signalling and its expression correlates with extracellular matrix production and cellular differentiation state in human chondrocytes. Osteoarthritis Cartilage. 2010;18(11):1518-27.

74 Estrada KD, Wang W, Retting KN, Chien $C T$, Elkhoury FF, Heuchel R, et al. Smad7 regulates terminal maturation of chondrocytes in the growth plate. Dev Biol. 2013;382(2):375-84.

75 Ueno M, Maeno T, Nomura M, AoyagiIkeda K, Matsui H, Hara K, et al. Hypoxiainducible factor- 1 alpha mediates TGFbeta-induced PAI-1 production in alveolar macrophages in pulmonary fibrosis. Am J Physiol Lung Cell Mol Physiol. 2011;300(5):L740-52.

76 Dennler S, Itoh S, Vivien D, ten Dijke P, Huet S, Gauthier JM. Direct binding of Smad3 and Smad4 to critical TGF beta- 
inducible elements in the promoter of human plasminogen activator inhibitortype 1 gene. Embo J. 1998;17(11):3091100.

77 Wrana JL, Attisano L, Carcamo J, Zentella A, Doody J, Laiho M, et al. TGF beta signals through a heteromeric protein kinase receptor complex. Cell. 1992;71(6):100314.

78 Dennler S, Huet S, Gauthier JM. A short amino-acid sequence in $\mathrm{MH} 1$ domain is responsible for functional differences between Smad 2 and Smad3. Oncogene. 1999;18(8):1643-8.

79 Dimova EY, Jakubowska MM, Kietzmann T. CREB binding to the hypoxia-inducible factor-1 responsive elements in the plasminogen activator inhibitor-1 promoter mediates the glucagon effect. Thromb Haemost. 2007;98(2):296-303.

80 Kvietikova I, Wenger RH, Marti HH, Gassmann M. The hypoxia-inducible factor-1 DNA recognition site is CAMPresponsive. Kidney Int. 1997;51(2):564-6.

81 Wu X, Chang MS, Mitsialis SA, Kourembanas $S$. Hypoxia regulates bone morphogenetic protein signaling through C-terminal-binding protein 1. Circ Res. 2006;99(3):240-7.

82 Ghayor C, Chadjichristos C, Herrouin JF, Ala-Kokko L, Suske G, Pujol JP, et al. Sp3 represses the Sp1-mediated transactivation of the human

COL2A1 gene in primary and dedifferentiated chondrocytes. J Biol Chem. 2001;276(40):36881-95.

83 Yang X, Chen L, Xu X, Li C, Huang C, Deng CX. TGF-beta/Smad3 signals repress chondrocyte hypertrophic differentiation and are required for maintaining articular cartilage. J Cell Biol. 2001;153(1):35-46. 



\section{Increased TGF- $\beta$ and BMP Levels and Improved Chondrocyte-Specific Marker Expression In Vitro under Cartilage-Specific Physiological Osmolarity.}

Timur UT, Caron MMJ, van den Akker G, van der Windt A, Visser J, van Rhijn LW, Weinans H, Welting TJM, Emans PJ, Jahr H Int J Mol Sci. 2019;20(4). 


\section{Abstract}

\section{Objective:}

During standard expansion culture (i.e., plasma osmolarity, $280 \mathrm{mOsm}$ ) human articular chondrocytes dedifferentiate, making them inappropriate for autologous chondrocyte implantation to treat cartilage defects. Increasing the osmolarity of culture media to physiological osmolarity levels of cartilage (i.e., $380 \mathrm{mOsm}$ ), increases collagen type II (COL2A1) expression of human articular chondrocytes in vitro, but the underlying molecular mechanism is not fully understood. We hypothesized that TGF- $\beta$ superfamily signaling may drive expression of $\mathrm{COL} 2 A 1$ under physiological osmolarity culture conditions.

\section{Material \& Methods:}

Human articular chondrocytes were cultured in cytokine-free medium of 280 or 380 mOsm with or without siRNA mediated TGF- $\beta 2$ knockdown (RNAi). Expression of TGF- $\beta$ isoforms, and collagen type II was evaluated by RT-qPCR and immunoblotting. TGF- $\beta 2$ protein secretion was evaluated using ELISA and TGF- $\beta$ bioactivity was determined using an established reporter assay. Involvement of BMP signaling was investigated by culturing human articular chondrocytes in the presence or absence of BMP inhibitor dorsomorphin and BMP bioactivity was determined using an established reporter assay.

\section{Results:}

Physiological cartilage osmolarity (i.e., physosmolarity) most prominently increased TGF- $\beta 2$ mRNA expression and protein secretion as well as TGF- $\beta$ bioactivity. Upon TGF- $\beta 2$ isoformspecific knockdown, gene expression of chondrocyte marker $C O L 2 A 1$ was induced. TGF- $\beta 2$ RNAi under physosmolarity enhanced TGF- $\beta$ bioactivity. BMP bioactivity increased upon physosmotic treatment, but was not related to TGF- $\beta 2$ RNAi. In contrast, dorsomorphin inhibited COL2A1 mRNA expression in human articular chondrocytes independent of the osmotic condition. 


\section{Conclusion:}

Our data suggest a role for TGF- $\beta$ superfamily member signaling in physosmolarityinduced mRNA expression of collagen type II. As physosmotic conditions favor the expression of $C O L 2 A 1$ independent of our manipulations, contribution of other metabolic, post-transcriptional or epigenetic factors cannot be excluded in the underlying complex and interdependent regulation of marker gene expression. Dissecting these molecular mechanisms holds potential to further improve future cell-based chondral repair strategies.

\section{Keywords:}

Chondrocyte, osmolarity, TGF- $\beta$ superfamily, signalling, collagen type II, bone morphogenetic proteins.

\section{Introduction}

Articular cartilage defects do not heal spontaneously and recent data suggest that treatment of these cartilage defects by microfracture (MF) procedures are inferior to autologous chondrocyte implantation $(\mathrm{ACl})^{1,2}$ due to biomechanically inferior repair tissue ${ }^{3}$. Despite $\mathrm{ACl}$ being superior to microfracture, it is not always characterized by hyaline cartilage repair tissue ${ }^{4}$. Further improvements of currently available chondrocyte-based treatment approaches such as the $\mathrm{ACl}$ are thus needed.

Chondrocytes are the main cell type found in cartilage (i.e., about 1-5\% v/v) and responsible for maintaining the cartilage extracellular matrix $(\mathrm{ECM})^{5}$. $\mathrm{ACl}$ involves in vitro expansion of human articular chondrocytes (HACs) prior to re-implantation into the cartilage defect. During in vitro expansion chondrocytes inevitably lose their specific phenotype and dedifferentiate with increasing passages making them gradually less suitable for autologous cell therapies ${ }^{6}$. Dedifferentiation of HACs is characterized by reduced expression of aggrecan (ACAN) and collagen type II (COL2A1) mRNA, probably being the most important cartilage-specific markers, and accompanied by an increased fibroblast-like phenotype ${ }^{6}$. 
Cartilage requires a high osmotic value of its interstitial fluid to maintain its hydrostatic pressure and viscoelastic properties, for which negatively charged glycosaminoglycan side chains of the proteoglycans (PGs) are crucial to attract mobile cations and water into the ECM environment. The intact collagen network, in contrast, restricts the inherent swelling force of the ECM and determines the relatively high osmolarity of this extracellular fluid ${ }^{5}$. The latter ranges between 380 and 450 mOsm in healthy cartilage (i.e., physiological osmolarity $)^{5}$, which is markedly higher than that of plasma levels or standard culture medium (around $280 \mathrm{mOsm})^{7}$. In analogy to using "physoxia" to describe physiological oxygenation levels in cartilage, avoiding the term hypoxia ${ }^{8}$, we would like to introduce physiological osmolarity as "physosmotic". We and others have already shown that cultured chondrocytes are osmo-responsive and improve ECM synthesis accordingly $y^{5,9,10}$. However, the underlying molecular mechanism is poorly understood.

Transforming growth factor (TGF- $\beta$ ) plays an indispensable role in cartilage repair and homeostasis ${ }^{11,12}$. This pleiotropic growth factor is the prototypic member of the TGF- $\beta$ superfamily, which further includes, among others, the large subfamily of bone morphogenetic proteins (BMPs) ${ }^{13}$. Three mammalian isoforms of TGF- $\beta$ have been described, with non-redundant functions in vivo ${ }^{14,15}$. In chondrocytes, TGF- $\beta$ has been implicated in the transcription of collagen type $\mathrm{II}^{16}$. Canonically, TGF- $\beta$ ligands bind to the TGF- $\beta$ type II receptor (TGFBRII) which, in most cells, then recruits the type I receptor activin-like kinase 5 (ALK5) to phosphorylate intracellular effector molecules SMAD-2 and -3 to regulate transcriptional activity ${ }^{17}$. It was shown that in chondrocytes TGF- $\beta$ can also signal through an alternative receptor, $A L K 1^{18}$ to phosphorylate SMAD1/5/8, rather than SMAD2/3. The ALK5/ALK1 ratio now appears to be responsible for the seemingly contradictory actions of TGF- $\beta$ in chondrocytes ${ }^{19}$. Context-dependent ambivalent actions of TGF- $\beta$ on articular chondrocytes have been reviewed ${ }^{12}$, underscoring its key role in chondrocyte ECM synthesis and homeostasis.

Since TGF- $\beta$ is known to induce $\operatorname{COL} 2 A 1$ expression in chondrocytes ${ }^{18}$, it is tempting to speculate that increased $C O L 2 A 1$ expression in in vitro HAC cultures upon physosmotic treatment, may be caused by stimulated TGF- $\beta$ signaling. Currently, however, little is known about how osmolarity may induce endogenous TGF- $\beta$ signalling, which holds especially 
for chondrocytes. Dissecting molecular mechanisms underlying physosmotic induction of chondrocyte markers might aid in further improving cell-based chondral repair strategies, as well as improving HAC culture conditions for research purposes ${ }^{20}$.

In the present study, we therefore aim to elucidate whether changes in TGF- $\beta$ signalling underlie the cartilage physosmolar induction of chondrocyte marker gene expression in in vitro HAC cultures.

\section{Materials and Methods}

\subsection{Cartilage and Chondrocyte Isolation}

Human articular cartilage was explanted from macroscopically normal areas of the femoral condyles and tibial plateau of nine patients undergoing total knee replacement surgery for osteoarthritis (OA). The Erasmus MC and the Maastricht University Medical Centre institutional policy on the use of residual human surgical material specifically states that no informed consent is needed in the case of residual surgical material. However, an approval from the institutional Medical Ethical Committee (MEC) for the use of this material is required. The MEC approved this study and assigned approval ID: MEC2004-322 and MEC08-4-028 (23 June 2008).

Cartilage was separated from the subchondral bone and cut into small pieces using a sterile surgical blade. Cartilage pieces were digested overnight at $37^{\circ} \mathrm{C}$ in collagenase type II solution (300 U/mL in HEPES buffered DMEM/F12 supplemented with antibiotics (Invitrogen, Carlsbad, CA, USA), 280 mOsm) under continuous agitation 10,46,47,48. Medium osmolarity was experimentally adjusted to 380 mOsm (physosmotic medium i.e., PM) by adding sterile $\mathrm{NaCl}$ as reported earlier ${ }^{10}$. The preparation was rinsed with $0.9 \% \mathrm{NaCl}$ over a $70 \mu \mathrm{m}$ cell strainer and plated in culture flasks. 


\subsection{Chondrocyte Expansion and Culturing}

Briefly, primary $\mathrm{HACs}$ were cultured (humidified atmosphere at $37^{\circ} \mathrm{C}, 5 \% \mathrm{CO}_{2}$ ) for expansion in monolayers at a seeding density of $7500 \mathrm{cells} / \mathrm{cm}^{2}$ in culture medium consisting of DMEM/F12 (Invitrogen) with 10\% fetal calf serum (FCS) (Sigma-Aldrich, St. Louis, MO, USA) and 1\% antibiotic/antimycotic (Invitrogen) corresponding to their isolation osmolarity; 280 mOsm (osmotic control medium, i.e., OCM) or 380 mOsm (physosmotic medium i.e., PM). Once cells reached confluency, they were trypsinized, resuspended, and replated into 175 $\mathrm{cm}^{2}$ flasks. Within four weeks after harvest early passage HACs (P1, P2) were seeded in highdensity monolayers $\left(20,000\right.$ cells $\left./ \mathrm{cm}^{2}\right)$ and were cultured in OCM or PM, respectively, for an additional 7 days before analysis. Moreover, HACs were cultured for 7 days, including a $72 \mathrm{~h}$ serum free period in order to collect conditioned medium for TGF- $\beta$ protein analyses (TGF- $\beta 2$ isoform-specific ELISA and TGF- $\beta$ bioassay). Experiments were performed in technical replicates from six donors.

\subsection{RNA Expression Analysis}

According to the Minimum Information for Publication of Quantitative Real-Time PCR Experiments (MIQE) guidelines ${ }^{49}$, we subsequently aim at reporting suggested essential information: (i) the experimental design is outlined elsewhere in this section, with the numbers within each group reported as" $n$ "per analyses, (ii) the sample dissection, processing and storage has been reported earlier by us $^{10}$, (iii) total RNA extraction, purification, and quantification thereof are also reported in much detail ${ }^{10}$, as was (iv) the RT reaction, both using commercially available Eurogentec kits. Other essential details on the reaction conditions of the CDNA synthesis has also been previously reported ${ }^{10}$. With respect to $(v)$ qPCR target information, we aimed at using the latest Entrez Gene Symbols, designed our assays using the National Center for Biotechnology Information (NCBI)'s database RefSeq sequences ${ }^{50}$, performed NCBI's Primer-Blast to verify specificity in silico and report NCBI Gene IDs. Real-time quantitative PCR (RT-qPCR) was performed using Mesagreen ${ }^{\mathrm{TM}}$ qPCR mastermix plus for SYBR Green (Eurogentec, Maastricht, The Netherlands) and a CFX96 RealTime PCR Detection system (Biorad, Hercules, CA, USA for amplification with the following profile: initial denaturation $10 \mathrm{~min}$ at $95^{\circ} \mathrm{C}$, followed by 50 cycles of amplification ( $15 \mathrm{~s}$ at 
$95^{\circ} \mathrm{C}$ and $1 \mathrm{~min}$ at $60^{\circ} \mathrm{C}$ ), and followed by a dissociation curve. Specificity of the Primer Designer $^{\mathrm{TM}}$ (ThermoFisher Scientific, Waltham, MA, USA) designed and mfold-checked amplicons ( $>70<250 \mathrm{bp}$; default secondary structure exclusion settings) were checked by agarose gel electrophoresis to exclude primer dimers and post run melting curve evaluation and assays were selected to have PCR efficiencies of $>0.95$. Data analysis: data were normalized to an index of stably-expressed reference genes that were pre-evaluated to be stably expressed across samples by BestKeeper software (Microsoft, Redmond, WA, USA) as was reported elsewhere by our group ${ }^{2,10}$. All NTCs had $C_{q} s \geq 39$ and GOls with $C_{q} s \geq$ 35 were excluded from analyses. Relative expression was calculated according to the deltadelta $C_{\mathrm{T}}$ method. Not earlier reported oligonucleotide sequences are listed in Table 1 and the statistical methods are reported elsewhere in this section. 
Table 1: oligonucleotide sequences

\begin{tabular}{|c|c|c|c|}
\hline $\begin{array}{c}\text { GENE } \\
\text { AMPLICON }\end{array}$ & $\mathrm{IDT}_{\mathrm{M}}$ & $\begin{array}{l}\text { FORWARD/SENSE } \\
(5 \nabla-3 \rrbracket) \text { NT POSITIONS }\end{array}$ & $\begin{array}{l}\text { REVERSE/ANTISENSE } \\
(5 \square-3 \rrbracket) \text { NT POSITIONS }\end{array}$ \\
\hline COL2A1 $44 \mathrm{bp}$ & $\begin{array}{c}1280 \\
62.0 / 62.4\end{array}$ & $\begin{array}{c}\text { TGGACGATCAG GCGAAACC } \\
3570-3588\end{array}$ & $\begin{array}{c}\text { GCTGCGGATGCT CTCAATCT } \\
\text { 3813-3794 }\end{array}$ \\
\hline TGFB1 $209 \mathrm{bp}$ & $\begin{array}{c}7040 \\
61.4 / 60.7\end{array}$ & $\begin{array}{c}\text { CTAATGGTGGA } \\
\text { AACCCACAACG 334-355 }\end{array}$ & $\begin{array}{l}\text { TATCGCCAGGAAT } \\
\text { TGTTGCTG 542-522 }\end{array}$ \\
\hline TGFB2 154 bp & $\begin{array}{c}7042 \\
2.3 / 62.9\end{array}$ & $\begin{array}{c}\text { CCATCCCGCCC ACTTTCTAC } \\
434-453\end{array}$ & $\begin{array}{c}\text { AGCTCAATCCGTT } \\
\text { GTTCAGGC 587-567 }\end{array}$ \\
\hline TGFB3 $121 \mathrm{bp}$ & $\begin{array}{c}7043 \\
0.9 / 60.3\end{array}$ & $\begin{array}{c}\text { GGAAAACACCGA } \\
\text { GTCGGAATAC 279-300 }\end{array}$ & $\begin{array}{c}\text { GCGGAAAACCTT } \\
\text { GGAGGTAAT 399-379 }\end{array}$ \\
\hline ALK1 $194 \mathrm{bp}$ & $942.3 / 62.3$ & $\begin{array}{c}\text { CATCGCCTCAG } \\
\text { ACATGACCTC 777-797 }\end{array}$ & $\begin{array}{c}\text { GTTTGCCCTGTG } \\
\text { TACCGAAGA 970-950 }\end{array}$ \\
\hline ALK5 $167 \mathrm{bp}$ & $\begin{array}{c}7046 \\
60.6 / 61.1\end{array}$ & $\begin{array}{l}\text { ACGGCGTTACAGT GTTTCTG } \\
94-113\end{array}$ & $\begin{array}{c}\text { GCACATACAAAC } \\
\text { GGCCTATCTC 260-239 }\end{array}$ \\
\hline GAPDH $101 b p$ & $\begin{array}{c}2597 \\
2.0 / 62.9\end{array}$ & $\begin{array}{c}\text { CTGGGCTACACT GAGCACC } \\
694-712\end{array}$ & $\begin{array}{c}\text { AAGTGGTCGTTG } \\
\text { AGGGCAATG 794-774 }\end{array}$ \\
\hline$T G F-\beta 2$ siRNA & - & $\begin{array}{l}\text { CTAATGGTGGAAA } \\
\text { CCCACAACG }\end{array}$ & $\begin{array}{l}\text { TATCGCCAGGAA } \\
\text { TTGTTGCTG }\end{array}$ \\
\hline
\end{tabular}

Primer sequences for $R T-q P C R$ and oligonucleotide sequences for $R N A i$ are listed in the $5 \nabla-3 \bigotimes$ direction. Gene, NCBI Gene Symbol; ID, NCBI Gene ID; bp, base pairs; $n$ t positions, location of primers. Note the following newer aliases for above-listed gene symbols: ALK1 (ACVRL1), ALK5 (TGFBR1).

\subsection{Immunoblotting}

HACs were washed with $0.9 \% \mathrm{NaCl}$ and lysed in RIPA buffer. Extracts were sonicated on ice using the Soniprep 150 (MSE, London, UK). Insoluble material was removed by centrifugation $\left(13,000 \times g, 4{ }^{\circ} \mathrm{C}\right)$. The BCA protein assay (Sigma-Aldrich) was used to determine protein concentration. Polypeptides were separated by SDS-PAGE (sodium 
dodecyl sulfate polyacrylamide gel electrophoresis) and transferred to nitrocellulose membranes by electroblotting. Primary antibodies (all 1:100 dilution) for immunodetection were polyclonal goat anti-COL2A1 1320-01, Southern Biotech, Birmingham, AL, USA), and mouse monoclonal anti-GAPDH (10R-1261096, Fitzgerald, MA, USA). Bound primary antibodies were detected with secondary immunoglobulins conjugated with horseradish peroxidase (Dako) and visualized by enhanced chemiluminescence (ECL). ECL signals were quantified using ImageJ $1.46 \mathrm{f}$ software (National Institutes of Health, Bethesda, MA, USA), and relative differences, corrected for background and housekeeper, were determined as compared to control conditions.

\section{$2.5 \quad$ TGF- $\beta 2$ ELISA}

To determine TGF- $\beta 2$ in the secretome, medium was collected and centrifuged at 1200 rpm for $8 \mathrm{~min}$ to remove cell debris. The cleared supernatant was collected and stored at $-80{ }^{\circ} \mathrm{C}$ until further use. TGF- $\beta 2$ concentration was quantified spectrophotometrically using an enzyme-linked immunosorbent assay (ELISA; Demeditec Diagnostics GmbH, Kiel, Germany). TGF- $\beta 2$ concentrations in the samples were calculated from a standard curve according to manufacturer's instructions.

\subsection{TGF- $\beta$ Bioassay}

To verify that the secreted TGF- $\beta$ as measured by ELISA is biologically active, we next employed an established luciferase assay, using the CAGA-luc Smad2/3 reporter.Human embryonic kidney cells were seeded at $3 \times 10^{4} /$ well in 24-well plates and transiently transfected with $150 \mathrm{ng}$ of the reporter construct and $75 \mathrm{ng}$ of PRL-TK vector (Promega, Madison, WI, USA), an internal control for transfection efficiency, using FuGENE 6 transfection reagent (Roche Diagnostics, Basel, Switzerland). Twenty-four hours after transfection, cells were incubated for $2 \mathrm{~h}$ in medium containing $0.2 \% \mathrm{FCS}$, followed by 16 $\mathrm{h}$ incubation with $10 \mathrm{ng} / \mathrm{mL}$ TGF- $\beta 2$ as a positive control, DMEM/F12 as a negative control or $300 \mu \mathrm{L}$ conditioned medium (see above, ELISA). Twenty-four hours after stimulation, the firefly and Renilla luciferase activities were measured using the Dual-Luciferase Reporter Assay System (Promega, Madison, WI, USA). 


\subsection{RNAi Experiments}

Primary HACs from three OA patients were cultured at OCM for two weeks and then seeded in high-density monolayers $\left(20,000\right.$ cells $\left./ \mathrm{cm}^{2}\right)$. A TGF- $\beta 2$-specific siRNA duplex (Table 1 ) and a scrambled siRNA control duplex were used (Eurogentec, Seraing, Belgium) ${ }^{47}$. HACs were transfected with siRNAs (100 nM) at OCM using HiPerFect (Qiagen, Hilden, Germany) according to the manufacturer's protocol. One day after transfection, HACs were refreshed with either OCM or PM in the presence or absence of dorsomorphin (10 $\mu \mathrm{M}$, Santa Cruz Biotechnologies, Santa Cruz, CA, USA). Forty-eight hours after stimulation cells were harvested for mRNA expression or protein analyses. HACs were also seeded and cultured with either DMSO (1:1000) or dorsomorphin $(10 \mu \mathrm{M})$. One day after seeding, cells were either refreshed with OCM or PM, and $48 \mathrm{~h}$ later harvested for gene expression analyses. In another experiment, SW1353 cells were seeded in high-density monolayers (30,000 cells/ $\mathrm{cm}^{2}$. Cells were transfected with the previously described CAGA-luc Smad2/3 reporter or the BRE-luc reporter using FuGene transfection reagent (Promega, Madison, WI, USA) at $\mathrm{OCM}^{51}$. The gaussia luciferase reporter construct was used as an internal control for transfection efficiency. One day after transfection of the reporters, the previously described TGF- $\beta 2$-specific siRNA duplex and a scrambled siRNA control duplex were transfected (100 $\mathrm{nM}$ ) at OCM using HiPerFect (Qiagen, Hilder, Germany). Five hours after siRNA transfection medium was refreshed with either OCM or PM. Forty-eight hours later, cells were processed and their luciferase activity was measured by a luciferase reporter assay system (Promega, Madison, WI, USA).

\subsection{Statistical Analysis}

Statistical analysis was performed using SPSS 13.0 software (SPSS Inc., Chicago, IL, USA). Continuous variables were tested for normality using Kolmogorov-Smirnov test and normality plots were visually assessed for skewness. All samples for gene expression analysis and TGF- $\beta 2$ measurements in medium were processed and analyzed individually with replicate measurements per donor. Gene expression levels, TGF- $\beta 2$ protein expression and luciferase activity between HACs cultured in PM or OCM were compared by an unpaired $t$-test. Data obtained from RNAi experiments were analyzed by a mixed linear model test. In 
the model, conditions with or without TGF- $\beta 2$ knockdown and with or without physosmotic treatment were considered as fixed factors, while the cartilage donor was considered as a random factor. Adjustment for multiple comparisons was made by a Bonferonni's post hoc comparison test. $p<0.05$ was considered to indicate levels of statistically significant difference.

\section{Results}

\subsection{Cartilage Physosmotic Culture Induces Specific TGF- $\beta$ Isoform Expression in HACs}

Confirming our earlier results ${ }^{10}$, culturing HACs for seven days in physosmotic conditions (380 mOsm, physosmotic medium, PM) results in significantly $(p \leq 0.0001)$ elevated COL2A 1 mRNA expression, as compared to 280 mOsm (i.e., osmotic control medium, OCM) (Figure $1 \mathrm{~A}$ ). To determine whether this increased $C O L 2 A 1$ expression upon physosmotic treatment may be caused by stimulated specific TGF- $\beta$ isoform induced signalling, mRNA expression of the three human TGF- $\beta$ isoforms (TGFB1-3) was measured. PM selectively induced expression of TGFB2 (two-fold, $p<0.0001$ )) and TGFB3 (1.5-fold, $p<0.0001$ ), respectively. In contrast, expression of TGFB1 was not significantly altered by changes in medium osmolarity (Figure 1B). 
A

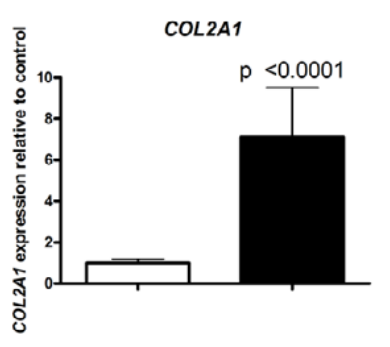

$\square$ OCM

PM
B

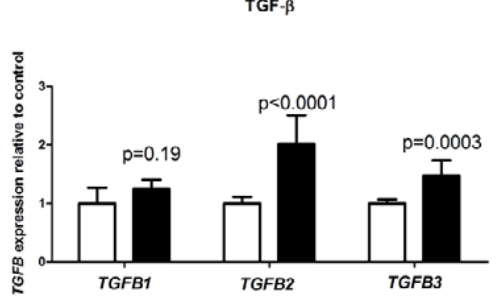

Figure 1: Physosmolarity-induced changes in gene expression of chondrocytes in vitro.

Isolating and expanding HACs at PM for 7 days (black bars) significantly increased gene expression of COL2A1 (A), as well as TGFB2 and TGFB3 as compared to control (OCM; white bars) (B). Gene expression of TGFB1 was not significantly affected (B). $m R N A$ levels were determined relatively to control OCM conditions by RT-qPCR (normalized for housekeeper expression) in HACs. Data are from six donors measured in duplicate and presented as the mean \pm standard deviation.

\subsection{Physosmolarity Increases Secretion of Bioactive TGF- $\beta 2$}

As PM most prominently increased TGFB2 mRNA abundance, we next aimed at confirming if this resulted in increased TGF- $\beta 2$ protein level, using a TGF- $\beta 2$ isoform-specific ELISA assay. HACs were cultured in either serum free (SF) medium or with $10 \%$ FCS and TGF- $\beta 2$ secretion in culture supernatants was measured after seven days. TGF- $\beta 2$ secretion was largely independent of the presence of serum in the culture medium and showed a 1.6fold (10\% FCS, $p=0.003$ ) and two-fold (serum-free, $p=0.006$ ) increase in PM as compared to OCM (Figure 2A). The osmolarity-dependent change in TGFB2 gene expression is thus predictive for TGF- $\beta 2$ protein secretion in culture supernatant in response to PM. To determine whether the secreted TGF- $\beta 2$ is also bioactive, we performed an established bioassay that reports a TGF- $\beta$ specific activation of the TGF- $\beta$ signaling pathway. Briefly, the TGF- $\beta$-responsive SMAD response element-mediated firefly luciferase signal is normalized to a constitutively expressed Renilla luciferase signal, to provide relative activity ${ }^{21}$. In agreement with increased TGF- $\beta 2$ secretion in PM, this conditioned PM had a significantly $(p<0.0001)$ increased TGF- $\beta$ bioactivity $(2.3$-fold; Figure $2 \mathrm{~B})$, as compared to conditioned OCM. 
A TGF- $\beta 2$ protein

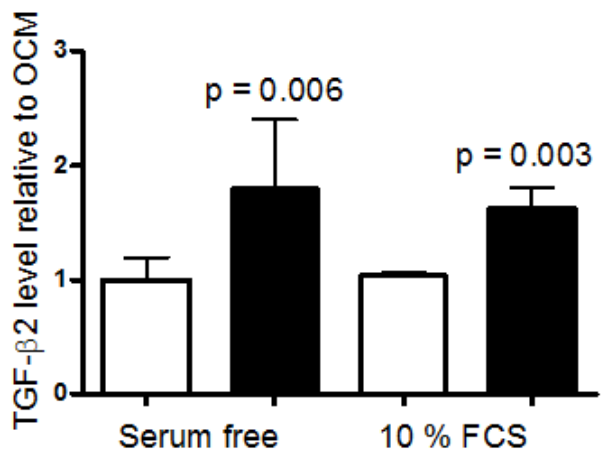

B

TGF- $\beta$ bioactivity

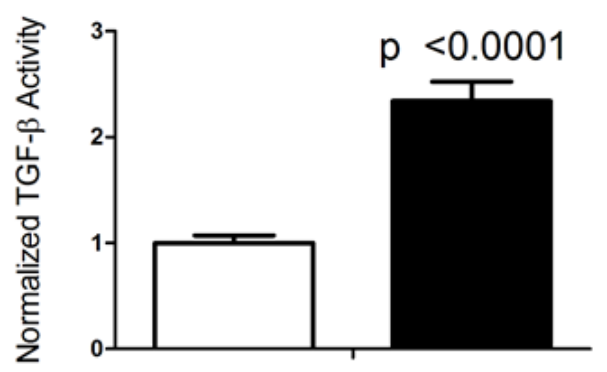

C

Figure 2: Physosmotic culture medium (PM) increases TGF- $\beta 2$ secretion and TGF- $\beta$ bioactivity in HACs.

In HACs cultured for seven days (serum-free cultures on the left and 10\% FCS cultures on the right) TGF- $\beta 2$ protein levels were determined by specific TGF- $\beta 2$ ELISA in PM (black bars) or OCM (white bars) (A). TGF- $\beta$ bioactivity was determined by TGF- $\beta$ bioassay in $72 \mathrm{~h}$ serum starved conditioned medium from PM and OCM HAC cultures (B). Corresponding ALK5/ALK1 gene expression ratio was determined in samples from Figure 1 (C). Data are from 3 donors measured in duplicate and are presented as mean \pm standard deviation relative to control OCM conditions. 
On the receptor level ALK5, but not ALK1, appears to be essential for TGF- $\beta$ induced phosphorylation of $\mathrm{SMAD}^{18}$, and therefore we further investigated the expression ratio of $A L K 5 / A L K 1$ in response to PM to get an indication if the increased TGF- $\beta$ might be able to induce canonical signaling. In accordance with the TGF- $\beta$ bioassay, the ALK5/ $A L K 1$ expression ratio was significantly shifted in favor of increased ALK5 expression in chondrocytes cultured in PM as compared to OCM ( $p=0.027)$ (Figure 2C). These data indicate that physosmotic culture conditions improve activation of ALK5 driven TGF- $\beta$ signaling.

\subsection{TGF- $\beta 2$ Isoform-Specific Knockdown in HAC Cultures in vitro}

To investigate whether a causal relation exists between the increased $C O L 2 A 1$ expression and TGF- $\beta 2$ secretion after treatment with PM, we performed TGF- $\beta 2$ knockdown experiments using RNAi (siRNA) in our HAC cultures. First, we evaluated the isoform-specificity of RNAi before treatment with $\mathrm{PM}$ at $\mathrm{t}=0$ : TGF- $\beta 2$ gene expression was specifically and significantly down-regulated upon RNAi when compared to control and other TGF- $\beta$ isoforms (Figure 3) $(p=0.001)$.

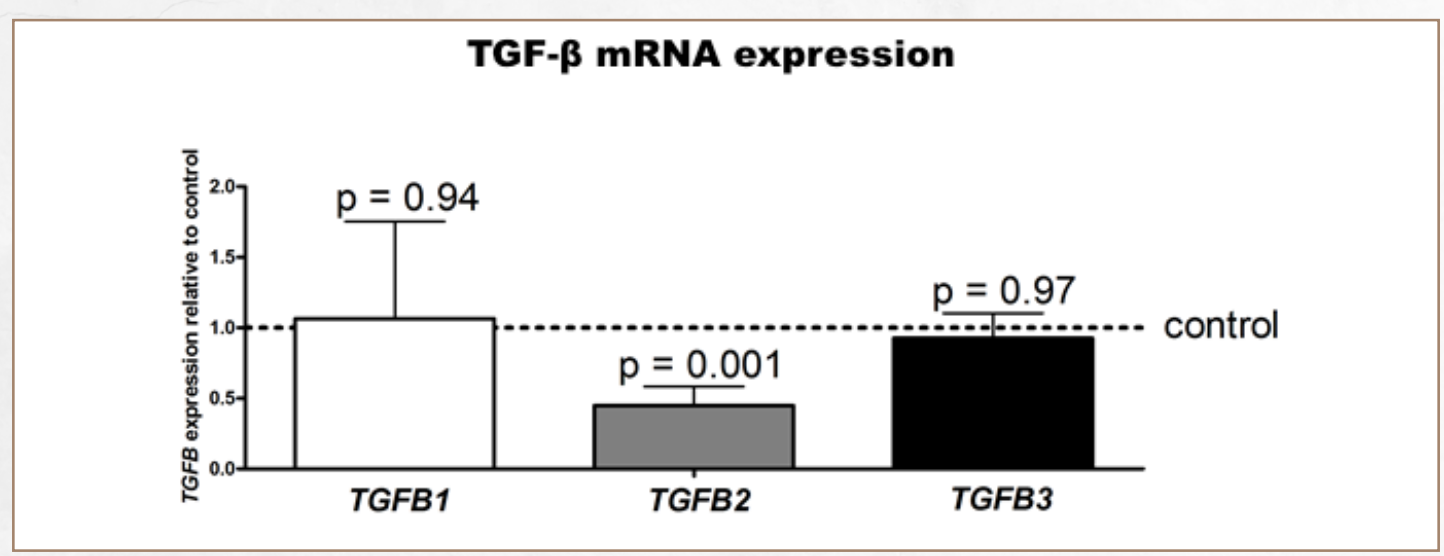

Figure 3: TGF- $\beta 2$ RNAi efficacy and specificity in HACs.

TGFB1, TGFB2, and TGFB3 gene expression was determined by RT-qPCR upon TGF- $\beta 2$-specific knockdown using transfected siRNAs (in OCM conditions). Data are the means \pm standard deviation of duplicate measurements from three donors relative to control conditions (scrambled siRNA) and were normalized to housekeeper expression. Control condition is indicated by the dotted line (set to 1). 


\subsection{TGF- $\beta 2$ RNAi Combined with Physosmotic Treatment Increases COL2A 1 Gene Expression in HACs}

We subsequently determined the consequence of TGF- $\beta 2$ RNAi on COL2A1 gene expression $48 \mathrm{~h}$ upon stimulation with PM as compared to OCM. PM significantly increased COL2A1 after $48 \mathrm{~h}$ (i.e., 1.8-fold, $p=0.01$ ) (Figure $4 \mathrm{~A}$ ).

TGF- $\beta 2$ knockdown, did not alter COL2A1 expression in OCM (Figure 4A). However, TGF- $\beta 2$ RNAi with PM stimulation after $48 \mathrm{~h}$ resulted in higher $C O L 2 A 1$ expression compared to OA HACs cultured at PM without TGF- $\beta 2$ RNAi $(p=0.04)$ (Figure 4 A).

To determine if the increased COL2A1 expression upon TGF- $\beta 2$ knockdown under physosmotic conditions (i.e., in PM) was accompanied by an increased reporter assay activity, we repeated the experiment in the established chondrosarcoma cell line SW135322,23. We measured CAGA-12 luciferase activity $48 \mathrm{~h}$ after stimulation with PM with TGF- $\beta 2$ RNAi. Bioactivity of TGF- $\beta$ displayed a similar pattern as COL2A1 expression: stimulation with PM increased CAGA-12 luciferase activity $(p=0.03)$ as compared to the control condition (i.e., OCM, Figure $4 B$ ). While TGF- $\beta 2$ knockdown at OCM did not alter CAGA-12 luciferase activity, stimulation with PM in combination with TGF- $\beta 2$ knockdown significantly increased the activity of this TGF- $\beta$ signaling-specific reporter as compared to the same osmotic stimulation without TGF- $\beta 2$ knockdown $(p=0.02)$.

COL2A1 gene expression data were confirmed on protein level. As shown in Figure $4 C$, PM increased $C O L 2 A 1$ protein levels. In addition, COL2A1 protein levels were higher at PM combined with TGF- $\beta 2$ knockdown than in HACs cultured at PM alone (Figure 4D). 
A

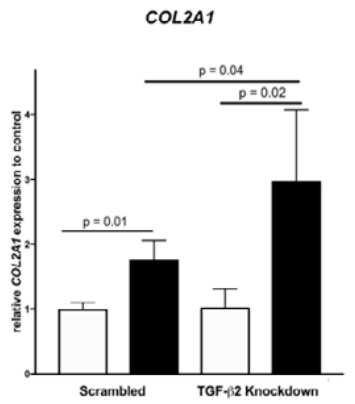

C

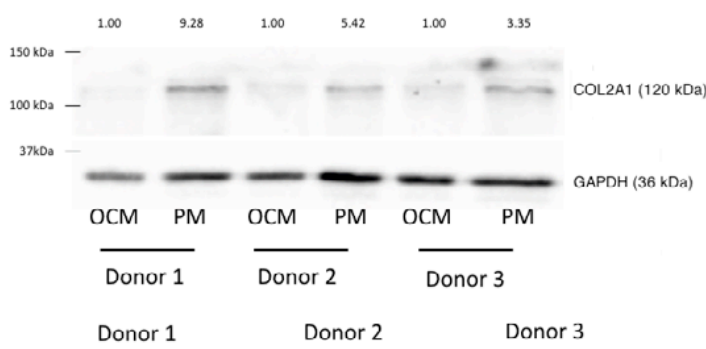

B
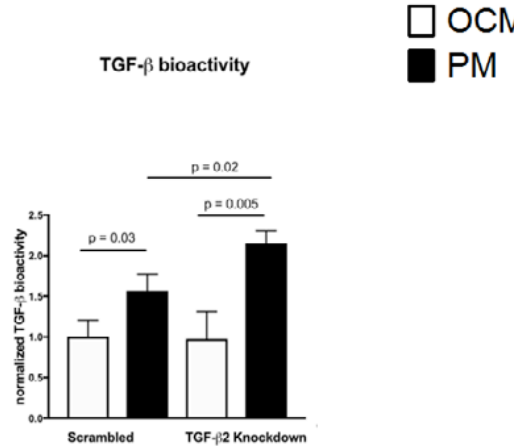

D

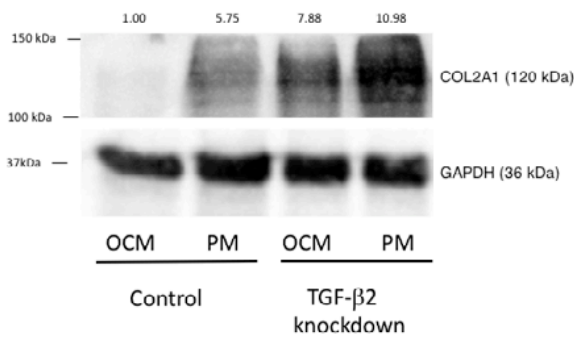

Figure 4: TGF- 22 RNAi combined with physosmotic treatment increases COL2A1 gene expression and TGF- $\beta$ bioactivity in HACs.

Expression of COL2A1 was measured by RT-qPCR replicates $(n=3)$ in control conditions (left) and after TGF- $\beta 2$ RNAi (right) in OCM (white bars) or PM (black bar) conditions $48 \mathrm{~h}$ after physosmotic stimulation (A). TGF- $\beta$ bioactivity in media from SW1353 cultures with or without TGF- $\beta$ knockdown from PM and OCM cultures. Data are normalized means \pm standard deviation relative to control OCM condition ( $B)$. Collagen type II (COL2A1) protein expression was confirmed by immunoblotting in HACs from three donors. Molecular weight markers in $k D a$ are shown on the left. The numbers across the top depict the relative quantity $(C, D)$.

Since BMP signaling has been shown to be also involved in COL2A1 expression, we next evaluated BMP-specific BRE reporter activity under the same in vitro conditions. As shown in Figure 5A, PM significantly increased BRE activity compared to the OCM control condition $(p=0.002)$. In contrast, TGF- $\beta 2$ knockdown did not alter BRE activity at both PM and OCM 
compared to conditions without TGF- $\beta 2$ knockdown. Under TGF- $\beta 2$ knockdown, PM again increased BMP reporter activity as compared to OCM ( $p=0.002$, Figure $5 \mathrm{~A})$.

We further evaluated the effect of an established BMP signaling inhibitor, Dorsomorphin, on COL2A1 expression levels when TGF- $\beta 2$ knockdown was combined with physosmotic stimulation.

First, we confirmed the attenuating effect of inhibiting BMP signaling under culture conditions without TGF- $\beta 2$ knockdown. BMP signaling inhibition significantly decreased COL2A1 expression levels at both PM and OCM compared to vehicle controls, while COL2A1 expression levels at PM were still significantly elevated compared to OCM (Figure $5 B)$. Under culture conditions with TGF- $\beta 2$ knockdown, dorsomorphin again decreased COL2A1 expression, while $C O L 2 A 1$ expression was again significantly elevated at PM as compared to OCM (Figure 5B). COL2A1 expression levels in conditions with TGF- $\beta 2$-specific knockdown in combination with blocked BMP signaling were suppressed in both OCM and PM, while COL2A 1 expression remained relatively always higher in PM as compared to OCM irrespective of the TGF- $\beta 2$ knockdown and blocked BMP signalling (Figure $5 C$ ). 
A

\section{BMP bioactivity}

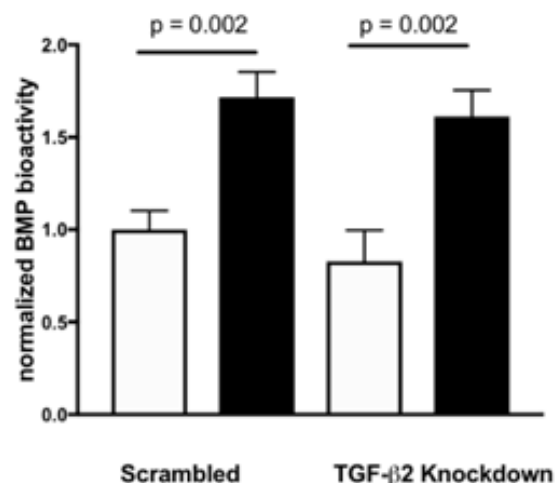

B

COL2A1

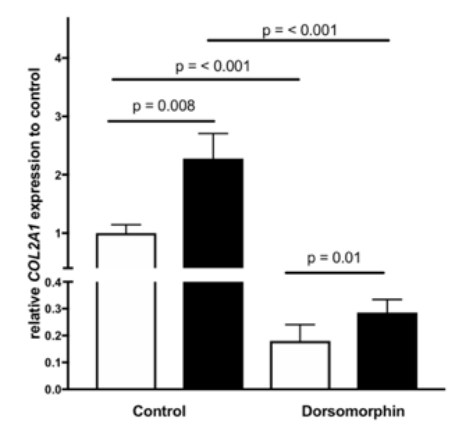

\section{$\square$ OCM}

PM

C

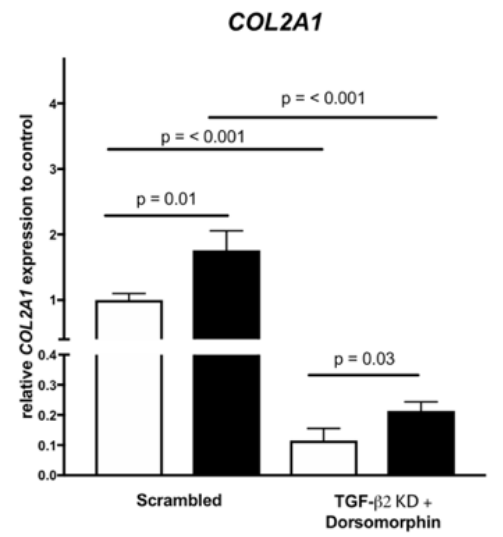

Figure 5: Blocking of BMP signalling decreases COL2A 1 expression of chondrocytes irrespective of osmolarity.

Bioassays in SW1353 cells show a largely TGF- $\beta 2$ knockdown-independent, but osmolaritydependent induction of BMP-responsiveness. Data are the normalized means \pm standard deviation $(n=3)$ relative to control OCM condition $(A)$. Physosmolar conditions further significantly elevated COL2A1 expression as compared to vehicle controls at OCM (B). Dorsomorphin (10 $\mu M)$-mediated inhibition of BMP signaling significantly suppressed COL2A1 expression in both osmolarities (B), but COL2A1 expression remained relatively higher in $P M$ as compared to OCM irrespective of BMP signaling. Combining TGF- $\beta 2$ knockdown and dorsomorphin showed the same pattern as dorsomorphin alone (C). Data from five donors were measured in duplicates and are presented as normalized means \pm standard deviation relative to control OCM condition. Data is normalized means \pm standard relative to control OCM condition (replicate measurements, three donors). 


\section{Discussion}

In the present study, we investigated whether physiological osmolarity (PM) is able to improve expression of key cartilage ECM marker COL2A1 in chondrocytes (HACs), through facilitating TGF- $\beta$ superfamily signalling.

We reported earlier that expansion of HACs in PM (i.e., $380 \mathrm{mOsm}$ ) improved COL2A1 marker gene and protein expression ${ }^{10}$ and now reveal a correlation between improved expression of key chondrocyte marker COL2A1 and upregulated TGF- $\beta$ family member ligands (e.g., TGF- $\beta 2,-\beta 3$ ) in PM. Interestingly, of all three prototypic isoforms of this family, only TGF- $\beta 2$ was prominently osmo-dependently regulated in our study. Of all three human isoforms, several reports support a relatively more potent role of TGF- $\beta 2$ in stimulating ECM synthesis: first, expression of TGF- $\beta 2$, but not TGF- $\beta 1$, is reduced in cartilage of old compared to young mice, suggesting a possible chondroprotective role ${ }^{24}$. Secondly, only TGF- $\beta 2$ is characterized by unique upstream response elements in its $\mathrm{P} 1$ promoter ${ }^{25}$, suggesting its isoform specific regulation. TGF- $\beta 2$ can further suppress collagenase mediated proteolytic degradation of collagen type II in human cartilage ${ }^{26}$ and preserved the chondrocyte phenotype in physoxic high density in vitro cultures ${ }^{2}$. TGF- $\beta 2$ also more potently induces SMAD2 phosphorylation at 10 and $250 \mathrm{pM}$ as compared to TGF- $\beta 1$ and TGF- $\beta 3^{16}$. Furthermore, TGF- $\beta 1$ and TGF- $\beta 3$, but not TGF- $\beta 2$, bind to endoglin ${ }^{27}$, which is known to inhibit SMAD3 driven ECM production in chondrocytes ${ }^{28}$. Collectively, this prompted us to postulate that TGF- $\beta 2$ signalling might trigger the increased collagen type II expression.

More than twice as much TGF- $\beta 2$ protein was measured in conditioned PM compared to medium of plasma osmolarity (OCM). As TGF- $\beta$ can be secreted noncovalently attached to its prodomain, requiring additional processing to be activated from latency ${ }^{16}$, we subsequently used a functional bio-assay to investigate TGF- $\beta$ activity. A twofold increase in TGF- $\beta$ activity in conditioned PM was observed, confirming our gene- and protein-expression data. We next used a functional TGF- $\beta$ bioassay with a SMAD3 responsive element as TGF- $\beta 2$ induced SMAD3-driven transcriptional activity may cause subsequent expression 
of $C O L 2 A 1$ in chondrocytes ${ }^{18}$. The endogenous TGF- $\beta$ activity measured in the conditioned PM reached $50 \%$ of the activity of the exogenously added positive TGF- $\beta$ control (10 ng/ $\mathrm{mL}$ ) used in the bioassay. This translates to a concentration of about $5 \mathrm{ng} / \mathrm{mL}$ active TGF- $\beta$ in conditioned PM, a concentration which is sufficient for SMAD3 phosphorylation ${ }^{29}$. As the TGF- $\beta$ bioassay is not isoform specific, we are unfortunately unable to exclude a potential contribution of other TGF- $\beta$ isoforms to the observed effects.

Thus, a limitation of our study is that we cannot rule out a contribution of antagonistic TGFBRIlike pseudo-receptors, MAPKs, like P38 MAPK or ERK1/2, in our experiments ${ }^{30}$. These have been shown to contribute to effects of hyperosmotic stimulation in chondrocytes ${ }^{30}$, at least at a high osmotic value (380 vs. 550 mOsm). Tew et al. further underscored the importance of post-transcriptional regulation in response to osmotic changes and, interestingly, while downstream transcriptional regulators of TGF- $\beta$ signaling were induced, expression of TGF- $\beta$ receptors (i.e., TGFBR2) and certain SMADs were downregulated ${ }^{30}$.

Of note, our physosmotic treatment also shifted receptor expression from TGF- $\beta$ type I receptor ALK1 towards relatively more canonical TGF- $\beta$ type I receptor ALK5 abundance. This is in agreement with our TGF- $\beta$ bioassay, since it is well established that ALK5 potentiates TGF- $\beta$-induced SMAD3-driven transcriptional activity of the $C O L 2 A 1$ promotor ${ }^{18}$. Cartilagespecific deletion of ALK5 induces an osteoarthritis-like phenotype in mice, underscoring its chondroprotective function in cartilage ${ }^{31}$. A limitation of the present study is that we could not study receptor expression on protein level to answer this, due to their low expression levels ${ }^{16}$.

A bioinformatics-driven approach suggested an involvement of TGF- $\beta 3$ at high end osmotic values ${ }^{30}$, which we cannot confirm nor rule out as we focused on TGF- $\beta 2$. The latter appeared to be the most prominently regulated isoform under physiological conditions. High osmolarity is able to down-regulate not only TGFRI mRNA expression, but also TAB1, SMAD3 and BMP signaling inhibitor Smad7 ${ }^{30}$. Altogether, the response to extracellular osmotic values appears complex and seems to depend not only on the species, but also on cell type and its pathological state. Even the exact zonal location the chondrocytes are derived from may also influence the extent of the response to osmotic stimulation ${ }^{32}$. 
We further aimed to elucidate the role of physosmotic-driven TGF- $\beta 2$ signaling on collagen expression by a ligand-specific knockdown approach. Unexpectedly, anti-TGF- $\beta 2$ RNAi increased collagen type II expression upon TGF- $\beta 2$ specific knockdown. We, therefore, next investigated if a counter-regulatory increase in TGF- $\beta$ bioactivity might have caused the increased $C O L 2 A 1$ expression and evaluated SMAD3 driven transcriptional activity. We did this in SW1353 chondrosarcoma cells as a model for human chondrocytes ${ }^{23}$, which resulted in a similarly increased TGF- $\beta$ bioactivity. Interestingly, however, the bioactivity increased even further when physosmotic treatment was combined with TGF- $\beta 2$ knockdown as compared to physosmotic treatment alone. Given that SMAD3 can transcriptionally induce $C O L 2 A 1$ expression ${ }^{18}$, this may indicate a compensatory increase in TGF- $\beta$ bioactivity upon TGF- $\beta 2$ knockdown under physosmotic conditions. Post-transcriptional processes may also interfere with collagen expression under these conditions and may explain the increase in type II collagen protein. Earlier, SOX9 mRNA decay was shown to be influenced by high osmolarity. This led to a p38 MAPK-dependent increase in SOX9 protein and consequently enhanced COL2A1 transcription. Of note, high end osmolarity destabilized COL2A 1 mRNA and reduced its overall expression ${ }^{30,33}$. In freshly isolated chondrocytes, osmotic stimulation thus increased SOX9, but decreased COL2A1, mRNA levels post-transcriptionally ${ }^{33}$. In our study, for some experiments we used SW1353 and not freshly isolated chondrocytes. Furthermore, we shifted the osmotic environment from plasma level to a (moderate) cartilage-specific physosmotic level and not from $380 \mathrm{mOsm}$ to high end osmolarity ( $>500$ mOsm) as in the latter study. Together, differences in the osmotic baseline, the quality of the osmotic shift, and a different timing may at least partially explain contradictions between reported results.

Since BMP-signalling also regulates $\operatorname{COL} 2 A 1$ expression in chondrocytes, we additionally evaluated BMP bioactivity under physosmotic conditions in combination with TGF- $\beta 2$ knockdown. Cross-talk between different TGF- $\beta$ superfamily members can have synergistic or antagonistic effects ${ }^{34}$. Physosmotic treatment significantly increased BMP responsive element (BRE) activity under both in vitro culture conditions, with or without knockdown. There was no TGF- $\beta 2$ knockdown specific effect on BRE signaling, while BMP-signaling inhibitor dorsomorphin was able to attenuate $\operatorname{COL} 2 A 1$ expression in both conditions. 
When combining TGF- $\beta 2$ RNAi and pharmacological inhibition (i.e., dorsomorphin), COL2A1 expression appeared to be largely BMP-dependent (Figure 5) as BMP signaling inhibition reduced $C O L 2 A 1$ expression to $20 \%$ of the baseline level and $10 \%$ of the TGF- $\beta 2$ knockdown control. Thus, while TGF- $\beta$ superfamily members interdependently influence expression of this chondrocyte marker, physomotic conditions apparently always favor its expression independent of our means of TGF- $\beta$ superfamily signalling manipulation.

The quantity of the osmotic pressure appears to be as important as its quality. To this end, recent studies confirm that using physiological salt solutions may be more appropriate than using sorbitol. Hyperosmolar potassium treatment attenuate protein production of catabolic and inflammatory OA markers in a 3D in vitro model, at values of $\sim 490 \mathrm{mOsm}^{35}$. A study of experimentally injured rat and bovine cartilage reported chondroprotection by raising osmolarity of irrigation solutions ${ }^{36}$. However, also here normal saline ( $300 \mathrm{mOsm}$ ) was compared to sucrose-mediated hyperosmolar saline solution $(600 \mathrm{mOsm})^{36}$. We reported earlier that sodium is specifically enriched in the ECM of cartilage ${ }^{10,37,38}$ and using $\mathrm{NaCl}$ to alter osmotic values appears to be more physiological than using e.g., sorbitol or sucrose solutions. Although chondrocytes in vitro do not tolerate hyperosmolar stresses above about 380 mOsm for too long ${ }^{10}$, in vivo the situation may be different. All experiments of the present study were performed in $2 \mathrm{D}$, while results might differ in $3 \mathrm{D}$ cultures ${ }^{32}$, which is a limitation.

We showed that expression of several TGF- $\beta$ superfamily member ligands, their receptors and target genes is altered in cultured human chondrocytes in physosmolar in vitro culture. However, the cellular responses to extracellular osmotic changes are complex ${ }^{39}$ and both, macromolecular crowding and high ionic strength, may trigger a plethora of cell signaling cascades. High intracellular ionic strength enhances NFAT5 activity in chondrocytic cells ${ }^{10,40}$ and more universally in mammalian cell ${ }^{39}$. Basically, elevating the extracellular osmolarity causes, at least temporarily, a state of molecular crowding from the presence of a total high weight per volume concentration of functionally unrelated soluble macromolecules ${ }^{41}$. This may indirectly affect interactions of soluble macromolecules with membranes, other structural elements or molecular chaperones. 
In summary, physosmotic conditions preserve the phenotype of articular chondrocytes in vitro, a process to which TGF- $\beta$ superfamily members seem to contribute. Although we could not proof a link between increased activity of this superfamily and increased COL2A 1 expression in physosmotic cultures, the osmotic component appears prevailing. The TGF- $\beta$ superfamily ${ }^{42}$ consists of more than 35 members of which we only analyzed prototypic members (i.e.,TGF- $\beta$ s and BMPs) of each major branch ${ }^{43}$ in more detail. Within this setting, our rational approach further cannot exclude TGF- $\beta$ mediated responses that are independent of Smad proteins ${ }^{44}$. Molecular crowding might affect protein structure, folding, shape, conformational stability, binding of small molecules, enzymatic activity, protein-protein interactions, protein-nucleic acid interactions, and pathological aggregation ${ }^{45}$ and should be addressed in future studies.

\section{Author Contributions}

U.T.T., M.C., G.v.d.A., T.W., and H.J. designed the study. U.T.T. and M.C. performed the experiments. U.T.T. wrote the manuscript, and analyzed and interpreted the data. M.C., A.v.d.W., T.W., H.J., P.E., L.v.R., H.W., and J.V. analyzed and interpreted the data, and critically revised the manuscript. All authors approved the final version of the manuscript.

\section{Funding}

H.J.,H.W. and U.T.T. are members of the D-BOARD Consortium; This project has received funding from the European Union's Seventh Framework Programme for Research, Technological Development, and Demonstration under Grant Agreement no. 305815 (HEALTH.2012.2.4.5-2). We are further indebted to START of the Faculty of Medicine of the RWTH Aachen and the Aachen-Jülich-Haifa Umbrella Cooperation (acronym SmartCart). This project was also financially supported by the Dutch Arthritis Foundation (grant LLP14).

\section{Conflicts of Interest}

The authors declare that they have no conflicts of interest. 


\section{References}

1 Brittberg M. Autologous chondrocyte transplantation. Clin. Orthop. Relat. Res. 1999:147-155. doi: 10.1097/00003086199910001-00016.

2 Das R., Timur U.T., Edip S., Haak E., Wruck C., Weinans H., Jahr H. Tgf-beta2 is involved in the preservation of the chondrocyte phenotype under hypoxic conditions. Ann. Anat. 2015;198:1-10.doi: 10.1016/j.aanat.2014.11.003.

3 Chawla A., Twycross-Lewis R., Maffulli N. Microfracture produces inferior outcomes to other cartilage repair techniques in chondral injuries in the paediatric knee. Br. Med. Bull. 2015;116:93-103. doi: 10.1093/ bmb/ldv040.

4 Falah M., Nierenberg G., Soudry M., Hayden M., Volpin G. Treatment of articular cartilage lesions of the knee. Int. Orthop. 2010;34:621-630. doi: 10.1007/ s00264-010-0959-y.5 Urban J.P., Hall A.C., Gehl K.A. Regulation of matrix synthesis rates by the ionic and osmotic environment of articular chondrocytes. J. Cell. Physiol. 1993;154:262-270. doi: 10.1002/jcp.1041540208.

6 Benya P.D., Padilla S.R., Nimni M.E. Independent regulation of collagen types by chondrocytes during the loss of differentiated function in culture. Cell. 1978;15:1313-1321. doi: 10.1016/00928674(78)90056-9.

Bhalla A., Sankaralingam S., Dundas R., Swaminathan R., Wolfe C.D., Rudd A.G. Influence of raised plasma osmolality on clinical outcome after acute stroke. Stroke. 2000;31:2043-2048. doi: 10.1161/01. STR.31.9.2043.

Anderson D.E., Markway B.D., Weekes K.J., McCarthy H.E., Johnstone B. Physioxia promotes the articular chondrocyte-like phenotype in human chondroprogenitorderived self-organized tissue. Tissue Eng. Part A. 2017 doi: 10.1089/ten. tea.2016.0510.

9 Johnson Z.I., Shapiro I.M., Risbud M.V. Extracellular osmolarity regulates matrix homeostasis in the intervertebral disc and articular cartilage: Evolving role of tonebp. Matrix Biol. 2014;40:10-16. doi: 10.1016/j. matbio.2014.08.014.

10 Van der Windt A.E., Haak E., Das R.H., Kops N., Welting T.J., Caron M.M., van Til N.P., Verhaar J.A., Weinans H., Jahr H. Physiological tonicity improves human chondrogenic marker expression through nuclear factor of activated t-cells 5 in vitro. Arthritis. Res. Ther. 2010;12:R100. doi: 
10.1186/ar3031.

11 Van der Kraan P.M., Buma P., van Kuppevelt T., van den Berg W.B. Interaction of chondrocytes, extracellular matrix and growth factors: Relevance for articular cartilage tissue engineering. Osteoarthr. Cartil. 2002;10:631-637. doi: 10.1053/ joca.2002.0806.

12 Van der Kraan P.M., Blaney Davidson E.N., Blom A., van den Berg W.B. Tgfbeta signaling in chondrocyte terminal differentiation and osteoarthritis: Modulation and integration of signaling pathways through receptor-smads. Osteoarthr. Cartil. 2009;17:1539-1545. doi: 10.1016/j.joca.2009.06.008.

13 Miyazawa K., Shinozaki M., Hara T., Furuya T., Miyazono K. Two major smad pathways in tgf-beta superfamily signalling. Genes Cells. 2002;7:1191-1204. doi: 10.1046/j.1365-2443.2002.00599.x.

14 Roberts A.B., Sporn M.B., Assoian R.K., Smith J.M., Roche N.S., Wakefield L.M., Heine U.I., Liotta L.A., Falanga V., Kehrl J.H., et al. Transforming growth factor type beta: Rapid induction of fibrosis and angiogenesis in vivo and stimulation of collagen formation in vitro. Proc. Natl. Acad. Sci. USA. 1986;83:4167-4171. doi: 10.1073/pnas.83.12.4167.

15 Sanford L.P., Ormsby I., Gittenbergerde Groot A.C., Sariola H., Friedman R.,
Boivin G.P., Cardell E.L., Doetschman T. Tgfbeta2 knockout mice have multiple developmental defects that are non-overlapping with other tgfbeta knockout phenotypes. Development. 1997;124:2659-2670.

16 Parker W.L. Tgf- $\beta$ Receptors on Human Chondrocytes: Hetero-Oligomerization and Function. McGill University; Montreal, QC, Canada: 2003.

17 Heldin C.H., Miyazono K., ten Dijke P. Tgfbeta signalling from cell membrane to nucleus through smad proteins. Nature. 1997;390:465-471. doi: 10.1038/37284.

18 Finnson K.W., Parker W.L., ten Dijke P., Thorikay M., Philip A. Alk1 opposes alk5/smad3 signaling and expression of extracellular matrix components in human chondrocytes. J. Bone Miner. Res. 2008;23:896-906. doi: 10.1359/ jbmr.080209.

19 Blaney Davidson E.N., Remst D.F., Vitters E.L., van Beuningen H.M., Blom A.B., Goumans M.J., van den Berg W.B., van der Kraan P.M. Increase in alk1/alk5 ratio as a cause for elevated mmp-13 expression in osteoarthritis in humans and mice. J. Immunol. 2009;182:7937-7945. doi: 10.4049/jimmunol.0803991.

20 Harrison P.E., Ashton I.K., Johnson W.E., Turner S.L., Richardson J.B., Ashton B.A. The in vitro growth 
of human chondrocytes. Cell

Tissue Bank. 2000;1:255-260. doi:

10.1023/A:1010131729208.

21 Dennler S., Itoh S., Vivien D., ten Dijke P., Huet S., Gauthier J.M. Direct binding of smad 3 and smad4 to critical tgf betainducible elements in the promoter of human plasminogen activator inhibitortype 1 gene. EMBO J. 1998;17:3091-3100. doi: 10.1093/emboj/17.11.3091.

22 Zheng Z., Le H., Chen W., Shen W., Ouyang $\mathrm{H}$. Progress on treatment of tendinopathy with platelet-enriched plasma. Zhejiang Da Xue Xue Bao Yi Xue Ban. 2016;45:179186.

23 Gebauer M., Saas J., Sohler F., Haag J., Söder S., Pieper M., Bartnik E., Beninga J., Zimmer R., Aigner T. Comparison of the chondrosarcoma cell line sw1353 with primary human adult articular chondrocytes with regard to their gene expression profile and reactivity to il1 beta. Osteoarthr. Cartil. 2005;13:697-708. doi: 10.1016/j.joca.2005.04.004.

24 Blaney Davidson E.N., Scharstuhl A., Vitters E.L., van der Kraan P.M., van den Berg W.B. Reduced transforming growth factor-beta signaling in cartilage of old mice: Role in impaired repair capacity. Arthritis Res. Ther. 2005;7:R1338-R1347. doi: 10.1186/ $\operatorname{ar} 1833$.

25 Roberts A.B., Sporn M.B. Differential expression of the tgf-beta isoforms in embryogenesis suggests specific roles in developing and adult tissues. Mol. Reprod. Dev. 1992;32:91-98. doi: 10.1002/ mrd.1080320203.

26 Tchetina E.V., Antoniou J., Tanzer M., Zukor D.J., Poole A.R. Transforming growth factor-beta2 suppresses collagen cleavage in cultured human osteoarthritic cartilage, reduces expression of genes associated with chondrocyte hypertrophy and degradation, and increases prostaglandin e(2) production. Am. J. Pathol. 2006;168:131-140. doi: 10.2353/ ajpath.2006.050369.

27 Cheifetz S., Bellon T., Cales C., Vera S., Bernabeu C., Massague J., Letarte $M$. Endoglin is a component of the transforming growth factor-beta receptor system in human endothelial cells. J. Biol. Chem. 1992;267:19027-19030.

Finnson K.W., Parker W.L., Chi Y., Hoemann C.D., Goldring M.B., Antoniou J., Philip A. Endoglin differentially regulates tgfbeta-induced $\operatorname{smad} 2 / 3$ and $\operatorname{smad} 1 / 5$ signalling and its expression correlates with extracellular matrix production and cellular differentiation state in human chondrocytes. Osteoarthr. Cartil. 2010;18:1518-1527. doi: 10.1016/j. joca.2010.09.002.

29 Remst D.F., Blaney Davidson E.N., Vitters E.L., Bank R.A., van den Berg W.B., van der 
Kraan P.M. Tgf-ss induces lysyl hydroxylase

$2 \mathrm{~b}$ in human synovial osteoarthritic fibroblasts through alk5 signaling. Cell Tissue Res. 2014;355:163-171. doi: 10.1007/s00441-013-1740-5.

30 Tew S.R., Vasieva O., Peffers M.J., Clegg P.D. Post-transcriptional gene regulation following exposure of osteoarthritic human articular chondrocytes to hyperosmotic conditions. Osteoarthr. Cartil. 2011;19:1036-1046. doi: 10.1016/j. joca.2011.04.015.

31 Wang Q., Tan Q., Xu W., Qi H., Chen D., Zhou S., Ni Z., Kuang L., Guo J., Huang J. Cartilage-specific deletion of alk 5 gene results in a progressive osteoarthritislike phenotype in mice. Osteoarthr. Cartil. 2017;25:1868-1879. doi: 10.1016/j. joca.2017.07.010.

32 Takada E., Mizuno S. Reproduction of characteristics of extracellular matrices in specific longitudinal depth zone cartilage within spherical organoids in response to changes in osmotic pressure. Int. J. Mol. Sci. 2018;19:1507. doi: 10.3390/ ijms19051507.

33 Tew S.R., Peffers M.J., McKay T.R., Lowe E.T., Khan W.S., Hardingham T.E., Clegg P.D. Hyperosmolarity regulates sox $9 \mathrm{mrna}$ posttranscriptionally in human articular chondrocytes. Am. J. Physiol. Cell Physiol. 2009;297:C898-C906. doi: 10.1152/ ajpcell.00571.2008.
34 Guo X., Wang X.F. Signaling cross-talk between tgf-beta/bmp and other pathways. Cell Res. 2009;19:71-88. doi: 10.1038/cr.2008.302.

35 Erndt-Marino J., Trinkle E., Hahn M.S. Hyperosmolar potassium (K+) Treatment Suppresses Osteoarthritic Chondrocyte Catabolic and Inflammatory Protein Production in a 3-Dimensional In vitro Model. Cartilage. 2017 doi: 10.1177/1947603517734028.

36 Eltawil N.M., Ahmed S., Chan L.H., Simpson A.H.R.W., Hall A.C. Chondroprotection in models of cartilage injury by raising the temperature and osmolarity of irrigation solutions. Cartilage. 2018;9:313-320. doi: 10.1177/1947603516688511.

37 Van der Windt A.E., Jahr H., Farrell E., Verhaar J.A., Weinans H., van Osch G.J. Calcineurin inhibitors promote chondrogenic marker expression of dedifferentiated human adult chondrocytes via stimulation of endogenous tgfbeta1 production. Tissue Eng. Part A. 2010;16:1-10. doi: 10.1089/ ten.tea.2009.0082.

38 Van der Windt A.E., Haak E., Kops N., Verhaar J.A., Weinans H., Jahr H. Inhibiting calcineurin activity under physiologic tonicity elevates anabolic but suppresses catabolic chondrocyte markers. Arthritis Rheum. 2012;64:1929-1939. doi: 10.1002/ art.34369. 
39 Bounedjah O., Hamon L., Savarin P.,

Desforges B., Curmi P.A., Pastré D.

Macromolecular crowding regulates assembly of mrna stress granules after osmotic stress: New role for compatible osmolytes. J. Biol. Chem. 2012;287:24462458. doi: 10.1074/jbc.M111.292748.

40 Caron M.M., van der Windt A.E., Emans P.J., van Rhijn L.W., Jahr H., Welting T.J. Osmolarity determines the in vitro chondrogenic differentiation capacity of progenitor cells via nuclear factor of activated t-cells 5. Bone. 2013;53:94-102. doi: 10.1016/j.bone.2012.11.032.

41 Rivas G., Minton A.P. Macromolecular crowding in vitro, in vivo, and in between. Trends Biochem. Sci. 2016;41:970-981. doi: 10.1016/j.tibs.2016.08.013.

42 Massagué J. How cells read tgfbeta signals. Nat. Rev. Mol. Cell Biol. 2000;1:169-178. doi: 10.1038/35043051.

43 Van der Kraan P.M. The changing role of $\operatorname{tgf} \beta$ in healthy, ageing and osteoarthritic joints. Nat. Rev. Rheumatol. 2017;13:155163. doi: 10.1038/nrrheum.2016.219.

44 Shi Y., Massagué J. Mechanisms of tgfbeta signaling from cell membrane to the nucleus. Cell. 2003;113:685-700. doi: 10.1016/S0092-8674(03)00432-X.

45 Kuznetsova I.M., Turoverov K.K., Uversky V.N. What macromolecular crowding can do to a protein. Int. J. Mol. Sci.
2014;15:23090-23140. doi: 10.3390/ ijms151223090.

46 Caron M.M., Emans P.J., Coolsen M.M., Voss L., Surtel D.A., Cremers A., van Rhijn L.W., Welting T.J. Redifferentiation of dedifferentiated human articular chondrocytes: Comparison of $2 \mathrm{~d}$ and $3 \mathrm{~d}$ cultures. Osteoarthr. Cartil. 2012;20:11701178. doi: 10.1016/j.joca.2012.06.016.

47 Caron M.M., Emans P.J., Surtel D.A., van der Kraan P.M., van Rhijn L.W., Welting T.J. Bapx-1/nkx-3.2 acts as a chondrocyte hypertrophy molecular switch in osteoarthritis. Arthritis Rheumatol. 2015;67:2944-2956. doi: 10.1002/ art.39293.

48 Das R.H., van Osch G.J., Kreukniet M., Oostra J., Weinans H., Jahr H. Effects of individual control of ph and hypoxia in chondrocyte culture. J. Orthop. Res. 2009 doi: 10.1002/jor.20994.

49 Bustin S.A., Benes V., Garson J.A., Hellemans J., Huggett J., Kubista M., Mueller R., Nolan T., Pfaffl M.W., Shipley G.L., et al. The miqe guidelines: Minimum information for publication of quantitative real-time pcr experiments. Clin. Chem. 2009;55:611-622. doi: 10.1373/ clinchem.2008.112797.

50 Maglott D., Ostell J., Pruitt K.D., Tatusova T. Entrez gene: Gene-centered information at ncbi. Nucleic Acids Res. 2011;39:D52- 
D57. doi: $10.1093 /$ nar/gkq1237.

51 Korchynskyi O., ten Dijke P. Identification and functional characterization of distinct critically important bone morphogenetic protein-specific response elements in the id1 promoter. J. Biol. Chem. 2002;277:4883-4891. doi: 10.1074/jbc. M111023200. 


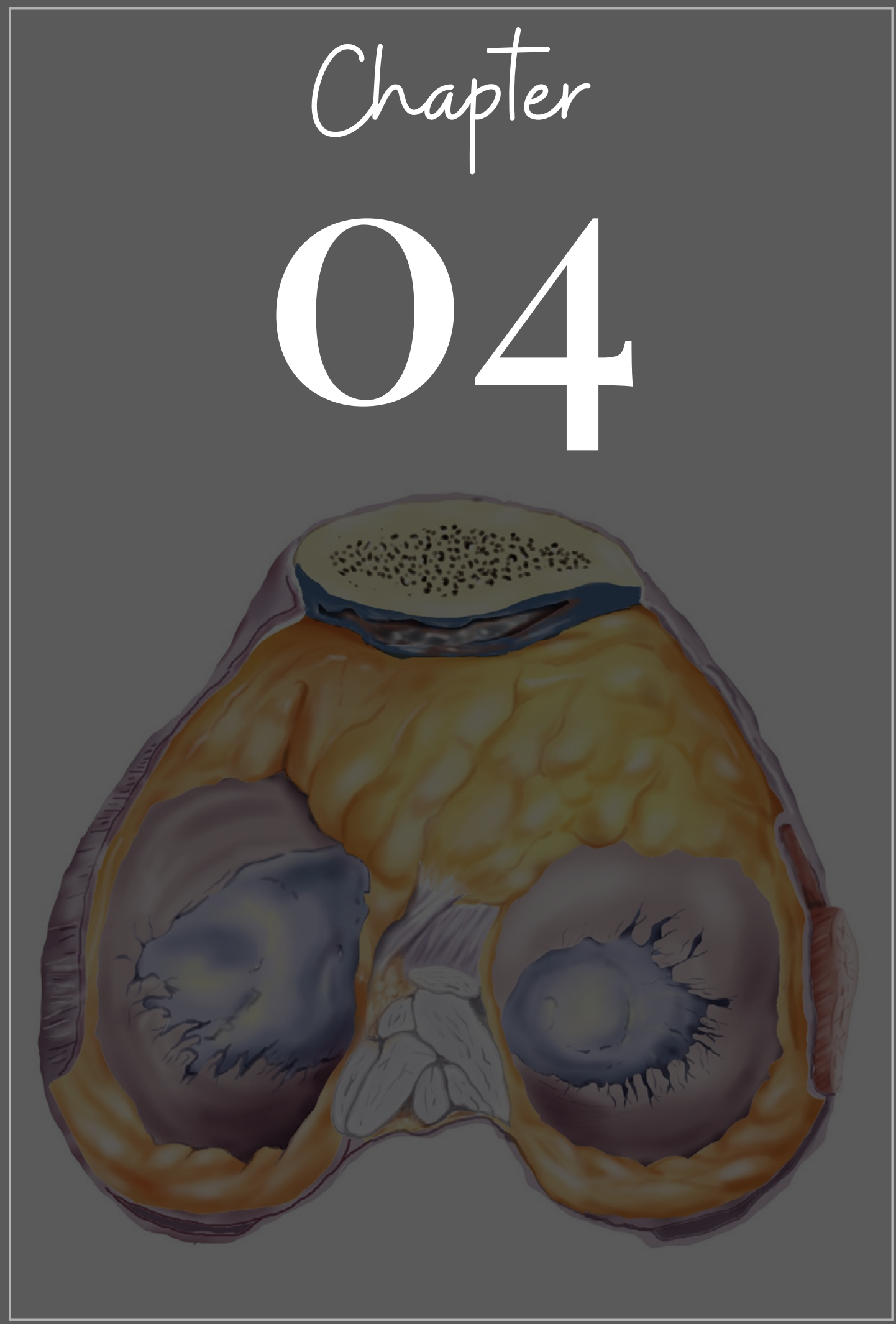




\section{Celecoxib-Mediated Reduction of Prostanoid Release in Hoffa's Fat Pad from Donors with Cartilage Pathology Results in an Attenuated Inflammatory Phenotype.}

Timur UT, Caron MMJ, Bastiaansen-Jenniskens YM, Welting TJM, van Rhijn LW, van Osch G, Emans PJ Osteoarthritis Cartilage. 2018;26(5):697-706. 


\section{Abstract}

\section{Objective:}

The Hoffa's fat pad (HFP) is an intra-articular adipose tissue which is situated under and behind the patella. It contains immune cells next to adipocytes and secretes inflammatory factors during osteoarthritis (OA). In this study, we compared the release profile of prostanoids, which are involved in inflammation, of HFP from OA patients vs patients with a focal cartilage defect (CD) without evidence for OA on MRI and investigated the prostanoid modulatory anti-inflammatory action of celecoxib on HFP.

\section{Material \& Methods:}

Prostanoid release was analyzed in conditioned medium of HFP explant cultures from 17 osteoarthritic patients and 12 CD patients, in the presence or absence of celecoxib. Furthermore, gene expression of COX enzymes and expression of genes indicative of a pro-inflammatory or anti-inflammatory phenotype of HFP was analyzed.

\section{Results:}

Prostanoid release by HFP from knee OA patients clustered in two subgroups with high and low prostanoid producers. HFP from high prostanoid producers released higher amounts of $\mathrm{PGE}_{2}, \mathrm{PGF}_{2 \mathrm{a}}$ and $\mathrm{PGD}_{2}$ compared to HFP from CD patients. PGE 2 release by OA HFP was positively associated with expression of genes known to be expressed by $\mathrm{M} 1$ macrophages, indicating a role for macrophages. Celecoxib modulated prostanoid release by HFP, and also modulated the inflammation ratio towards a more favorable anti-inflammatory M2 phenotype, most effectively in patients with higher prostanoid release profiles.

\section{Conclusion:}

In knee OA patients with inflamed HFP's, celecoxib may exert positive effects in the knee joint via decreasing the release of prostanoids produced by the HFP and by favorably modulating the anti-inflammatory marker expression in HFP. 


\section{Introduction}

Knee osteoarthritis $(\mathrm{OA})$ is a multifactorial disease characterized by cartilage deterioration and subchondral sclerosis'. An inflammatory component in this disease is now acknowledged $^{2}$. Next to cartilage and synovium, studies have shown the ability of the Hoffa's fat pad (HFP) to secrete inflammatory mediators able to induce inflammatory and destructive responses in knee OA ${ }^{3,4}$. The HFP is an adipose tissue located intra-articularly behind and under the patella ${ }^{4}$. Important molecules involved in inflammatory processes are prostanoids. While prostanoids have been shown to be secreted by the HFP', modulation of prostanoid secretion by HFP and potential consequences of such modulation on inflammatory processes in HFP has not been investigated.

The major rate-limiting step in the biosynthesis of prostanoids is the cyclooxygenase (COX) dependent production of $\mathrm{PGH}_{2}{ }^{6}$. The prostanoid family consists of five different subtypes: $\mathrm{PGE}_{2}, \mathrm{PGD}_{2}, \mathrm{PGI}_{2}, \mathrm{PGF}_{2 a}$ and Thromboxane $\mathrm{A}_{2}\left(\mathrm{TXA}_{2}\right)$ and these subtypes are synthesized from $\mathrm{PGH}_{2}$ by dedicated enzymes ${ }^{7}$. COX-1 is regarded as the 'housekeeping' COX, responsible for the production of basal prostanoid levels, which are thought to maintain local homeostasis ${ }^{8}$. On the other hand, COX-2 is considered to be inflammatory, since its expression is upregulated in inflamed joint tissues ${ }^{8}$. Indeed, COX-2 expression in the HFP has been shown to be increased upon inflammatory stimulation ${ }^{3}$, and while it is now well established that COX-2 expression is upregulated in inflamed joint tissues ${ }^{8}$, the consequences of altered COX-2 expression on the production of its main downstream prostanoid products are poorly documented in OA. Different prostanoid subtypes such as $\mathrm{PGE}_{2}$ and $\mathrm{PGF}_{2 a}$ have been shown to be involved in catabolic and pro-fibrotic responses in knee $\mathrm{OA}^{9,10,11}$, and thus a broader insight into the involvement of specific prostanoids in OA-related inflammatory processes will be essential to understand their contribution in OA. Since the HFP contains nerve fibers ${ }^{4}$ and considering the pronociceptive effects of different prostanoid subtypes ${ }^{12,13,14}$, prostanoids produced by the HFP may provide valuable targets for anti-inflammatory and pain therapy in the OA knee joint. Several risk factors have been described which predispose for knee OA, one of which are cartilage defects $(C D s)^{15}$. Defining the difference between a CD and'pre-osteoarthritis'still represents a major 
challenge. Although Gierman and coworker have shown that there was a slight difference in the inflammatory profile of HFP between OA and non-OA donors ${ }^{5}$, the HFP from patients with a CD vs HFP from OA patients has never been studied to our knowledge and may provide further insight in the inflammatory pathogenesis of both overlapping diseases $O A$ and CDs. Therefore, the main goal of this study was to evaluate the secretion of prostanoid subtypes by the HFP from knee OA patients and compare with prostanoid secretion by the HFP of CD patients. In addition, correlations were investigated between prostanoid secretion from HFP and expression of inflammatory markers in the HFP, to evaluate the general inflammatory status of the tissue. Finally, since COX-2 has been considered as an important inflammatory factor in $\mathrm{HFP}^{3}$, we sought to determine the anti-inflammatory actions of celecoxib, a specific COX-2 inhibitor, on HFP.

\section{Material \& Methods}

\subsection{Preparation of Hoffa's Fat Pad Conditioned Medium}

The Medical Ethical Committee (MEC) of Maastricht University approved this study and assigned approval ID: MEC 11-4-040.17. HFPs were obtained as anonymous material from human subjects with endstage OA (Kellgren \& Lawrence grade three-four) who underwent total knee arthroplasty (TKA). Since the autologous chondrocyte transplantation (ACT) procedure is performed less frequently than a TKA for endstage OA, 12 HFPs were obtained from human subjects with a single $C D$ who underwent an ACT procedure (ACT; Chondrocelect Tigenix, Leuven Belgium). CDs were either due to trauma or osteochondritis dissecans and patients did not show any signs of OA on X-ray and MRI. These HFP's were used to generate HFP conditioned medium (HCM) at a concentration of $100 \mathrm{mg}$ tissue/ $\mathrm{mL}$ using DMEM/F12 (Life Technologies, Carlsbad US), 1\% ITS, 1\% antibiotic/antimycotic (Life Technologies) in a humidified atmosphere at $37^{\circ} \mathrm{C}, 5 \% \mathrm{CO}_{2}$ as reported previously ${ }^{16}$. The inner part of HFP was cut into small explants to avoid the presence of synovial tissue. Explants were selected randomly throughout the entire tissue and used at a concentration of $100 \mathrm{mg}$ tissue/mL medium to create OA HCM or CD HCM. A stock solution of $10 \mathrm{mM}$ celecoxib (LC Laboratories, Woburn, MA, US) was made in dimethylsulfoxide (DMSO, Sigma 
Aldrich, St. Louis, MO, US) and added 1:1,000 to medium with pieces of HFP to obtain a $10 \mu \mathrm{M}$ concentration. DMSO was also added 1:1,000 to HFP cultures without celecoxib as a control. In addition, three patients in the OA group were cultured with 2.5, 10 and 100 $\mu \mathrm{M}$ celecoxib to examine a dose response. In accordance with the method described by Clockaerts et al., medium was harvested after $24 \mathrm{~h}$, centrifuged at 1,200 RPM for 8 min and the supernatant was frozen at $-80^{\circ} \mathrm{C}^{16}$. Media were stored for a maximum of 8 weeks before analysis. HFP explants were frozen in liquid nitrogen and stored at $-80^{\circ} \mathrm{C}$ until being processed for RNA isolation.

\subsection{Prostanoid, Interleukin-6 and Interleukin-1 $\beta$ Measurement in HCM}

Concentrations of $\mathrm{PGE}_{2^{\prime}} \mathrm{PGF}_{2 a^{\prime}}, \mathrm{PGD}_{2}$ and $\mathrm{TXB}_{2}$ (a stable metabolite of $\mathrm{TXA}_{2}$ ) were determined in OA HCM and CD HCM by a competitive Enzyme-Linked Immunosorbent Assay according to the manufacturer's instructions (ELISA, Cayman Chemicals, Ann Arbor, $\mathrm{MI}, \mathrm{US}$ ) as reported previously ${ }^{17}$. Concentrations of interleukin- 6 and interleukin- $1 \beta$ in HCM was determined according to the manufacturer's instructions of the human IL- 6 and IL-1 $\beta$ Quantikine ELISA Kits (R\&D Systems, MI, US).

\subsection{RNA Isolation and Quantitative RT-PCR}

Frozen HFP was homogenized with a Mikro-Dismembrator and suspended in $1 \mathrm{ml}$ TRIzol/100 mg tissue. RNA was extracted and CDNA was made as reported previously ${ }^{16}$. Real time quantitative PCR (RT-qPCR) was performed using Mesagreen qPCR mastermix plus for SYBR Green (Eurogentec). A CFX96 Real-Time PCR Detection system (Biorad) was used for amplification: initial denaturation $95^{\circ} \mathrm{C}$ for $10 \mathrm{~min}$, followed by 40 cycles of amplification (denaturing $15 \mathrm{~s}$ at $95^{\circ} \mathrm{C}$ and annealing $1 \mathrm{~min}$ at $60^{\circ} \mathrm{C}$ ) as reported previously ${ }^{17}$. Validated primer sequences can be found in Supplementary Table 1. Gene expression was normalized to a best housekeeper ratio based on gene expression levels of GAPDH, PPIA and $28 S^{18}$ and data were analyzed according to the $2^{\wedge}-\triangle \Delta C T$ method ${ }^{19}$. Housekeeper gene expression was found to be stable (data not shown). 


\subsection{Statistical Analysis}

SPSS Inc., Chicago, USA (version 20) was used for statistical analyses. A minimum of five explants was used per experimental condition. All samples for gene expression analysis and cytokine measurements in medium were processed and analyzed individually with a single measurement per donor. Continuous variables were tested for normality using Kolmogorov-Smirnov test.

$\mathrm{PGE}_{2}$ release data were not normally distributed and a Mann-Whitney $U$ test was performed to evaluate differences between $\mathrm{PGE}_{2}$ release by OA HFP and CD HFP. Based on PGE release data, OA patients were further divided into two subgroups, which was based on an arbitrarily chosen $P G E_{2}$ release threshold. An inflammation ratio was calculated, using $I L 6$, IL1B, CD86 and TNFA as markers associated with pro-inflammatory or M1 macrophages and CD206, IL10, CD163 and CCL18 as markers associated with anti-inflammatory or $\mathrm{M} 2$ macrophages ${ }^{20}$. The mean of the relative expression of pro-inflammatory genes per sample, was divided over the mean of the relative expression of anti-inflammatory genes per sample. Gene expression data, the inflammation ratio, prostanoid release and cytokine release data of these two OA subgroups and CD patients were then log transformed and subjected into a general linear model. For celecoxib treatments in the patient groups, the celecoxib treatment itself was defined as a fixed factor in a general linear model. Correlations between prostanoid levels and expression of markers associated with inflammation were calculated using the Spearman's rank correlation test.

Differences in clinical parameters BMI, and age between $O A$ and $C D$ patients were analyzed using an independent Student's $t$-test, differences in duration of symptoms and K\&L grade between $O A$ and $C D$ patients were analyzed using a Mann-Whitney $U$ test and differences in gender using a Pearson Chi-square test. Bonferroni's post hoc comparisons test was used to adjust for multiple comparisons. Mean $\pm 95 \%$ coincidence intervals are included in the figures. 


\section{Results}

\subsection{Hoffa's Fat Pad from OA Patients Releases Higher Amounts of Prostanoids than Hoffa's Fat Pad from CD Patients, which is correlated to PTGS2 Expression}

Demographical data of HFP from OA and CD patients can be found in Table I. Age and K\&L grade were the only significantly different factors between the two patient groups ( $p<$ 0.001 ) for both parameters. The mean age of OA patients was $63.8 \pm 1.9$ years and the mean age of $C D$ patients was $26.1 \pm 7.9$ years, while the mean $K \& L$ grade was 3.3 for OA patients and 0 for CD patients (Table I). In the HFP of OA and CD patients we first examined mRNA expression levels of the prostanoid synthesizing COX-1 and COX-2 enzymes (encoded by PTGS1 and PTGS2). No significant differences were observed in PTGS1 and PTGS2 mRNA expression between HFP of OA and CD patients (Figure 1A). To investigate COX enzyme activity, we next analyzed $\mathrm{PGE}_{2}$ release (the major prostanoid subtype synthesized by different intra-articular tissues and generally acknowledged to be the most inflammatory prostanoid subtype ${ }^{21,22}$ ) in culture supernatants of OA and CD HFP. Release of PGE $_{2}$ was 30-fold higher by OA HFP in comparison to CD HFP $(p=0.0005)$ (Figure $1 A)$. However, a wide variation in $\mathrm{PGE}_{2}$ release by $\mathrm{OA}$ donors was observed, and the donors clustered into two groups: a subgroup with higher (higher than 25,000 pg/ml PGE 2 : high $\mathrm{PGE}_{2} \mathrm{OA}$ group, designated with \# in Figure 1A) or lower (lower than 25,000 pg/ml: low $\mathrm{PGE}_{2} \mathrm{OA}$ group, designated with \#\# in Figure 1A) PGE 2 release profiles. 


\section{Table I Clinical Characteristics}

\begin{tabular}{|l|l|l|}
\hline \multicolumn{2}{c|}{ OA PATIENTS } & \multicolumn{1}{c|}{ CD PATIENTS } \\
\hline Number & 17 & 12 \\
\hline Male:Female & $8: 9$ & $8: 4$ \\
\hline Age, mean \pm SD (in years) & $63.8 \pm 1.9$ & $26.1 \pm 7.9$ \\
\hline BMI, mean \pm SD & $29 \pm 6.4$ & $24 \pm 3$ \\
\hline Kellgren \& Lawrence, mean \pm SD & $3.3 \pm 0.5$ & $0 \pm 0$ \\
\hline
\end{tabular}
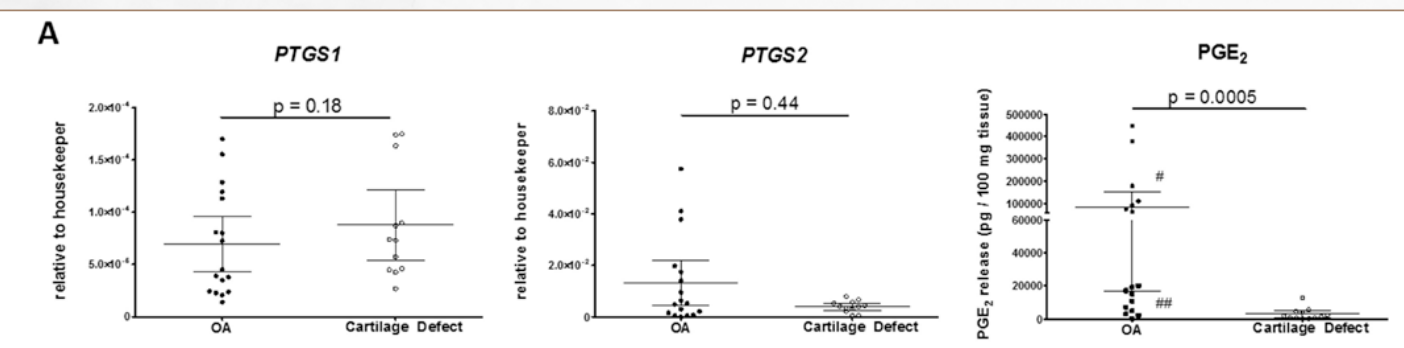

B

$\mathrm{PGE}_{2}$ vs. PTGS1

$\mathrm{PGE}_{2}$ vs. PTGS2

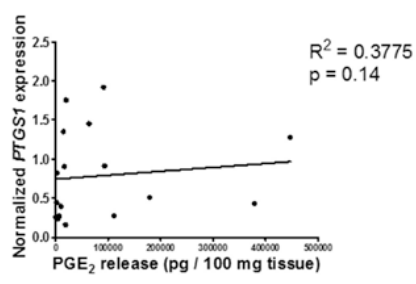

C

PTGS1

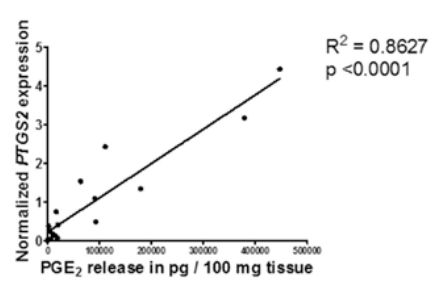

PTGS2
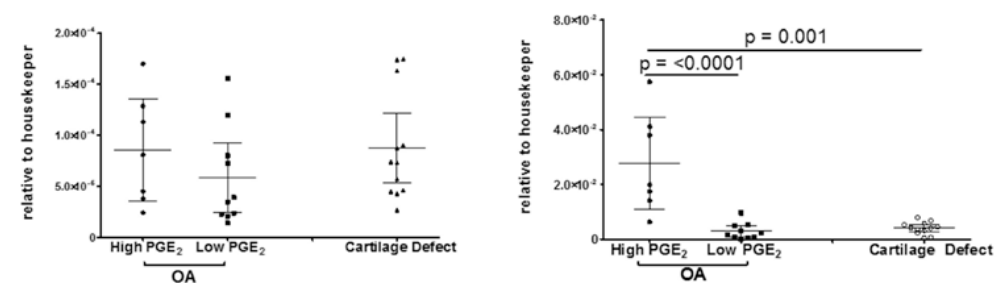
Figure 1: Higher PGE ${ }_{2}$ release from OA Hoffa's fat pad (HFP) than cartilage defect (CD) HFP.

Relative PTGS1 (left figure), PTGS2 (middle figure) mRNA expression and PGE ${ }_{2}$ release (right figure) by osteoarthritis (OA) and CD HFP $24 \mathrm{~h}$ after culturing. In the right figure, the high $P G E_{2} O A$ group is designated with \# and the low $P G E_{2} O A$ group is designated with \#\#. Each dot or square represents normalized gene expression data or absolute $P G E_{2}$ levels released in culture medium in pg/100 $\mathrm{mg}$ tissue from separate patients. Data is presented in scatter dot plots with mean $\pm 95 \% \mathrm{Cl}(\mathrm{A})$. Spearman correlation coefficients between $P G E_{2}$ release in culture medium and PTGS1 (left figure) or PTGS2 (right figure) MRNA expression in HFP at $24 \mathrm{~h}$ after culturing. $R^{2}$ and $p$ values are provided within each graph (B). PTGS1 mRNA (left figure) and PTGS2 mRNA (right figure) expression in HFP from the high $P G E_{2} O A$, low $P G E_{2} O A$ and $C D$ patients. Data is presented in scatter dot plots with mean $\pm 95 \% \mathrm{Cl}(\mathrm{C}) . \mathrm{N}=17$ for $O A$ HFP and $\mathrm{N}=12$ for $C D$ HFP.

While we did not find a correlation between $\mathrm{PGE}_{2}$ release by OA HFP and PTGS1 expression $\left(R^{2}=0.337, \mathrm{p}=0.14\right)$, a strong correlation between $\mathrm{PGE}_{2}$ release and PTGS2 expression in $\operatorname{HFP}\left(R^{2}=0.86, \mathrm{p} \leq 0.0001\right)$ was observed (Figure 1B). In accordance with these data, patients in the high $\mathrm{PGE}_{2}$ OA group displayed 9.6-fold higher PTGS2 (but not PTGS1) expression levels in comparison to patients from the low PGE ${ }_{2}$ OA subgroup $(p \leq 0.0001)$ and 6.8 -fold higher in comparison to CD patients $(p=0.001)$ (Figure 1C).

HFP from both the high and the low $\mathrm{PGE}_{2} \mathrm{OA}$ group released more $\mathrm{PGE}_{2}$ than HFP from $C D$ patients (Figure $2 A$ ). Release of prostanoid subtypes $P G F_{2 a}$ and $P G D_{2}$ followed similar dynamics as $\mathrm{PGE}_{2}$ and release of these prostanoids was significantly higher in HFP from the high $\mathrm{PGE}_{2} \mathrm{OA}$ group, while release of $\mathrm{TXB}_{2}$ by HFP was not significantly different between $O A$ and $C D$ patients (Figure 2A-D). Significant correlations were found between $P F_{2 a^{\prime}} P G_{2}$ and $\mathrm{TXB}_{2}$ release and the inflammation-induced PTGS2 expression in HFP (Figure 2E). No significant correlations were found between $\mathrm{PGF}_{2 \mathrm{a}^{\prime}} \mathrm{PGD}_{2}$ and $\mathrm{TXB}_{2}$ release and $\mathrm{PTGS} 1$ levels (Figure 2E). The differential prostanoid release between $\mathrm{OA}$ patients could not be related to several clinical parameters such as age, duration of symptoms, gender, BMI or K\&L grade (Supplementary Figure 1). 
A

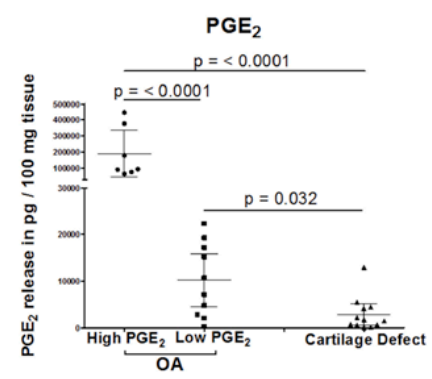

C

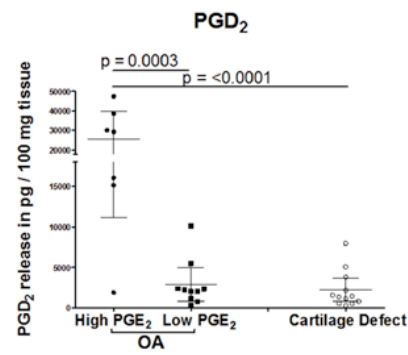

B

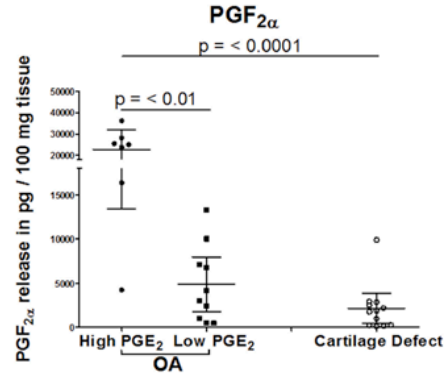

D

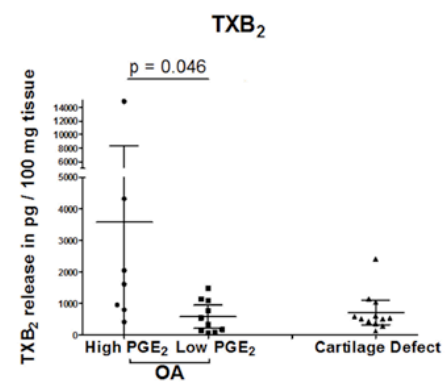

E

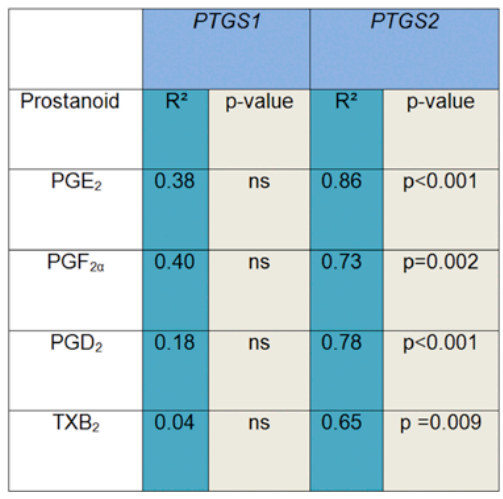

Figure 2: Higher prostanoid release from OA HFP than from CD HFP.

$P G E_{2}(A), P G F_{2 a}(B), P G D_{2}(C)$ and $T X B_{2}(D)$ release from HFP in pg/100 mg tissue. Data is presented in scatter dot plots with mean $\pm 95 \% \mathrm{Cl}$. Spearman correlation coefficients between $P G E_{2} P G F_{2 d} P G D_{2}$ , TXB ${ }_{2}$ release and PTGS mRNA expression in OA HFP (E). $N=17$ for OA HFP and $N=12$ for CD HFP. 


\subsection{High Prostanoid Release by OA HFP is Accompanied by High Expression of Inflammatory Markers}

We next investigated whether the high prostanoid release from OA HFP was accompanied by alterations in other markers involved in inflammation. Since it has been shown that HFP contains macrophages ${ }^{16}$, we specifically included the expression of markers in the HFP associated with a pro-inflammatory macrophage phenotype, and markers associated with an anti-inflammatory macrophage phenotype ${ }^{20,21,22,23}$. HFP from the high $\mathrm{PGE}_{2} \mathrm{OA}$ group displayed 10.5-fold higher gene expression levels of pro-inflammatory marker IL6compared to the low $\mathrm{PGE}_{2} \mathrm{OA}$ group $(\mathrm{p} \leq 0.0001)$ and 8.3 -fold higher compared to $C D$ patients $(p=$ 0.0002). Another inflammatory marker, $I L 1 B$, showed similar expression patterns between the three patient groups with 3.4-fold higher expression levels in the high $\mathrm{PGE}_{2} \mathrm{OA}$ group compared to the low $\mathrm{PGE}_{2} \mathrm{OA}$ group $(p=0.02)$ and 3.2-fold higher compared to $C D$ patients $(p=0.05)$ (Figure $3 A$ ). IL-6 protein release by HFP showed the same pattern as mRNA data (Figure $3 A$ ). IL-1 $\beta$ protein release by HFP could only be detected in four samples, which were all conditioned media collected from patients in the high $\mathrm{PGE}_{2} \mathrm{OA}$ group (Figure 3A). Gene expression levels of the pro-inflammatory marker TNFA was not different between the HFPs of the three patient groups (Figure 3A). 
A

\section{Pro-inflammatory markers}
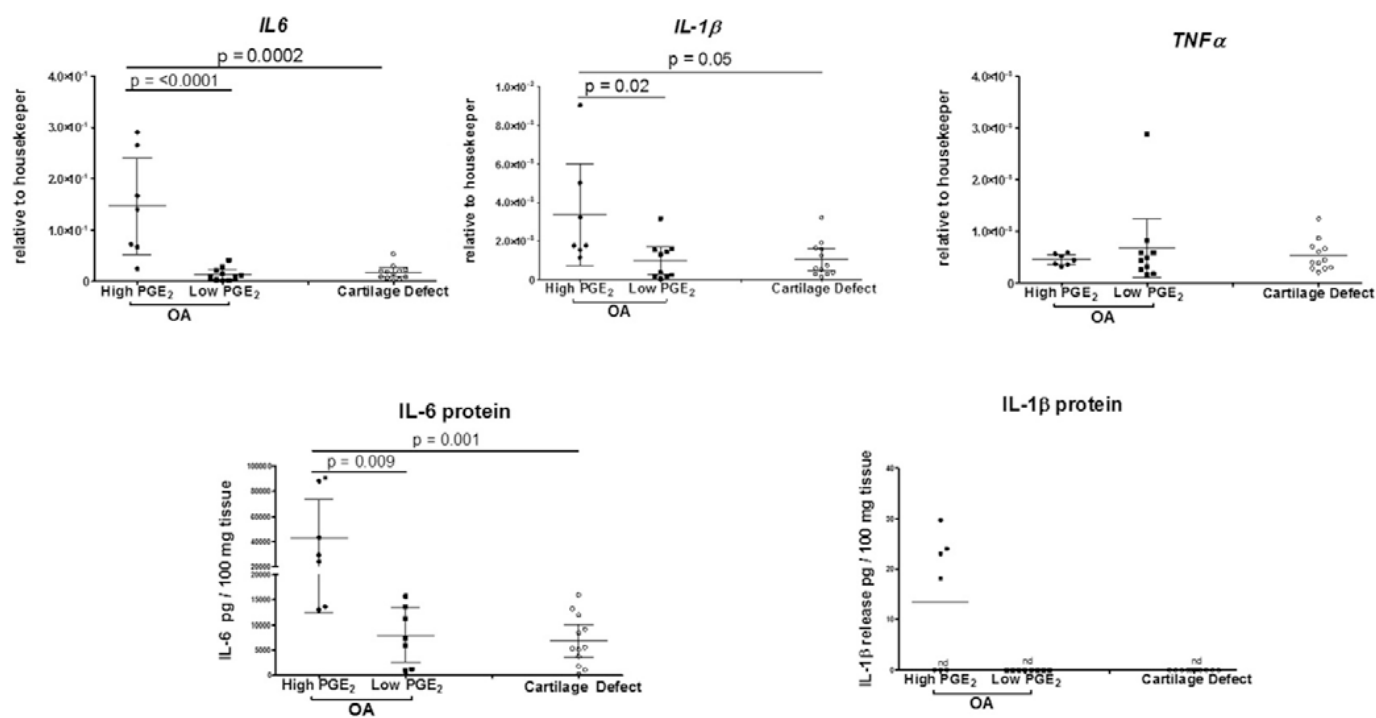

IL-1 $\beta$ protein

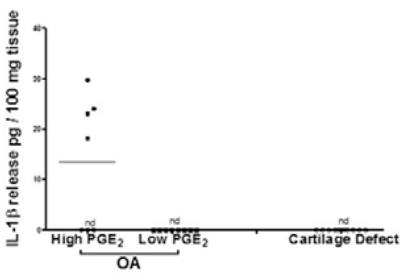

B

\section{Markers associated with macrophages}

CD163

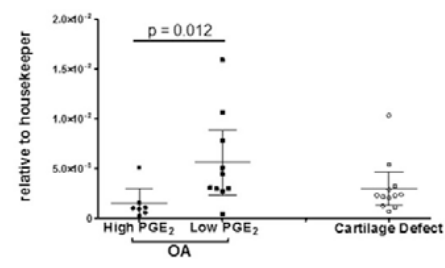

CCL18

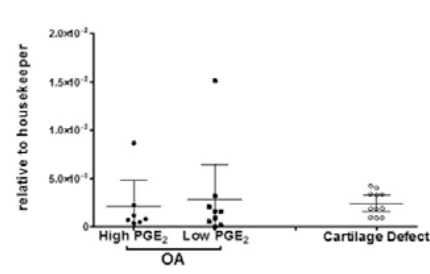

CD206

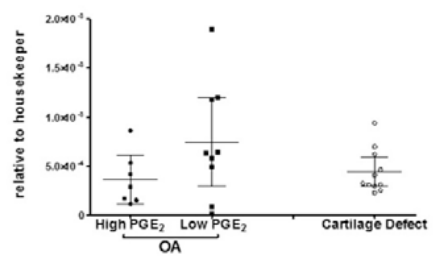

IL-10

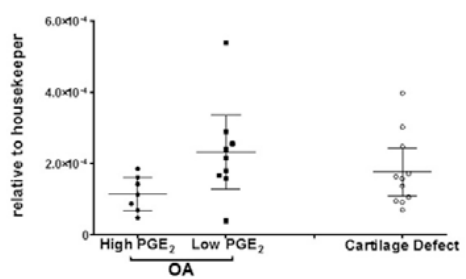


C

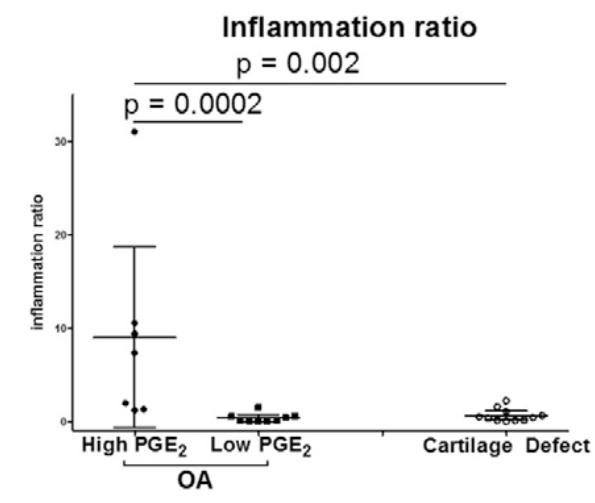

D

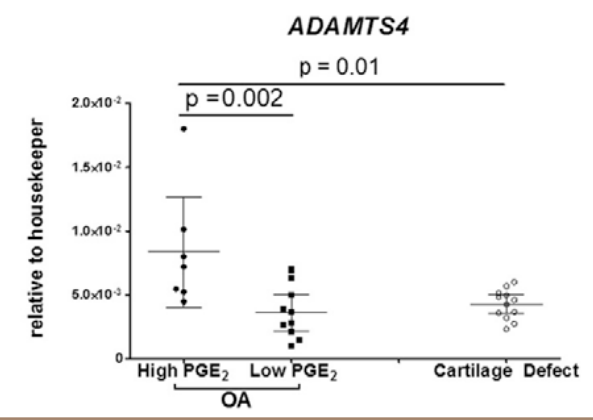

\section{$\mathrm{PGE}_{2}$ vs. inflammation ratio}
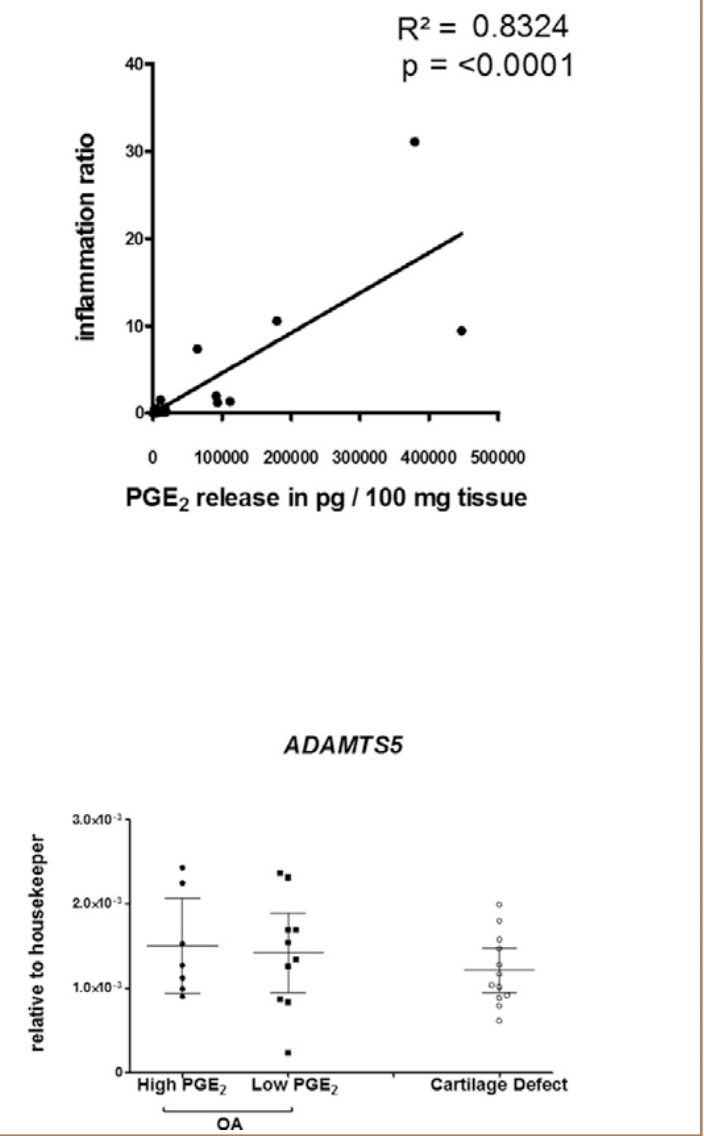

Figure 3: More inflammatory phenotype OA HFP than CD HFP.

Gene expression levels of pro-inflammatory markers (IL6, IL1B, TNFA) and protein release levels of IL-6 and IL-1 $\beta$ (A) and markers associated with macrophages (CD86, CD163, IL10, CCL18, CD206) (B) in HFP from the high $\mathrm{PGE}_{2} \mathrm{OA}$ group, low $\mathrm{PGE}_{2} \mathrm{OA}$ group and Cartilage Defect group. Data is presented in scatter dot plots with mean $\pm 95 \%$ Cl. Inflammation ratio in $\mathrm{HFP}$ from the high $P G E_{2} O A$ group, low $P G E_{2} O A$ group and Cartilage Defect group (left figure, data represented in scatter dot plots with mean $\pm 95 \% \mathrm{Cl}$ ) and association $\mathrm{PGE}_{2}$ release and inflammation ratio in HFP (right figure). Each dot represents data from separate patients (C). Gene expression levels of the inflammatory aggrecanase ADAMTS4 and non-inflammatory aggrecanase ADAMTS5 in high $P G E_{2} O A$ group, low $P G E_{2} O A$ group and Cartilage Defect group. Data is presented in scatter dot plots with mean $\pm 95 \%$ $C I(D) . N=17$ for $O A$ HFP and $N=12$ for CD HFP. 
Gene expression levels of the marker associated with anti-inflammatory macrophages, CD163 was 3.7-fold lower $(p=0.012)$ in HFP from the high PGE $_{2}$ OA group compared to HFP from the low $\mathrm{PGE}_{2} \mathrm{OA}$ group (Figure $3 \mathrm{~B}$ ). Gene expression levels of the pro-inflammatory marker CD86 and of the anti-inflammatory markers IL-10, CCL18 and CD206 were not statistically different between HFPs from OA or CD patients (Figure 3B). The higher proinflammatory and the lower anti-inflammatory marker gene expression in HFP from the high $\mathrm{PGE}_{2} \mathrm{OA}$ group resulted in a 21.4-fold higher inflammation ratio than the HFP from the low $\mathrm{PGE}_{2} \mathrm{OA}$ group $(p=0.0002)$ and 9.7-fold higher than the HFP from CD patients $(p=0.002$ ) (Figure $3 C)$. $P G E_{2}$ release was positively associated with expression of proinflammatory markers and negatively associated with expression of anti-inflammatory markers, resulting in a strong correlation $\left(R^{2}=0.83, p \leq 0.0001\right)$ of the inflammation ratio with $\mathrm{PGE}_{2}$ release by HFP (Figure 3C; separate correlation of pro- and anti-inflammatory markers with $\mathrm{PGE}_{2}$ release can be found in Supplementary Figure 2).

Since inflammation in $\mathrm{OA}$ is often accompanied by expression of proteolytic enzymes ${ }^{24}$ and transcription of the extracellular proteolyticenzyme ADAMTS4is responsive to inflammatory stimuli and ADAMTS5 is being considered as a non-inflammatory aggrecanase ${ }^{25,26}$, we evaluated the mRNA expression levels of these two aggrecanases in the HFP. The mRNA expression of ADAMTS4, but not ADAMTS5, was 2.3-fold higher in HFP from the high PGE OA group than the HFP from the low $\mathrm{PGE}_{2} \mathrm{OA}$ group $(\mathrm{p}=0.002)$ and 2 -fold higher than the HFP from CD patients $(\mathrm{p}=0.01)$, which is in concert with an inflammatory and noninflammatory association of ADAMTS4 and ADAMTS5 respectively (Figure 3D).

\subsection{Celecoxib Reduces Prostanoid Release by OA and CD HFP}

We next asked whether specific COX-2 inhibition by celecoxib in OA and CD HFPs has inflammation-attenuating effects. First, the concentration of celecoxib that is able to most efficiently reduce prostanoid release was determined by culturing HFP of three OA patients in the presence of $2.5,10$ or $100 \mu \mathrm{M}$ celecoxib. These three patients were selected randomly, without information about their distribution to either low or high $\mathrm{PGE}_{2} \mathrm{OA}$ group. Celecoxib at a dose of $100 \mu \mathrm{M}$ was highly effective in reducing $\mathrm{PGE}_{2}$ release by HFP ( $\left.p \leq 0.0001\right)$, but considering the possibility that higher doses of celecoxib may result in reduced COX-2 
selectivity ${ }^{27}$, we chose to use $10 \mu \mathrm{M}$ celecoxib in our experiments as this concentration was able to significantly reduce $\mathrm{PGE}_{2}$ release by at least $85 \%$ from HFP from all three patients ( $p$ $=0.002$ ) (Figure 4A).

A

$\mathrm{PGE}_{2}$

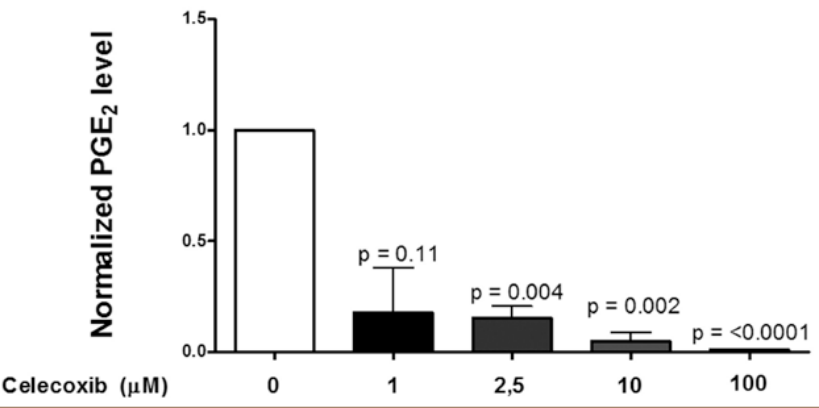




\section{B}

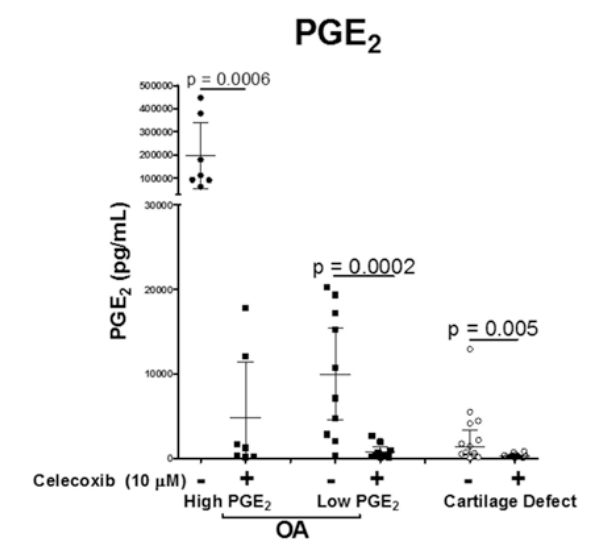

\section{$\mathrm{PGD}_{2}$}

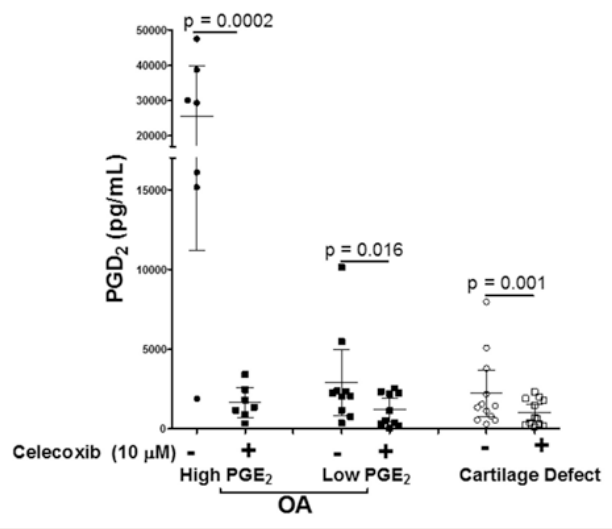

PGF $_{2 \alpha}$

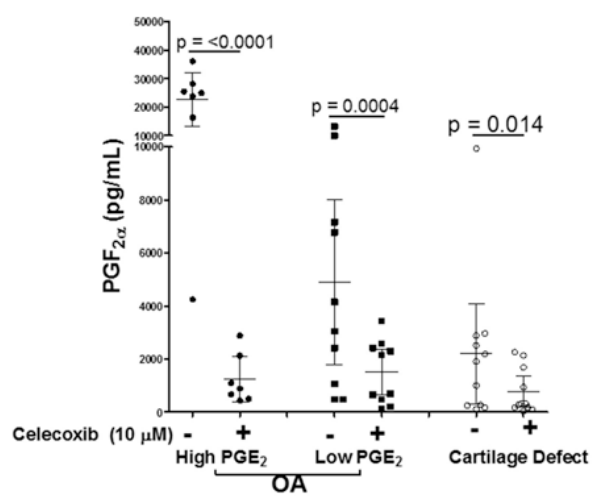

$\mathrm{TXB}_{2}$

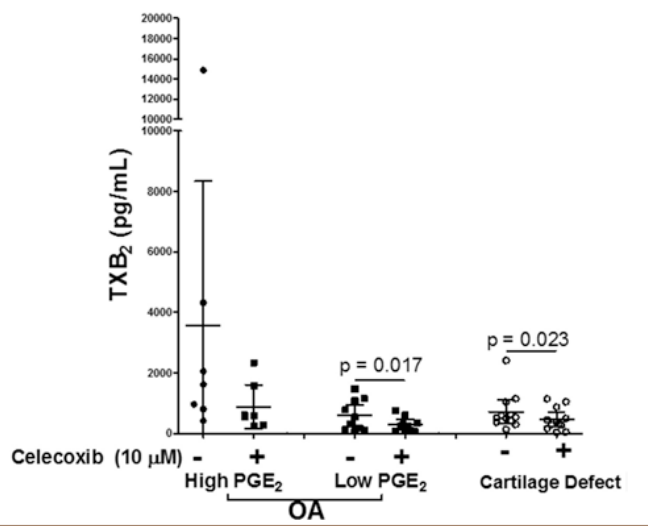

Figure 4: Celecoxib reduces prostanoid release by $O A$ and CD HFP.

$P G E_{2}$ release in culture medium by OA HFP from three patients with increasing concentrations of celecoxib. Data represent normalized $P G E_{2}$ levels in three $O A$ patients. The $P G E_{2}$ release in culture medium of HFP cultured without celecoxib was set to 1. Bars show the mean $\pm S D$ (A). Effects of celecoxib on $P G E_{2} P G F_{2 a}, P G D_{2}$ and $T X B_{2}$ release in Hoffa's fat pad conditioned medium (HCM) from the high and low $P G E_{2} O A$ groups and $C D$ group. Data is presented in scatter dot plots with mean \pm $95 \% \mathrm{Cl}(B) . \mathrm{N}=17$ for OA HFP and $\mathrm{N}=12$ for CD HFP. 
Celecoxib significantly reduced $\mathrm{PGE}_{2^{\prime}} \mathrm{PGF}_{2 \mathrm{a}}$ and $\mathrm{PGD}_{2}$ release from HFP from the high $\mathrm{PGE}_{2}$ (40.6-fold, $p=0.0006,18.5$-fold, $p<0.0001$ and 15.5 -fold, $p=0.0002$ respectively), low $P E_{2}$ (12.1-fold, $p=0.0002,3.2$-fold, $p=0.0004$ and 2.4-fold, $p=0.016$ respectively) and CD group $\left(p=0.005, p=0.014\right.$ and $p=0.001$ respectively). Celecoxib also significantly reduced $T_{X B_{2}}$ release by HFP from the low $\mathrm{PGE}_{2}$ group (2.1-fold, $\mathrm{p}=0.017$ ) and HFP from CD patients (1.6fold, $p=0.023$ ) (Figure 4B).

\subsection{Celecoxib Acts Anti-Inflammatory on the Inflamed OA HFP}

Since $\mathrm{PGE}_{2}$ release was positively associated with the inflammation ratio, we next investigated the consequences of reducing prostanoid release on the expression of markers associated with inflammation. Celecoxib reduced IL6 expression by 3.5 -fold $(p=0.018$ ) (Figure $5 A$ ) and IL-6 protein release by 3.9-fold $(p=0.001$ ) (Figure 5B) in HFP from the high $\mathrm{PGE}_{2} \mathrm{OA}$ group. No significant alterations in IL6 expression and IL-6 protein release were observed in HFP from the low $\mathrm{PGE}_{2} \mathrm{OA}$ group (Figure $5 \mathrm{~A}$ and $5 \mathrm{~B}$ ). In HFP from CD patients, celecoxib decreased IL6 mRNA expression by 1.3 -fold $(p=0.002)$, but no significant effect was observed on IL-6 protein release after celecoxib treatment (Figure $5 A$ and $5 B$ ). Celecoxib also reduced IL-1 $\beta$ protein release to non-detectable levels by HFP from the four patients (Figure $3 A$ ) in the high $P E_{2} O A$ group, in which IL-1 $\beta$ was detectable (Figure $5 C$ ). Furthermore, celecoxib increased gene expression of CD163 by 2.1 -fold ( $p=$ $0.05), I L 10$ by 2 -fold ( $p=0.035$ ) and $C C L 18$ by 1.5 -fold ( $p=0.032$ ) in HFP from the high $\mathrm{PGE}_{2} \mathrm{OA}$ group (Figure 5D). The specific modulation of gene expression levels of pro- and anti-inflammatory markers in HFP from the high $\mathrm{PGE}_{2} \mathrm{OA}$ group resulted in significant modulation of the inflammation ratio in HFP from the high $\mathrm{PGE}_{2} \mathrm{OA}$ group by 5 -fold ( $p=$ 0.007), while no significant alteration in this ratio in HFP from the low $P_{G} E_{2} O A$ group ( $p=$ 0.259 ) and CD patients ( $p=0.084$ ) (Figure $5 E$ ) was observed. 


\section{Chapter 4}

A

Effects of celecoxib on

pro-inflammatory gene expression in HFP

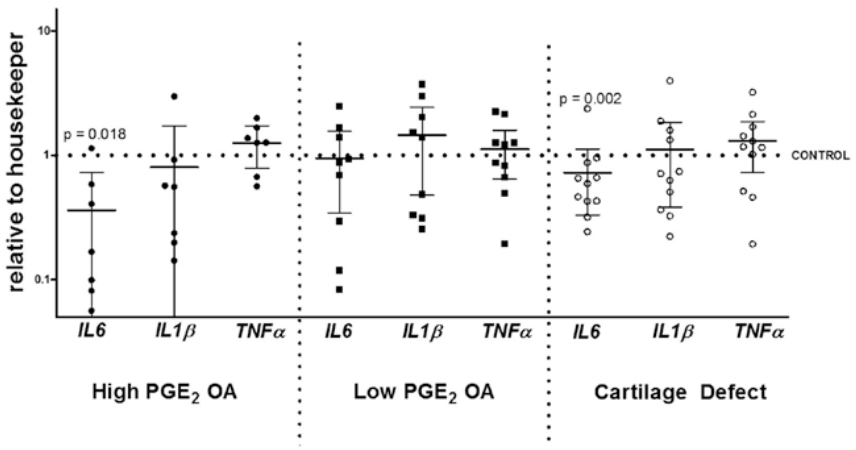

B

IL-6 release

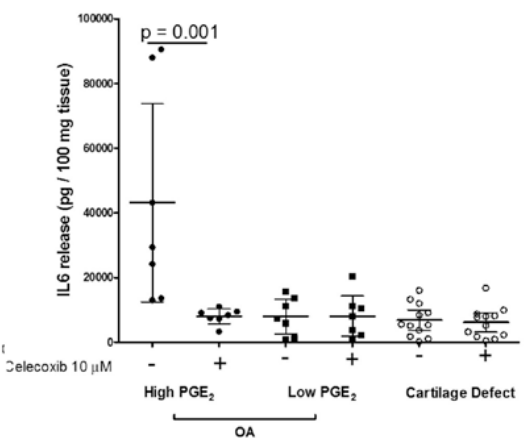

C

High $\mathrm{PGE}_{2} \mathrm{OA}-\mathrm{IL}-1 \beta$ release

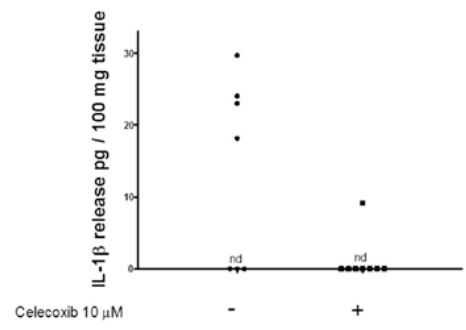


D

Effects of celecoxib on

markers associated with macrophages

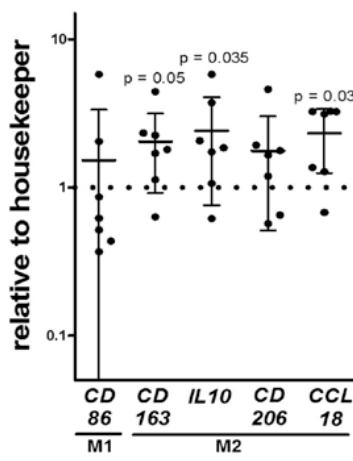

High $\mathrm{PGE}_{2} \mathrm{OA}$

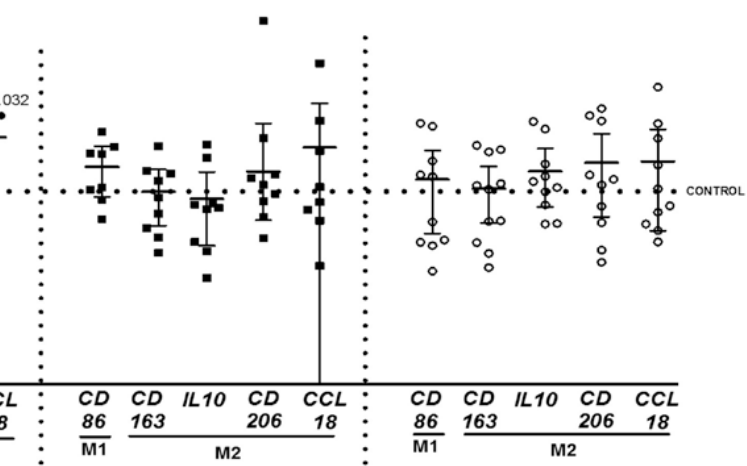

LoW $\mathrm{PGE}_{2} \mathrm{OA}$
Cartilage Defect

E

Inflammation ratio

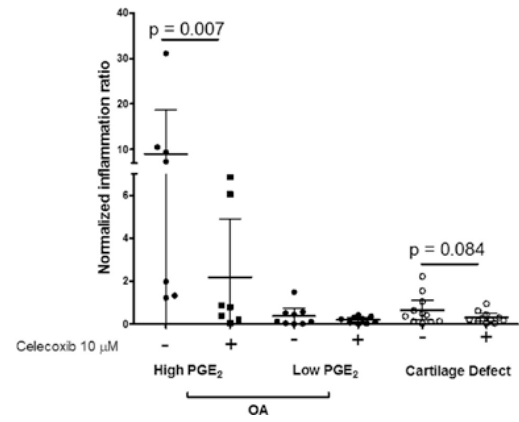

Figure 5: Anti-inflammatory effects of celecoxib in inflamed HFP's.

Effects of celecoxib on gene expression levels of pro-inflammatory markers (IL6, IL1B and TNFa) Normalized gene expression level of the control condition was set to 1 (horizontal dotted line) (A). Effects of celecoxib on protein levels of pro-inflammatory markers IL-6 (B) and IL-1 $\beta$ (C). Effects of celecoxib on gene expression levels of markers associated with macrophages (CD86, CD163, IL10, CD206 and CCL18) Normalized gene expression level of the control condition was set to 1 (horizontal dotted line) (D). Data is presented in scatter dot plots with mean $\pm 95 \% \mathrm{Cl}$. Each dot or square represents separate patients. Effects of celecoxib on the inflammation ratio in HFP from the high and low $P G E_{2} O A$ group and in HFP from CD patients. Data is presented in scatter dot plots with mean $\pm 95 \% \mathrm{Cl}(E) . N=16$ for $O A$ HFP and $N=10$ for CD HFP. 


\section{Discussion}

To get a broader insight into the involvement of specific prostanoids in OA-related inflammatory processes we compared the release profile of prostanoids between HFP from OA patients vs HFP from patients without $O A$ but with a focal $C D$, and investigated the modulatory effects of celecoxib on prostanoid production by HFP.

We here show that specific prostanoids $\mathrm{PGE}_{2^{\prime}}, \mathrm{PGF}_{2 \mathrm{a}}$ and $\mathrm{PGD}_{2}$ are released in higher amounts by HFP from OA patients compared to HFP from patients with CDs. Prostanoid release by OA HFP clustered in two subgroups with high and low prostanoid producers and celecoxib was able to attenuate the inflammatory phenotype in OA HFP most effectively in donors with a more inflammatory phenotype.

Our findings are in accordance with previous work from Massicotte et al. showing variable secretion of $\mathrm{PGE}_{2}$ by subchondral osteoblasts from knee OA patients, which distributed to 2 $\mathrm{OA}$ subgroups ${ }^{28}$. In our study, in addition to $\mathrm{PGE}_{2}$, release of two other prostanoid subtypes $\mathrm{PGF}_{2 a}$ and $\mathrm{PGD}_{2}$, but not $\mathrm{TXB}_{2^{\prime}}$, were higher in the high $\mathrm{PGE}_{2} \mathrm{OA}$ group than the CD group, and correlated with increased COX-2 expression. Our data show that specific prostanoid subtypes are released from the OA HFP and may participate in the inflammatory response in the HFP. These findings indicate that depending on its inflammatory status, the HFP is an important contributor of inflammatory mediators found in synovial fluid of OA patients ${ }^{29}$.

Different possible explanations for the observed differential inflammatory phenotype between $O A$ patients can be given. First, a different subtype of knee OA patients might exist. We correlated our findings to several parameters such as sex, age, BMI and K\&L grade, but did not find any associations (Supplementary Figure 1). Possible associations between these parameters and HFP inflammation will be valuable to investigate in the future with greater experimental groups. Secondly, the duration of OA development or phase in OA disease progression can be different between patients. Unfortunately, information about the duration of symptoms was sometimes missing, and if reported, described concisely. Third, the HFP is reported to contain immune cells, and in particular macrophages ${ }^{16}$. 
As the distribution of all the different cells present in HFP might not be homogeneous, different inflammatory release profiles between OA patients might be caused by this inhomogeneity. To circumvent this, the entire obtained HFP was cut into small pieces and explants were randomly divided over the different samples.

One other study compared prostanoid release profiles by HFP between OA and non-OA patients ${ }^{5}$. In that study, the precursor of prostanoid subtypes, arachidonic acid, was shown to be higher secreted by OA vs non-OA HFP. In our study, the difference in downstream prostanoid metabolites of arachidonic acid was more prominent between $\mathrm{OA}$ and non-OA donors, which was partly unexpected because $C D$ patients have been demonstrated to display elevated levels of inflammatory cytokines such as IL-6 and IFN-y in synovial fluid compared to a healthy control group ${ }^{30}$. Possible explanations between our results and the results of Gierman et al. may be related to the different method of prostanoid analysis, the variation in prostanoid release in OA patients or age.

$\mathrm{PGE}_{2}$ release by OA HFP was positively associated with a calculated inflammation ratio of the HFP, and celecoxib modulated this inflammation ratio specifically in patients with higher prostanoid release profiles (the high $\mathrm{PGE}_{2} \mathrm{OA}$ group). This indicates that this modulatory capacity is dependent on the level of inflammation. Skewing of the inflammation ratio in HFP by celecoxib might potentially have an effect on pain sensation. Inflammatory factors can contribute to sensitization of the joint ${ }^{31}$, while anti-inflammatory factors can have analgesic effects ${ }^{32}$. Indeed, in addition to the synovium, HFP in knee OA patients is gaining interest as a potential source of pain in knee $\mathrm{OA}^{4}$.

Adipocytes in adipose tissue have been shown to produce mediators such as IL-6, IL-1 $\beta$ and IL-10 and therefore adipocytes may be the cell source responsible for the increased prostanoids, IL-1 $\beta$ and IL- 6 release we have observed in the high $\mathrm{PGE}_{2} \mathrm{OA}$ group. Future experiments will further elucidate the cell source responsible for this increased release and will also provide further insights into the source of cells mostly affected by the action of celecoxib. Moreover longer incubation periods with celecoxib may result in more pronounced anti-inflammatory effects and influencing the inflammatory status of the 
adipocyte in the tissue may also have indirect anti-inflammatory effects on other cell types in the HFP.

Celecoxib also reduced prostanoid release in HFP from CD patients. Since targeting proinflammatory cytokines has been shown to prevent cartilage degradation in vivo following knee injury ${ }^{33}$ and the link between pro-inflammatory factors and cartilage degradation is increasingly being recognized ${ }^{24,33}$, celecoxib may be used to improve the outcome of cartilage regeneration strategies or act preventive on progression into $\mathrm{OA}$ in patients with CDs.

Taken together, we here show for the first time that patients with knee OA display a differential inflammatory profile in their HFP compared to patients with CDs, which may be of use when developing future therapies (e.g., pharmaceutical and regenerative). Decreasing prostanoid release by OA HFP with celecoxib can modulate the general inflammatory phenotype in HFP. We expect that in a subset of knee OA patients presenting with inflamed HFP's, celecoxib may have the potency to exert an anti-inflammatory action via decreasing the release of prostanoids produced by the HFP and modulate the inflammatory phenotype of the HFP.

\section{Author Contributions}

U.T.T., conception and design, collection and assembly of data, data analysis and interpretation, manuscript writing, final approval of the manuscript, M.C., Y.BJ., T.W., L.R., G.O., P.E., conception and design, data analysis and interpretation, manuscript writing, final approval of the manuscript.

\section{Competing Interests}

Prof. Dr LW. Van Rhijn, dr. TJM. Welting and dr. PJ. Emans have a patent US 20130123314 A1 issued. The patent describes an improved method for repairing damaged cartilage and/ or preventing cartilage degeneration in tissue, in particular in a joint by administering a 
pharmaceutically active agent not in the intra-articular cavity but directly into the fat pad of a joint.

\section{Acknowledgements}

This work was supported by the academic fund of Maastricht University Medical Center, Dutch Arthritis Foundation (LLP11 and LLP14) and Annadal Foundation . The funding supported materials and personel. The sponsors had no influence on gathering and interpretation of data.

\section{Supplementary Data}

The supplementary data belonging to this article can be found online (https://www. oarsijournal.com/article/S1063-4584(18)30094-3/fulltext\#supplementaryMaterial). 


\section{References}

1 Hunter D.J., Felson D.T.: Osteoarthritis. BMJ 2006; 332: pp. 639-642.

2 Berenbaum F.: Osteoarthritis as an inflammatory disease (osteoarthritis is not osteoarthrosis!). Osteoarthritis Cartilage 2013; 21: pp. 16-21.

3 Clockaerts S., Bastiaansen-Jenniskens Y.M., Feijt C., de Clerck L., Verhaar J.A., Zuurmond A.M., et. al.: Cytokine production by infrapatellar fat pad can be stimulated by interleukin 1 beta and inhibited by peroxisome proliferator activated receptor alpha agonist. Ann Rheum Dis 2012; 71: pp. 1012-1018.

4 Clockaerts S., Bastiaansen-Jenniskens Y.M., Runhaar J., van Osch G.J., van Offel J.F., Verhaar J.A., et. al.: The infrapatellar fat pad should be considered as an active osteoarthritic joint tissue: a narrative review. Osteoarthr Cartil 2010; 18: pp. 876882.

5 Gierman L.M., Wopereis S., van El B., Verheij E.R., Werff-van der Vat B.J., Bastiaansen-Jenniskens Y.M., et. al.: Metabolic profiling reveals differences in concentrations of oxylipins and fatty acids secreted by the infrapatellar fat pad of donors with end-stage osteoarthritis and normal donors. Arthritis Rheum 2013; 65: pp. 2606-2614.

Pelletier J.P., DiBattista J.A., Roughley P., McCollum R., Martel-Pelletier J.: Cytokines and inflammation in cartilage degradation. Rheum Dis Clin N Am 1993; 19: pp. 545-568.

Ricciotti E., FitzGerald G.A.: Prostaglandins and inflammation. Arterioscl Thromb Vasc Biol 2011; 31: pp. 986-1000.

8 Martel-Pelletier J., Pelletier J.P., Fahmi H.: Cyclooxygenase-2 and prostaglandins in articular tissues. Semin Arthritis Rheum 2003; 33: pp. 155-167.

9 Attur M., Al-Mussawir H.E., Patel J., Kitay A., Dave M., Palmer G., et. al.: Prostaglandin E2 exerts catabolic effects in osteoarthritis cartilage: evidence for signaling via the EP4 receptor. J Immunol 2008; 181: pp. 5082-5088.

10 Eymard F., Pigenet A., Citadelle D., FlouzatLachaniette C.H., Poignard A., Benelli C., et. al.: Induction of an inflammatory and prodegradative phenotype in autologous fibroblast-like synoviocytes by the infrapatellar fat pad from patients with knee osteoarthritis. Arthritis Rheum 2014; 66: pp. 2165-2174.

11 Bastiaansen-Jenniskens Y.M., Wei W., Feijt 
C., Waarsing J.H., Verhaar J.A., Zuurmond A.M., et. al.: Stimulation of fibrotic processes by the infrapatellar fat pad in cultured synoviocytes from patients with osteoarthritis: a possible role for prostaglandin f2alpha. Arthritis Rheum 2013; 65: pp. 2070-2080.

12 Uda R., Horiguchi S., Ito S., Hyodo M., Hayaishi O.: Nociceptive effects induced by intrathecal administration of prostaglandin D2, E2, or F2 alpha to conscious mice. Brain Res 1990; 510: pp. 26-32.

13 Reinold H., Ahmadi S., Depner U.B., Layh B., Heindl C., Hamza M., et. al.: Spinal inflammatory hyperalgesia is mediated by prostaglandin E receptors of the EP2 subtype. J Clin Invest 2005; 115: pp. 673679.

14 Minami T., Uda R., Horiguchi S., Ito S., Hyodo M., Hayaishi O., et. al.: Allodynia evoked by intrathecal administration of prostaglandin F2 alpha to conscious mice. Pain 1992; 50: pp. 223-229.

15 Ryd L., Brittberg M., Eriksson K., Jurvelin J.S., Lindahl A., Marlovits S., et. al.: Preosteoarthritis: definition and diagnosis of an elusive clinical entity. Cartilage 2015; 6: pp. 156-165.

16 Bastiaansen-Jenniskens Y.M., Clockaerts S., Feijt C., Zuurmond A.M., StojanovicSusulic V., Bridts C., et. al.: Infrapatellar fat pad of patients with end-stage osteoarthritis inhibits catabolic mediators in cartilage. Ann Rheum Dis 2012; 71: pp. 288-294.

17 Caron M.M., Emans P.J., Cremers A., Surtel D.A.M., van Rhijn L.W., Welting T.J.M., et. al.: Indomethacin induces differential effects on in vitro endochondral ossification depending on the chondrocyte's differentiation stage. J Orthop Res Off Publ Orthop Res Soc 2016;

18 Pfaffl M.W., Tichopad A., Prgomet C., Neuvians T.P.: Determination of stable housekeeping genes, differentially regulated target genes and sample integrity: BestKeeper-Excel-based tool using pair-wise correlations. Biotechnol Lett 2004; 26: pp. 509-515.

19 Livak K.J., Schmittgen T.D.: Analysis of relative gene expression data using realtime quantitative PCR and the 2(-Delta Delta C(T)) Method. Methods 2001; 25: pp. 402-408. S1046-S2023 (01)91262-9 [pii]

20 Utomo L., Bastiaansen-Jenniskens Y.M., Verhaar J.A., van Osch G.J.: Cartilage inflammation and degeneration is enhanced by pro-inflammatory (M1) macrophages in vitro, but not inhibited directly by anti-inflammatory (M2) macrophages. Osteoarthritis Cartilage 2016; 24: pp. 2162-2170.

21 Brock T.G., McNish R.W., Peters-Golden 
M.: Arachidonic acid is preferentially metabolized by cyclooxygenase- 2 to prostacyclin and prostaglandin E2. J Biol Chem 1999; 274: pp. 11660-11666.

22 Knott l., et. al.: Induction of cyclooxygenase by interleukin 1 : comparative study between human synovial cells and chondrocytes. J Rheumatol 1994; 21: pp. 462-466.

23 Mosser D.M., Edwards J.P.: Exploring the full spectrum of macrophage activation. Nat Rev Immunol 2008; 8: pp. 958-969.

24 Goldring M.B., et. al.: Roles of inflammatory and anabolic cytokines in cartilage metabolism: signals and multiple effectors converge upon MMP-13 regulation in osteoarthritis. Eur Cell Mater 2011; 21: pp. 202-220.

25 Roberts S., Evans H., Wright K., van Niekerk L., Caterson B., Richardson J.B., et. al.: ADAMTS-4 activity in synovial fluid as a biomarker of inflammation and effusion. Osteoarthr Cartil 2015; 23: pp. 1622-1626.

26 Bau B., Gebhard P.M., Haag J., Knorr T., Bartnik E., Aigner T., et. al:: Relative messenger RNA expression profiling of collagenases and aggrecanases in human articular chondrocytes in vivo and in vitro. Arthritis Rheum 2002; 46: pp. 2648-2657.

27 Welting T.J., Caron M.M., Emans P.J., Janssen M.P., Sanen K., Coolsen M.M., et. al:: Inhibition of cyclooxygenase-2 impacts chondrocyte hypertrophic differentiation during endochondral ossification. Eur Cell Mater 2011; 22: pp. 420-436. discussion 436-427

28 Massicotte F., Lajeunesse D., Benderdour M., Pelletier J.P., Hilal G., Duval N., et. al.: Can altered production of interleukin1 beta, interleukin-6, transforming growth factor-beta and prostaglandin E(2) by isolated human subchondral osteoblasts identify two subgroups of osteoarthritic patients. Osteoarthr Cartil 2002; 10: pp. 491-500.

29 Brenner S.S., Klotz U., Alscher D.M., Mais A., Lauer G., Schweer H., et. al.: Osteoarthritis of the knee-clinical assessments and inflammatory markers. Osteoarthr Cartil 2004; 12: pp. 469-475.

30 Tsuchida A.I., Beekhuizen M., t Hart M.C., Radstake T.R., Dhert W.J., Saris D.B., et. al:: Cytokine profiles in the joint depend on pathology, but are different between synovial fluid, cartilage tissue and cultured chondrocytes. Arthritis Res Ther 2014; 16: pp. 441.

31 Miller R.E., Miller R.J., Malfait A.M.: Osteoarthritis joint pain: the cytokine connection. Cytokine 2014; 70: pp. 185193. 
32 Pannell M., et. al.: Adoptive transfer of M2 macrophages reduces neuropathic pain via opioid peptides. J Neuroinflammation 2016; 13: pp. 262.

33 Furman B.D., Mangiapani D.S., Zeitler E., Bailey K.N., Horne P.H., Huebner J.L., et. al:: Targeting pro-inflammatory cytokines following joint injury: acute intra-articular inhibition of interleukin-1 following knee injury prevents post-traumatic arthritis. Arthritis Res Ther 2014; 16: pp. R134. 


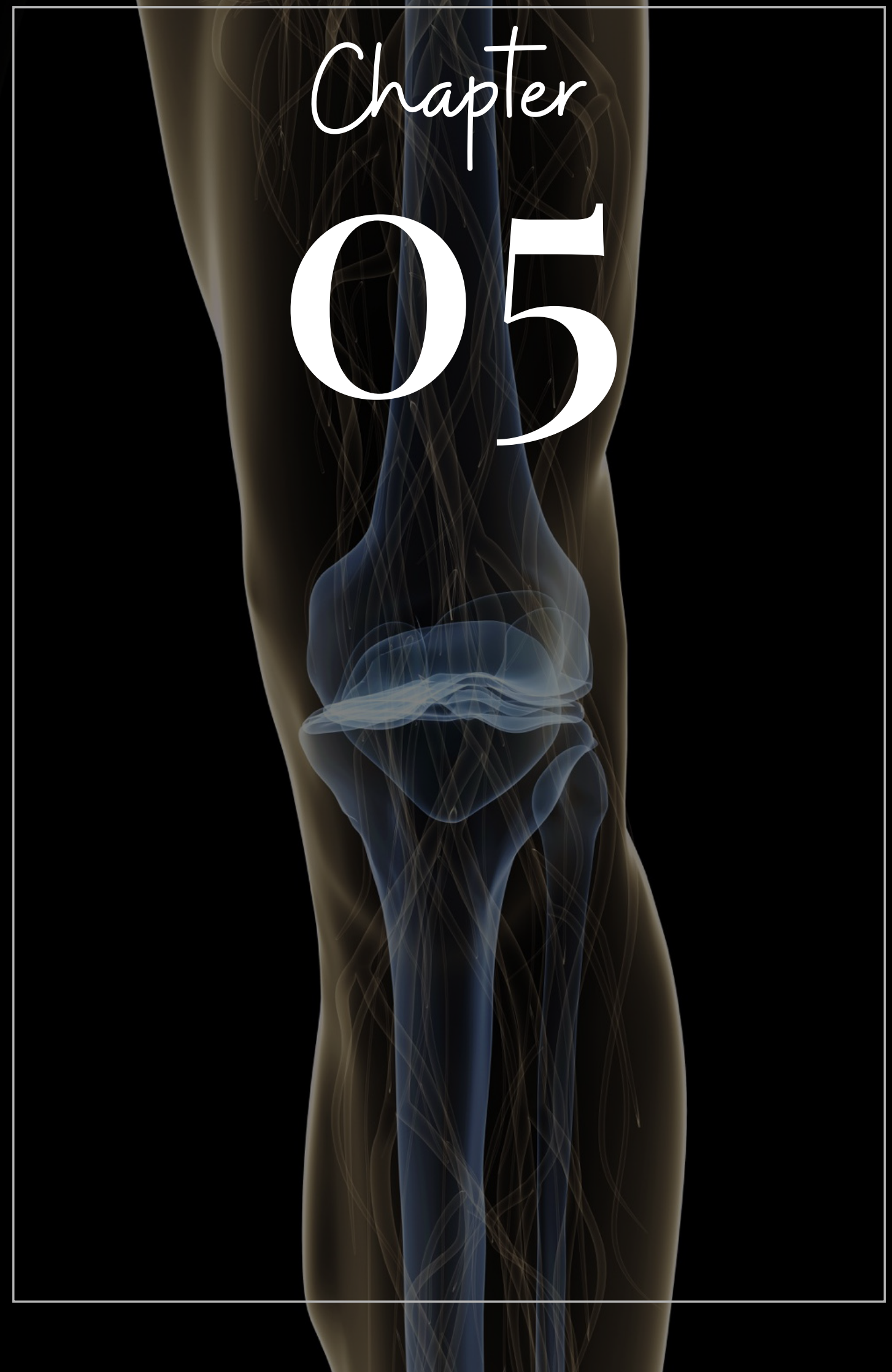




\section{Chondroprotective Actions of Selective COX-2 Inhibitors In Vivo: A Systematic Review.}

Timur UT, Caron M.J., Jeuken R.M., Bastiaansen-Jenniskens Y.M., Welting T.J.M., van Rhijn L.W., van Osch G.J.V.M., Emans P.J. Int. J Mol Sci. 2020 21(18). 


\section{Abstract}

\section{Objective:}

Knee osteoarthritis $(\mathrm{OA})$ is a condition mainly characterized by cartilage degradation. Currently, no effective treatment exists to slow down the progression of OA-related cartilage damage. Selective COX-2 inhibitors may, next to their pain killing properties, act chondroprotective in vivo.

\section{Material \& Methods:}

To determine whether the route of administration is important for the efficacy of the chondroprotective properties of selective COX-2 inhibitors, a systematic review was performed according to the PRISMA guidelines. Studies investigating OA-related cartilage damage of selective COX-2 inhibitors in vivo were included.

\section{Results:}

Nine of the fourteen preclinical studies demonstrated chondroprotective effects of selective COX-2 inhibitors using systemic administration. Five clinical studies were included and, although in general non-randomized, failed to demonstrate chondroprotective actions of oral selective COX-2 inhibitors. All of the four preclinical studies using bolus intra-articular injections demonstrated chondroprotective actions, while one of the three preclinical studies using a slow release system demonstrated chondroprotective actions.

\section{Conclusion:}

Despite the limited evidence in clinical studies that have used the oral administration route, there seems to be a preclinical basis for considering selective COX-2 inhibitors as disease modifying osteoarthritis drugs when used intra-articularly. Intra-articularly injected selective COX-2 inhibitors may hold the potential to provide chondroprotective effects in vivo in clinical studies.

\section{Keywords:}

Selective COX-2 inhibitors, intra-articular injection, knee osteoarthritis, DMOADs 


\section{Introduction}

Knee osteoarthritis $(\mathrm{OA})$ is a condition that leads to pain and is mainly characterized by cartilage degradation'. Currently, drug treatments provide symptomatic pain relief but no effective treatment exists to slow down progression of OA-related cartilage damage' Pain-killing drug therapies include non-steroidal anti-inflammatory drugs (NSAIDs). NSAIDs provide pain relief by blocking cyclooxygenase (COX)-dependent prostanoid synthesis. Prostanoids are an important family of signaling molecules present in synovial fluid ${ }^{2}$. At least two COX isoforms have been described, COX-1 and COX-2, the latter being considered as the inflammatory isoform ${ }^{3}$. Selective COX-2 inhibitors have been developed to specifically target the inflammatory COX-2 while circumventing inhibition of the COX-1 isoform. While selective COX-2 inhibitors may provide an effective means for pain relief, targeting the inflammatory COX-2 may be also a promising approach to inhibit cartilage degradation and thereby slow down knee OA progression ${ }^{3}$. This hypothesis is supported by the accumulating evidence showing that inflammation precedes $\mathrm{OA}$ disease progression ${ }^{3,4}$.

From the anti-nerve growth factor clinical trials it became clear that next to a substantial improvement in pain, patients also displayed structural OA disease progression ${ }^{5}$. This emphasizes the importance of treatment strategies not only providing pain relief, which will lead to a vicious self-perpetuating cycle of joint overloading and OA progression, but also providing the ability for disease modification.

The actions of non-selective COX inhibitors on cartilage degradation in vitro and in vivo have been excellently reviewed in the past ${ }^{6}$. Moreover, ex vivo and in vivo actions of the selective COX-2 inhibitor celecoxib on cartilage degradation, synovial inflammation and osteoclast metabolism have also been reviewed and date back to $2011^{7}$. Recently, an updated review of studies published until 2016 has been conducted on the OA disease-modifying actions of celecoxib on different $\mathrm{OA}$ tissues. This review confirms the contradictive reports regarding the chondroprotective actions of celecoxib both ex vivo and in vivo. Based on these reviews, it still remains obscure whether selective COX-2 inhibitors can be used in vivo to protect cartilage and slow down the progression of knee OA. One of the explanations of 


\section{Chapter 5}

the contradictive reports found in the literature regarding the potential of selective COX-2 inhibitors may be related to the route of administration. Specifically, scarcely vascularized tissues such as cartilage and meniscus, which are important participants in knee OA, may be modified differentially after systemic oral treatment compared to intra-articular treatment ${ }^{8,9}$. To date, the role of the route of administration on the chondroprotective effects of selective COX-2 inhibitors remains unclear. Therefore, the objective of this review was to systematically review available literature on chondroprotective properties of selective COX-2 inhibitors in preclinical models for OA or in clinical OA studies depending on the route of administration.

\section{Materials and Methods}

\subsection{Search Strategy and Data Extraction}

MEDLINE and EMBASE databases were systematically searched on all studies relating intra-articular or oral treatment of knee OA patients with selective COX-2 inhibitors. The search was conducted in May 2020 according to the search strategy and data collection guidelines of the preferred reporting items for systematic reviews and meta-analyses (PRISMA) statement. A manual search of the Cochrane library yielded no relevant articles. Upon reading the full-text key papers snowballing searching manually reference lists of the included articles was allowed. Disagreements between the reviewers were resolved by consensus.

After disregarding duplicates, the title and the abstract of articles were independently screened by two obserfvers according to predefined criteria. The search query was as follows:

("Osteoarthritis"[Mesh] OR OA OR osteoarthritis) AND ("Knee"[Mesh] OR Knee [tiab]) AND (((COX-2 [tiab] OR COX2 [tiab] OR Cyclooxygenase 2 [tiab] OR"Cyclooxygenase 2"[Mesh]) AND (inhibitor [tiab] or inhibition [tiab] or limitation [tiab] or limiting [tiab])) OR celecoxib [tiab] OR etoricoxib [tiab] OR rofecoxib [tiab] or valdecoxib [tiab] or lumiracoxib [tiab] or 
mavacoxib [tiab] or meloxicam [tiab] or VA441 [tiab] or MK-0966 [tiab] or gw406381 [tiab] or SC-58635 [tiab] or VA692 [tiab] or VA694 [tiab] or SC-236 [tiab]) AND ((oral [tiab] AND (suppletion [tiab] OR supplements [tiab] OR supplementation [tiab] OR treatment [tiab] OR ingestion [tiab] OR medication [tiab] OR tablets [tiab] OR intake [tiab] OR absorption [tiab])) OR treatment OR ((intraarticular [tiab] OR intra-articular [tiab]) AND (injection [tiab] OR therapy [tiab] OR supplementation [tiab] OR suppletion [tiab]))).

\subsection{Articles Were Selected Based on Inclusion and Exclusion Criteria}

\section{Inclusion Criteria:}

i. Presenting data about chondroprotective effects of COX-2 inhibitors;

The chondroprotective effect is defined as any effect that leads to significantly less cartilage degradation evidenced either through imaging, biochemical analysis or on histology.

ii. Either in vivo animal studies or clinical studies involving human knee OA patients;

iii. Intra-articular therapies with COX-2 inhibitors;

iv. Systemic therapies with COX-2 inhibitors.

\section{Exclusion Criteria:}

i. Studies solely investigating non-selective cox-inhibitors;

ii. Studies investigating actions of celecoxib inhibitors on pain modulation in knee $\mathrm{OA}$;

iii. Studies investigating other joints than the knee;

iv. Studies reporting solely in vitro data.

Two observers systematically extracted study data based on the inclusion and exclusion criteria. The risk of bias of the included studies was evaluated using the SYRCLE's risk of bias tool for animal studies ${ }^{10}$ and the Cochrane risk of bias tool ${ }^{11}$ for human studies. 


\section{Results}

The search strategy yielded 25 articles for inclusion (Figure 1). We identified preclinical and clinical studies investigating chondroprotective actions of selective COX-2 inhibitors either via systemic administration or via intra-articular delivery. Using the SYRCLE's risk of bias tool for preclinical studies, we observed that outcome measurements were in general blinded, but randomization sequences were not always reported increasing the risk for selection bias (supplementary data) ${ }^{10}$. For clinical studies, the Cochrane risk bias tool revealed that clinical studies were non-randomized, displaying a high risk of selection and performance bias (supplementary data) ${ }^{11}$. 


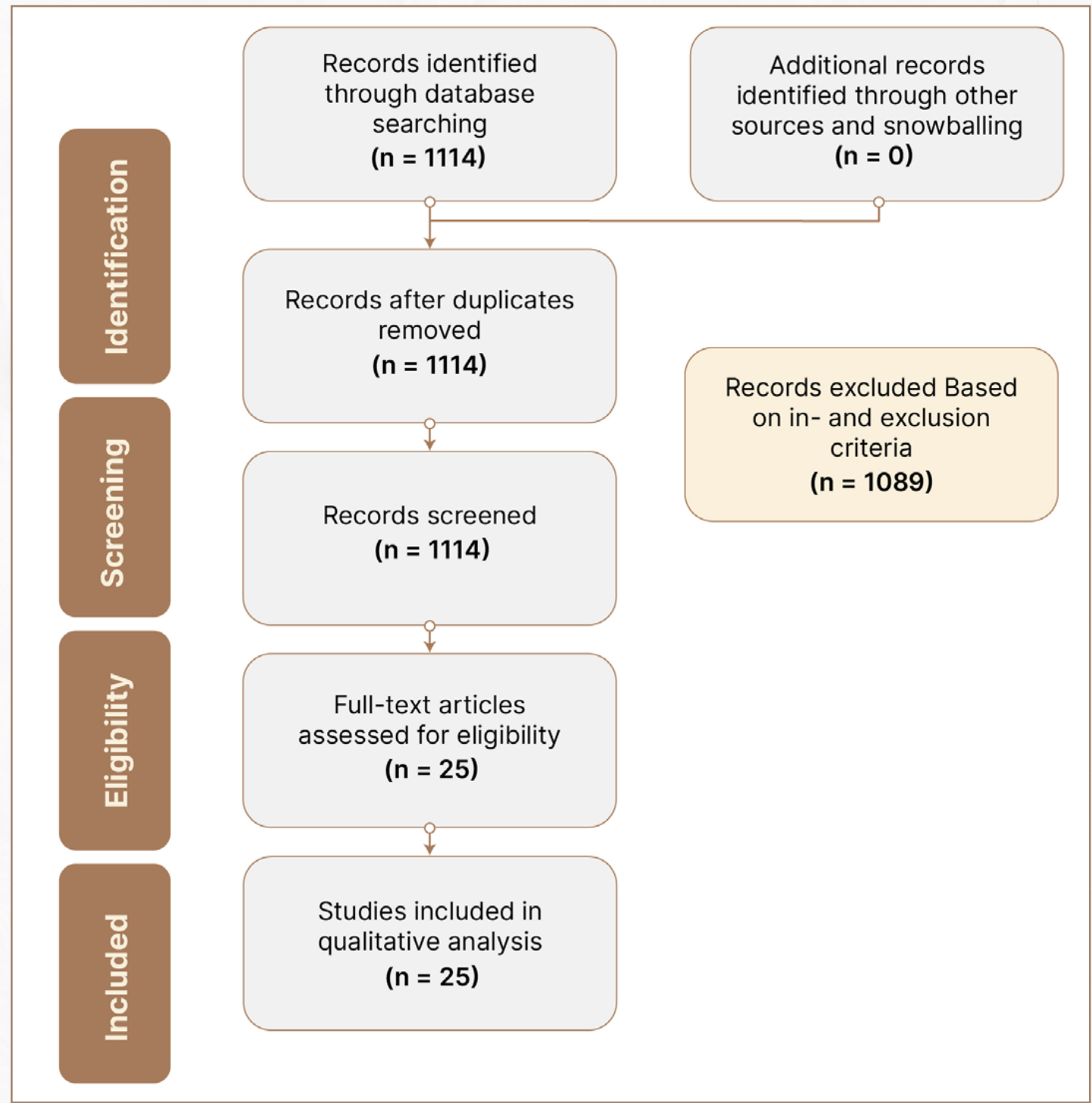

Figure 1: PRISMA flowchart.

PRISMA flowchart showing the yield of the search and inclusion of studies leading to the 25 included studies. 


\section{Chapter 5}

The following sections will discuss the main results of the included 25 studies and compare chondroprotective actions of selective COX-2 inhibitors when used systemically or intraarticularly.

\subsection{Preclinical Studies: Oral and Intraperitoneal Administration}

Fourteen of the included studies have investigated chondroprotective actions of selective COX-2 inhibitors after systemic administration (Table 1). Most studies focused on chondroprotective action of the selective COX-2 inhibitor celecoxib ${ }^{12,13,14,15,16,17,18,19,20,21}$, while other studies investigated chondroprotective actions of meloxicam ${ }^{22,23}$ and etoricoxib ${ }^{24,25}$. Four studies that investigated chondroprotective actions of selective COX-2 inhibitors in surgically induced OA models failed to demonstrate chondroprotective actions when the drug was administered directly after OA induction ${ }^{12,14,18,22}$. On the other hand, Dai et al. demonstrated chondroprotective actions of celecoxib, as evidenced by an improved macroscopic and histological OARSI score, in a surgically induced pig OA model, in which treatment was started one week after surgery ${ }^{20}$. Further support of chondroprotective actions of selective COX-2 inhibitors comes from a study in a surgically induced rat OA model, where treatment with oral etoricoxib decreased OA-related cartilage damage as evidenced by an improved Pritzker score compared to controls ${ }^{24}$. Chondroprotective actions of celecoxib were also shown in a study in which the Achilles tendon transection rat knee OA model was used ${ }^{15}$. It was shown that compared to controls, chondrocyte apoptosis was lower after oral administration of celecoxib ${ }^{15}$. 
Table 1: The schematic of studies investigating chondroprotective effects of systemically administered selective COX-2 inhibitors.

\begin{tabular}{|c|c|c|c|c|c|c|c|c|}
\hline Authors & Species & $\begin{array}{l}\text { COX-2 } \\
\text { Inhibitor }\end{array}$ & OA Model & $\begin{array}{l}\text { Dosing } \\
\text { Regime }\end{array}$ & $\begin{array}{l}\text { Start of } \\
\text { Treatment }\end{array}$ & $\begin{array}{l}\text { Timepoint of } \\
\text { Evaluation }\end{array}$ & $\begin{array}{l}\text { Evaluation } \\
\text { of cartilage } \\
\text { Degradation }\end{array}$ & Main Findings \\
\hline $\begin{array}{l}\text { Mastbergen } \\
\text { et al. } .^{12}\end{array}$ & Canine & Celecoxib & Groove & $\begin{array}{l}\text { Daily } 200 \\
\text { mg }\end{array}$ & $\begin{array}{l}\text { Directly after } \\
\text { surgery }\end{array}$ & $\begin{array}{l}15 \text { weeks after } \\
\text { OA induction }\end{array}$ & $\begin{array}{l}\text { Histology: } \\
\text { Modified Mankin } \\
\text { Biochemistry: } \\
\text { PG content, } \\
\text { synthesis and } \\
\text { release }\end{array}$ & $\begin{array}{l}\text { No difference in } \\
\text { histological scores, } \\
\text { no difference in PG } \\
\text { content, synthesis } \\
\text { or release }\end{array}$ \\
\hline Huh et al..$^{13}$ & Rabbit & Celecoxib & Collagenase & $\begin{array}{l}\text { Daily } 100 \\
\mathrm{mg} / \mathrm{kg}\end{array}$ & $\begin{array}{l}\text { Directly after } \\
\text { OA induction }\end{array}$ & $\begin{array}{l}4 \text { weeks after } \\
\text { OA induction }\end{array}$ & $\begin{array}{l}\text { Histology: } \\
\text { Colombo score for } \\
\text { cartilage } \\
\text { and synovitis score } \\
\text { for synoviummRNA } \\
\text { analysis PTGS1, } \\
\text { PTGS2, MMP1 } \\
\text { and MMP3 }\end{array}$ & $\begin{array}{l}\text { Improved } \\
\text { histological score } \\
\text { in celecoxib } \\
\text { group vs. control, } \\
\text { decreased MMP-1 } \\
\text { mRNA expression } \\
\text { in celecoxib group } \\
\text { vs. control }\end{array}$ \\
\hline Jones et al. ${ }^{22}$ & Rat & Meloxicam & $\begin{array}{l}\mathrm{MCLT}+\mathrm{ACLT}+ \\
\mathrm{MMx}\end{array}$ & $\begin{array}{l}\text { Daily } 3 \mathrm{mg} / \\
\mathrm{kg}\end{array}$ & $\begin{array}{l}\text { Directly after } \\
\text { OA induction }\end{array}$ & $\begin{array}{l}8 \text { weeks after } \\
\text { OA induction }\end{array}$ & $\begin{array}{l}\text { Histology: } \\
\text { Modified Mankin }\end{array}$ & $\begin{array}{l}\text { No difference in } \\
\text { histological score } \\
\text { meloxicam vs. } \\
\text { control }\end{array}$ \\
\hline Fukai et al..$^{14}$ & Mouse & Celecoxib & $M C L T+M M x$ & $\begin{array}{l}\text { Daily } 10 \\
\mathrm{mg} / \mathrm{kg} \text { or } \\
30 \mathrm{mg} / \mathrm{kg}\end{array}$ & $\begin{array}{l}\text { Directly after } \\
\text { surgery }\end{array}$ & $\begin{array}{l}12 \text { weeks after } \\
\text { OA induction }\end{array}$ & $\begin{array}{l}\text { Histology: } \\
\text { Pritzker score }\end{array}$ & $\begin{array}{l}\text { No difference } \\
\text { in Pritzker score } \\
\text { celecoxib vs. } \\
\text { control. }\end{array}$ \\
\hline Ou et al..$^{15}$ & Rat & Celecoxib & $\begin{array}{l}\text { Achilles } \\
\text { tendon } \\
\text { transection }\end{array}$ & $\begin{array}{l}\text { Daily } 24 \\
\mathrm{mg} / \mathrm{kg}\end{array}$ & $\begin{array}{l}\text { Directly after } \\
\text { surgery }\end{array}$ & & $\begin{array}{l}\text { Histology:Type } \\
\text { Il collagen Tunel } \\
\text { staining }\end{array}$ & $\begin{array}{l}\text { No difference in } \\
\text { type Il collagen } \\
\text { content in } \\
\text { celecoxib vs. } \\
\text { control, decreased } \\
\text { chondrocyte } \\
\text { apoptosis in } \\
\text { celecoxib group. }\end{array}$ \\
\hline $\begin{array}{l}\text { Ashkavand } \\
\text { et al. }{ }^{16}\end{array}$ & Rat & Celecoxib & MIA & $\begin{array}{l}\text { Daily } 100 \\
\mathrm{mg} / \mathrm{kg}\end{array}$ & $\begin{array}{l}\text { Directly after } \\
\text { OA induction }\end{array}$ & $\begin{array}{l}15 \text { days after } \\
\text { OA induction }\end{array}$ & $\begin{array}{l}\text { Histology: Own } \\
\text { developed score }\end{array}$ & $\begin{array}{l}\text { Improved } \\
\text { histological score } \\
\text { in the celecoxib } \\
\text { group. Superior } \\
\text { chondro- } \\
\text { protective effects } \\
\text { when celecoxib } \\
\text { is combined with } \\
\text { silymarin }\end{array}$ \\
\hline
\end{tabular}


PRECLINICAL STUDIES USING ORAL ADMINISTRATION

\begin{tabular}{|c|c|c|c|c|c|c|c|c|}
\hline Authors & Species & $\begin{array}{l}\text { COX-2 } \\
\text { Inhibitor }\end{array}$ & OA Model & $\begin{array}{l}\text { Dosing } \\
\text { Regime }\end{array}$ & $\begin{array}{l}\text { Start of } \\
\text { Treatment }\end{array}$ & $\begin{array}{l}\text { Timepoint of } \\
\text { Evaluation }\end{array}$ & $\begin{array}{l}\text { Evaluation } \\
\text { of cartilage } \\
\text { Degradation }\end{array}$ & Main Findings \\
\hline Moon et al. ${ }^{17}$ & Rat & Celecoxib & MIA & $\begin{array}{l}\text { Daily } 2.5 \\
\mathrm{mg} / \mathrm{kg}\end{array}$ & $\begin{array}{l}\text { Directly after } \\
\text { OA induction }\end{array}$ & $\begin{array}{l}7 \text { days after } \\
\text { OA induction }\end{array}$ & $\begin{array}{l}\text { Histology: } \\
\text { Modified Mankin }\end{array}$ & $\begin{array}{l}\text { No difference in } \\
\text { Modified Mankin } \\
\text { celecoxib vs. } \\
\text { control. Synergistic } \\
\text { beneficial action } \\
\text { when celecoxib } \\
\text { is added to } \\
\text { rebamipide }\end{array}$ \\
\hline $\begin{array}{l}\text { Panahifar et } \\
\text { al. }{ }^{18}\end{array}$ & Rat & Celecoxib & $\begin{array}{l}\text { ACLT + MCLT + } \\
\text { MMx }\end{array}$ & $\begin{array}{l}\text { Daily } 2.86 \\
\mathrm{mg} / \mathrm{kg}\end{array}$ & $\begin{array}{l}\text { Directly after } \\
\text { surgery }\end{array}$ & $\begin{array}{l}4,8 \text { and } 12 \\
\text { weeks after } \\
\text { OA induction }\end{array}$ & $\begin{array}{l}\text { Histology: } \\
\text { Modified Mankin }\end{array}$ & $\begin{array}{l}\text { No difference in } \\
\text { histological score } \\
\text { celecoxib vs. } \\
\text { control. }\end{array}$ \\
\hline Li et al. ${ }^{19}$ & Rat & Celecoxib & Collagenase & $\begin{array}{l}\text { Daily } 0.25 \\
\mathrm{mg}\end{array}$ & $\begin{array}{l}6 \text { weeks after } \\
\text { surgery }\end{array}$ & $\begin{array}{l}10 \text { weeks after } \\
O A \text { induction }\end{array}$ & $\begin{array}{l}\text { Histology: } \\
\text { Colombo score and } \\
\text { Biochemistry: } \\
\text { CTX-II content in } \\
\text { serum, Caspase } 3 \\
\text { activity in tissue } \\
\text { homogenate }\end{array}$ & $\begin{array}{l}\text { Improved } \\
\text { histological score } \\
\text { in celecoxib group } \\
\text { vs. control, higher } \\
\text { CTX-II content in } \\
\text { celecoxib group, } \\
\text { lower Caspase } \\
3 \text { activity in } \\
\text { celecoxib group. } \\
\text { More pronounced } \\
\text { effects when } \\
\text { celecoxib is } \\
\text { combined with } \\
\text { diacerein }\end{array}$ \\
\hline Dai et al. ${ }^{20}$ & Pig & Celecoxib & MMx & $\begin{array}{l}20 \mathrm{mg} / \mathrm{kg} \\
\text { daily }\end{array}$ & $\begin{array}{l}1 \text { week after } \\
\text { surgery }\end{array}$ & $\begin{array}{l}12 \text { weeks after } \\
\text { surgery }\end{array}$ & $\begin{array}{l}\text { Macroscopic:| } \\
\text { OARSI score } \\
\text { Histology: } \\
\text { OARSI score } \\
\text { COL-II and AGC } \\
\text { immunohisto- } \\
\text { chemistry }\end{array}$ & $\begin{array}{l}\text { Improved } \\
\text { macroscopic } \\
\text { and histological } \\
\text { score celecoxib } \\
\text { group vs. control, } \\
\text { no difference in } \\
\text { COL-II and AGC } \\
\text { expression }\end{array}$ \\
\hline Nagy et al. ${ }^{23}$ & Rat & Meloxicam & MIA & $\begin{array}{l}\text { Daily } 0.2 \\
\mathrm{mg} / \mathrm{kg} \text { or } 1 \\
\mathrm{mg} / \mathrm{kg}\end{array}$ & $\begin{array}{l}3 \text { weeks after } \\
\text { OA induction }\end{array}$ & $\begin{array}{l}11 \text { weeks after } \\
O A \text { induction }\end{array}$ & $\begin{array}{l}\text { Histology: OARSI } \\
\text { score }\end{array}$ & $\begin{array}{l}\text { Improved } \\
\text { histological } \\
\text { score at both } \\
\text { doses meloxicam } \\
\text { compared to } \\
\text { control }\end{array}$ \\
\hline Tu et al..$^{21}$ & Mouse & Celecoxib & $\begin{array}{l}\text { Spontaneous } \\
\text { OA (STR/Ort } \\
\text { mouse) }\end{array}$ & $\begin{array}{l}\text { Daily } 8 \mathrm{mg} / \\
\mathrm{kg}\end{array}$ & $\begin{array}{l}3 \text { months old } \\
\text { mice }\end{array}$ & $\begin{array}{l}4 \text { weeks } \\
\text { after start } \\
\text { treatment }\end{array}$ & $\begin{array}{l}\text { Histology: OARSI } \\
\text { score }\end{array}$ & $\begin{array}{l}\text { Improved OARSI } \\
\text { score in celecoxib } \\
\text { group vs. controls, }\end{array}$ \\
\hline
\end{tabular}




\begin{tabular}{|c|c|c|c|c|c|c|c|c|}
\hline \multicolumn{9}{|c|}{ PRECLINICAL STUDIES USING ORAL ADMINISTRATION } \\
\hline Authors & Species & $\begin{array}{l}\text { COX-2 } \\
\text { Inhibitor }\end{array}$ & OA Model & $\begin{array}{l}\text { Dosing } \\
\text { Regime }\end{array}$ & $\begin{array}{l}\text { Start of } \\
\text { Treatment }\end{array}$ & $\begin{array}{l}\text { Timepoint of } \\
\text { Evaluation }\end{array}$ & $\begin{array}{l}\text { Evaluation } \\
\text { of cartilage } \\
\text { Degradation }\end{array}$ & Main Findings \\
\hline Wen et al..$^{24}$ & Rat & Etoricoxib & ACLT & $\begin{array}{l}6.7 \mathrm{mg} / \mathrm{kg} \\
\text { or } 33.3 \mathrm{mg} / \\
\mathrm{kg} \text { three } \\
\text { times per } \\
\text { week }\end{array}$ & $\begin{array}{l}8 \text { weeks after } \\
\text { surgery }\end{array}$ & $\begin{array}{l}21 \text { weeks after } \\
\text { surgery }\end{array}$ & $\begin{array}{l}\text { Histology: Pritzker } \\
\text { score for cartilage }\end{array}$ & $\begin{array}{l}\text { Improved } \\
\text { histological score } \\
\text { in the etoricoxib } \\
\text { group versus } \\
\text { control }\end{array}$ \\
\hline \multicolumn{9}{|c|}{ PRECLINICAL STUDIES USING INTRA-PERITONEAL INJECTIONS } \\
\hline Liu et al.25 & Mouse & Etoricoxib & DMM & $\begin{array}{l}5 \mathrm{mg} / \mathrm{kg}, \\
10 \mathrm{mg} / \mathrm{kg}, \\
20 \mathrm{mg} / \mathrm{kg} \\
\text { three times } \\
\text { per week }\end{array}$ & $\begin{array}{l}2 \text { days after } \\
\text { OA induction }\end{array}$ & $\begin{array}{l}30 \text { days after } \\
\text { surgery }\end{array}$ & $\begin{array}{l}\text { Histology: OARSI } \\
\text { score }\end{array}$ & $\begin{array}{l}\text { No difference in } \\
\text { histological score } \\
\text { etoricoxib versus } \\
\text { control. }\end{array}$ \\
\hline
\end{tabular}

ACLT: Anterior Cruciate Ligament Transection, CLX: celecoxib, DMM: destabilization medial menisCus, ETX: etoricoxib, MCLT: Medial Collateral Ligament Transection, MIAl: Monosodium lodoacetate, MMx: medial meniscectomy, NP: nanoparticle, pMMx: partial medial meniscectomy, PG: proteoglycan.

Next to surgically induced $O A$ models, the monosodium iodoacetate (MIA) rat OA model ${ }^{16,17,23}$, the collagenase OA model ${ }^{13,19}$ and the spontaneous OA mouse model (STR/ Ort $)^{21}$ were also used to investigate chondroprotective actions of selective COX-2 inhibitors celecoxib $13,16,17,19,21$ and meloxicam ${ }^{23}$. In these studies, chondroprotective actions of selective COX-2 inhibitors were observed after oral administration as evidenced by improved histological scores compared to the controls.

While the aforementioned studies investigated chondroprotective actions of drugs administered orally, one study investigated chondroprotective actions of etoricoxib when administered intraperitoneally ${ }^{25}$. In this study, treatment with intraperitoneal etoricoxib injections was started two days after surgically inducing OA using the destabilization of the medial meniscus (DMM) mouse model ${ }^{25}$ and histological analysis did not demonstrate a reduction in $\mathrm{OA}$-related cartilage damage.

In conclusion, there is conflicting evidence regarding the chondroprotective actions of systemically administered selective COX-2 inhibitors since five studies did not show 
chondroprotective actions, while nine studies showed chondroprotective actions after systemic administration with selective COX-2 inhibitors.

\subsection{Preclinical Studies: Intra-Articular Administration}

Next to in vivo studies investigating chondroprotective actions of selective COX-2 inhibitors administered orally, seven studies focused on their chondroprotective actions when used intra-articularly (Table 2). These studies evaluated several selective COX-2 inhibitors such as celecoxib ${ }^{26,27,28,29}$, parecoxib ${ }^{30}$, meloxicam ${ }^{31}$ and etoricoxib ${ }^{32}$. All studies used surgically induced OA models. Chondroprotective actions, as evidenced by improved histological scores, were shown in three studies after intra-articular administration with selective COX2 inhibitors ${ }^{26,30,31}$. Four studies investigated chondroprotective actions of selective COX-2 inhibitors when incorporated in a drug delivery system (DDS). Dong et al. used celecoxibloaded liposomes or liposomes loaded with a combination of celecoxib and hyaluronic acid to study OA-related cartilage damage in a surgically induced rabbit OA model ${ }^{27}$. No difference in histological scores was reported when rats received celecoxib-loaded liposomes, while liposomes loaded with both celecoxib and hyaluronic acid exerted a chondroprotective effect compared to control injections ${ }^{27}$.

Table 2: The schematic of studies investigating chondroprotective effects of intra-articularly administered selective COX-2 inhibitors.

\section{PRECLINICAL STUDIES USING INTRA-ARTICULAR INJECTIONS}

\begin{tabular}{|c|c|c|c|c|c|c|c|c|}
\hline Authors & Species & $\begin{array}{l}\text { COX-2 } \\
\text { Inhibitor }\end{array}$ & OA Model & $\begin{array}{l}\text { Dosing } \\
\text { Regime }\end{array}$ & $\begin{array}{l}\text { Start of } \\
\text { Treatment }\end{array}$ & $\begin{array}{l}\text { Timepoint } \\
\text { of } \\
\text { Evaluation }\end{array}$ & $\begin{array}{l}\text { Evaluation of } \\
\text { Cartilage Damage }\end{array}$ & Main Findings \\
\hline Jean et al. ${ }^{30}$ & Rat & Parecoxib & ACLT & $\begin{array}{l}\text { Weekly } 100 \mu \mathrm{g} \\
\text { parecoxib for } \\
5 \text { consecutive } \\
\text { weeks }\end{array}$ & $\begin{array}{l}\text { Eight } \\
\text { weeks after } \\
\text { surgery }\end{array}$ & $\begin{array}{l}20 \text { weeks } \\
\text { after } \\
\text { surgery }\end{array}$ & $\begin{array}{l}\text { Histology: Mankin } \\
\text { score }\end{array}$ & $\begin{array}{l}\text { Improved } \\
\text { histological scores } \\
\text { in the parecoxib } \\
\text { group compared to } \\
\text { controls }\end{array}$ \\
\hline Jiang et al..$^{26}$ & Rabbit & Celecoxib & $\begin{array}{l}\text { ACLT+PCLT + } \\
\text { MMx }\end{array}$ & $\begin{array}{l}\text { Weekly } 1.2 \mathrm{mg} \\
\text { celecoxib for } \\
5 \text { consecutive } \\
\text { weeks }\end{array}$ & $\begin{array}{l}\text { Directly } \\
\text { after } \\
\text { surgery }\end{array}$ & $\begin{array}{l}12 \text { weeks } \\
\text { after } \\
\text { surgery }\end{array}$ & $\begin{array}{l}\text { Histology: Mankin } \\
\text { score }\end{array}$ & $\begin{array}{l}\text { Improved } \\
\text { histological scores } \\
\text { in the Celecoxib } \\
\text { group compared to } \\
\text { controls }\end{array}$ \\
\hline
\end{tabular}




\section{PRECLINICAL STUDIES USING INTRA-ARTICULAR INJECTIONS}

\begin{tabular}{|c|c|c|c|c|c|c|c|c|}
\hline Authors & Species & $\begin{array}{l}\text { COX-2 } \\
\text { Inhibitor }\end{array}$ & OA Model & $\begin{array}{l}\text { Dosing } \\
\text { Regime }\end{array}$ & $\begin{array}{l}\text { Start of } \\
\text { Treatment }\end{array}$ & $\begin{array}{l}\text { Timepoint } \\
\text { of } \\
\text { Evaluation }\end{array}$ & $\begin{array}{l}\text { Evaluation of } \\
\text { Cartilage Damage }\end{array}$ & Main Findings \\
\hline Dong et al. ${ }^{27}$ & Rat & Celecoxib & $\begin{array}{l}\text { ACLT+ PCLT+ } \\
M C L T+M M x\end{array}$ & $\begin{array}{l}\text { Single injection: } \\
0.15 \mathrm{mg} \\
\text { celecoxib } \\
\text { incorporated } \\
\text { in DDS }\end{array}$ & $\begin{array}{l}\text { One week } \\
\text { after } \\
\text { surgery }\end{array}$ & $\begin{array}{l}2 \text { weeks } \\
\text { after } \\
\text { surgery }\end{array}$ & $\begin{array}{l}\text { Histology: Colombo } \\
\text { score }\end{array}$ & $\begin{array}{l}\text { Improved } \\
\text { histological } \\
\text { score only when } \\
\text { celecoxib is } \\
\text { combined with HA } \\
\text { in a DDS compared } \\
\text { to controls }\end{array}$ \\
\hline Wen et $a l^{31}$ & Rat & Meloxicam & ACLT & $\begin{array}{l}\text { Weekly } 0.25 \\
\text { or } 1 \mathrm{mg} \\
\text { meloxicam for } \\
5 \text { consecutive } \\
\text { weeks }\end{array}$ & $\begin{array}{l}\text { Five weeks } \\
\text { after } \\
\text { surgery }\end{array}$ & $\begin{array}{l}20 \text { weeks } \\
\text { after } \\
\text { surgery }\end{array}$ & $\begin{array}{l}\text { Histology: Pritzker } \\
\text { score }\end{array}$ & $\begin{array}{l}\text { Lower Pritzker } \\
\text { score in the } \\
\text { meloxicam group } \\
\text { versus control }\end{array}$ \\
\hline $\begin{array}{l}\text { Janssen et } \\
\text { al. }{ }^{28}\end{array}$ & Rat & Celecoxib & $A C L T+p M M x$ & $\begin{array}{l}\text { Single injection: } \\
0.015 \mathrm{mg} \\
\text { celecoxib } \\
\text { incorporated } \\
\text { in DDS }\end{array}$ & $\begin{array}{l}\text { Four weeks } \\
\text { after } \\
\text { surgery }\end{array}$ & $\begin{array}{l}16 \text { weeks } \\
\text { after } \\
\text { surgery }\end{array}$ & $\begin{array}{l}\text { Histology: OARSI } \\
\text { score }\end{array}$ & $\begin{array}{l}\text { No difference in } \\
\text { histological score } \\
\text { in celecoxib loaded } \\
\text { microspheres vs. } \\
\text { control }\end{array}$ \\
\hline $\begin{array}{l}\text { Tellegen et } \\
\text { al. }^{29}\end{array}$ & Rat & Celecoxib & $A C L T+p M M x$ & $\begin{array}{l}\text { Single injection: } \\
0.015,0.115 \\
\text { or } 0.195 \mathrm{mg} \\
\text { celecoxib } \\
\text { incorporated } \\
\text { in DDS }\end{array}$ & $\begin{array}{l}\text { Four weeks } \\
\text { after } \\
\text { surgery }\end{array}$ & $\begin{array}{l}16 \text { weeks } \\
\text { after } \\
\text { surgery }\end{array}$ & $\begin{array}{l}\text { Histology: OARSI } \\
\text { score }\end{array}$ & $\begin{array}{l}\text { No difference in } \\
\text { histological score } \\
\text { in celecoxib loaded } \\
\text { microspheres vs. } \\
\text { control }\end{array}$ \\
\hline Liu et al. ${ }^{32}$ & Rat & Etoricoxib & $A C L T$ & $\begin{array}{l}\text { Three } \\
\text { injections: } \\
-10 \mu \mathrm{M} \\
\text { etoricoxib } \\
\text { in } 100 \mu \mathrm{L} \\
\mathrm{NaCl}-6.93 \mu \mathrm{g} \\
\text { ETX-NPs, drug } \\
\text { loading unclear }\end{array}$ & $\begin{array}{l}\text { Three, six } \\
\text { and nine } \\
\text { weeks after } \\
\text { surgery }\end{array}$ & $\begin{array}{l}12 \text { weeks } \\
\text { after } \\
\text { surgery }\end{array}$ & $\begin{array}{l}\text { Histology: OARSI } \\
\text { score Immunohisto- } \\
\text { chemistry }\end{array}$ & $\begin{array}{l}\text { Improved } \\
\text { histological score } \\
\text { in ETX-NP, but not } \\
\text { ETX, compared to } \\
\text { control. }\end{array}$ \\
\hline
\end{tabular}

ACLT: Anterior Cruciate Ligament Transection, CLX: celecoxib, DDS: drug delivery system, ETX: etoricoxib, HA: hyaluronic acid, MCLT: Medial Collateral Ligament Transection, MMS: modified mankin score, MMx: medial meniscectomy, NP: nanoparticle, pMMx: partial medial meniscectomy.

In an earlier study ${ }^{28}$, our group has investigated chondroprotective effects of celecoxibloaded polyesteramide (PEA) microspheres in a surgically induced rat OA model. While celecoxib-loaded microspheres reduced $\mathrm{PGE}_{2}$ as measured in homogenates from knees in this experiment, we could not find chondroprotective effects of celecoxib-loaded 


\section{Chapter 5}

PEA microspheres as measured by the OARSI score ${ }^{28}$. In another study, Tellegen et al. ${ }^{29}$ evaluated effects of the aforementioned celecoxib-loaded PEA microspheres on cartilage degeneration in a surgically induced rat OA model. Consistent with our study, no chondroprotective action of celecoxib-loaded PEA microspheres was observed. In contrast to the findings of the aforementioned two studies, one study investigating controlled release of etoricoxib demonstrated chondroprotective actions as evidenced by improved histological scores compared to controls ${ }^{32}$.

In conclusion, when used intra-articularly, three studies report chondroprotective actions of selective COX-2 inhibitors. On the other hand, there is conflicting evidence regarding chondroprotective actions of selective COX-2 inhibitors incorporated in intra-articular drug delivery systems: two studies failed to demonstrate chondroprotective actions, one study shows chondroprotective actions only when celecoxib is combined with HA and one study demonstrated chondroprotective activity.

\subsection{Clinical Studies}

Four clinical studies investigated chondroprotective actions of selective COX-2 inhibitors via oral administration, while there were no studies investigating chondroprotective actions of selective COX-2 inhibitors after intra-articular administration (Table 3). 
Table 3: The schematic overview of clinical studies investigating chondroprotective effects of systemically administered selective COX-2 inhibitors.

\begin{tabular}{|c|c|c|c|c|c|c|c|}
\hline \multicolumn{8}{|c|}{ CLINICAL STUDIES USING ORAL ADMINISTRATION } \\
\hline Authors & Species & $\begin{array}{l}\text { COX-2 } \\
\text { Inhibitor }\end{array}$ & OA Grade & $\begin{array}{l}\text { Dosing } \\
\text { Regime }\end{array}$ & $\begin{array}{l}\text { Treatment } \\
\text { Duration }\end{array}$ & $\begin{array}{l}\text { Evaluation } \\
\text { of Cartilage } \\
\text { Damage }\end{array}$ & Chondroprotection \\
\hline $\begin{array}{l}\text { Tindall et } \\
\text { al. }{ }^{33}\end{array}$ & Human & Celecoxib & $\begin{array}{l}\text { K\&L } 2 \\
\text { and } 3\end{array}$ & $\begin{array}{l}\text { Daily } 200 \text { or } \\
400 \mathrm{mg}\end{array}$ & 12 months & $\begin{array}{l}\text { Radiographs of } \\
\text { the knee }\end{array}$ & $\begin{array}{l}\text { No difference in JSW, } \\
\text { subchondral sclerosis, cysts, } \\
\text { malalignment or tilting after } \\
12 \text { months of treatment with } \\
\text { celecoxib }\end{array}$ \\
\hline $\begin{array}{l}\text { Sawitzke } \\
\text { et al. } .^{34}\end{array}$ & Human & Celecoxib & $\begin{array}{l}\text { K\&L } 2 \\
\text { and } 3\end{array}$ & Daily $200 \mathrm{mg}$ & 24 months & $\begin{array}{l}\text { Radiographs of } \\
\text { the knee }\end{array}$ & $\begin{array}{l}\text { No significant differences } \\
\text { in JSW loss in celecoxib vs. } \\
\text { controls }\end{array}$ \\
\hline $\begin{array}{l}\text { De Boer } \\
\text { et al. }{ }^{35}\end{array}$ & Human & Celecoxib & $\begin{array}{l}\text { Not } \\
\text { specified }\end{array}$ & Daily $200 \mathrm{mg}$ & 4 weeks & $\begin{array}{l}\text { Biochemical } \\
\text { cartilage } \\
\text { analysis:PG } \\
\text { synthesis rate, PG } \\
\text { release and PG } \\
\text { content }\end{array}$ & $\begin{array}{l}\text { Increased PG synthesis rate, } \\
\text { decreased PG release and } \\
\text { increased PG content in the } \\
\text { celecoxib group vs. controls. } \\
\text { Decreased release of il-1, TNF-a } \\
\text { and mmp-activity in celecoxib } \\
\text { group vs. control }\end{array}$ \\
\hline $\begin{array}{l}\text { Raynauld } \\
\text { et al. }{ }^{36}\end{array}$ & Human & Celecoxib & $\begin{array}{l}\text { K\&L } 2 \\
\text { and } 3\end{array}$ & Daily $200 \mathrm{mg}$ & 12 months & Quantitative MRI & $\begin{array}{l}\text { No difference in cartilage } \\
\text { volume loss in celecoxib group } \\
\text { vs. a historical cohort control } \\
\text { group }\end{array}$ \\
\hline
\end{tabular}

JSW: Joint space width, K\&L: Kellgren and Lawrence, PG: proteoglycan.

Tindall et al.33 included patients diagnosed with knee $\mathrm{OA}$ in a prospective open-label trial. Patients with OA received celecoxib orally at two dosages throughout a 12-month study period. Long-term celecoxib treatment did not result in significant changes of joint space width (JSW) at 1 year after treatment as assessed radiographically. Moreover, when radiographic knee OA progression during the study was compared to radiographic knee OA progression prior to the start of the study, no significant differences were detected ${ }^{33}$.

Sawitzke et al. ${ }^{34}$ conducted a placebo-controlled study of patients with knee OA in which patients received placebo or celecoxib orally on a daily basis. No significant differences were found in JSW loss compared to placebo at 24 months, while Kellgren and Lawrence grade 2 knees showed a trend towards less JSW loss. In contrast to the findings of the 


\section{Chapter 5}

aforementioned clinical studies, a study performed by de Boer et al. suggested that celecoxib might exert chondroprotective actions ${ }^{35}$. In this study, patients with end-stage knee OA were treated with orally supplemented celecoxib 28 days prior to total knee replacement surgery. Compared to patients that did not receive celecoxib, cartilage samples of patients that received celecoxib showed increased proteoglycan (PG) synthesis, decreased PG release and an increased PG content.

Raynould et al. conducted a study in which patients with knee OA were enrolled receiving celecoxib orally throughout a 12-month study period ${ }^{36}$. After correcting for potential confounders, celecoxib treatment did not show any protective effect on cartilage volume loss compared to a historical knee OA cohort loss, as assessed by quantitative MRI.

In conclusion, evidence of chondroprotective actions of selective COX-2 inhibitors in human patients is low, since three human in vivo studies failed to show chondroprotective effects of orally administered celecoxib, while only one study suggests that celecoxib may act chondroprotective in humans.

The selectivity of the COX-2 inhibitors that were used in the preclinical and clinical studies described in this review has been compared by Riendeau et al. ${ }^{37}$. The COX-2 selectivity may play a role in the chondroprotective outcome of a selective COX-2 inhibitor, but the number of studies described in this systematic review was too small to draw any conclusions. An overview of the half maximal inhibitory concentration $\left(\mathrm{IC}_{50}\right)$ values for COX-1 and COX-2 of these selective COX-2 inhibitors together with the COX-1/COX-2 IC $\mathrm{C}_{50}$ ratio is provided in Table 4. 
Table 4: The schematic overview of the half maximal inhibitory concentration $\left(I C_{50}\right)$ values and the COX-1/COX-2 IC ${ }_{50}$ ratio of various selective COX-2 inhibitors. Adapted from ${ }^{37}$.

\begin{tabular}{|c|c|c|c|}
\hline DRUG & $I C_{50} C O X-1(\mu M)$ & $I C_{50} C O X-2(\mu M)$ & $\begin{array}{c}\text { COX-1/COX-2 IC } \\
\text { RATIO }\end{array}$ \\
\hline Meloxicam & 1.4 & 0.7 & 2 \\
\hline Celecoxib & 6.7 & 0.87 & 7.7 \\
\hline Etoricoxib & 116 & 1.1 & 105 \\
\hline Parecoxib & 26.1 & 0.87 & 30 \\
\hline
\end{tabular}




\section{Discussion}

The main finding of this systematic review is that the administration route plays a major role in determining chondroprotective actions of selective COX-2 inhibitors. The intraarticular administration route may be promising, since studies using bolus intra-articular administration of selective COX-2 inhibitors show chondroprotective effects. On the other hand, conflicting evidence exists when selective COX-2 inhibitors are incorporated into a drug delivery system. While preclinical studies point out to a potential chondroprotective role of COX-2 inhibitors, clinical studies did not investigate the intra-articular administration route and failed to confirm chondroprotective actions of systemically administered selective COX-2 inhibitors.

Discrepancies in chondroprotective actions of selective COX-2 inhibitors observed in the preclinical studies may be related to the route of administration. While six of the fourteen studies using systemic administration failed to demonstrate chondroprotective actions of selective COX-2 inhibitors, all studies that applied intra-articular bolus injections demonstrated chondroprotective actions. Interestingly, all clinical studies included in this systematic review evaluated chondroprotective actions using the systemic administration route. Since these studies failed to demonstrate chondroprotective actions, it will be of interest to investigate the chondroprotective actions of selective COX-2 inhibitors using the intra-articular administration route for clinical studies. We did not encounter studies comparing chondroprotective effects of systemic versus intra-articularly administration of selective COX-2 inhibitors, but we believe this will be of interest to investigate in the future.

Improved chondroprotection of intra-articular injections with selective COX-2 inhibitor compared to a saline control condition may be related to increased bioavailability of the drug in the knee joint compared to systemic administrations. In addition, in a total joint disease such as knee $\mathrm{OA}^{38,39,40,41}$, intra-articular administration of drugs may be more effective compared to systemic treatment due to the presence of scarcely vascularized tissues such as cartilage and meniscus ${ }^{8}$. Since COX-2 inhibitors can have an effect on all joint tissues, it is unclear whether the chondroprotective effect is a direct result of COX-2 
inhibition in chondrocytes or an effect of COX-2 inhibition of other joint tissues.

Others and we failed to show a reduction of OA-related cartilage damage by celecoxib, when incorporated in an intra-articular drug delivery system ${ }^{28,29}$. It is a possibility that prolonged release of celecoxib may counteract potential chondroprotective effects due to increased loading of the affected joint indirectly caused by the analgesic effects of COX2 inhibitors. These findings corroborate earlier observations in clinical studies, in which patients treated with anti-NGF demonstrated an increase in OA-related cartilage damage possibly due to joint overloading ${ }^{5}$.

COX-2 inhibitors are expected to have anti-inflammatory effects by inhibiting the synthesis of prostanoids. Prostanoid subtypes are considered as inflammatory mediators ${ }^{2}$ and are involved in cartilage degradation ${ }^{3}$, but also in other pathophysiologic OA processes in different joint tissues such as synovial fibrosis and chondrocyte hypertrophy ${ }^{42,43}$. However, also anti-inflammatory actions of certain prostanoid subtypes have been shown ${ }^{2}$, and therefore identifying downstream targets of the COX-2 pathway may further aid in antiinflammatory treatment for knee OA. Inflammatory processes have been suggested to precede knee $\mathrm{OA}^{4,44}$ and to be involved in structural disease progression ${ }^{4}$. A window of opportunity may exist, in which modulating the inflammatory status of the knee joint via intra-articular treatment with selective COX-2 inhibitors may lead to OA disease modification. The initiation of treatment may thus be important for the treatment outcome. The studies performed by Wen et al..$^{24}$ and Dai et al. ${ }^{20}$ did not start treatment shortly after surgery and demonstrated chondroprotective actions of orally administered COX-2 inhibitors. It can be hypothesized that inhibiting inflammation directly after inducing a joint trauma may compromise cartilage regeneration, since inflammation is part of the early phases of natural tissue regeneration after a trauma ${ }^{45}$. This may explain why studies in surgical OA models fail to show chondroprotective effects when starting treatment directly after surgery. Moreover, the lack of a chondroprotective effect in clinical studies may be related to the stage of disease. Patients with knee OA are diagnosed in a stadium when the disease has progressed towards its end-stage ${ }^{46}$, and it can be hypothesized that at this stage the disease is in an irreversible stadium where drug-based disease modification is not effective anymore. In addition, knee $\mathrm{OA}$ is a heterogeneous disease showing variability in 
the rate of disease progression in human subjects ${ }^{47}$, while also the existence of distinct OA subtypes has been suggested ${ }^{18,48}$, suggesting that patient-tailored drug treatment needs to be developed. Finally, the outcome measurements of clinical studies, such as joint space narrowing on conventional radiography, may not be sensitive enough. With the ongoing advancements in cartilage imaging ${ }^{49}$, advanced techniques such as 7-tesla MRI imaging ${ }^{49}$ may provide a more sensitive means to evaluate multiple outcome domains relevant to the clinical and pathophysiological aspects of disease modifying osteoarthritis drug (DMOAD)mediated disease modification.

\section{Conclusions}

To date there is conflicting evidence regarding the ability of selective COX-2 inhibitors to be used as DMOADs. Preclinical studies have used different routes of administration, which may alter the chondroprotective outcome of selective COX-2 inhibitors in the knee joint where scarcely vascularized tissues are present. Other factors such as the OA model type, type of selective COX-2 inhibitor and disease stage seem also to be involved in the chondroprotective outcome of selective COX-2 inhibitors. Despite the limited evidence of data in clinical studies, there seems to be a preclinical basis for considering selective COX-2 inhibitors as DMOADs specifically when used intra-articularly.

\section{Patents}

TJM Welting is listed as inventor on patents: WO2017178251, WO2017178253 and US 20130123314. PJ Emans and LW van Rhijn are listed as inventors on patent US 20130123314. LW van Rhijn, PJ Emans and TJM Welting have shares in Chondropeptix and are CDO, CMO and CSO of Chondropeptix, respectively. 


\section{Supplementary Materials}

Supplementary materials can be found at https://www.mdpi.com/1422-0067/21/18/6962/ $\underline{\text { s1. }}$ 


\section{References}

1 Hunter D.J., Felson D.T. Osteoarthritis. BMJ. 2006;332:639-642. doi: 10.1136/ bmj.332.7542.639.

2 Ricciotti E., FitzGerald G.A. Prostaglandins and inflammation. Arterioscler Thromb Vasc. Biol. 2011;31:986-1000. doi: 10.1161/ ATVBAHA.110.207449.

3 Martel-Pelletier J., Pelletier J.P., Fahmi H. Cyclooxygenase-2 and prostaglandins in articular tissues. Semin. Arthritis Rheum. 2003;33:155-167. doi: 10.1016/S00490172(03)00134-3.

4 Ayral X., Pickering E.H., Woodworth T.G., Mackillop N., Dougados M. Synovitis: A potential predictive factor of structural progression of medial tibiofemoral knee osteoarthritis-Results of a 1 year longitudinal arthroscopic study in 422 patients. Osteoarthritis Cartilage. 2005;13:361-367. doi: 10.1016/j. joca.2005.01.005.

5 Miller R.E., Block J.A., Malfait A.M. Nerve growth factor blockade for the management of osteoarthritis pain: What can we learn from clinical trials and preclinical models? Curr. Opin. Rheumatol. 2017;29:110-118. doi: 10.1097/ BOR.0000000000000354.
6 Ding C. Do NSAIDs affect the progression of osteoarthritis? Inflammation. 2002;26:139-142. doi: 10.1023/A:1015504632021.

Zweers M.C., De Boer T.N., Van Roon J., Bijlsma J.W., Lafeber F.P., Mastbergen S.C. Celecoxib: Considerations regarding its potential disease-modifying properties in osteoarthritis. Arthritis Res. Ther. 2011;13:239. doi: 10.1186/ar3437.

Buckwalter J.A., Mankin H.J. Articular cartilage: Tissue design and chondrocytematrix interactions. Instr. Course Lect. 1998;47:477-486.

9 Makris E.A., Hadidi P., Athanasiou K.A. The knee meniscus: Structurefunction, pathophysiology, current repair techniques, and prospects for regeneration. Biomaterials. 2011;32:7411-7431. doi: 10.1016/j. biomaterials.2011.06.037.

10 Hooijmans C.R., Rovers M.M., De Vries R.B., Leenaars M., Ritskes-Hoitinga M., Langendam M.W. SYRCLE's risk of bias tool for animal studies. BMC Med. Res. Methodol. 2014;14:43. doi: 10.1186/14712288-14-43.

11 Van der Kraan P.M., Buma P., Van Kuppevelt 
T., Van den Berg W.B. Interaction of chondrocytes, extracellular matrix and growth factors: Relevance for articular cartilage tissue engineering. Osteoarthritis Cartilage. 2002;10:631-637. doi: 10.1053/ joca.2002.0806.

12 Mastbergen S.C., Marijnissen A.C., Vianen M.E., Zoer B., Van Roermund P.M., Bijlsma J.W., Lafeber F.P. Inhibition of COX-2 by celecoxib in the canine groove model of osteoarthritis. Rheumatology. 2006;45:405-413. doi: 10.1093/ rheumatology/kei187.

13 Huh J.E., Baek Y.H., Kim Y.J., Lee J.D., Choi D.Y., Park D.S. Protective effects of butanol fraction from Betula platyphyla var. japonica on cartilage alterations in a rabbit collagenase-induced osteoarthritis. J. Ethnopharmacol. 2009;123:515-521. doi: 10.1016/j.jep.2008.08.028.

14 Fukai A., Kamekura S., Chikazu D., Nakagawa T., Hirata M., Saito T., Hosaka Y., Ikeda T., Nakamura K., Chung U., et al. Lack of a chondroprotective effect of cyclooxygenase 2 inhibition in a surgically induced model of osteoarthritis in mice. Arthritis Rheum. 2012;64:198-203. doi: 10.1002/art.33324.

15 Ou Y., Tan C., An H., Jiang D., Quan Z., Tang K., Luo X. Selective COX-2 inhibitor ameliorates osteoarthritis by repressing apoptosis of chondrocyte. Med. Sci. Monit. 2012;18:BR247-BR252. doi: 10.12659/
MSM.882901.

16 Ashkavand Z., Malekinejad H., Amniattalab A., Rezaei-Golmisheh A., Vishwanath B.S. Silymarin potentiates the anti-inflammatory effects of Celecoxib on chemically induced osteoarthritis in rats. Phytomedicine. 2012;19:1200-1205. doi: 10.1016/j.phymed.2012.07.008.

17 Moon S.J., Park J.S., Jeong J.H., Yang E.J., Park M.K., Kim E.K., Park S.H., Kim H.Y., Cho M.L., Min J.K. Augmented chondroprotective effect of coadministration of celecoxib and rebamipide in the monosodium iodoacetate rat model of osteoarthritis. Arch. Pharm. Res. 2013;36:116-124. doi: 10.1007/s12272-013-0010-0.

18 Panahifar A., Jaremko J.L., Tessier A.G., Lambert R.G., Maksymowych W.P., Fallone B.G., Doschak M.R. Development and reliability of a multi-modality scoring system for evaluation of disease progression in pre-clinical models of osteoarthritis: Celecoxib may possess disease-modifying properties. Osteoarthritis Cartilage. 2014;22:16391650. doi: 10.1016/j.joca.2014.06.013.

19 Li Z., Meng D., Li G., Xu J., Tian K., Li Y. Celecoxib Combined with Diacerein Effectively Alleviates Osteoarthritis in Rats via Regulating JNK and p38MAPK Signaling Pathways. Inflammation. 2015;38:1563-1572. doi: 10.1007/s10753- 
015-0131-3.

20 Dai M.W., Chu J.G., Tian F.M., Song H.P., Wang Y., Zhang Y.Z., Zhang L.

Parathyroid hormone(1-34) exhibits more comprehensive effects than celecoxib in cartilage metabolism and maintaining subchondral bone micro-architecture in meniscectomized guinea pigs. Osteoarthritis Cartilage. 2016;24:11031112. doi: 10.1016/j.joca.2016.01.007.

21 Tu M., Yang M., Yu N., Zhen G., Wan M., Liu W., Ji B., Ma H., Guo Q., Tong P., et al. Inhibition of cyclooxygenase-2 activity in subchondral bone modifies a subtype of osteoarthritis. Bone Res. 2019;7:29. doi: 10.1038/s41413-019-0071-x.

22 Jones M.D., Tran C.W., Li G., Maksymowych W.P., Zernicke R.F., Doschak M.R. In vivo microfocal computed tomography and micro-magnetic resonance imaging evaluation of antiresorptive and antiinflammatory drugs as preventive treatments of osteoarthritis in the rat. Arthritis Rheum. 2010;62:2726-2735. doi: 10.1002/art.27595.

23 Nagy E., Vajda E., Vari C., Sipka S., Farr A.M., Horvath E. Meloxicam ameliorates the cartilage and subchondral bone deterioration in monoiodoacetateinduced rat osteoarthritis. PeerJ. 2017;5:e3185. doi: 10.7717/peerj.3185.

24 Wen Z.H., Lin Y.Y., Chang Y.C., Tang C.C.,
Hsieh S.P., Lee H.P., Sung C.S., Chen W.F., Lee C.H., Jean J.H. The COX-2 inhibitor etoricoxib reduces experimental osteoarthritis and nociception in rats: The roles of TGF-beta1 and NGF expressions in chondrocytes. Eur. J. Pain. 2020;24:209222. doi: 10.1002/ejp.1478.

25 Liu B., Ji C., Shao Y., Liang T., He J., Jiang H., Chen G., Luo Z. Etoricoxib decreases subchondral bone mass and attenuates biomechanical properties at the early stage of osteoarthritis in a mouse model. Biomed Pharmacother. 2020;127:110144. doi: 10.1016/j.biopha.2020.110144.

26 Jiang D., Zou J., Huang L., Shi Q., Zhu X., Wang G., Yang H. Efficacy of intra-articular injection of celecoxib in a rabbit model of osteoarthritis. Int. J. Mol. Sci. 2010;11:4106. doi: 10.3390/ijms 11104106 .

27 Dong J., Jiang D., Wang Z., Wu G., Miao L., Huang L. Intra-articular delivery of liposomal celecoxib-hyaluronate combination for the treatment of osteoarthritis in rabbit model. Int. J. Pharm. 2013;441:285-290. doi: 10.1016/j. ijpharm.2012.11.031.

28 Janssen M., Timur U.T., Woike N., Welting T.J., Draaisma G., Gijbels M., van Rhijn L.W., Mihov G., Thies J.C., Emans P.J. Celecoxib-loaded PEA microspheres as an auto regulatory drug-delivery system after intra-articular injection. J. Control Release. 2016;244:30-40. doi: 10.1016/j. 
jconrel.2016.11.003.

29 Tellegen A.R., Rudnik-Jansen I., Pouran B., De Visser H.M., Weinans H.H., Thomas R.E., Kik M.J.L., Grinwis G.C.M., Thies J.C., Woike N., et al. Controlled release of celecoxib inhibits inflammation, bone cysts and osteophyte formation in a preclinical model of osteoarthritis. Drug Deliv. 2018;25:1438-1447. doi: 10.1080/10717544.2018.1482971.

30 Jean Y.H., Wen Z.H., Chang Y.C., Hsieh S.P., Tang C.C., Wang Y.H., Wong C.S. Intraarticular injection of the cyclooxygenase-2 inhibitor parecoxib attenuates osteoarthritis progression in anterior cruciate ligament-transected knee in rats: Role of excitatory amino acids. Osteoarthritis Cartilage. 2007;15:638-645. doi: 10.1016/j.joca.2006.11.008.

31 Wen Z.H., Tang C.C., Chang Y.C., Huang S.Y., Chen C.H., Wu S.C., Hsieh S.P., Hsieh C.S., Wang K.Y., Lin S.Y., et al. Intra-articular injection of the selective cyclooxygenase-2 inhibitor meloxicam (Mobic) reduces experimental osteoarthritis and nociception in rats. Osteoarthritis Cartilage. 2013;21:19761986. doi: 10.1016/j.joca.2013.09.005.

32 Liu P., Gu L., Ren L., Chen J., Li T., Wang X., Yang J., Chen C., Sun L. Intra-articular injection of etoricoxib-loaded PLGA-PEGPLGA triblock copolymeric nanoparticles attenuates osteoarthritis progression. Am.
J. Transl. Res. 2019;11:6775-6789.

33 Tindall E.A., Sharp J.T., Burr A., Katz T.K., Wallemark C.B., Verburg K., Lefkowith J. A 12-month, multicenter, prospective, open-label trial of radiographic analysis of disease progression in osteoarthritis of the knee or hip in patients receiving celecoxib. Clin Ther. 2002;24:2051-2063. doi: 10.1016/S0149-2918(02)80096-0.

34 Sawitzke A.D., Shi H., Finco M.F., Dunlop D.D., 3rd Bingham C.O., Harris C.L., Singer N.G., Bradley J.D., Silver D., Jackson C.G., et al. The effect of glucosamine and/or chondroitin sulfate on the progression of knee osteoarthritis: A report from the glucosamine/chondroitin arthritis intervention trial. Arthritis Rheum. 2008;58:3183-3191. doi: 10.1002/ art.23973.

35 De Boer T.N., Huisman A.M., Polak A.A., Niehoff A.G., Van Rinsum A.C., Saris D., Bijlsma J.W.J., Lafeber F.J.P.G., Mastbergen S.C. The chondroprotective effect of selective COX-2 inhibition in osteoarthritis: Ex vivo evaluation of human cartilage tissue after in vivo treatment.

Osteoarthritis Cartilage. 2009;17:482-488. doi: 10.1016/j.joca.2008.09.002

36 Raynauld J.P., Martel-Pelletier J., Beaulieu
A., Bessette L., Morin F., Choquette
D., Haraoui B., Abram F., Pelletier J.P.
An open-label pilot study evaluating by magnetic resonance imaging the 
potential for a disease-modifying effect of celecoxib compared to a modelized historical control cohort in the treatment of knee osteoarthritis. Semin. Arthritis Rheum. 2010;40:185-192. doi: 10.1016/j. semarthrit.2009.10.003.

37 Riendeau D., Percival M.D., Brideau C., Charleson S., Dubé D., Ethier D., Falgueyret J.P., Friesen R.W., Gordon R., Greig G., et al. Etoricoxib (MK-0663): Preclinical Profile and Comparison with other agents that selectively inhibit Cyclooxygenase-2. J. Pharmacol. Exp. Ther. 2001;296:558-566.

38 Loeser R.F., Goldring S.R., Scanzello C.R., Goldring M.B. Osteoarthritis: A disease of the joint as an organ. Arthritis Rheum. 2012;64:1697-1707. doi: 10.1002/ art.34453.

39 Clockaerts S., Bastiaansen-Jenniskens Y.M., Runhaar J., Van Osch G.J., Van Offel J.F., Verhaar J.A., de Clerck L.S., Somville J. The infrapatellar fat pad should be considered as an active osteoarthritic joint tissue: A narrative review. Osteoarthritis Cartilage. 2010;18:876-882. doi: 10.1016/j. joca.2010.03.014.

Weinberg J.B., Fermor B., Guilak F. Nitric oxide synthase and cyclooxygenase interactions in cartilage and meniscus: Relationships to joint physiology, arthritis, and tissue repair. Subcell Biochem. 2007;42:31-62.
41 De Lange-Brokaar B.J., loan-Facsinay A., Van Osch G.J., Zuurmond A.M., Schoones J., Toes R.E., Huizinga T.W.J., Kloppenburg M. Synovial inflammation, immune cells and their cytokines in osteoarthritis: A review. Osteoarthritis Cartilage. 2012;20:1484-1499. doi: 10.1016/j. joca.2012.08.027.

42 Bastiaansen-Jenniskens Y.M., Wei W., Feijt C., Waarsing J.H., Verhaar J.A., Zuurmond A.M., Hanemaaijer R., Stoop R., van Osch G.J.V.M. Stimulation of fibrotic processes by the infrapatellar fat pad in cultured synoviocytes from patients with osteoarthritis: A possible role for prostaglandin f2alpha. Arthritis Rheum. 2013;65:2070-2080. doi: 10.1002/ art.37996.

43 Welting T.J., Caron M.M., Emans P.J., Janssen M.P., Sanen K., Coolsen M.M., Voss L., Surtel D.A., Cremers A., Voncken J., et al. Inhibition of cyclooxygenase- 2 impacts chondrocyte hypertrophic differentiation during endochondral ossification. Eur. Cell Mater. 2011;22:420-437. doi: 10.22203/ eCM.v022a31.

44 Felson D.T., Niu J., Neogi T., Goggins J., Nevitt M.C., Roemer F., Torner J., Lewis C.E., Guermazi A. Synovitis and the risk of knee osteoarthritis: The MOST Study. Osteoarthritis Cartilage. 2016;24:458-464. doi: 10.1016/j.joca.2015.09.013.

45 Karin M., Clevers H. Reparative 
inflammation takes charge of tissue regeneration. Nature. 2016;529:307-315.

doi: 10.1038/nature17039.

46 Glyn-Jones S., Palmer A.J., Agricola R., Price A.J., Vincent T.L., Weinans H., Carr A.J. Osteoarthritis. Lancet. 2015;386:376-387. doi: 10.1016/S0140-6736(14)60802-3.

47 Karsdal M.A., Christiansen C., Ladel C., Henriksen K., Kraus V.B., BayJensen A.C. Osteoarthritis--a case for personalized health care? Osteoarthritis Cartilage. 2014;22:7-16. doi: 10.1016/j. joca.2013.10.018.

48 Waarsing J.H., Bierma-Zeinstra S.M., Weinans $\mathrm{H}$. Distinct subtypes of knee osteoarthritis: Data from the Osteoarthritis Initiative. Rheumatology. 2015;54:16501658. doi: 10.1093/rheumatology/kev100.

49 Oei E.H.G., Wick M.C., Muller-Lutz A., Schleich C., Miese F.R. Cartilage Imaging: Techniques and Developments. Semin. Musculoskelet. Radiol. 2018;22:245-260. doi: 10.1055/s-0038-1639471. 


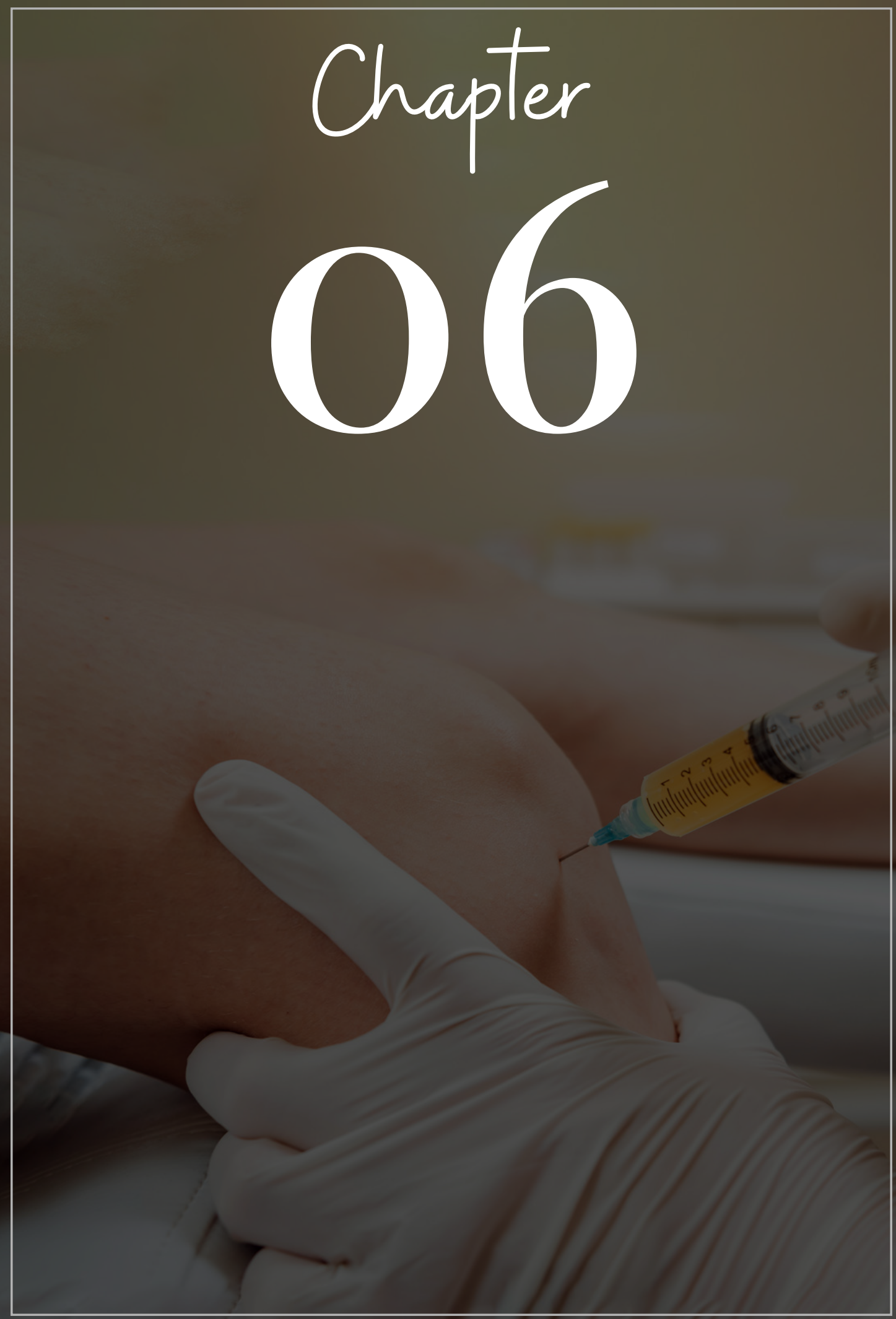




\section{Celecoxib-Loaded PEA Microspheres as an Auto Regulatory Drug-Delivery System After Intra-Articular Injection}

Janssen M, Timur UT, Woike N, Welting TJM, Draaisma G, Gijbels M, Van Rhijn LW, Mihov G, Thies J, Emans PJ. J Control Release. 2016;244(Pt A):30-40. (shared first author) 


\section{Abstract}

\section{Objective:}

In this study, we investigated the potential of celecoxib-loaded polyester amide (PEA) microspheres as an auto-regulating drug delivery system for the treatment of pain associated with knee osteoarthritis (OA).

\section{Material \& Methods:}

Celecoxib release from PEA microspheres and inflammation responsive release of a small molecule from PEA was investigated in vitro. To investigate biocompatibility and degradation behavior in vivo, celecoxib-loaded PEA microspheres were injected in OAinduced (ACLT+pMMx) or contralateral healthy knee joints of male Lewis rats. Bioactivity of celecoxib from loaded PEA microspheres was confirmed by $\mathrm{PGE}_{2}$ measurements in total rat knee homogenates.

\section{Results:}

Inflammation responsive release of a small molecule from PEA was observed when PEA was exposed to cell lysates obtained from a neutrophil-like $\mathrm{HI}-60$ cell line. Following a short initial burst release of $\sim 15 \%$ of the total drug load in the first days, celecoxib was slowly released throughout a period of $>80$ days. Intra-articular biocompatibility was demonstrated histologically, where no cartilage damage or synovial thickening and necrosis were observed after intra-articular injections with PEA microspheres. Degradation of PEA microspheres was significantly higher in $O A$ induced knees compared to contralateral healthy knee joints, while loading the PEA microspheres with celecoxib significantly inhibited degradation, indicating a drug delivery system with auto regulatory behavior. 


\section{Conclusion:}

In conclusion, this study suggests the potential of celecoxib-loaded PEA microspheres to be used as a safe drug delivery system with auto regulatory behavior for treatment of pain associated with $O A$ of the knee.

\section{Keywords:}

Autoregulation; Drug-delivery; Microspheres; Osteoarthritis; Polyester amide; Slow release.

\section{Introduction}

Osteoarthritis $(O A)$ is the most common form of arthritis and constitutes a large medical healthcare economic burden worldwide, leading to pain and physical disability'. Systemic treatment with non-steroidal anti-inflammatory drugs (NSAIDs) has shown to provide effective pain relief in patients with knee $\mathrm{OA}$, but its systemic use is associated with gastrointestinal and cardiac adverse effects ${ }^{2,3}$. This limits its potential use in a chronic disease such as $\mathrm{OA}$, where long term treatment is required. Therefore, an intra-articular drug delivery system (DDS) is necessary, which circumvents side effects associated with systemic treatment and allows prolonged local drug residence time $\mathrm{A}^{4}$. Because $\mathrm{OA}$ is a chronic disease characterized by a variation in inflammation intensity ${ }^{4}$ an attractive therapeutic approach would be intra-articular injection with a DDS which is inflammation-responsive. Loading an inflammation-responsive DDS with an anti-inflammatory drug may result in an auto regulatory DDS: the level of inflammation will impact degradation of the DDS and drug release, quenching inflammation, decreasing degradation and thus dosing the release.

Importantly, a DDS which can be used as an intra-articular treatment for OA should present a set of properties 5 . Firstly, the DDS should be responsive to the osteoarthritic disease process and able to slowly release a drug throughout time. Secondly, the DDS should be biocompatible and able to safely degrade in a knee joint. Finally, drug release from the DDS would be desired to slow the rate of its own release. 
A candidate for such a DDS with auto regulatory behavior is a polyester amide (PEA) based injectable microsphere formulation. PEA polymers are based on a-amino acids, aliphatic dicarboxylic acids, and aliphatic $a-\omega$ diols ${ }^{6}$. The presence of amino acids in PEA makes it susceptible to enzymatic degradation by proteolytic enzymes. Several studies have reported this mechanism of degradation of PEA by enzymes such as a-chymotrypsin, elastase, papain and protease $K$, which are enzymes belonging to the serine protease family $7,8,9,10,11$. Since serine proteases are present in synovial fluid and a key component of the inflammatory response, drug release from a PEA based DDS is potentially reactive to the disease process in inflammation related conditions such as $\mathrm{OA}^{12,13}$.

A candidate anti-inflammatory drug to incorporate into PEA microspheres is the COX2 inhibitor celecoxib, which is an anti-inflammatory drug that has been shown to be an effective analgesic for OA related pain ${ }^{14}$. Celecoxib, when administered systemically, has been reported to raise the risk for cardiovascular events, however incorporating the drug in a PEA based DDS for intra-articular administration can circumvent these side effects ${ }^{15}$. PEA has already been demonstrated to have a good biocompatibility, is applied clinically in drug eluting stents and is being investigated for ophthalmologic indications ${ }^{16,17}$. However its use in the treatment of arthritic diseases has not yet been described.

In this study, we investigated the use of PEA microspheres as an auto-regulatory intraarticular DDS in OA treatment. First, we examined inflammation-responsive release of a small molecule from PEA in vitro in the presence or absence of a serine protease inhibitor. Next, biocompatibility, degradation and effects on OA progression of celecoxib-loaded PEA microspheres were investigated in experimental OA in vivo.

\section{Material \& Methods}

\subsection{Synthesis of Polymer and Preparation of PEA Microspheres}

PEA was synthesized in accordance to procedures reported previously $y^{16,18,19}$. The selected PEA is depicted on Figure 1 and it comprises three types of building blocks randomly 
distributed along the polymer chain. Polymer characterization can be found in Table 1. For the preparation of microspheres, PEA was dissolved in dichloromethane (Merck Millipore). 5 $w t \%$ celecoxib was added to the solution and homogenized by sonication. The suspension was added to $20 \mathrm{~mL}$ of cold water containing $1 \mathrm{wt} \%$ of poly(vinyl alcohol) (Sigma Aldrich) under high shear, using an ultra-Turrax. After a stable suspension was obtained the particles were let to harden in $100 \mathrm{~mL}$ of water containing $1 \mathrm{wt} \%$ of poly(vinyl alcohol) for $12 \mathrm{~h}$. Excess of water and surfactant was removed by rinsing and centrifugation. Finally, particles were frozen, dried under vacuum and stored at $-15^{\circ} \mathrm{C}$ until being used.

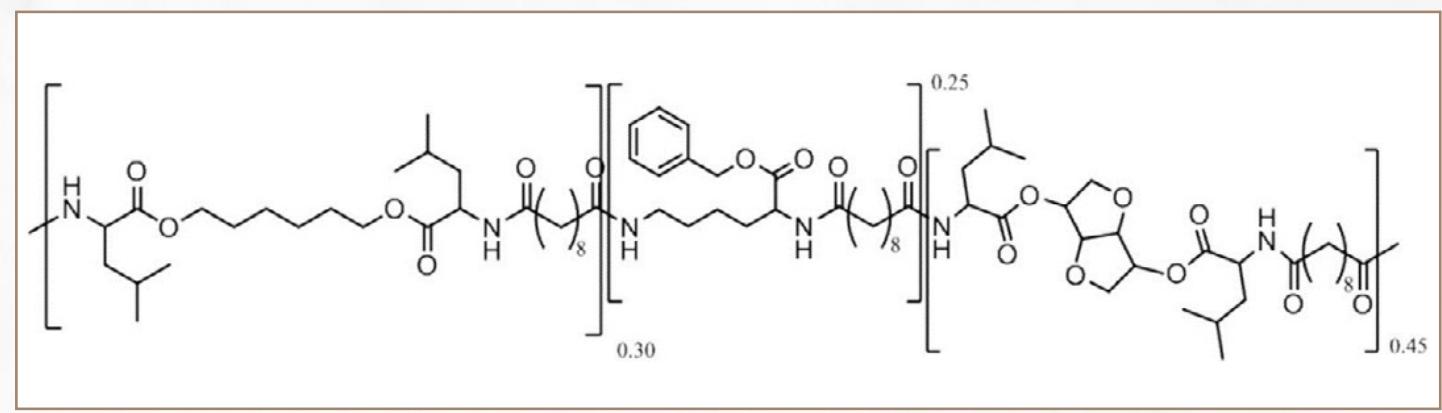

Figure 1: Structure of PEA III AC Bz, random copolymer consisting of building blocks $A, B$ and C.

Table 1. Polymer characterization. The relative ratio between the polymer building blocks was determined by 1 H NMR. Tg of the polymer was determined under dry conditions.

\begin{tabular}{|c|c|c|c|c|} 
& $\begin{array}{c}\text { MN } \\
\text { (KDA) }\end{array}$ & $\begin{array}{c}\text { POLYDISPERSITY } \\
\text { INDEX (PDI) }\end{array}$ & $\begin{array}{c}\text { GLASS TRANSITION } \\
\text { TEMPERATURE (Tg) }\end{array}$ & $\begin{array}{c}\text { RELATIVE RATIO } \\
\text { A:B:C }\end{array}$ \\
\hline PEA III Ac Bz & 55 & 1.6 & $57^{\circ} \mathrm{C}$ & $0.31: 0.26: 0.43$ \\
\hline
\end{tabular}




\subsection{Determining Particle Size, Particle Morphology and Loading Efficiency of Celecoxib in PEA Microspheres}

Size distribution of particles was measured using a Malvern Mastersizer 2000. Morphological examination of PEA microspheres was performed using SEM (Versa 3D FEG-ESEM). For determination of celecoxib loading efficiency, $10 \mathrm{mg}$ of freeze dried microparticles were weighed and dissolved in methanol and shaken until a clear solution was obtained. Next, samples were subjected to analysis with High Performance Liquid Chromatography (HPLC) using a Waters e2695 Alliance HPLC with a UV detector. The method was obtained from the pharmacopeia collection.

\subsection{Release kinetics of PEA based Celecoxib-Loaded Microspheres In Vitro}

For the evaluation of the in vitro release kinetics of celecoxib from PEA microspheres, at least $10 \mathrm{mg}$ of microspheres were placed in centrifuge tubes and immersed in phosphate buffered saline (PBS) at $37^{\circ} \mathrm{C}$ under gentle shaking. After centrifugation, part of the buffer was removed and replaced with fresh buffer at defined time points such as $1 \mathrm{~h}, 4 \mathrm{~h}, 1$ day, 2 days, 4 days, and 7 days until completion of the release study. The PBS solution with released API was transferred to HPLC vials and stored in the freezer until HPLC analysis.

\subsection{HI-60 Cell Culture and Cell Lysate}

The promyelocytic cell-line $\mathrm{HI}-60$ (98070106) was purchased at the European Collection of Cell Cultures (ECACC). HI-60 cells were cultured in RPMI 1640 medium containing 2 mM L-glutamine (Sigma Aldrich R8758). The culture medium was supplemented with $10 \%$ sterile filtered fetal bovine serum (Sigma Aldrich F2442) and $100 \mathrm{U} / \mathrm{mL}$ streptomycin and $100 \mathrm{U} / \mathrm{mL}$ penicillin. Cells were cultured at $37^{\circ} \mathrm{C}$ and $5 \% \mathrm{CO}_{2}$ without any shaking and were passaged every $2-3$ days to keep cell concentration between $0.1 * 10^{6}$ and $1 * 10^{6}$ cells $/ \mathrm{mL}$. During passaging, cells were centrifuged a $300 \times g$ and seeded in fresh full medium at a concentration of $0.1-0.2 * 10^{6}$ cells $/ \mathrm{mL}$. 


\subsubsection{Viability and Cell Counting}

Cells were counted using the Guava Viacount reagent (Merck Millipore \# 4000-0040) on a Guava EasyCyte plus flow cytometer according to the manufacturer's instructions. Viability was also determined within the same method.

\subsubsection{Differentiation}

HI-60 cells were differentiated toward neutrophil like cells using the DMSO method. For this method cells were incubated in full medium supplemented with $1.25 \%$ sterile filtered DMSO for 5 days. Cells were seeded at a concentration of $0.2 * 10^{6}$ cells $/ \mathrm{mL}$ at the start of the differentiation process and reached $\pm 1 * 10^{6}$ cells $/ \mathrm{mL}$ after 5 days.

\subsubsection{Lysates}

Cells were lysed by $3-5$ freeze-thaw cycles from liquid nitrogen to a $37^{\circ} \mathrm{C}$ water bath. Cells were generally kept for $10 \mathrm{~min}$ in liquid nitrogen and $10 \mathrm{~min}$ in the water bath. Cell lysis was confirmed by microscopic analysis. The process was repeated till $\pm 100 \%$ lysed cells were obtained.

\subsection{In Vitro Fluorescein Release from PEA Films}

Degradation driven release of PEA in vitro was investigated by loading PEA III Ac Bz films with 9.1 wt\% fluorescein. 101.3 mg fluorescein and $999.3 \mathrm{mg}$ PEA III Ac Bz were dissolved in $19 \mathrm{~mL}$ ethanol. The solution was left overnight to dissolve under gentle agitation on an orbital shaker. $8 \mathrm{~mL}$ of the polymer fluorescein solution was pipetted in a Teflon mold, with a diameter of $5 \mathrm{~cm}$ and placed in a desiccator. Under a gentle nitrogen flow the solvent was allowed to evaporate in $18 \mathrm{~h}$. The nitrogen flow dried films were removed and dried further under vacuum at $70{ }^{\circ} \mathrm{C}$ for $48 \mathrm{~h}$. A sample of the film was analyzed for residual ethanol by ${ }^{1} \mathrm{H}$ NMR analysis in $\mathrm{CDCl}_{3^{\prime}}$, the characteristic methylene quartet at $3.7 \mathrm{ppm}$ and methyl triplet at $1.2 \mathrm{ppm}$ of ethanol were not observed. $6 \mathrm{~mm}$ round disks were punched out of the dried film and were used for the release experiment. Two release series were started both in triplicate for 60 days. At each time point the solutions were refreshed. Series 
1 released in PBS buffer for the entire period (diffusion driven release). Series 2 started with release in PBS buffer for 26 days. After 26 days, a HI-60 neutrophil like cell lysate was added for a period of 7 days. Next, a serine protease inhibitor 4-(2-aminoethyl)benzenesulfonyl fluoride hydrochloride (AEBSF) $(0.5 \mathrm{mM})$ was added to the lysate solution for a duration of 14 days and finally a $\mathrm{HI}-60$ neutrophil like cell lysate without serine protease inhibitor was added during the final stages of the release experiment. Fluorescein release was quantified with a spectrophotometric assay.

\subsection{Collection of Synovial Fluid and Synovium}

Synovial fluid and synovial tissues were obtained as anonymous left-over material from 5 patients with knee OA undergoing total knee replacement. This study was approved by the local ethical committee (MEC 08-4-028). Synovial fluid was directly centrifuged at $1200 \mathrm{rpm}$ for $8 \mathrm{~min}$ and the supernatant was aliquoted and stored at $-80^{\circ} \mathrm{C}$. Synovial tissue was washed thoroughly with $0.9 \% \mathrm{NaCl}$ and cut into pieces of approximately 50 $\mathrm{mg}$ and cultured at a concentration of $100 \mathrm{mg} / \mathrm{mL}$ in Dulbecco's modified eagle medium (DMEM) (Invitrogen) supplemented with 1\% antibiotic/antimycotic. After 72 h, synovium conditioned medium was collected, centrifuged at $1200 \mathrm{rpm}$ for $8 \mathrm{~min}$ and the supernatant was aliquoted and stored at $-80^{\circ} \mathrm{C}$.

\subsection{Protease Assay in Synovial Fluid and Synovium Conditioned Media}

A protease assay kit (EnzChek Protease Assay Kit for green fluorescence, Thermo Fisher) was used in accordance with the manufacturer's instructions to determine proteolytic activity in synovial fluid and synovium conditioned media.

First, $10 \mu \mathrm{L}$ of AEBSF (Sigma Aldrich) $(10 \mathrm{mM})$ or $10 \mu \mathrm{L}$ of a Tris- $\mathrm{HCl}$ buffer (10 mM Tris-HCl, $\mathrm{pH} 7.8,0.2 \mathrm{mM}$ sodium azide) was added to $100 \mu \mathrm{L}$ of synovial fluid (ten times diluted in $1 \times$ digestion buffer), synovium conditioned medium samples, positive control $(1 \mu \mathrm{g} / \mathrm{mL}$ chymotrypsin, dissolved in DMEM medium) or negative control (DMEM medium only) and pre-incubated for $1 \mathrm{~h}$ at room temperature. 
Then, pre-incubated samples or controls were incubated at $37{ }^{\circ} \mathrm{C}$ with a fluorescently labeled casein solution, which was prepared in Tris-HCl buffer, in an end concentration of $5 \mu \mathrm{g}$ casein/ $\mathrm{mL}$. After $24 \mathrm{~h}$, fluorescence was determined in a Spectramax M2 microplate reader (Molecular Devices): excitation $=485 \mathrm{~nm}$, emission $=530 \mathrm{~nm}$.

\section{$2.8 \quad$ In Vivo Studies}

\subsubsection{Induction of Osteoarthritis In Vivo}

All animal experimental protocols were approved by the Maastricht University Animal Ethics Committee (DEC13-052). Eighty-six skeletally mature, 12 weeks old male Lewis rats (Charles River Laboratories) were allowed to acclimatize for 1 week before the initial start of the experiments. Animals were housed in groups of 2 and fed ad libitum. Osteoarthritis was surgically induced in the right knee of eighty-six rats according to a previously described method ${ }^{20}$. Rats were anesthetized in a chamber containing 3\% isoflurane (Isoflo, Abbott Laboratories, USA). The knee joint was shaved, cleaned and disinfected with iodine (Eurovet Animal Health, the Netherlands). The skin was incised with a longitudinal incision over the knee joint. A medial parapatellar approach was used. In short, the joint capsule was incised on the medial side of the patella, which provided access to the joint space. The patella was dislocated laterally and the anterior cruciate ligament (ACL) was transected using a surgical blade (size 11). Transection of the ligament was confirmed by a manually performed anterior drawer test. In addition, the anterior part of the medial meniscus was removed using a surgical scissor. The joint capsule and skin were closed with Vycril 4-0 suture. No wound infection was noticed after ACLT and PMMx surgery. The wound healed within 1 week and no difference in use of the operated and non-operated leg was observed. Animals were allowed to move freely in their cage and were checked daily for general health and experiment-related discomfort throughout the experiment.

\subsubsection{Intra-Articular Injections}

Four weeks after surgery, rats were randomly assigned to 3 experimental groups which consisted of intra-articular injections of $25 \mu \mathrm{L}$ in both the operated and non-operated 


\section{Chapter 6}

leg with $0.9 \% \mathrm{NaCl}$, non-loaded microspheres (15 mg particles $/ \mathrm{mL}$ ) or celecoxib-loaded microspheres (15 mg particles $/ \mathrm{mL}$, loaded with $3.9 \mathrm{wt} . \%$ celecoxib). One, three and twelve weeks after injection, rats were anesthetized with $1 \%$ isoflurane and sacrificed by cervical dislocation. Rats were divided in three analysis groups; 1 . analysis of in vivo celecoxib release by measuring $\mathrm{PGE}_{2}$ content in total rat knee homogenates $(n=7$ per experimental group), 2. analysis of PEA degradation by measuring PEA content in knee joints ( $n=6$ per experimental group), 3. analysis of biocompatibility and OA severity by scoring histological sections of rat knee joints semi-quantitatively and using the OARSI histopathology initiative for the rat ( $n=7$ per experimental group) (Figure 2). 


\section{Experimental Set-Up}

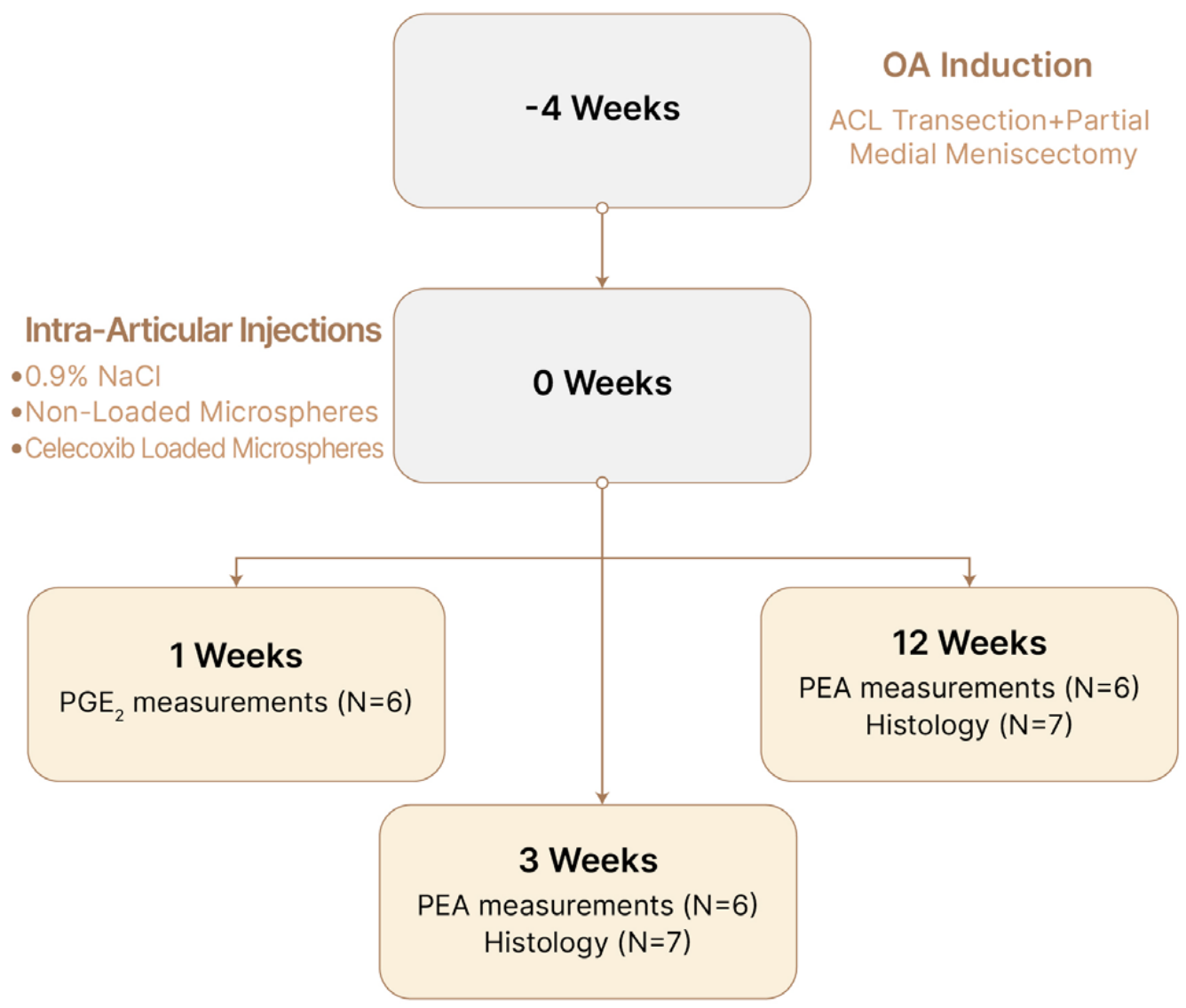

\section{Figure 2: Experimental set-up in vivo study.}

$O A$ was induced in the right knee of 12 weeks old Lewis rats by ACLT + pMMx surgery. After 4 weeks, OA-induced and contralateral healthy knees were injected with $0.9 \% \mathrm{NaCl}$ (control), nonloaded microspheres and celecoxib-loaded microspheres. One week after intra-articular injections rats where sacrificed for $P G E_{2}$ measurements. Directly, three and twelve weeks after intra-articular injections rats where sacrificed for PEA measurements and histology. 


\subsection{3 $\mathrm{PGE}_{2}$ Measurement in Knee Joints}

Rat knee joints were carefully resected and snap frozen in liquid nitrogen. Total rat knee joints were homogenized using a Mikro-Dismembrator, weighed and dissolved in $1 \mathrm{~mL}$ of $0.1 \mathrm{M}$ phosphate buffer, $\mathrm{pH} 7.4$, containing $1 \mathrm{mM}$ EDTA and $10 \mu \mathrm{M}$ indomethacin per 100 $\mathrm{mg}$ of tissue. Tissue homogenates were then spun down at 15,000 rpm for $10 \mathrm{~min}$ after which $50 \mu \mathrm{L}$ of the supernatant was used for PGE $_{2}$ measurements with an ELISA (Cayman Chemical) according to the manufacturer's instructions. PGE $_{2}$ content (in mg) was estimated from a calibration curve $\mathrm{PGE}_{2}$.

\subsubsection{PEA Measurement in Knee Joints}

To evaluate in vivo degradation of microspheres, rats were sacrificed directly, three or twelve weeks after intra-articular injections. Right and left knee joints were roughly cleared from muscle. Femur and tibia were cut on a $1.5 \mathrm{~cm}$ distance from the knee joint, while leaving the joint capsule intact. Knee joints were hydrolyzed by adding $8 \mathrm{~mL}$ of $6 \mathrm{~N}$ $\mathrm{HCl}$ and incubated at $90^{\circ} \mathrm{C}$ for $\pm 40 \mathrm{~h}$. Next, samples were subjected to analysis by liquid chromatography combined with mass spectrometry. PEA content (in $\mathrm{mg}$ ) was estimated from a calibration curve with PEA (DSM Biomedicals).

\subsubsection{Tissue Preparation and Histology}

Rat knee joints were carefully resected and fixed with 3.7\% paraformaldehyde in $0.1 \mathrm{M}$ phosphate buffered saline at $4{ }^{\circ} \mathrm{C}$ for 1 week. Next, tissues were decalcified in $0.5 \mathrm{M}$ EDTA solution ( $\mathrm{pH}$ 7.8) for 8 weeks. After confirmation of decalcification on X-ray, knee joints were cut in two equal halves along the medial collateral ligament in the frontal plane in order to directly get access to the central weight bearing region of the joint. The posterior halves of the knees were dehydrated by transferring it through solutions of increasing ethanol concentration until $100 \%$ ethanol was reached. After a final $24 \mathrm{~h}$ dehydration step in cold $100 \%$ acetone at $4{ }^{\circ} \mathrm{C}$, specimens were infiltrated with Technovit 8100 (Werheim, Germany) at $4{ }^{\circ} \mathrm{C}$ for 4 weeks. After this, specimens were placed into polyethylene-embedding molds. Polymerization solution, prepared according to the protocol of the manufacturer, 
was poured into the molds and air-contact was prevented by covering the cavities with plastic films. The embedding form was placed on a thin layer of ice and polymerization was allowed for $24 \mathrm{~h}$ at $4{ }^{\circ} \mathrm{C}$. After hardening was complete, specimens were blocked with Histobloc and Technovit 3040 (Werheim, Germany) and removed from the molds. Sections ( $5 \mu \mathrm{m}$ ) were cut from the blocks using a rotation microtome (Leica), stretched on distilled water and mounted on uncoated glass slides at $80^{\circ} \mathrm{C}$. Slides were subjected to Thionin staining for routine histological examination by light microscopy (Axioscope A1, Axiovision LE release 4.8.2, Carl Zeiss, Germany).

\subsubsection{Biocompatibility Scoring}

Synovium and tissue around microspheres in histological sections were evaluated semiquantitatively for the presence of giant cells, macrophages and fibroblast like cells at three and twelve weeks after intra-articular injections by an experienced animal pathologist microscopically (Nikon digital camera DMX1200 and ACT-1 v2.63 software, Nikon Instruments Europe, Amstelveen, The Netherlands).

\subsubsection{OA Scoring}

Thionin stained sections were scored according to the OARSI histopathology initiative for the rat ${ }^{20}$. The OARSI score evaluates the medial tibial plateau of a knee joint, because this is the region with the most prominent OA features in the ACLT + pMMx model ${ }^{20}$. Measurements of parameters needed for the OARSI score were made using the Axiovision software.

\subsubsection{Data Analyses and Statistics}

Protease activity in synovial fluid or synovium conditioned medium samples with or without a specific serine protease inhibitor AEBSF was compared using a paired one tailed $t$-test. $\mathrm{PGE}_{2}$ content in total rat knee homogenates between knees injected with celecoxibloaded or non-loaded microspheres was compared using an unpaired one tailed $t$-test. Semi-quantitative scores on histological sections intra-articular injected with non-loaded 
or celecoxib-loaded microspheres were compared using a chi-squared test. PEA content in intra-articular injected $\mathrm{OA}$ and healthy knees at different time points were compared using a Kruskal-Wallis test, followed by a post hoc analysis. Differences between healthy and OA knees in knees injected with non-loaded or loaded microspheres were evaluated using a Wilcoxon's matched pairs signed rank test. Statistical differences in histology scores in OA-induced knees at 3 and 12 weeks after intra-articular injections were analyzed using a Kruskal-Wallis test.

\section{Results}

\subsection{Release of a Small Molecule from PEA is Inflammation Responsive In Vitro}

An effective tool to study the potential inflammation-responsive drug release from PEA in vitro, is the HI-60 neutrophil like cell line, which is a commonly used model to study neutrophil functions and inflammatory cell responses ${ }^{21}$. The hypothesis for an inflammation responsive release rate of a small molecule from PEA was challenged by loading the polymer with fluorescein and evaluating the fluorescein release rate after exposure of the fluorescein-loaded PEA to HI-60 cell lysates in vitro.

Following an initial burst release, release of fluorescein in PBS buffer was low and followed zero order release kinetics (Figure 3). After zero order release kinetics was reached, a HI-60 cell lysate was added to the fluorescein loaded polymer. As shown in Figure 3, this resulted in increased release of fluorescein. Subsequent addition of a serine protease inhibitor, 4-(2-aminoethyl) benzene sulfonyl fluoride hydrochloride (AEBSF), to the cell lysate reduced the fluorescein release rate to release rates seen in PBS buffer. In conclusion, release of a small molecule from PEA was responsive to inflammation-related serine protease derived PEA degradation. 


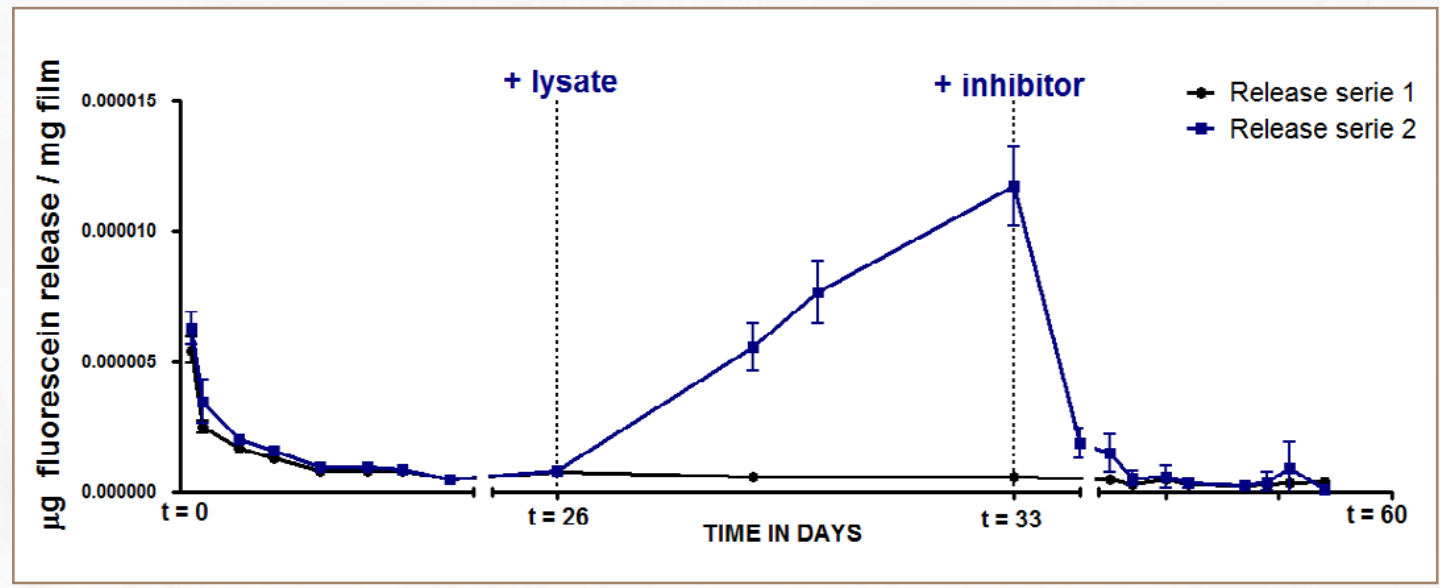

Figure 3: Inflammation responsive release of a small molecule from PEA.

PEA was loaded with fluorescein and incubated in PBS buffer for 60 days (release series 1). Alternatively, fluorescein loaded PEA was incubated in PBS buffer, a HI-60 neutrophil like cell lysate was added after 26 days and a HI-60 neutrophil like cell lysate + a serine protease inhibitor AEBSF $(0.5 \mathrm{mM})$ after 33 days. Finally, lysate without inhibitor was added after 47 days (release series 2). Absorbance was measured spectrophotometrically at $490 \mathrm{~nm}$. Data are mean $\pm S D, N=3$ per time point.

\subsection{Serine Proteases are Present Intra-Articular and Produced by Osteoarthritic Synovial Tissue In Vitro}

After confirming inflammation-responsive release of a small molecule from PEA by serine proteases, we next evaluated serine protease activity in synovial fluid and synovium conditioned medium of OA patients. Synovial fluid or synovium conditioned media contained proteolytic activity and a specific serine protease inhibitor AEBSF was able to significantly reduce proteolytic activity in synovial fluid and synovium conditioned medium, indicating that at least a part of the proteolytic activity detected is serine protease driven (Figure 4). 


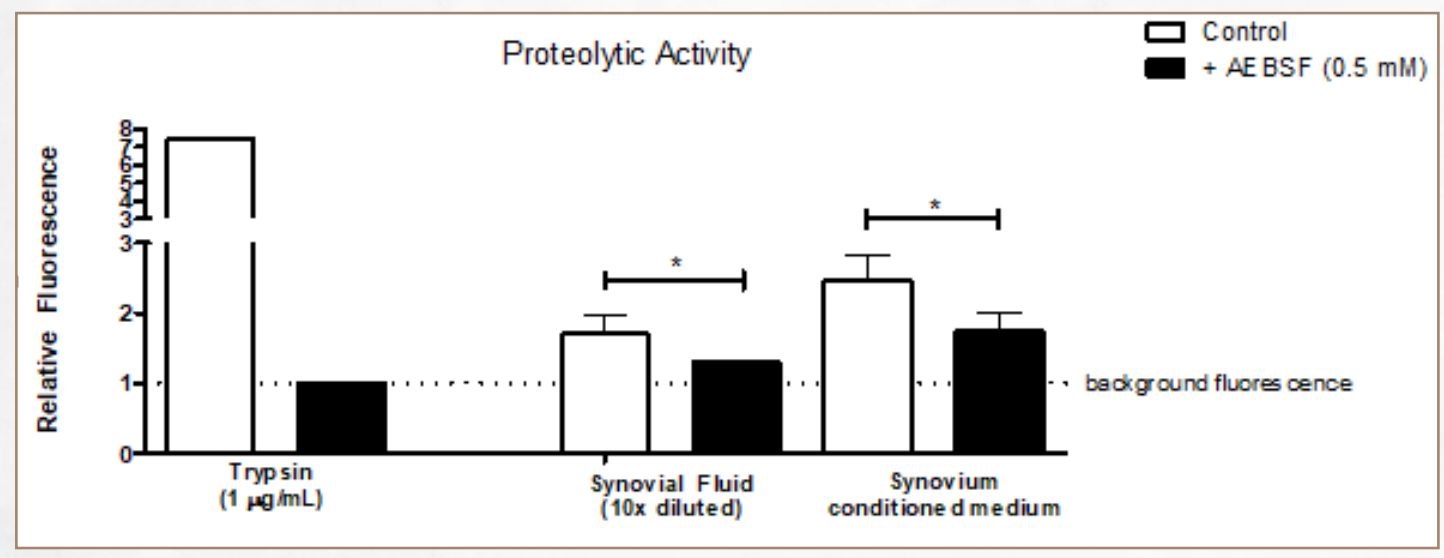

Figure 4: Serine protease activity in synovial fluid and synovial tissue from OA patients.

Synovial fluid (ten times diluted) or synovium conditioned media were incubated with a fluorescein labeled casein and fluorescence was measured $24 \mathrm{~h}$ after incubation. Trypsin $(1 \mu \mathrm{g} / \mathrm{mL})$ was used as a positive control.

\subsection{Celecoxib is Released from PEA Microspheres In Vitro and Bioactive In Vivo}

Celecoxib-loaded PEA microspheres were prepared and SEM analysis showed spherical structures (Figure 5A). Particle size was found to be 10-100 $\mu \mathrm{m}$ (Figure 5B). 
A

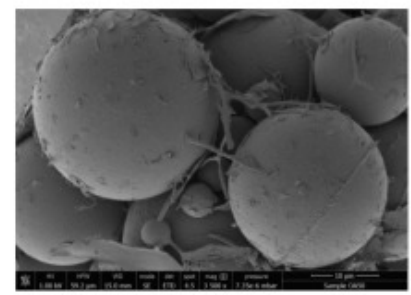

C

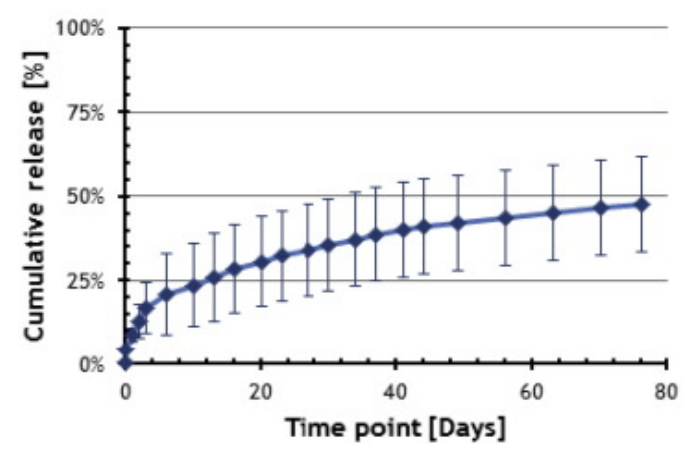

B

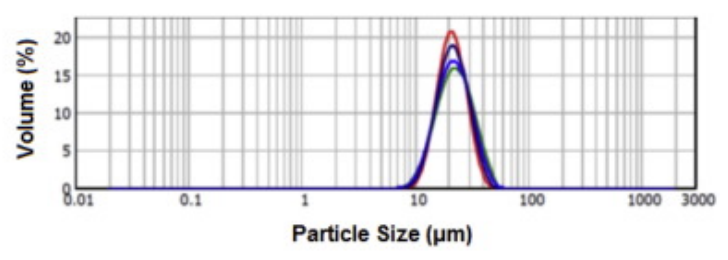

D

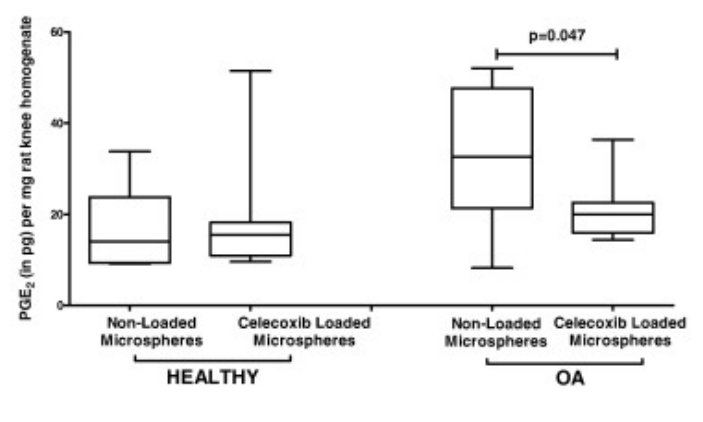

Figure 5: Celecoxib from celecoxib-loaded PEA microspheres is released in vitro and bioactive in vivo.

Scanning electron microscope image of PEA microspheres (A) and size distribution of PEA microspheres (B). The concentration of celecoxib release in PBS medium as determined by HPLC throughout time. The release is expressed in percentage of theoretical celecoxib load (C). $P G E_{2}$ content (in pg per mg knee homogenate) in total OA rat knee homogenates 1 week after injections with non-loaded or celecoxib-loaded microspheres ( $n=7$ for non-loaded microspheres and $n=7$ for celecoxib-loaded microspheres) (D).

To investigate whether celecoxib-loaded PEA microspheres are able to slowly release celecoxib, in vitro release performance was determined throughout 80 days. Following a short initial burst release of $\sim 15 \%$ of total drug load in the first days, celecoxib was slowly released throughout time (Figure $5 \mathrm{C}$ ).

Celecoxib release and bioactivity in vivo were evaluated by measuring $\mathrm{PGE}_{2}$ content in healthy or OA-induced total rat knee homogenates, injected with non-loaded or celecoxib-loaded PEA microspheres. One week after injections with celecoxib-loaded PEA microspheres, $P G E_{2}$ content was significantly lower $(p=0.047)$ in OA knees injected 
with celecoxib-loaded microspheres compared to OA knees injected with non-loaded microspheres, indicating that celecoxib is released from PEA microspheres and bioactive in vivo (Figure $5 \mathrm{D}$ ).

\subsection{Entrapment of Microspheres within the Synovial Membrane and Biocompatibility}

Intra-articular biocompatibility of PEA microspheres was investigated by scoring histological sections of rat knees injected with non-loaded or celecoxib-loaded microspheres semiquantitatively.

Non-loaded and loaded microspheres were found in all OA and healthy knees 3 weeks after injections. The microspheres were found to be entrapped in the synovium and no necrosis or thickening of the synovium as a reaction to the injection of the microspheres was observed (Figure 6A). Microspheres were surrounded by mononuclear inflammatory cells and giant cells (Figure $6 \mathrm{~B}$ and C). Small microspheres $5 \mu \mathrm{m}$ in size where seen, but also bigger microspheres 15-20 $\mu \mathrm{m}$ in size. Twelve weeks after injection, microspheres were smaller in size and not found in all knees. Microspheres could be found in 2 OA-induced and 2 healthy knees injected with non-loaded microspheres and 3 OA-induced and 4 healthy knees injected with celecoxib-loaded microspheres. Semi-quantitative scoring of histological sections revealed a slight to moderate presence of giant cells, macrophages and fibroblast-like cells surrounding the microspheres in a greater part of the animals. No significant differences were observed in semi-quantitative scoring of histological sections between rats injected with loaded or non-loaded PEA microspheres (Table 2). 


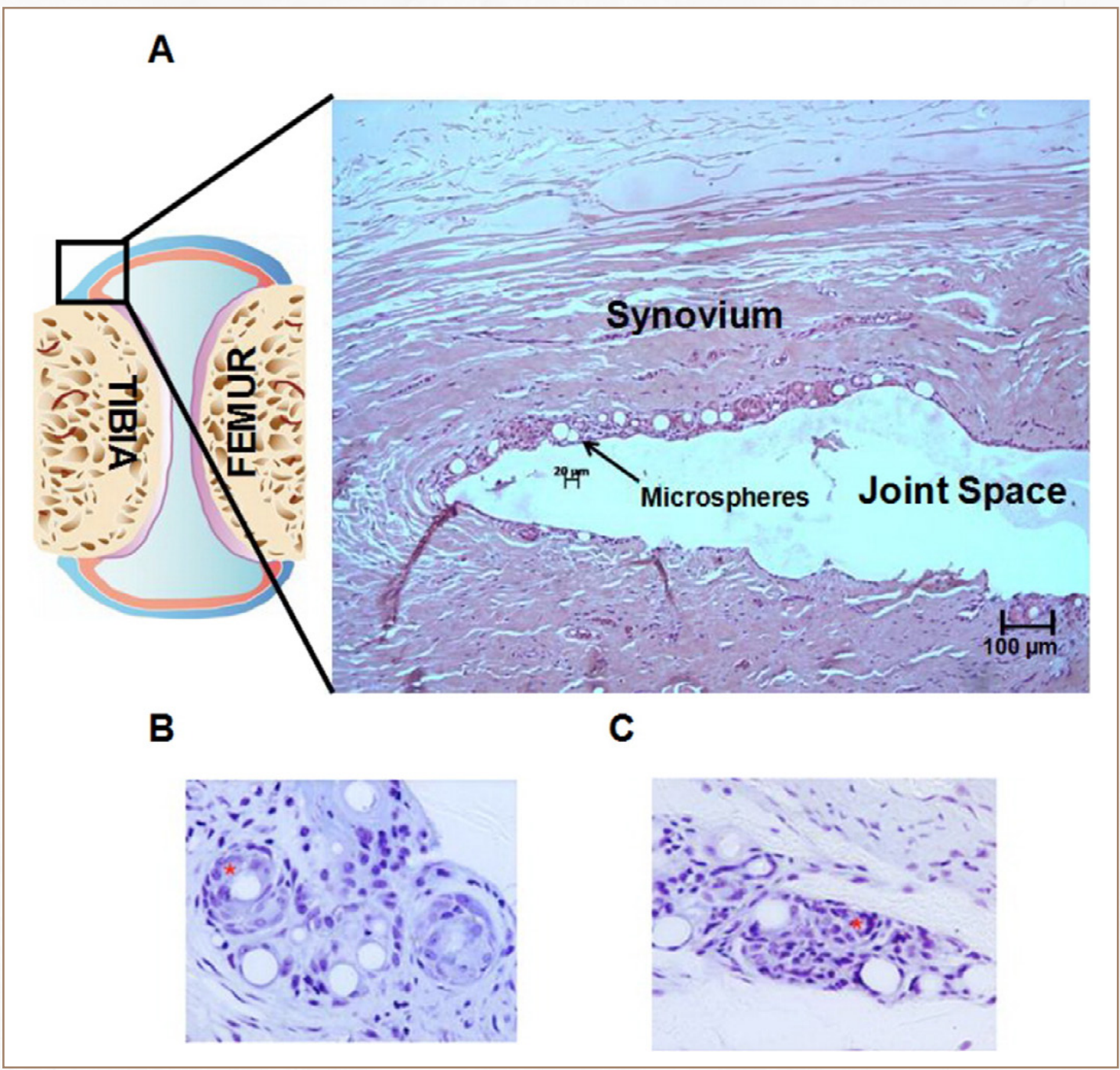

Figure 6: Entrapment of microspheres in the synovium.

Haematoxylin \& eosin stained section of healthy knee 3 weeks after injection with non-loaded microspheres (A). Thionin stained sections of OA-induced knees 3 weeks after injection non-loaded microspheres (40 $\times$ magnification) (B) or celecoxib-loaded microspheres (40 $\times$ magnification) (C). Red asterisks in (B) and (C) depict a giant cell. 


\section{Chapter 6}

Table 2. Semi-quantitative histological assessment of the amount of giant cells, macrophages or fibroblast like cells surrounding the microspheres. Numbers in table indicate amount of animals.

\begin{tabular}{|c|c|c|c|c|c|c|}
\hline \multirow{2}{*}{$\begin{array}{l}\text { THREE WEEKS } \\
\text { AFTER INTRA- } \\
\text { ARTICULAR } \\
\text { INJECTIONS }\end{array}$} & \multicolumn{2}{|c|}{$\begin{array}{c}\text { Giant cells } \\
\text { (number of animals) }\end{array}$} & \multicolumn{2}{|c|}{$\begin{array}{c}\text { Macrophages } \\
\text { (number of animals) }\end{array}$} & \multicolumn{2}{|c|}{$\begin{array}{l}\text { Fibroblast like cells } \\
\text { (number of animals) }\end{array}$} \\
\hline & 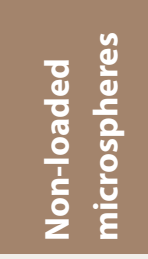 & 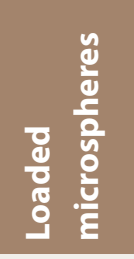 & 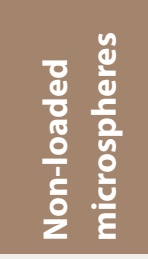 & 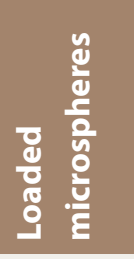 & 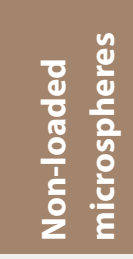 & 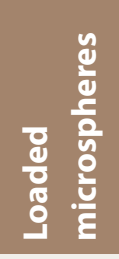 \\
\hline \multicolumn{7}{|c|}{ OA KNEES } \\
\hline Absent & 0 & 0 & 0 & 2 & 1 & 1 \\
\hline Slightly present & 3 & 3 & 2 & 1 & 4 & 4 \\
\hline Moderately present & 3 & 2 & 3 & 3 & 1 & 1 \\
\hline $\begin{array}{l}\text { Very abundantly } \\
\text { present }\end{array}$ & 0 & 1 & 1 & 0 & 0 & 0 \\
\hline \multicolumn{7}{|c|}{ HEALTHY KNEES } \\
\hline Absent & 0 & 0 & 0 & 1 & 4 & 6 \\
\hline Slightly present & 1 & 2 & 2 & 0 & 1 & 0 \\
\hline Moderately present & 4 & 3 & 2 & 4 & 0 & 0 \\
\hline $\begin{array}{l}\text { Very abundantly } \\
\text { present }\end{array}$ & 0 & 1 & 1 & 1 & 0 & 0 \\
\hline
\end{tabular}




\begin{tabular}{|c|c|c|c|c|c|c|}
\hline \multirow{2}{*}{$\begin{array}{l}\text { TWELVE WEEKS } \\
\text { AFTER INTRA- } \\
\text { ARTICULAR } \\
\text { INJECTIONS }\end{array}$} & \multicolumn{2}{|c|}{$\begin{array}{c}\text { Giant cells } \\
\text { (number of animals) }\end{array}$} & \multicolumn{2}{|c|}{$\begin{array}{c}\text { Macrophages } \\
\text { (number of animals) }\end{array}$} & \multicolumn{2}{|c|}{$\begin{array}{l}\text { Fibroblast like cells } \\
\text { (number of animals) }\end{array}$} \\
\hline & 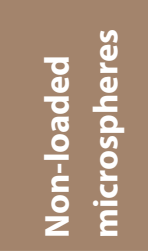 & 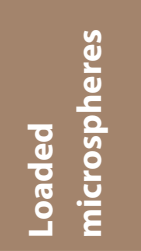 & 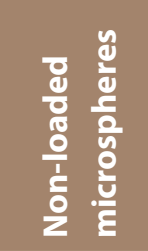 & 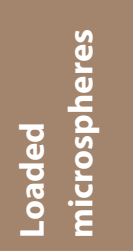 & 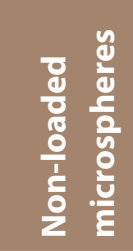 & 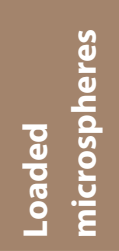 \\
\hline \multicolumn{7}{|c|}{ OA KNEES } \\
\hline Absent & 0 & 2 & 0 & 0 & 0 & 1 \\
\hline Slightly present & 0 & 1 & 1 & 0 & 1 & 1 \\
\hline Moderately present & 1 & 0 & 1 & 3 & 1 & 1 \\
\hline $\begin{array}{l}\text { Very abundantly } \\
\text { present }\end{array}$ & 1 & 0 & 0 & 0 & 0 & 0 \\
\hline \multicolumn{7}{|c|}{ HEALTHY KNEES } \\
\hline Absent & 0 & 0 & 0 & 1 & 1 & 2 \\
\hline Slightly present & 2 & 3 & 2 & 1 & 1 & 2 \\
\hline Moderately present & 0 & 1 & 0 & 2 & 0 & 0 \\
\hline $\begin{array}{l}\text { Very abundantly } \\
\text { present }\end{array}$ & 0 & 0 & 0 & 0 & 0 & 0 \\
\hline
\end{tabular}




\subsection{PEA Microspheres Degrade In Vivo and Show Auto-Regulatory Degrading Behavior}

To evaluate in vivo degradation of the microspheres, the amount of PEA was measured directly, three or twelve weeks after intra-articular injections with PEA microspheres.PEA content was not significantly different between healthy or OA-induced knees directly after injections with microspheres. Three weeks after intra-articular injections, PEA content was significantly reduced in OA-induced knees injected with both non-loaded and loaded microspheres by $34 \%$ and $31 \%$ respectively while PEA content in healthy knees injected with non-loaded and loaded microspheres was reduced by $7 \%$ and $9 \%$ respectively, not reaching statistical significance (Figure 7A).

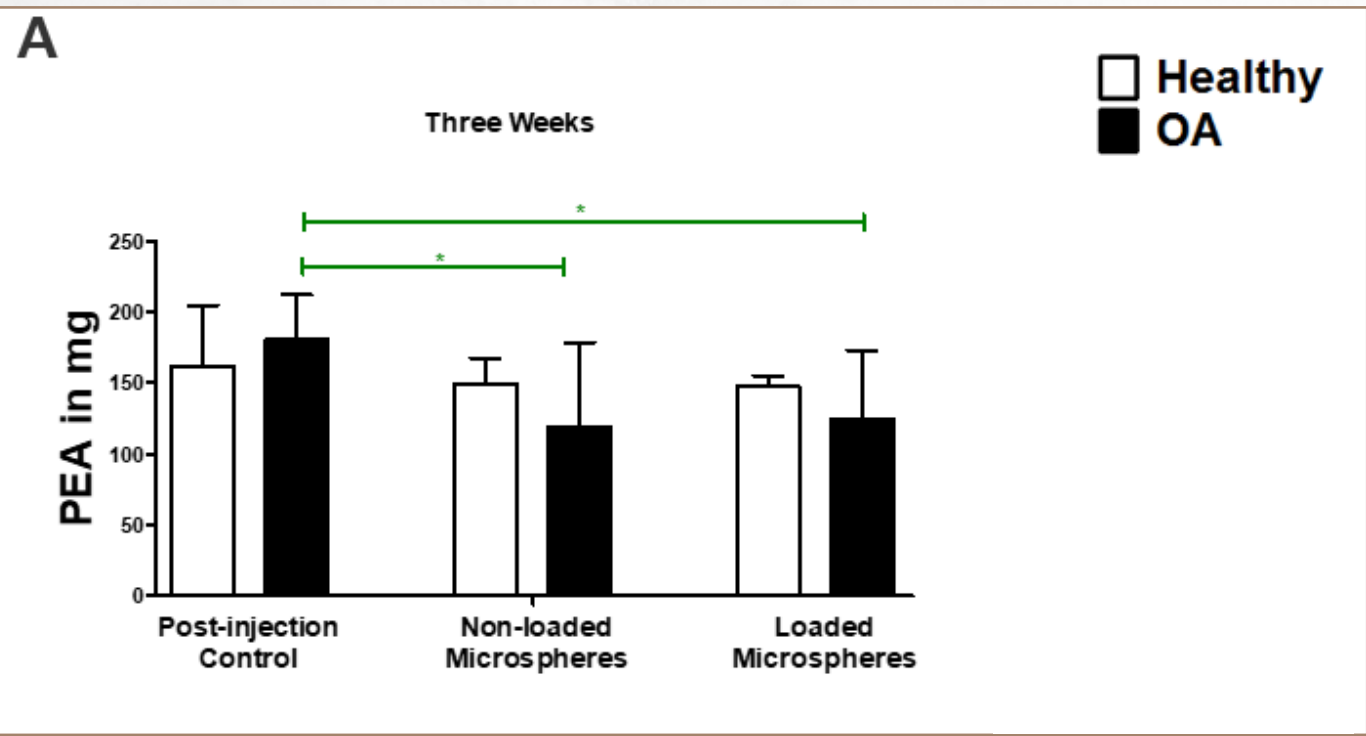




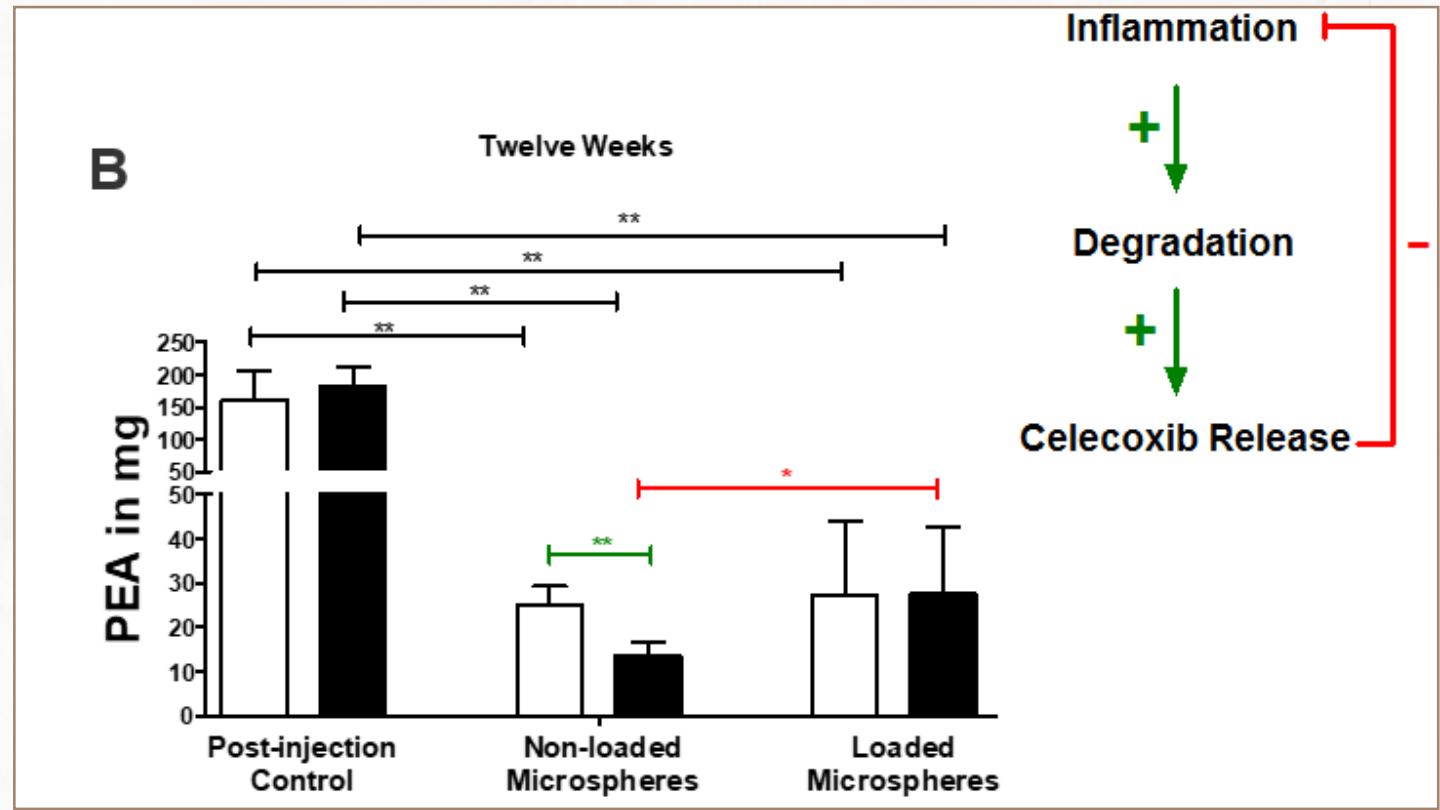

Figure 7: In vivo degradation of PEA microspheres and auto regulatory behavior of celecoxib-loaded PEA microspheres.

$P E A$ levels in knees measured directly after injection (post-injection control), three weeks and twelve weeks after injection. Data are mean $\pm S E M, N=6 .{ }^{*} P<0.05,{ }^{*} P<0.005$. Because no degradation is to be expected directly post injection, we injected celecoxib-loaded microspheres as controls at this time point (post-injection control).

Twelve weeks after intra-articular injections, healthy and OA-induced knees injected with both non-loaded and loaded microspheres showed significantly reduced PEA-levels ( $>$ $80 \%$ ), indicating that in vivo degradation of the microspheres occurred (Figure $7 \mathrm{~B}$ ).

Interestingly, PEA degradation was significantly higher in OA-induced knees injected with non-loaded microspheres, compared to healthy knees injected with non-loaded microspheres (Figure 7B). On the other hand, no significant differences were observed in PEA levels in OA-induced and healthy knees injected with celecoxib-loaded microspheres. Moreover, loading PEA microspheres with celecoxib significantly inhibited PEA degradation in OA-induced knees (Figure 7B). 


\subsection{In Vivo Effects of Intra-Articular Injections with Celecoxib on Joint Pathology}

After confirming in vivo degradation of PEA microspheres, we next evaluated the effects of injections with celecoxib-loaded microspheres on joint pathology in OA-induced rat knees.

Whole-joint histology revealed healthy cartilage in healthy knees (Figure 8), while OAinduced knees displayed OA-like changes twelve weeks after intra-articular injections (sixteen weeks after OA-induction) (Figure 8). No significant difference was observed in the OARSI cartilage degeneration score (Figure 9) between rats injected with $0.9 \% \mathrm{NaCl}$, nonloaded microspheres and celecoxib-loaded microspheres.

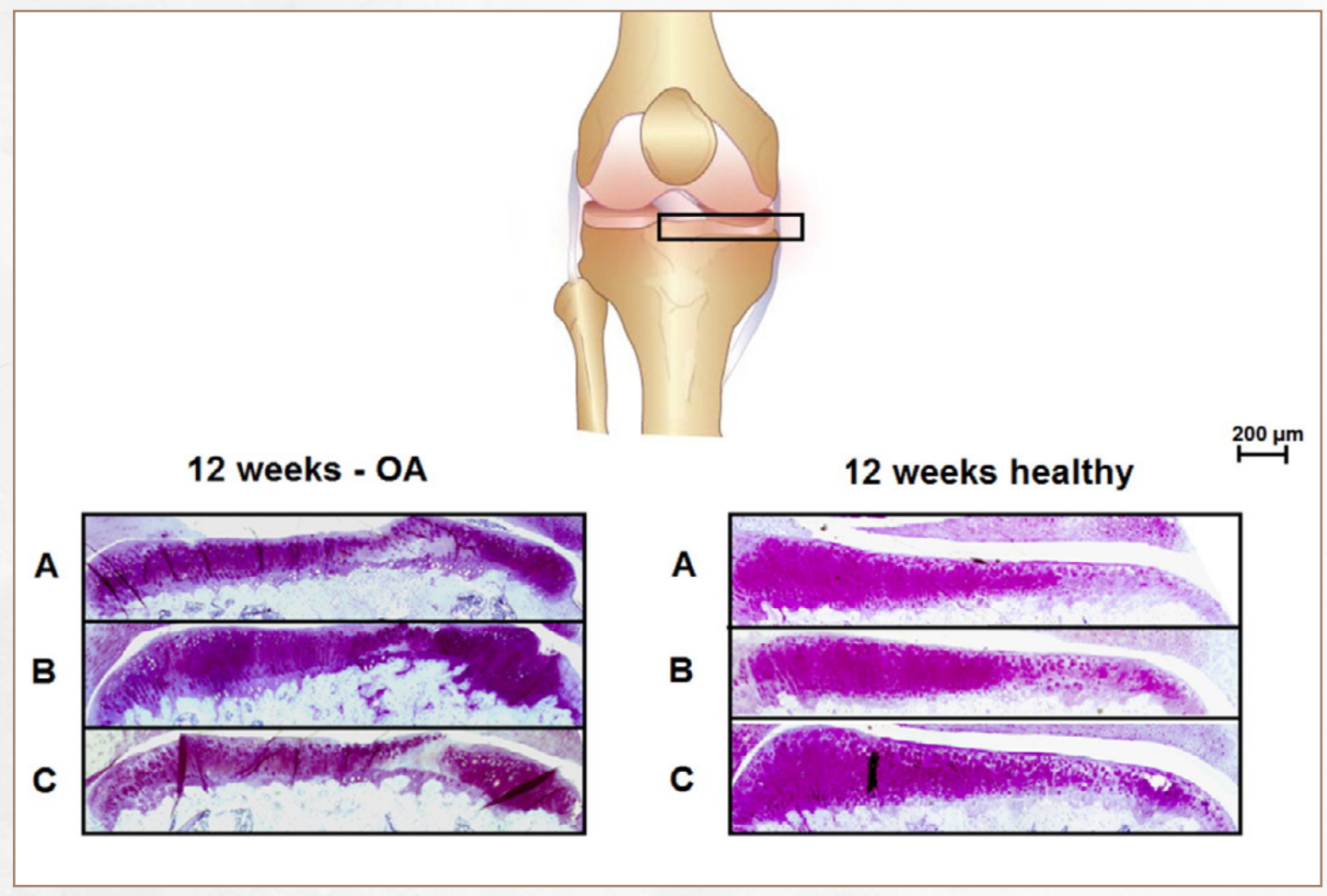

Figure 8: Twelve weeks after intra-articular injections with microspheres in OA-induced or healthy knees.

Thionin stained Histological sections of the medial tibial plateau of $O A$ (left panel, 16 weeks after $O A$ induction) or healthy knees (right panel) 12 weeks after injections with $0.9 \% \mathrm{NaCl}(A)$, non-loaded microspheres (B) and celecoxib-loaded microspheres (C). OA severity was comparable between all groups and injections with microspheres did not result in cartilage damage. 


\section{Cartilage Degeneration Score}

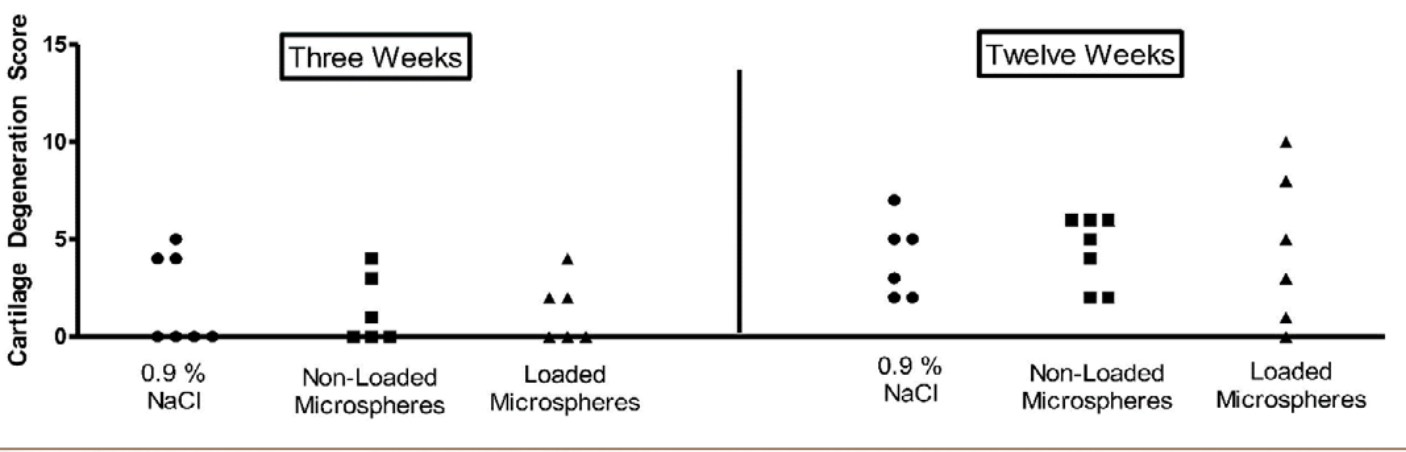

Figure 9: Effects of intra-articular injections with celecoxib on cartilage pathology in OAinduced rat knees.

Thionin stained histological sections of the medial tibial plateau of right rat knees were scored for cartilage degeneration score at 3 and 12 weeks after intra-articular injection with 0.9\% $\mathrm{NaCl}$, non-loaded microspheres or celecoxib-loaded microspheres. No significant differences were seen between groups. Each dot, square or triangle represents a separate animal. $N=7$ for control, $N=6$ for non-loaded microspheres, $N=6$ for loaded microspheres at week 3 and $N=6$ for control, $N=7$ for non-loaded microspheres, $N=6$ for loaded microspheres at week 12.

\section{Discussion}

In this study we have investigated the potential to use PEA as a biomaterial for an auto regulatory intra articular drug delivery system. First, inflammation-responsive release of a small molecule was confirmed in vitro. Next, PEA microspheres were loaded with an antiinflammatory drug celecoxib and investigated in vivo.

Release of a small molecule fluorescein from PEA was increased after exposure to lysates from the neutrophilic cell line $\mathrm{HI}-60$ and addition of a specific serine protease inhibitor reduced fluorescein release. This result indicates release of fluorescein from PEA after inflammation-related enzymatic degradation. Since serine proteases are key components of the inflammatory response ${ }^{12}$, these findings highlight the potential of PEA drug delivery systems to be used in drug delivery systems for the treatment of diseases with an 
inflammatory component such as osteoarthritis, in which drug release will be reactive to the disease process.

After conforming the inflammation responsive properties of PEA, biocompatibility of PEA microspheres was investigated in vivo. Intra-articular injection of microspheres was well tolerated: no abnormal behavior was observed in rats and also no infections occurred. All rats gained in weight equally (data not shown) and no death was observed. Three weeks after intra-articular injections, microspheres were found back in the knees of all rats injected with microspheres. The microspheres were entrapped in the synovium surrounded by giant cells, mononuclear inflammatory cells and fibroblast like cells. Entrapment of microspheres in the synovium has been shown earlier in rat and rabbit knees ${ }^{22,23}$. The synovial membrane displays ability to remove foreign particles, which is the most likely explanation for this phenomenon we observed ${ }^{24}$. Macrophages have been shown to take up particles in the micrometer size range ${ }^{25}$ : in our study we did not observe endocytosis of our microspheres. We did not see any necrosis or thickening of the synovium as a reaction to the injection of the microspheres, confirming biocompatibility of PEA microspheres. In short, we conclude a normal and mild foreign body response.

The fact that we found fewer microspheres twelve weeks after injections with PEA microspheres compared to three weeks after injections indicated in vivo degradation of the polymer, but we also evaluated degradation quantitatively by measuring PEA levels in total rat knee joints. PEA microspheres degraded in vivo and PEA levels were reduced to $20 \%$ twelve weeks after intra-articular injections. As OA is considered to have an inflammatory component, our hypothesis was that there would be more degradation of microspheres in an OA-induced knee. Consistent with this hypothesis, PEA degradation was significantly increased in an OA-induced knee compared to a healthy knee. Interestingly, loading the microspheres with celecoxib significantly reduced degradation as PEA levels were significantly higher in OA-induced knees injected with celecoxib-loaded microspheres compared to OA-induced knees injected with non-loaded microspheres. These in vivo data are in accordance with our in vitro data indicating that inflammatory cells are able to enzymatically degrade PEA microspheres, and that celecoxib is able to inhibit this process, 
highlighting the potential of celecoxib-loaded microspheres to use as a controlled DDS with an auto regulatory behavior.

Different carriers such as microspheres, liposomes and hydrogels have been investigated in intra-articular treatment with use of synthetic and natural polymers $26,27,28,29,30,31,32,33,34,35,36,37$. While most studies report intra-articular biocompatibility of the DDS investigated, information about degradation behavior of the DDS investigated in vivo is lacking. Bedouet et al. investigated PEG-hydrogel based microspheres and observed slow degradation over 60 days in vitro, but did not investigate degradation behavior in vivo ${ }^{22}$. In another study performed by Sandker et al., an acyl-capped PCLA-PEG-PCLA polymer based hydrogel depot was investigated ${ }^{38}$. Fast degradation of the hydrogel after intra-articular injection occurred and the depot could not be detected after 3 weeks. Arankumar et al. show intra-articular retention of PCL microparticles for 6 weeks, by using in vivo fluorescence imaging ${ }^{39}$. We here show retention of PEA microspheres for at least 12 weeks after intra-articular injection and in addition show an auto regulatory degradation behavior of PEA microspheres: an intra-articular DDS degradation mechanism not earlier described. This auto regulatory degradation behavior is beneficial from 2 points of view. Firstly, degradation and thus drug release will follow disease activity. Secondly, the microspheres potentially reside in the joint for a longer period of time and thus fewer injections will be needed.

Our PEA degradation data in vivo indicate slow and bioactive release of celecoxib over a period of 12 weeks. Bioactivity of celecoxib from PEA microspheres in vivo was also proven by performing $\mathrm{PGE}_{2}$ measurements in total rat knee homogenates. Rat knees injected with celecoxib-loaded PEA microspheres contained significantly lower $\mathrm{PGE}_{2}$ levels compared to rat knees injected with non-loaded PEA microspheres.

Based on in vitro release rates and average synovial fluid volume of a rat, in vivo celecoxib concentrations in the knee joint were calculated to be $10 \mu \mathrm{M}$, the concentration celecoxib in which efficient anti-inflammatory effects are shown in various intra-articular tissues ${ }^{40}$. However, extrapolation of release rates from in vitro to in vivo is complicated. In addition to diffusion derived release, degradation derived release is another important component influencing drug release in vivo. 


\section{Chapter 6}

Moreover drug release in vivo is influenced by the highly viscous synovial fluid ${ }^{41}$. Due to the small synovial fluid volumes in a rat knee, we were unable to investigate local celecoxib concentration in the synovial fluid. To determine celecoxib release in vivo and evaluate systemic celecoxib concentrations, we performed a celecoxib-specific ELISA on plasma samples of rats which received non-loaded and celecoxib-loaded PEA microspheres three, six, nine and twelve weeks after injections. The detection limit of this ELISA is $\sim 0.25 \mathrm{ng} / \mathrm{mL}$ and 10 out of 42 tested plasma samples of rats injected with loaded microspheres were just above detection limit versus 3 out of 42 tested plasma samples of rats injected with nonloaded microspheres. While we can only speculate about absolute celecoxib concentrations in plasma, these data indicate low systemic concentrations of celecoxib in vivo $(<0.5 \mathrm{ng} /$ $\mathrm{mL}$ ), which will result in reduced risk of systemic side effects. Radioactively labeling drugs such as celecoxib and examining release behavior in vivo may provide valuable data to predict release behavior of drugs loaded in a DDS in future experiments.

Because several studies have shown chondroprotective effects of celecoxib in vivo, we also evaluated the effects of intra-articular injections with celecoxib-loaded microspheres on $\mathrm{OA}$ progression ${ }^{42,43,44}$. Intra-articular injections with celecoxib-loaded microspheres did not result in reduced OA pathology as evaluated by histological analysis in cartilage, consistent with two other studies showing chondroneutral effects of celecoxib in vivo $^{32,45}$. Contradictory reports on OA modifying properties of celecoxib may be caused by differences in OA model used. Beneficial effects of celecoxib in OA models based on mechanical instability can be restrained by increased loading of the affected joint due to analgesic effects of celecoxib. Moreover, the amount of synovial inflammation is different in several OA models, and the effectiveness of an anti-inflammatory drug like celecoxib may be proportional to the amount of inflammation present. Although we investigated the amount of synovial inflammation in our OA model by scoring sub synovial proliferation and inflammatory cell infiltration on histological sections, synovitis at the time points we evaluated was too minimal even in untreated OA-induced knees, consistent with earlier reports ${ }^{46}$. Other models which display more inflammation ${ }^{47,48}$, may be useful to investigate the role of celecoxib on (synovial) inflammation. 


\section{Conclusion}

PEA microspheres displayed good intra-articular biocompatibility and degraded in an in vivo OA model. Degradation of PEA microspheres was significantly higher in an inflammatory environment, while loading the microspheres with celecoxib decreased PEA degradation suggesting a DDS with auto regulatory behavior. We propose the use of PEA microspheres loaded with an anti-inflammatory drug as an auto regulatory drug delivery system to evaluate analgesic and OA disease modifying effects of a broad range of drugs in knee OA.

\section{Acknowledgments}

This work was supported by the academic fund of Maastricht University Medical Center, Dutch Arthritis Foundation (LLP14) and Annadal Foundation of Maastricht University Medical Center. We gratefully acknowledge Dr. Marjolein Caron for the use of her illustrative images. 


\section{References}

1 Zhang Y, Jordan JM. Epidemiology of osteoarthritis. Clin Geriatr Med. 2010;26(3):355-69.

2 De Vecchis R, Baldi C, Di Biase G, Ariano C, Cioppa C, Giasi A, et al. Cardiovascular risk associated with celecoxib or etoricoxib: a meta-analysis of randomized controlled trials which adopted comparison with placebo or naproxen. Minerva Cardioangiol. 2014;62(6):437-48.

Mantry P, Shah A, Sundaram U. Celecoxib associated esophagitis: review of gastrointestinal side effects from cox-2 inhibitors. J Clin Gastroenterol. 2003;37(1):61-3.

4 Martel-Pelletier J. Pathophysiology of osteoarthritis. Osteoarthritis Cartilage. 2004;12 Suppl A:S31-3.

5 Janssen M, Mihov G, Welting T, Thies J, Emans P. Drugs and polymers for delivery systems in $\mathrm{OA}$ joints: clinical needs and opportunities. Polymers. 2014;6(3):799819.

6 Castaldo L CP, Maglio G, Palumbo R. Synthesis and preliminary characterization of polyesteramides containing enzymatically degradable amide bonds. Polym Bull. 1992;28:301-7.
7 Han S-I, Kim B-S, Kang S-W, Shirai H, Im SS. Cellular interactions and degradation of aliphatic poly (ester amide) s derived from glycine and/or 4-amino butyric acid. Biomaterials. 2003;24(20):3453-62.

Murase SK, Lv L-P, Kaltbeitzel A, Landfester K, del Valle LJ, Katsarava $\mathrm{R}$, et al. Amino acid-based poly (ester amide) nanofibers for tailored enzymatic degradation prepared by miniemulsionelectrospinning. RSC Advances. 2015;5(68):55006-14.

9 Botines E, Franco L, Puiggalí J. Thermal stability and degradation studies of alternating poly (ester amide) s derived from glycolic acid and $\omega$-amino acids. Journal of applied polymer science. 2006;102(6):5545-58.

10 Fan Y, Kobayashi M, Kise H. Synthesis and biodegradability of new polyesteramides containing peptide linkages. Polymer Journal. 2000;32(10):817-22.

11 Saotome Y, Miyazawa T, Endo T. Novel enzymatically degradable polymers comprising. ALPHA.-amino acid, 1, 2-ethanediol, and adipic acid. Chemistry Letters. 1991(1):21-4.

12 Sharony R, Yu P-J, Park J, Galloway AC, 
Mignatti P, Pintucci G. Protein targets of inflammatory serine proteases and cardiovascular disease. Journal of Inflammation. 2010;7(1):1.

13 Nakano S, Ikata T, Kinoshita I, Kanematsu J, Yasuoka S. Characteristics of the protease activity in synovial fluid from patients with rheumatoid arthritis and osteoarthritis. Clin Exp Rheumatol. 1999;17(2):161-70.

14 Williams GW, Hubbard RC, Yu SS, Zhao W, Geis GS. Comparison of once-daily and twice-daily administration of celecoxib for the treatment of osteoarthritis of the knee. Clin Ther. 2001;23(2):213-27.

15 Brophy JM. Celecoxib and cardiovascular risks. Expert Opin Drug Saf. 2005;4(6):1005-15.

16 Andrés-Guerrero V, Zong M, Ramsay E, Rojas B, Sarkhel S, Gallego B, et al. Novel biodegradable polyesteramide microspheres for controlled drug delivery in ophthalmology. Journal of Controlled Release. 2015;211:105-17.

17 Liu X, Costantini C, Bonnier H, Londero H, De Scheerder I. P535 Nitric oxide through biodegradable layer elective study for safety and efficacy (NOBLESSE)-first in man pilot trial. European Heart Journal. 2003;5(24):86.

18 Katsarava R, Beridze V, Arabuli N, Kharadze D, Chu C, Won C. Amino acid-based bioanalogous polymers. Synthesis, and study of regular poly (ester amide) $\mathrm{s}$ based on bis (a-amino acid) a, $\omega$-alkylene diesters, and aliphatic dicarboxylic acids. Journal of Polymer Science Part A: Polymer Chemistry. 1999;37(4):391-407.

19 Willems N, Mihov G, Grinwis G, van Dijk M, Schumann D, Bos C, et al. Safety of intradiscal injection and biocompatibility of polyester amide microspheres in a canine model predisposed to intervertebral disc degeneration. Journal of Biomedical Materials Research Part B: Applied Biomaterials. 2015.

20 Gerwin N, Bendele AM, Glasson S, Carlson CS. The OARSI histopathology initiative - recommendations for histological assessments of osteoarthritis in the rat. Osteoarthritis Cartilage. 2010;18 Suppl 3:S24-34.

21 Carrigan SO, Weppler AL, Issekutz AC, Stadnyk AW. Neutrophil differentiated HL-60 cells model Mac-1 (CD1 1b/CD18)independent neutrophil transepithelial migration. Immunology. 2005;115(1):10817.

22 Bedouet $\mathrm{L}$, Pascale F, Moine $\mathrm{L}$, Wassef M, Ghegediban SH, Nguyen $\mathrm{VN}$, et al. Intra-articular fate of degradable poly(ethyleneglycol)hydrogel microspheres as carriers for sustained drug delivery. Int J Pharm. 2013;456(2):536-44. 
23 Horisawa E, Kubota K, Tuboi I, Sato K, Yamamoto $\mathrm{H}$, Takeuchi $\mathrm{H}$, et al. Sizedependency of DL-lactide/glycolide copolymer particulates for intra-articular delivery system on phagocytosis in rat synovium. Pharm Res. 2002;19(2):132-9.

24 Iwanaga T, Shikichi M, Kitamura H, Yanase $\mathrm{H}$, Nozawa-Inoue K. Morphology and functional roles of synoviocytes in the joint. Arch Histol Cytol. 2000;63(1):17-31.

25 Tuovinen L, Ruhanen E, Kinnarinen T, Ronkko S, Pelkonen J, Urtti A, et al. Starch acetate microparticles for drug delivery into retinal pigment epithelium-in vitro study. J Control Release. 2004;98(3):40713.

26 Trif M, Guillen C, Vaughan DM, Telfer JM, Brewer JM, Roseanu A, et al. Liposomes as possible carriers for lactoferrin in the local treatment of inflammatory diseases. Exp Biol Med (Maywood). 2001;226(6):559-64.

27 Zhang Z, Huang G. Intra-articular lornoxicam loaded PLGA microspheres: enhanced therapeutic efficiency and decreased systemic toxicity in the treatment of osteoarthritis. Drug Deliv. 2012;19(5):255-63.

28 Tuncay M, Calis S, Kas HS, Ercan MT, Peksoy I, Hincal AA. In vitro and in vivo evaluation of diclofenac sodium loaded albumin microspheres. J Microencapsul. 2000;17(2):145-55.
29 Bozdag S, Calis S, Kas HS, Ercan MT, Peksoy I, Hincal AA. In vitro evaluation and intraarticular administration of biodegradable microspheres containing naproxen sodium. J Microencapsul. 2001;18(4):44356.

30 Fernandez-Carballido A, HerreroVanrell R, Molina-Martinez IT, Pastoriza P. Biodegradable ibuprofen-loaded PLGA microspheres for intraarticular administration. Effect of Labrafil addition on release in vitro. Int J Pharm. 2004;279(1-2):33-41.

31 Thakkar H, Sharma RK, Mishra AK, Chuttani K, Murthy RS. Celecoxib incorporated chitosan microspheres: in vitro and in vivo evaluation. J Drug Target. 2004;12(9-10):549-57.

32 Dong J, Jiang D, Wang Z, Wu G, Miao L, Huang L. Intra-articular delivery of liposomal celecoxib-hyaluronate combination for the treatment of osteoarthritis in rabbit model. Int J Pharm. 2013;441(1-2):285-90.

33 Butoescu N, Jordan O, Burdet $P$, Stadelmann P, Petri-Fink A, Hofmann $\mathrm{H}$, et al. Dexamethasone-containing biodegradable superparamagnetic microparticles for intra-articular administration: physicochemical and magnetic properties, in vitro and in vivo drug release. Eur J Pharm Biopharm. 2009;72(3):529-38. 
34 Elron-Gross I, Glucksam Y, Biton IE, Margalit R. A novel Diclofenac-carrier for local treatment of osteoarthritis applying live-animal MRI. J Control Release. 2009;135(1):65-70.

35 Petit A, Sandker M, Muller B, Meyboom $R$, van Midwoud $P$, Bruin $P$, et al. Release behavior and intra-articular biocompatibility of celecoxibloaded acetyl-capped PCLA-PEGPCLA thermogels. Biomaterials. 2014;35(27):7919-28.

36 Petit A, Redout EM, van de Lest $\mathrm{CH}$, de Grauw JC, Muller B, Meyboom R, et al. Sustained intra-articular release of celecoxib from in situ forming gels made of acetyl-capped PCLA-PEG-PCLA triblock copolymers in horses. Biomaterials. 2015;53:426-36.

37 Aydin O, Korkusuz F, Korkusuz P, Tezcaner A, Bilgic E, Yaprakci V, et al. In vitro and in vivo evaluation of doxycyclinechondroitin sulfate/PCLmicrospheres for intraarticular treatment of osteoarthritis. J Biomed Mater Res B Appl Biomater. 2015;103(6):1238-48.

38 Sandker MJ, Petit A, Redout EM, Siebelt M, Müller B, Bruin $P$, et al. In situ forming acyl-capped PCLA-PEG-PCLA triblock copolymer based hydrogels. Biomaterials. 2013;34(32):8002-11.

39 Arunkumar P, Indulekha S, Vijayalakshmi S,
Srivastava R. Synthesis, characterizations, in vitro and in vivo evaluation of Etoricoxib-loaded Poly (Caprolactone) microparticles - a potential Intra-articular drug delivery system for the treatment of Osteoarthritis. J Biomater Sci Polym Ed. 2016;27(4):303-16.

40 Timur U, Caron M, Bastiaansen-Jenniskens Y, Welting T, van Osch G, Emans P. PGE2 and PGF2 $a$ are secreted by the osteoarthritic infrapatellar fat pad and their release can be modulated by celecoxib. Osteoarthritis and Cartilage. 2016(24):S339.

41 Madsen CG, Skov A, Baldursdottir S, Rades T, Jorgensen L, Medlicott NJ. Simple measurements for prediction of drug release from polymer matrices-Solubility parameters and intrinsic viscosity. European Journal of Pharmaceutics and Biopharmaceutics. 2015;92:1-7.

42 Jiang D, Zou J, Huang L, Shi Q, Zhu X, Wang $G$, et al. Efficacy of intra-articular injection of celecoxib in a rabbit model of osteoarthritis. Int J Mol Sci. 2010;11(10):4106-13.

43 Ou Y, Tan C, An H, Jiang D, Quan Z, Tang K, et al. Selective COX-2 inhibitor ameliorates osteoarthritis by repressing apoptosis of chondrocyte. Med Sci Monit. 2012;18(6):BR247-52.

44 Anderson GD, Hauser SD, McGarity KL, 


\section{Chapter 6}

Bremer ME, Isakson PC, Gregory SA.

Selective inhibition of cyclooxygenase

(COX)-2 reverses inflammation and expression of COX-2 and interleukin 6 in rat adjuvant arthritis. J Clin Invest. 1996;97(11):2672-9.

45 Mastbergen SC, Marijnissen AC, Vianen ME, Zoer B, van Roermund PM, Bijlsma JW, et al. Inhibition of COX-2 by celecoxib in the canine groove model of osteoarthritis. Rheumatology (Oxford). 2006;45(4):405-

13.

46 Jukka Morko ZP, Jukka Vaaraniemi, Katja M Fagerlund, Jukka P Rissanen, Jenni Bernoulli and Jussi M Halleen Degenerative Changes in Knee Joints and Joint Pain in Surgically and Chemically Induced Rat Models of Osteoarthritis. ASBMR; Baltimore, Maryland, USA2013.

47 Adaes S, Mendonca M, Santos TN, CastroLopes JM, Ferreira-Gomes J, Neto FL. Intra-articular injection of collagenase in the knee of rats as an alternative model to study nociception associated with osteoarthritis. Arthritis Res Ther. 2014;16(1):R10.

48 Ross TN, Kisiday JD, Hess T, Mcllwraith CW. Evaluation of the inflammatory response in experimentally induced synovitis in the horse: a comparison of recombinant equine interleukin 1 beta and lipopolysaccharide. Osteoarthritis Cartilage. 2012;20(12):1583-90. 
Celecoxib-Loaded PEA Microspheres as an Auto Regulatory Drug-Delivery System after Intra-Articular Injection 

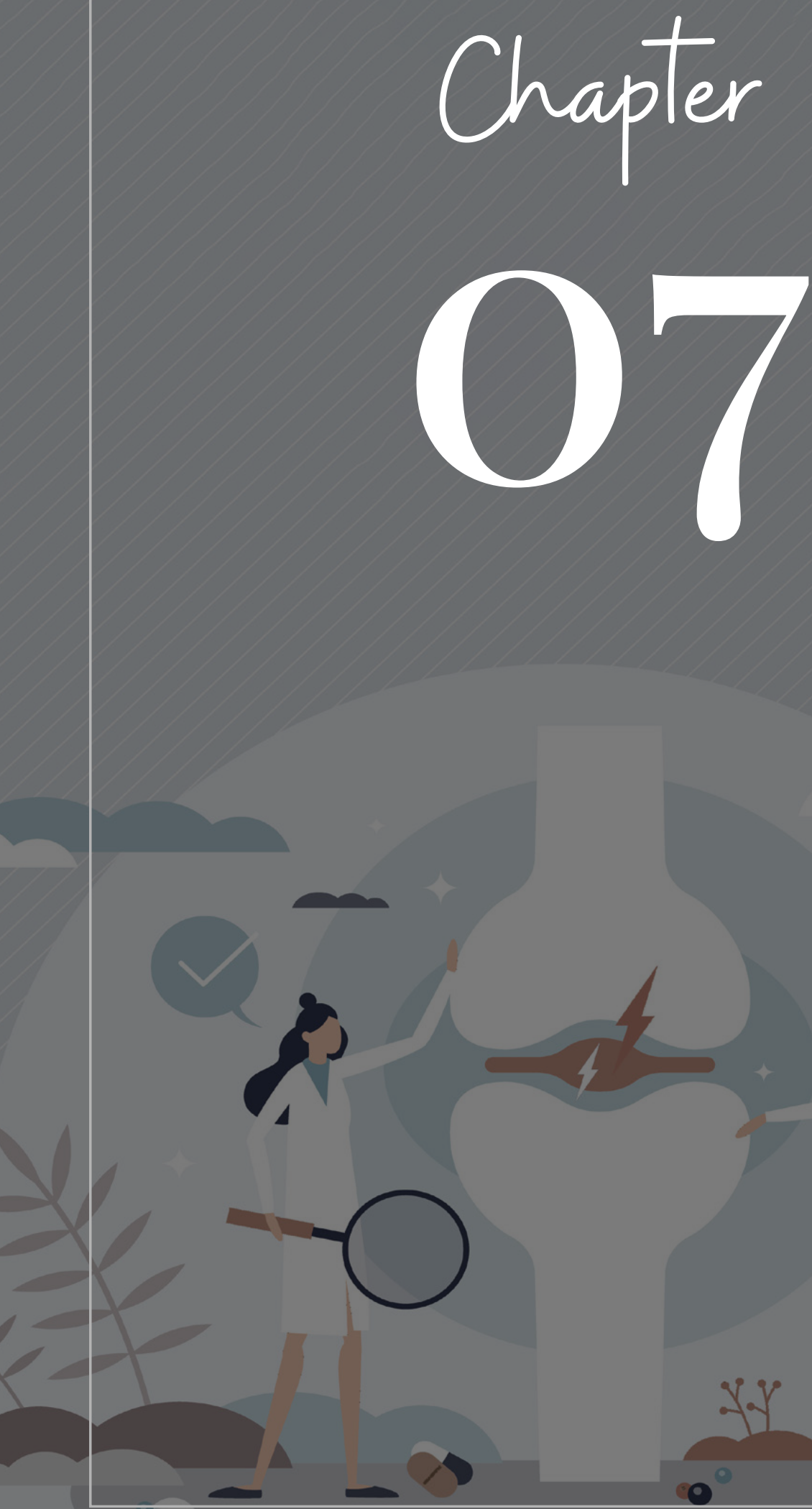


\section{Identification of Tissue Type-Dependent Proteins in Knee OA Synovial Fluid.}

Timur UT, Jahr H, Anderson J., Green D.C., Emans P.J., Smagul A., van Rhijn L.W., Peffers M.J., Welting T.J.M. Osteoarthritis Cartilage. 2020. 


\section{Abstract}

\section{Objective:}

For many proteins from osteoarthritic synovial fluid, their intra-articular tissue of origin remains unknown. In this study we performed comparative proteomics to identify osteoarthritis-specific and joint tissue-dependent secreted proteins that may serve as candidates for osteoarthritis biomarker development on a tissue-specific basis.

\section{Material \& Methods:}

Protein secretomes of cartilage, synovium, Hoffa's fat pad and meniscus from knee osteoarthritis patients were determined using liquid chromatography tandem mass spectrometry, followed by label-free quantification. Validation of tissue-dependent protein species was conducted by ELISA on independent samples. Differential proteomes of osteoarthritic and non-osteoarthritic knee synovial fluids were obtained via similar proteomics approach, followed by ELISA validation.

\section{Results:}

Proteomics revealed 64 proteins highly secreted from cartilage, 94 from synovium, 37 from Hoffa's fat pad and 21 from meniscus. Proteomic analyses of osteoarthritic vs nonosteoarthritic knee synovial fluid revealed 70 proteins with a relatively higher abundance and 264 proteins with a relatively lower abundance in osteoarthritic synovial fluid. Of the 70 higher abundance proteins, 23 were amongst the most highly expressed in the secretomes of a specific intra-articular tissue measured. Tissue-dependent release was validated for SLPI, C8, CLU, FN1, RARRES2, MATN3, MMP3 and TNC. Abundance in synovial fluid of tissuedependent proteins was validated for IGF2, AHSG, FN1, CFB, KNG and C8. 


\section{Conclusion:}

We identified proteins with a tissue-dependent release from intra-articular human knee OA tissues. A number of these proteins also had an osteoarthritis-specific abundance in knee synovial fluid. These proteins may serve as novel candidates for osteoarthritis biomarker development on a tissue-specific basis.

\section{Introduction}

Knee osteoarthritis $(\mathrm{OA})$ is an increasingly prevalent disabling condition with serious socioeconomic impact on a global scale ${ }^{1,2}$. Currently, no effective treatment exists to attenuate $\mathrm{OA}$ progression, and the current standard of care involves conservative painkilling drug therapies, physiotherapy and visco-supplementation of the affected joint. These therapies are all aimed at postponing total joint arthroplasty, which is an invasive surgical approach to alleviate the patient's OA-related pain and regain mobility when the condition reaches end-stage. Knee $\mathrm{OA}$ is currently diagnosed radiographically by significant joint space narrowing, osteophyte formation and subchondral bone lesioning ${ }^{3}$. However, these macroscopic changes are indicative of the disease progressing towards its end-stage, and often the patient presents with symptoms such as pain, joint stiffness and debilitating mobility limitations prior to diagnosis 4 .

The development of $\mathrm{OA}$ is multifactorial, comprising genetic, biomechanical, ageing, environmental, epigenetic, cellular, and metabolic factors contributing to the intraarticular disease process and ultimately leading to a final common pathway of articular cartilage degeneration ${ }^{4,5,6,7,8}$. Despite the fact that $\mathrm{OA}$ is recognized as a total-joint disease, intra-articular pathobiological processes occur in a tissue-specific manner ${ }^{5}$. Since the synovial fluid is in contact with many of the important intra-articular tissues, it represents a promising body fluid for developing OA biomolecular diagnostics to access the condition of the joint as whole, as well as with a potential for joint tissue-specific diagnostics ${ }^{9,10}$. 
In the search of diagnostic targets that are capable of identifying biomolecular changes in knee joint homeostasis, efforts have been made to understand the biomolecular composition of synovial fluid and to identify OA-related changes in its composition. Research has previously characterised OA-dependent proteomic, transcriptomic, metabolomic and lipidomic changes in the synovial fluid of the human knee joint ${ }^{10,11,12,13}$. From these studies it became evident that the knee joint synovial fluid composition undergoes a great number of detectable biomolecular changes specific for $\mathrm{OA}$, and depending on distinct OA subtypes, but also related to the severity of cartilage damage ${ }^{14,15,16,17}$. However, the origin of OA-driven alterations in the biomolecular composition of synovial fluid is poorly documented.

In this study, we aimed to delineate potential tissue-dependent proteins in the synovial fluid of knee OA patients. To this end, we performed a comparative proteomic analysis of the secretomes of Hoffa's fat pad, synovium, meniscus and articular cartilage of OA knees. Proteins with a tissue-dependent amount present in the secretomes were identified and the OA-specificity of their abundance was determined in knee synovial fluid. We expect that the identification of tissue-dependent and OA-related protein species from specific intra-articular tissues implicated in knee OA pathogenesis will fuel the development of novel synovial fluid-based diagnostic approaches aiming at grading and subtyping knee OA.

\section{Materials and Methods}

\subsection{OA Knee Tissue Secretomes}

Full thickness cartilage explants from medial and lateral femoral condyles, a synovial explant, an explant from Hoffa's fat pad (obtained from the core of the fat pad and avoiding synovial tissue adjacent to the fat pad) and explants from the medial and lateral menisci (avoiding synovial tissue present at the outer margins of the meniscus) were obtained as waste material following total knee arthroplasty for each of the four donors with end-stage knee OA (MEC approval 2017-0183) (Supplementary Table 1). These samples were designated 
as the dependent cohort. The same tissue explants were also collected from an additional 12 knee OA patients who underwent total knee arthroplasty and were designated as an independent cohort ( Supplementary Table 2). Tissue explants were rinsed thoroughly in $0.9 \% \mathrm{NaCl}$ and then pre-incubated at $37^{\circ} \mathrm{C}, 5 \% \mathrm{CO}_{2}$ for $24 \mathrm{~h}$ in a tissue/media ratio of $150 \mathrm{mg}$ tissue/ml medium (Dulbecco's Modified Eagle's Medium-F12 without phenol red (Thermofisher, Massachusetts, USA) supplemented with 1\% Glutamax (Thermofisher, Massachusetts, USA) and 1\% antibiotic/antimycotic (Invitrogen, Carlsbad, US)). After $24 \mathrm{~h}$ of pre-incubation, medium was fully refreshed at identical tissue/media ratio. Secretomes were then obtained following $48 \mathrm{~h}$ conditioning of these cultures. Secretomes were freshly processed by differential centrifugation (5 min at 1200 RPM, 10 min 15,000 RPM, room temperature). To inhibit proteolytic degradation of supernatants protease inhibitors were added (Complete Mini, EDTA-free Protease Inhibitor Cocktail, Sigma Aldrich, Saint Louis, USA). Secretomes samples were aliquoted and stored at $-80^{\circ} \mathrm{C}$ until further analysis.

\subsection{Synovial Fluid Collection and Processing}

Knee OA synovial fluid was used from three out of the four patients from the dependent cohort and 10 out of the 12 patients from the independent cohort (MEC approval 20170183) ( Supplementary Table 1 , patient 2, 3 and 4; Supplementary Table 2 , patient 6, 7, 8, 9 , $11,12,13,14,15$ and $16 . K \& L$ scores are indicated in these tables.). Knee OA synovial fluids were processed within half an hour of collection. Samples were processed by differential centrifugation (5 min at 1200 RPM, 10 min 15,000 RPM, room temperature). Non-OA knee synovial fluid from 10 individuals was purchased from Articular Engineering, Illinois, USA. Synovial fluid was collected directly from post mortem macroscopically normal joints and stored in aliquots at $-80^{\circ} \mathrm{C}$ until shipping. Details including race, age, sex and cause of death are included in Supplementary Table 3. To inhibit proteolytic degradation protease inhibitors were added (Complete Mini, EDTA-free Protease Inhibitor Cocktail, Sigma Aldrich, Saint Louis, USA). Synovial fluid samples were aliquoted and stored at $-80^{\circ} \mathrm{C}$ until further analysis. 


\subsection{Total Protein Content Measurements}

Total protein content was measured in samples using the Nano Orange Protein Quantification kit according to manufacturer's instructions (Invitrogen, Carlsbad, USA). Fluorescence was measured using a Tristar LB 942 (Berthold, Bald Wildbad, Germany) at $485 \mathrm{~nm}$ excitation and $590 \mathrm{~nm}$ emission.

\subsection{Sodium Dodecyl Sulphate-Polyacrylamide Gel Electrophoresis (SDS-PAGE) and Silver Staining}

Secretome samples (containing $1.25 \mu \mathrm{g}$ of total protein) of the dependent cohort were loaded on a $13 \%$ Sodium dodecyl sulphate-polyacrylamide gel electrophoresis (SDS-PAGE) gel (Protean II xi cell, Bio-Rad, Hercules, USA) and proteins were resolved by electrophoresis. The gel was silver stained to visualize protein bands (Pierce Silver Stain Kit, Thermofisher, Massachusetts, USA) according to the manufacturer's instructions.

\subsection{Enzyme-Linked Immune Sorbent Assay (ELISA) Validation}

Differential abundance of selected protein species in secretomes or synovial fluids was validated by ELISAs from various manufacturers (Supplementary Table 4). Measurements were performed according to the manufacturer's instructions.

\subsection{Liquid Chromatography Tandem Mass Spectrometry and Label-Free Quantification of Tissue Secretome Proteomes}

Proteolytic digestion was performed on $10 \mu \mathrm{g}$ protein of each individual sample using 10 $\mu \mathrm{l}$ Strataclean (Agilent, Genomics, UK). In-solution tryptic digestion of protein samples was carried out following sequential reduction and alkylation in $3 \mathrm{mM} \mathrm{DTT}\left(60^{\circ} \mathrm{C}\right.$ for $10 \mathrm{~min}$ ) and then $9 \mathrm{mM}$ iodoacetamide ( $30 \mathrm{~min}$ in the dark at room temperature) with trypsin at a ratio of 1:50 protein: trypsin ratio overnight at $37^{\circ} \mathrm{C}^{18}$. Samples were randomized for loading onto the instrument using Excel (Microsoft, USA). All samples were run in a single batch. $500 \mathrm{ng}$ of each tryptic digest was subjected to liquid chromatography tandem mass spectrometry (LC-MS/MS), using a $2 \mathrm{~h}$ gradient. Data-dependent analyses were conducted on a QExactive 
HF quadrupole-Orbitrap mass spectrometer coupled to a Dionex Ultimate 3000 RSLC nano-liquid chromatograph (Hemel Hempstead, UK). Sample digests were loaded onto a trapping column (Acclaim PepMap $100 \mathrm{C} 18,75 \mu \mathrm{m} \times 2 \mathrm{~cm}, 3 \mu \mathrm{m}$ packing material, $100 \AA$ ) using a loading buffer of $0.1 \%(\mathrm{v} / \mathrm{v})$ TFA, $2 \%(\mathrm{v} / \mathrm{v})$ acetonitrile in water for $7 \mathrm{~min}$ at a flow rate of $12 \mu \mathrm{L} \mathrm{min-1.The} \mathrm{trapping} \mathrm{column} \mathrm{was} \mathrm{then} \mathrm{set} \mathrm{in-line} \mathrm{with} \mathrm{an} \mathrm{analytical} \mathrm{column} \mathrm{(EASY-}$ Spray PepMap RSLC C18, $75 \mu \mathrm{m} \times 50 \mathrm{~cm}, 2 \mu \mathrm{m}$ packing material, $100 \AA$ ) and the peptides eluted using a linear gradient of $96.2 \% \mathrm{~A}(0.1 \%$ [v/v] formic acid):3.8 \% B (0.1\% [v/v [ formic acid in water/acetonitrile [80/20] [v/v]) to $50 \%$ A:50 \% B over 90 min at a flow rate of 300 $\mathrm{nL}$ min-1, followed by washing at 1\% A:99 \% B for 5 min and re-equilibration of the column to starting conditions. The column was maintained at $40^{\circ} \mathrm{C}$, and the effluent introduced directly into the integrated nano-electrospray ionisation source operating in positive ion mode. The mass spectrometer was operated in data dependent acquisition mode with survey scans between $\mathrm{m} / \mathrm{z350}-2000$ acquired at a mass resolution of 60,000 (FWHM) at $\mathrm{m}$ / $z$ 200. The maximum injection time was $100 \mathrm{~ms}$, and the automatic gain control was set to $3 \mathrm{e}^{6}$. The 12 most intense precursor ions with charges states of between $2+$ and $5+$ were selected for MS/MS with an isolation window of $2 \mathrm{~m} / \mathrm{z}$ units. The maximum injection time was $100 \mathrm{~ms}$, and the automatic gain control was set to $1 \mathrm{e}^{5}$. Fragmentation of the peptides was by higher-energy collisional dissociation using normalized collision energy of $30 \%$. Dynamic exclusion of mass/charge values to prevent repeated fragmentation of the same peptide was used with an exclusion time of $20 \mathrm{~s}$. For label-free quantification, the raw files of the acquired spectra were analyzed by the Progenesis QI software (Waters, Manchester, UK) ${ }^{19}$ which aligns the files and then peak picks for quantification by peptide abundance. Briefly, the top five spectra for each feature were exported from Progenesis QI and utilised for peptide identification with our local Mascot server (Version 2.6.2), searching against the Unihuman Reviewed database with carbamidomethyl cysteine as a fixed modification and methionine oxidation as a variable modification, peptide mass tolerance of $10 \mathrm{ppm}$ and fragment tolerance of $0.01 \mathrm{Da}$. 


\subsection{Liquid Chromatography Tandem Mass Spectrometry and Label-Free Quantification of Synovial Fluid Samples}

We utilized our previously optimised method for synovial fluid proteomics using Proteominer beads ${ }^{20}$. Briefly, individual synovial fluid samples were thawed and treated with $1 \mu \mathrm{g} / \mathrm{mL}$ hyaluronidase as previously described ${ }^{19}$ and centrifuged at $10000 \mathrm{~g}$ for 10 min to remove any particulates. Protein concentrations of synovial fluid were determined by Bradford assay (Thermofisher, Massachusetts, USA). A volume of sample equivalent to $5 \mathrm{mg}$ of protein was added to $10 \mu \mathrm{L}$ of ProteoMiner beads (BioRad, UK) according to the manufacturer's instructions. Beads were re-suspended in $80 \mu \mathrm{L}$ of $25 \mathrm{mM}$ ammonium bicarbonate and $5 \mu \mathrm{L}$ of $1 \%(\mathrm{w} / \mathrm{v})$ Rapigest SF (Waters, UK) added and the sample heated at $80^{\circ} \mathrm{C}$ for $10 \mathrm{~min}$. On bead trypsin digestion was undertaken ${ }^{19}$. Tryptic digests were subjected to LC-MS/MS, using a $2 \mathrm{~h}$ gradient using methods described above. Label-free quantification was undertaken using methods described above.

\subsection{Mass Spectrometry Proteomics Data}

The mass spectrometry proteomics data have been deposited to the ProteomeXchange Consortium via the PRIDE partner repository with the dataset identifier PXD014321 and 10.6019/PXD01432121.

\subsection{Statistical Analyses}

Statistical analysis was undertaken in Progenesis QI software (Waters, Manchester, UK). Proteins identified following label-free quantification were retained if they had at least two unique peptides. Protein abundances were logarithm (base 10) transformed and normalised relative to a selected reference sample.

To assess differences in normalised abundance in the dependent cohort between cartilage, Hoffa's fat pad, synovium and meniscus secretomes, we implemented repeated measures one-way analysis of variance (RM-ANOVA). For the RM-ANOVA, we specified our factor variable to be tissue and our within-subject dependent variable as the donors. No 
shrinkage methods were applied. Differentially expressed proteins between tissue-specific secretomes were defined as those with a false discovery rate (FDR) q value $<0.05$ and foldchange that exceeded 2 for any tissue ${ }^{22}$.

To assess differences in normalised protein abundance between the synovial fluid of $O A$ and non-OA donors, we implemented a one-way analysis of variance (ANOVA). The condition factor was set according to whether the protein originated from OA or non-OA synovial fluid. $O A$ and non-OA synovial fluid donors were independent donors. Differentially expressed proteins between $O A$ and non-OA synovial fluid were defined as those with an FDR q value $<0.05$ and a fold change that exceeded 2 between conditions ${ }^{22}$.

95\% confidence intervals for pairwise differences between means were generated for any statistically significant proteins as determined by the above criteria ( $R$, Version 4.0.1). The $95 \%$ confidence intervals were adjusted based on parameters of selection to allow for control of false coverage rate $(\mathrm{FCR})^{23,24}$.

Statistical analysis of tissue secretome Enzyme-linked immune sorbent assay (ELISA) data was performed using Graphpad Prism (version 7, La Jolla, California, USA). Data were logtransformed and protein abundances between cartilage, Hoffa's fat pad, synovium and meniscus were compared using a repeated measures ANOVA both for the dependent and the independent cohort. Multiple comparisons between tissues were performed using a Fisher's LSD test. Significance was accepted at a $P$ value $<0.05$. For the synovial fluid ELISA data, protein abundances in synovial fluid samples of $O A$ and non-OA donors were compared using a Mann-Whitney $U$ test. Significance was defined as a $P$-value of $<0.05$.

All principal component analysis calculations (PCA) were performed in R (Version 4.0.1). Log transformed normalised protein abundances were centered and scaled. For OA vs nonOA synovial fluid we used the prcomp function within the stats package to extract principal components ${ }^{25}$. For the multiple tissue secretomes dataset, due to the repeated measures design, we used the PCA function within the mixOmics package to generate a multilevel PCA plot that first calculates within subject variance prior to dimensionality reduction ${ }^{26}$. 


\section{Results}

\subsection{Preparation of OA Knee Tissue-Derived Secretomes}

Mean total protein concentration of cartilage secretomes samples was $233.4 \mu \mathrm{g} / \mathrm{mL}$ (range $191-285 \mu \mathrm{g} / \mathrm{mL}$ ), of Hoffa's fat pad secretomes $298.7 \mu \mathrm{g} / \mathrm{mL}$ (range 203-444 $\mu \mathrm{g} / \mathrm{mL}$ ), of synovium secretomes $326.5 \mu \mathrm{g} / \mathrm{mL}$ (range $253-404 \mu \mathrm{g} / \mathrm{mL}$ ) and of meniscus secretomes samples $275.0 \mu \mathrm{g} / \mathrm{mL}$ (range 167-362) $\mu \mathrm{g} / \mathrm{mL}$. To evaluate sample quality and potential gross differences in protein profiles in the different secretomes a silver stained SDS-PAGE demonstrated sharp, distinct bands, confirming sample quality (Figure 1). In addition, tissue-dependent enrichment of specific protein bands was observed. This indicates the presence of tissue-dependent proteins in the OA knee tissue secretomes.

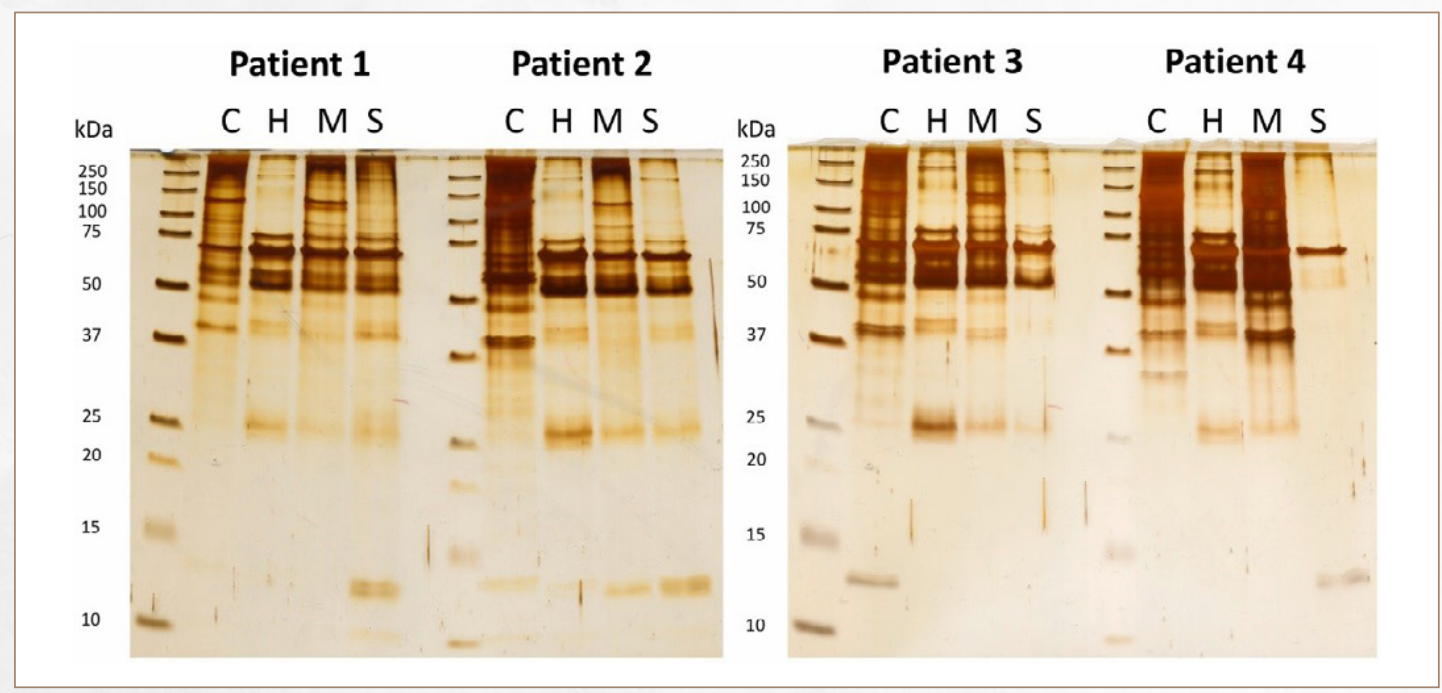

Figure 1: Confirmation of sample quality and gross differences in protein profiles in secretomes.

Scans of silver-stained acrylamide gels with patient numbers indicated. $C=$ cartilage, $H=$ Hoffa's fat pad, $M=$ meniscus, $S=$ synovium. Protein molecular weights $(\mathrm{kDa})$ are indicated on the left of both gels. 


\subsection{Identification of Protein Species in OA Knee Tissue Secretomes}

To identify the protein species in the OA knee tissue secretomes, label-free mass spectrometry proteomic analysis was undertaken. Principal component analysis of the acquired proteomes demonstrated tissue-dependent protein clustering (Figure 2A). A total of 216 proteins were identified with highest mean significant detection in one of the tissue type-dependent secretomes (Supplementary Table 5). From these 216 protein species, 64 were highest secreted from cartilage, 94 from synovium, 37 from Hoffa's fat pad and 21 from meniscus. Four examples of proteins with a tissue-dependent amount detected in the secretomes are shown in Figure 2B-E. The amount of Antileukoproteinase (SLPI) was highest in the secretome of cartilage and lowest in the secretome of synovium (Figure 2B). The lowest amount of Matrix metalloproteinase 3 (MMP3) was found in the secretome of Hoffa's fat pad and highest of cartilage (Figure 2C). The amount of Complement C 8 alpha chain (C8A) was highest in the meniscus secretome and lowest in secretome of synovium (Figure 2D). Finally, the amount of Retinoic acid receptor responder protein 2 (RARRES2) was highest in the secretome of cartilage and lowest in synovium secretome (Figure 2E). The OA knee tissue-dependent levels of these four protein species in the acquired secretomes was validated by means of ELISA (Figure $2 \mathrm{~F}-\mathrm{I}$ ). A full list of proteins with highest significant amount per tissue-specific secretome is provided in Supplementary Table 5 and a full list of differentially expressed proteins with the corresponding confidence intervals for each tissue is in Supplementary Table 6. 
Chapter 7

A

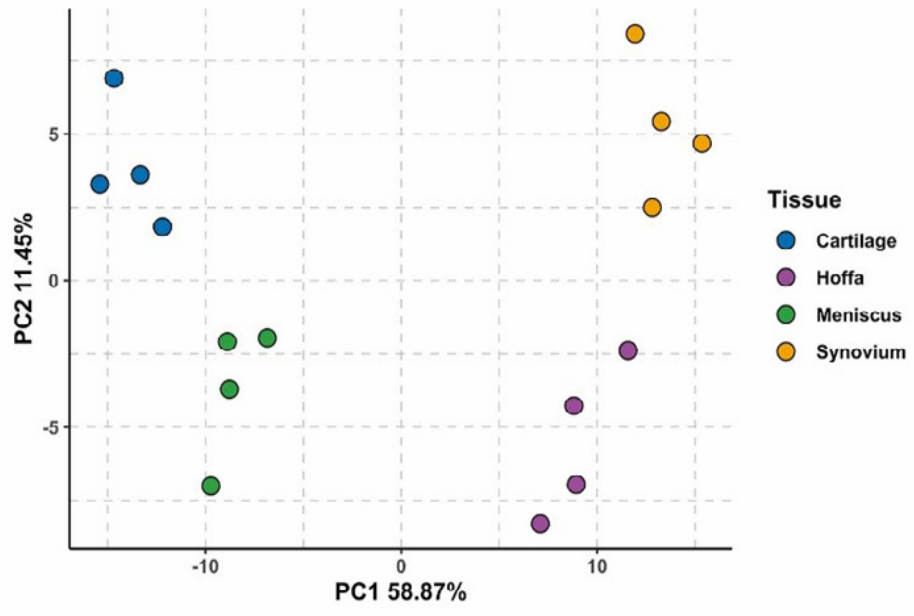




\section{Mass Spectrometry}

B

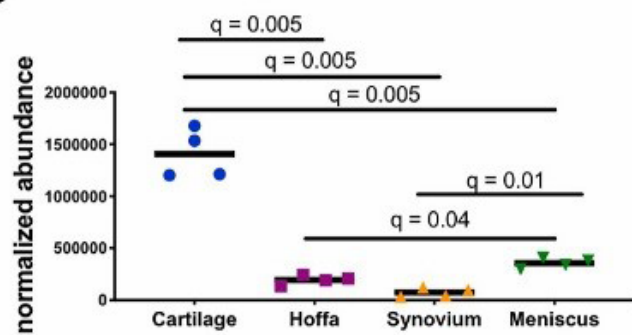

C

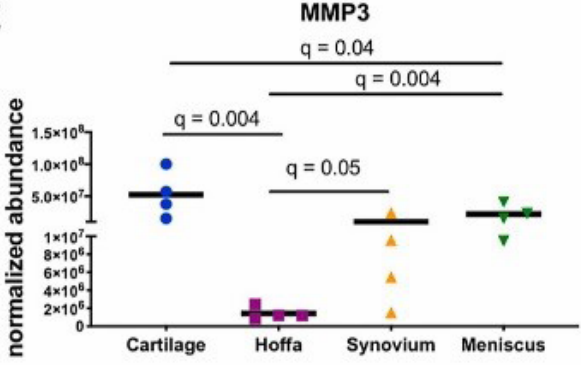

D
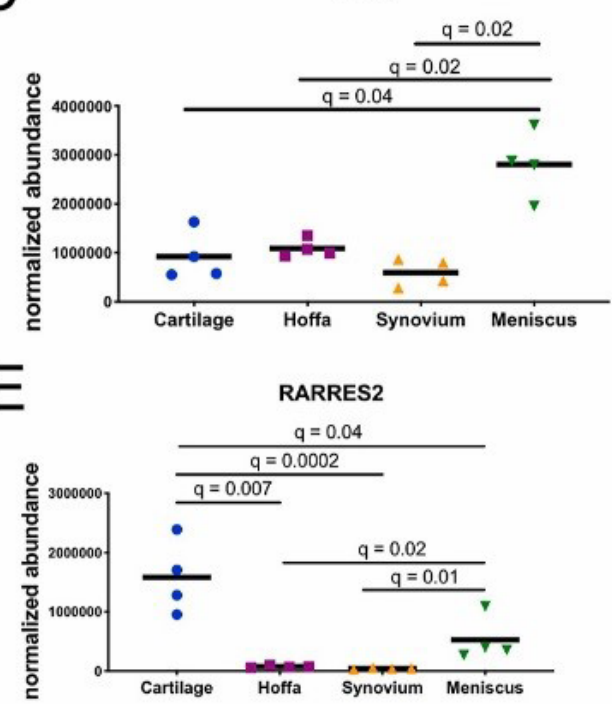

ELISA

$\mathrm{F}$

SLPI

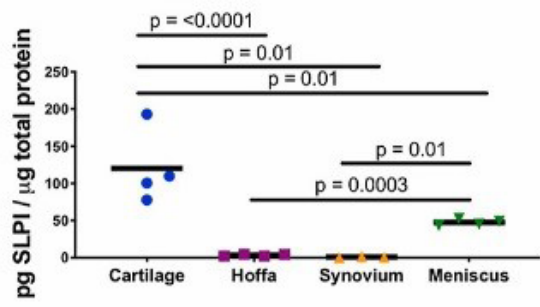

G

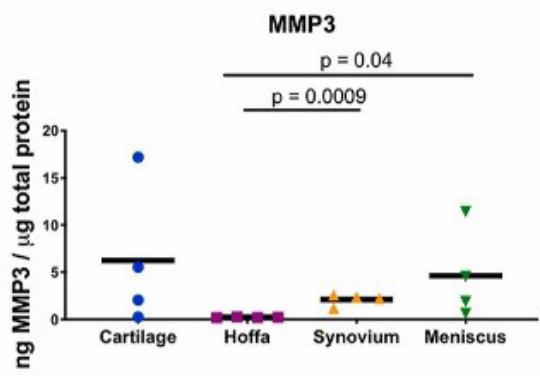

$\mathrm{H}$
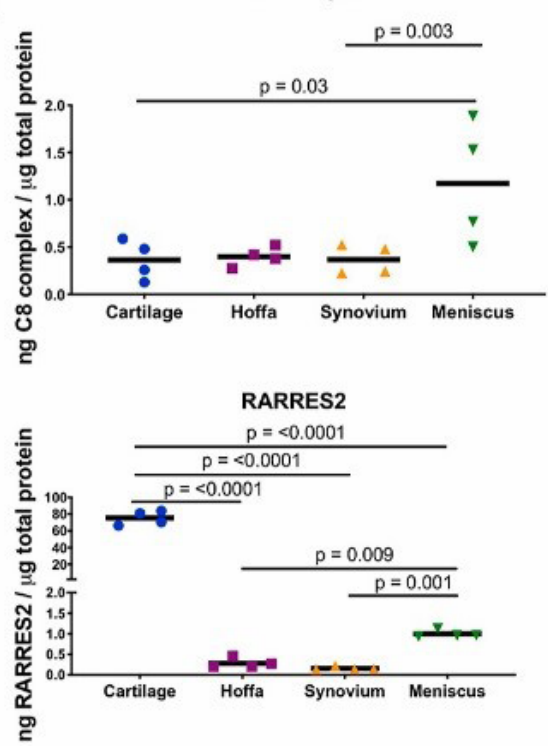
Figure 2: PCA analysis and ELISA validation of differentially expressed proteins in tissuespecific secretomes.

Principal Component Analyses following label-free quantification of secretome proteomes from the dependent cohort (A). Graphical representation of normalized abundance values of mass spectrometry data of four selected protein species which were found to be differentially expressed in a tissue-dependent fashion: SLPI (B), MMP3 (C), C8A (C), RARRES2 (D). ELISA-based validation of levels of SLPI (F), MMP3 (G), C8A (H), RARRES2 (I) in the tissue-dependent secretomes. Data are presented in scatter plots (individual patients are shown as separate dots) with mean values indicated as a horizontal line. Statistics following label-free quantification were calculated using a repeated measures ANOVA. $Q$ values were generated from resulting $P$ values using FDR correction for multiple testing. Statistical significance following ELISA analysis was calculated using a repeated measures ANOVA after log-transformation, followed by a Fisher's LSD test. Statistical significance is indicated in the figures.

\subsection{Validation of Tissue-Dependent Secretome Proteins in an Independent Cohort}

We next investigated whether our mass spectrometry data is applicable within a general knee OA population. To this end, the proteins measured in Figure 2 , and an additional selection of proteins with a highest amount in the secretomes of the tissues from Supplementary Table 5 was measured by ELISA in the tissue secretomes of 12 independent knee OA patients (the independent cohort; Supplementary Table 2). ELISA measurements were performed for SLPI, C8 complex, CLU, FN1, RARRES2, MATN3, MMP3 and Tenascin $\mathrm{C}$ (TNC) (Figure 3). The amount of SLPI in the secretome was highest from cartilage and lowest from synovium as revealed by mass spectrometry analysis (Supplementary Table 5) and this was confirmed by ELISA measurements in the independent cohort (Figure 3A). The C8A amount was highest in the secretome of meniscus and lowest in the secretome of synovium in our mass spectrometry data. ELISA analysis of C8 complex in the independent cohort confirmed the highest amount originating from meniscus (Figure 3B). The amount of Clusterin (CLU) was highest in the cartilage secretome and lowest in the Hoffa's fat pad secretome in the mass spectrometry data. ELISA analysis of the independent cohort validated this observation (Figure 3C). Mean Fibronectin 1 (FN1) amount was highest in the cartilage secretome and lowest in the secretomes of Hoffa's fat pad as concluded from mass spectrometry data and ELISA analysis validated this (Figure 3D). ELISA analysis 
further confirmed mass spectrometry data for RARRES2 amount, which was highest in the cartilage secretome and lowest in the synovium secretome (Figure 3E). Mass spectrometry data showed that Matrillin 3 (MATN3) amount was highest the secretome of cartilage and lowest in the Hoffa's fat pad secretome. The ELISA analysis of the independent cohort confirmed that MATN3 amount was highest in the cartilage secretome. However, this was not detectable in the secretome of Hoffa's fat pad or synovium (Figure 3F). The amount of MMP3 was lowest in the secretome of Hoffa's fat pad and highest the cartilage secretome in mass spectrometry data. Lowest MMP3 amount in tissue secretomes was also confirmed for Hoffa's fat pad by ELISA analysis of the independent cohort (Figure 3G). Finally, mean TNC amount was highest in the secretome of meniscus and lowest the Hoffa's fat pad secretomes in mass spectrometry analysis and this was confirmed by ELISA (Figure 3H). In conclusion, protein mass spectrometry analysis and ELISA validation of OA knee joint tissue-specific secretomes revealed the presence of many tissue-dependent proteins. 


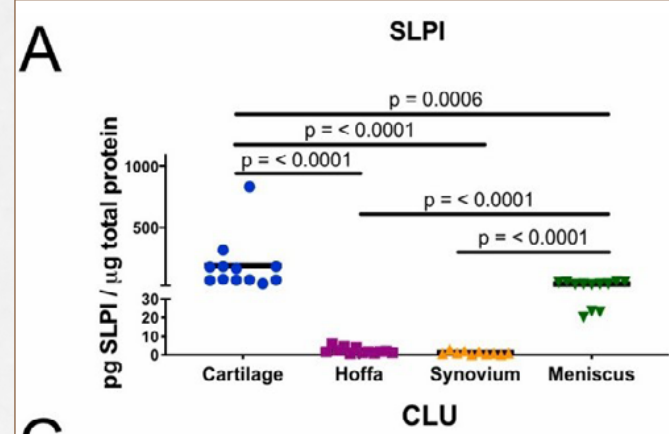

B

C8 complex

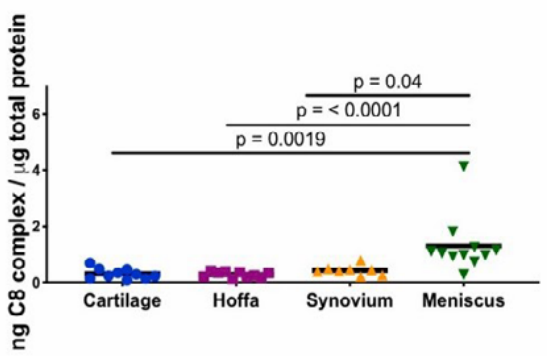

$D$

FN1

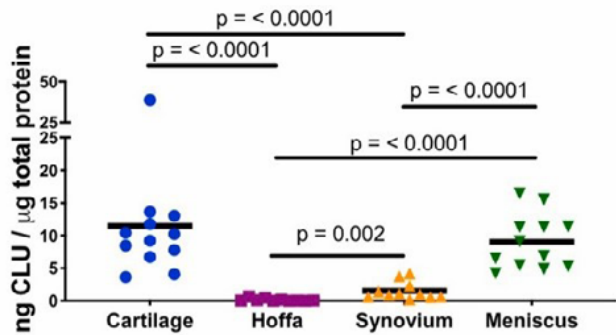

E

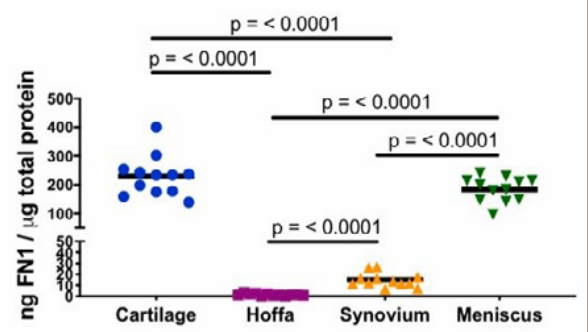

E

RARRES2

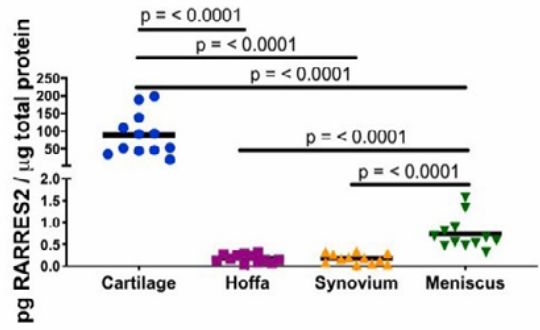

G

MMP3

$\mathrm{H}$
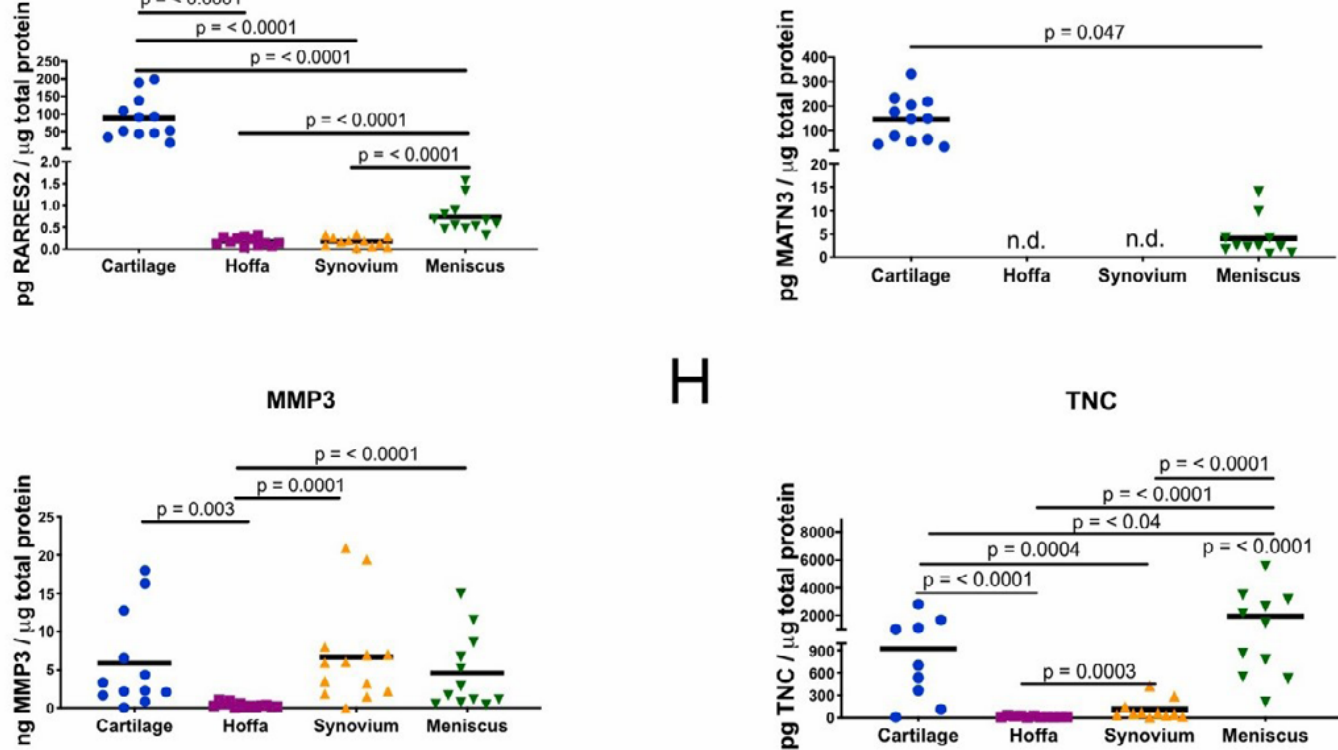

TNC

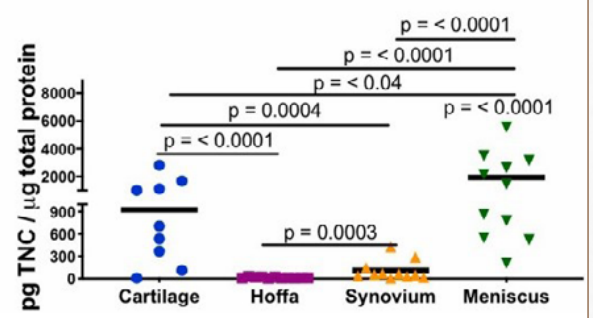




\section{Figure 3: Independent validation of secretome tissue specificity.}

ELISA-based validation of eight selected protein species which were found to be differentially expressed in a tissue-dependent fashion in the mass spectrometry data. SLPI (A), C8 complex (B), CLU (C), FN1 (D), RARRES2 (E), MATN3 (F), MMP3 (G), TNC (H). Data are presented in scatter plots (individual donors are shown as separate dots) with mean values indicated as a horizontal line. Statistical significance was calculated using a repeated measures ANOVA after log-transformation, followed by a Fisher's LSD test and is indicated in the figures.

\subsection{OA-Specific Abundance of Protein Species in Synovial Fluid}

Next, we sought to determine whether the OA knee joint tissue-dependent proteins identified above (Supplementary Table 5) showed an OA-specific abundance in knee joint synovial fluid. To address this question, we performed protein mass spectrometry and label-free quantification on knee joint synovial fluid from 10 patients with knee OA and from 10 individuals without $\mathrm{OA}$ and compared their proteomes. Principal component analysis of the acquired proteomes revealed defined group-specific clustering (Figure 4A). The abundance of 62 protein species was found to be significantly increased in OA synovial fluid compared to non-OA synovial fluid. A list of synovial fluid proteins with OA-specific enrichment is presented in Supplementary Table 7. Of these 62 protein species, 39 were also detected in the secretomes above. Of these 39 proteins, 19 were present in the secretomes in an OA knee joint tissue-dependent manner (Supplementary Tables 7 and 8). In addition, 234 protein species were present in significantly lower abundance in OA synovial fluid compared to non-OA synovial fluid. Of these 234 protein species, 56 were also detected in the secretomes. Of these 56 proteins, 54 were found to be present in the secretomes in a tissue-dependent manner (Supplementary Table 9). Next, we validated mass spectrometry results of the synovial fluid proteomes using ELISA assays. Validation was performed using knee OA synovial fluid samples of the knee OA patients from which we also used the tissues to generate tissue-conditioned media ( $n=13)$, and using the non-OA knee synovial fluid samples which were also used for the synovial fluid mass spectrometry analysis ( $n=$ 10). Six proteins that were significantly higher in $O A$ synovial fluid compared to non-OA synovial fluid (and some with an OA knee joint tissue-dependent release; Supplementary Tables 5 and 7 ) were selected for ELISA validation (IGF2, AHSG, FN1, CFB, KNG, C8 complex). For these proteins data following ELISA validation were highly concordant with our mass 


\section{Chapter 7}

spectrometry data (Figure 4). In addition to proteins with a higher abundance in OA synovial fluid, we also validated mass spectrometry data of two proteins with different expression dynamics. In the mass spectrometry data, the abundance of DCN (Decorin) was found to be significantly lower in OA synovial fluid compared to non-OA synovial fluid. The lower abundance of DCN in OA synovial fluid was validated by ELISA (Figure 5A and 5B). Furthermore, the abundance of ANG (Angiogenin) was not significantly different between $\mathrm{OA}$ and non-OA synovial fluid and this was confirmed with ELISA (Figure 5C and 5D).

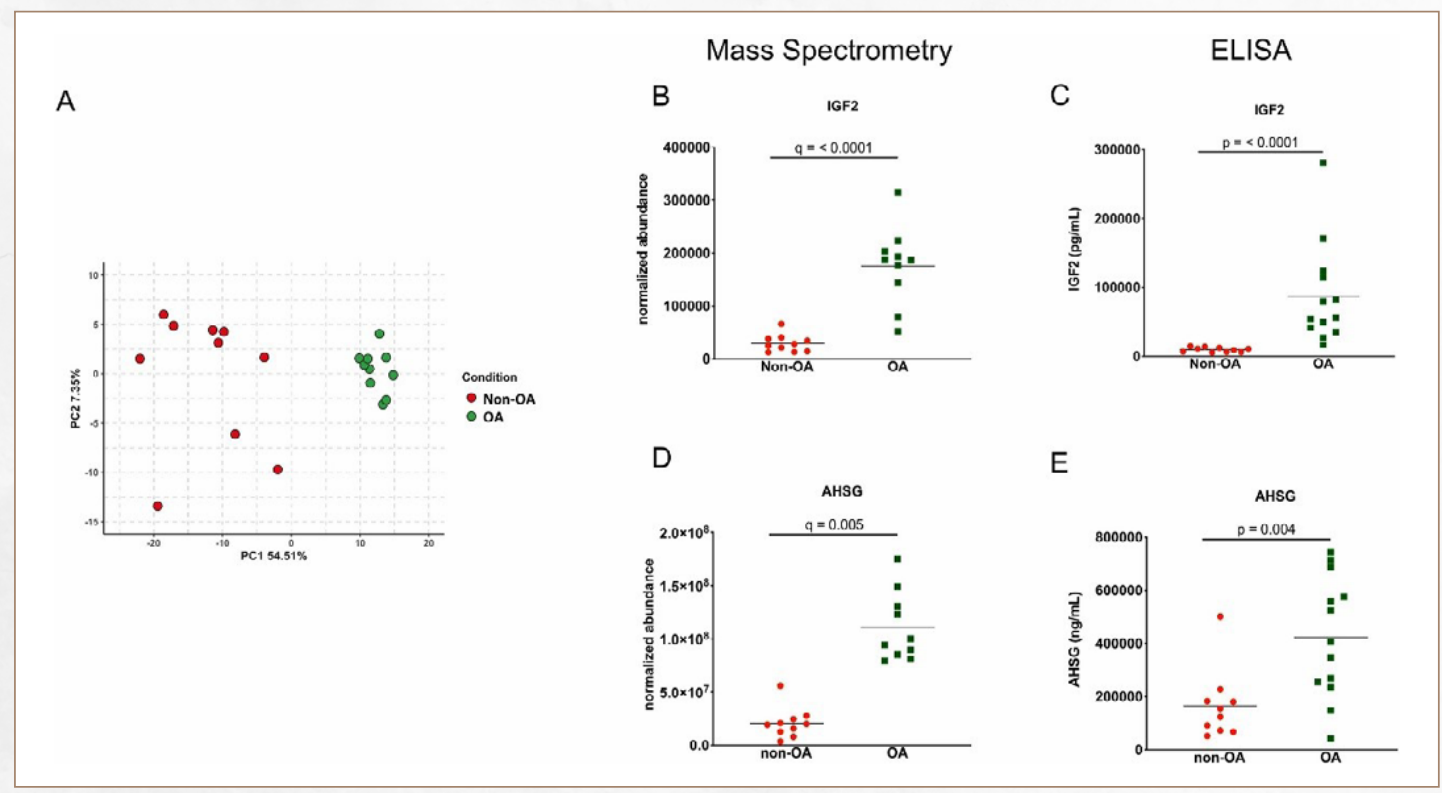




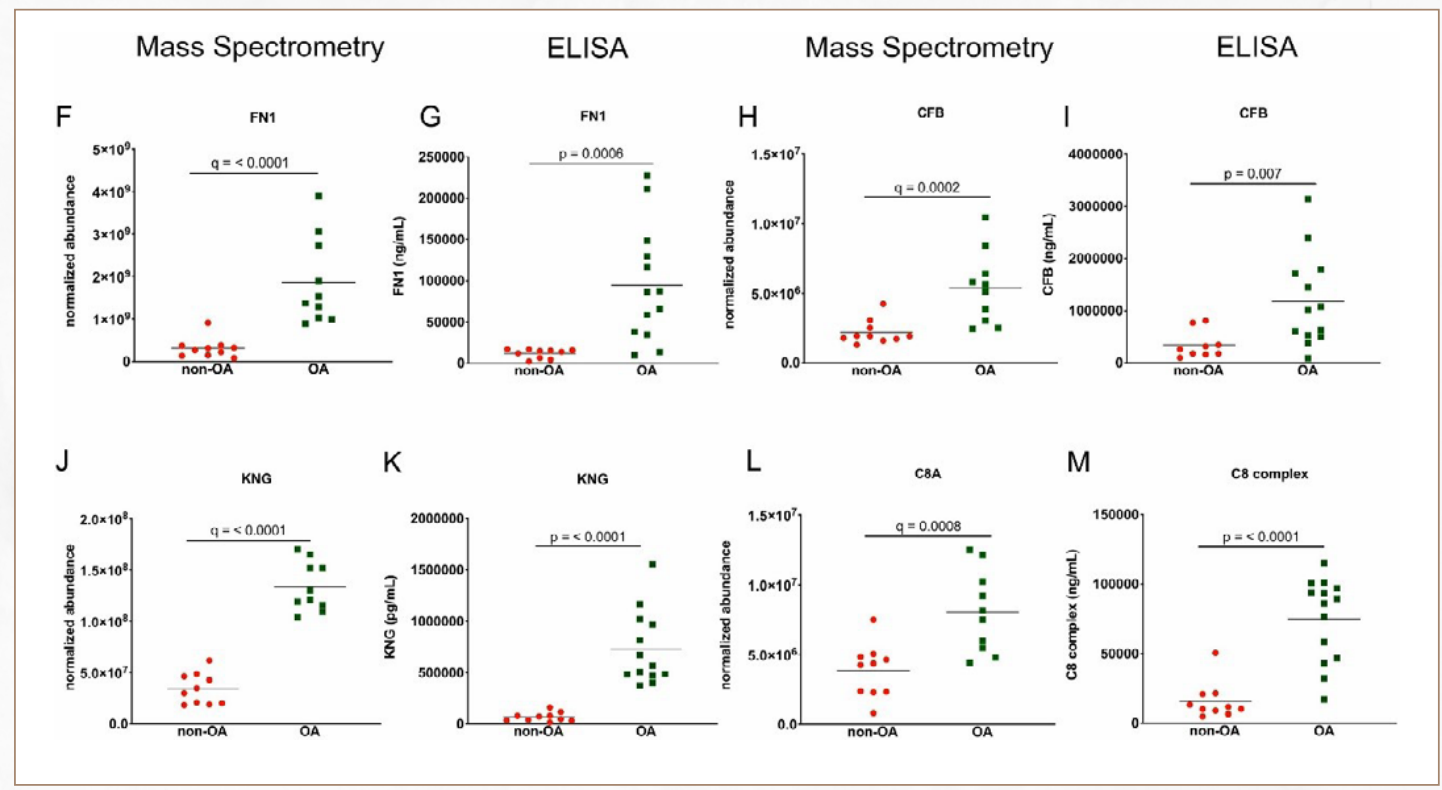

Figure 4: PCA analysis and ELISA validation of synovial fluid mass spectrometry data.

Principal Component Analyses following label-free quantification of knee OA and non-OA synovial fluids (A). Graphical representation of normalized abundance values of mass spectrometry data and accompanying ELISA validation of selected protein species that were found to be present in higher abundance in $O A$ vs non-OA synovial fluids (based on mass spectrometry analysis (Supplementary Table 7)). IGF2 (B/C), AHSG (D/E) FN1 (F/G), CFB (H/I), KNG (J/K), C8A and C8 complex (L/M). Data are presented in scatter plots (individual donors are shown as separate dots), with mean values indicated as a horizontal line. Statistics following label-free quantification were calculated using an ANOVA. $Q$ values were generated from resulting $P$ values using FDR correction for multiple testing. Statistical significance following ELISA analysis was calculated using a Mann-Whitney $U$ test. Statistical significance is indicated in the figures. 


\section{Mass Spectrometry}

A

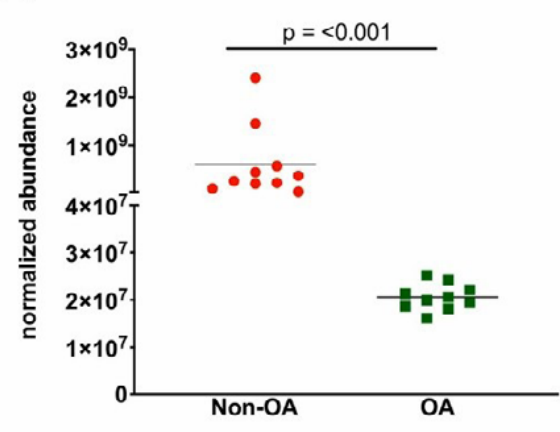

C

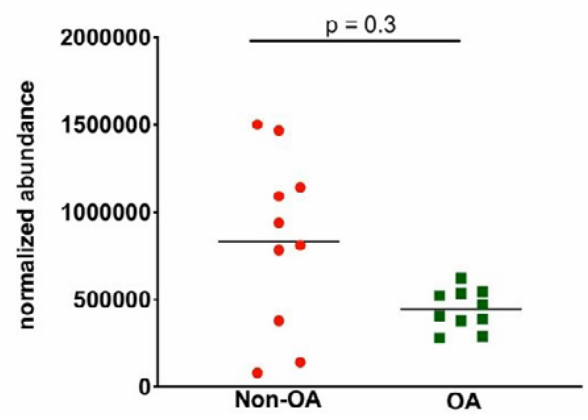

\section{ELISA}

B

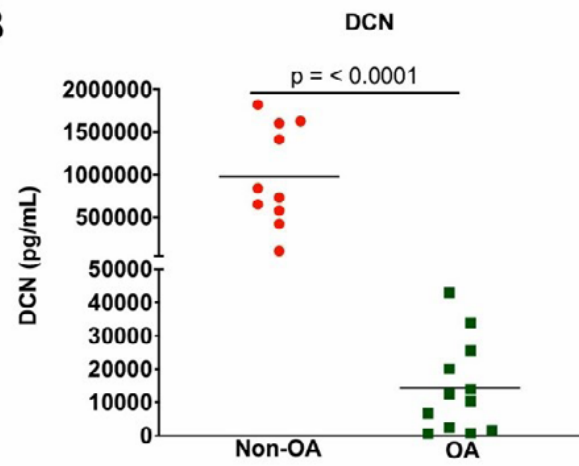

D

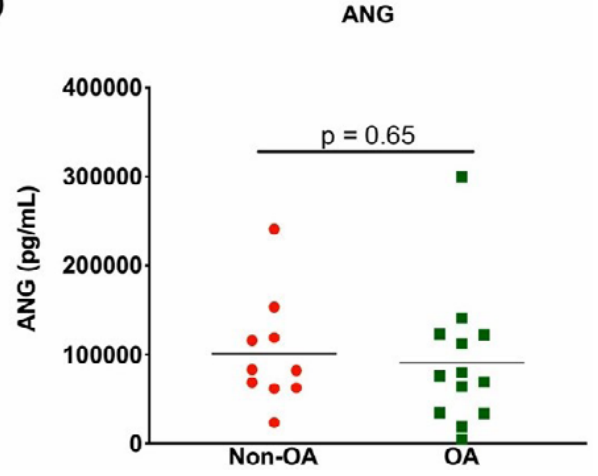

Figure 5: ELISA validation of synovial fluid mass spectrometry data.

Graphical representation of normalized abundance values of mass spectrometry data and accompanying ELISA validation of selected protein species that were found to be present in lower and equal abundance in $O A$ vs non-OA synovial fluids (based on mass spectrometry analysis). DCM $(A / B), A N G(C / D)$. Data are presented in scatter plots (individual donors are shown as separate dots), with mean values indicated as a horizontal line. Statistical significance was calculated using a MannWhitney $U$ test and is indicated in the figures. 


\section{Discussion}

In the search of diagnostic targets that are capable of identifying biomolecular changes in knee joint homeostasis, important efforts have been made to understand the proteomic composition of synovial fluid and to identify OA-related changes in its composition 10,19,27,28,29. However, the origin of OA-related alterations in the proteomic composition of synovial fluid remained poorly documented and biochemical markers generally lacked specificity to certain joint tissues ${ }^{30}$. In our study we identified 62 proteins with a significantly higher abundance in synovial fluids of osteoarthritic knees. A large part of the synovial fluid is created by ultrafiltration of plasma through the synovial membrane. Synovial fluid is in direct contact with different intra-articular tissues such as cartilage, synovium and meniscus as well as at an intimate distance from Hoffa's fat pad ${ }^{31}$. Thus, the source of protein species in the synovial fluid may be from the blood stream, proximity tissues or released by different intra-articular joint tissues into the synovial fluid. From the 62 proteins with an OA-specific higher abundance in knee synovial fluid, 39 were present in the secretomes of the investigated knee joint tissues. This indicates that their abundance in knee synovial fluid may depend on their release from Hoffa's fat pad, synovium, meniscus and/or articular cartilage. From these 39 proteins, 19 are of particular interest, since their amount is specifically highest in the secretome of one of the investigated intra-articular tissues (Supplementary Table 8). Our results strongly suggest that specific OA knee joint tissues differentially contribute to OA-related changes in the synovial fluid proteome of the knee joint. Earlier publications reported clear differences in protein profiles between OA and non-OA synovial fluids ${ }^{10,27,32}$. Specific joint tissues, such as cartilage and synovium, have been individually investigated as contributors to the levels of OA-related proteins (and protein fragments) in synovial fluid ${ }^{10,27,33,34,35}$. We have determined the protein secretomes of four different knee joint tissues and linked this to OA-specific changes in the synovial fluid proteome of the knee joint. Our findings therefore provide a comprehensive insight into the tissue-dependent origin of proteins in knee joint synovial fluid with an OA-specific abundance. 
Knowledge of the main tissue source of OA-specific proteins present in knee joint synovial fluid is expected to have important implications for understanding the progression of knee OA on the tissue level, as well as for the development of molecular diagnostics that may aid in the sub-/endotyping of knee OA. Also, efficacy studies of novel (experimental) treatments for knee OA will benefit from biomarkers that are able to report about the joint's health status on the tissue level. For instance, accumulating evidence suggests that complement system components play a key role in the pathogenesis of knee $\mathrm{OA}^{36,37}$. Of the four different explanted OA knee tissues the secretome of explanted OA meniscal tissue had the highest amount of Complement component $\mathrm{C} 8$. This suggests that $\mathrm{C} 8$ might be put forward as a potential synovial fluid biomarker to evaluate the efficacy of therapeutic interventions in knee OA due to meniscal pathology. Another protein whose abundance has been shown previously to be increased in OA synovial fluid is Clusterin ${ }^{27,36}$. While we confirmed this finding in our present study, our data additionally demonstrates the greatest amount of Clusterin is in the explant secretomes of cartilage and meniscal tissues. This points towards cartilage and meniscus as the tissues-of-origin of Clusterin levels in OA synovial fluid. The same holds true for Fibronectin, which has been shown to be more abundant in OA synovial fluid compared to non-OA synovial fluid ${ }^{27,36}$.

As a general study limitation we cannot exclude that some proteins in the tissue-specific secretomes and synovial fluid may originate from degradation products of cell death, extracellular matrix or the blood stream, respectively. However, regarding cell death, this is unlikely to play a major role since clear signs of viability have been reported for similar explant cultures ${ }^{14,38,39}$. Future investigations will further clarify the contribution of the intraarticular tissues to specific proteins in the synovial fluid.

A schematic overview demonstrating the numbers of proteins with a highest secretion from one of the investigated knee joint tissues and their OA-specific abundance in knee synovial fluid is shown in Figure 6 . In this respect, it is interesting to note that our study revealed that in addition to cartilage and synovium, the meniscus and Hoffa's fat pad are also likely to be significant contributors to the OA-specific protein composition of the synovial fluid of the knee joint. We expect that improved knowledge of the tissue-specific origin of OA-specific synovial fluid biomarkers will propel the understanding of the role of 
specific tissues in the progression of $\mathrm{OA}$ and fuel the development of improved synovial fluid-based diagnostic approaches aiming at grading and subtyping $\mathrm{OA}^{40,41}$.

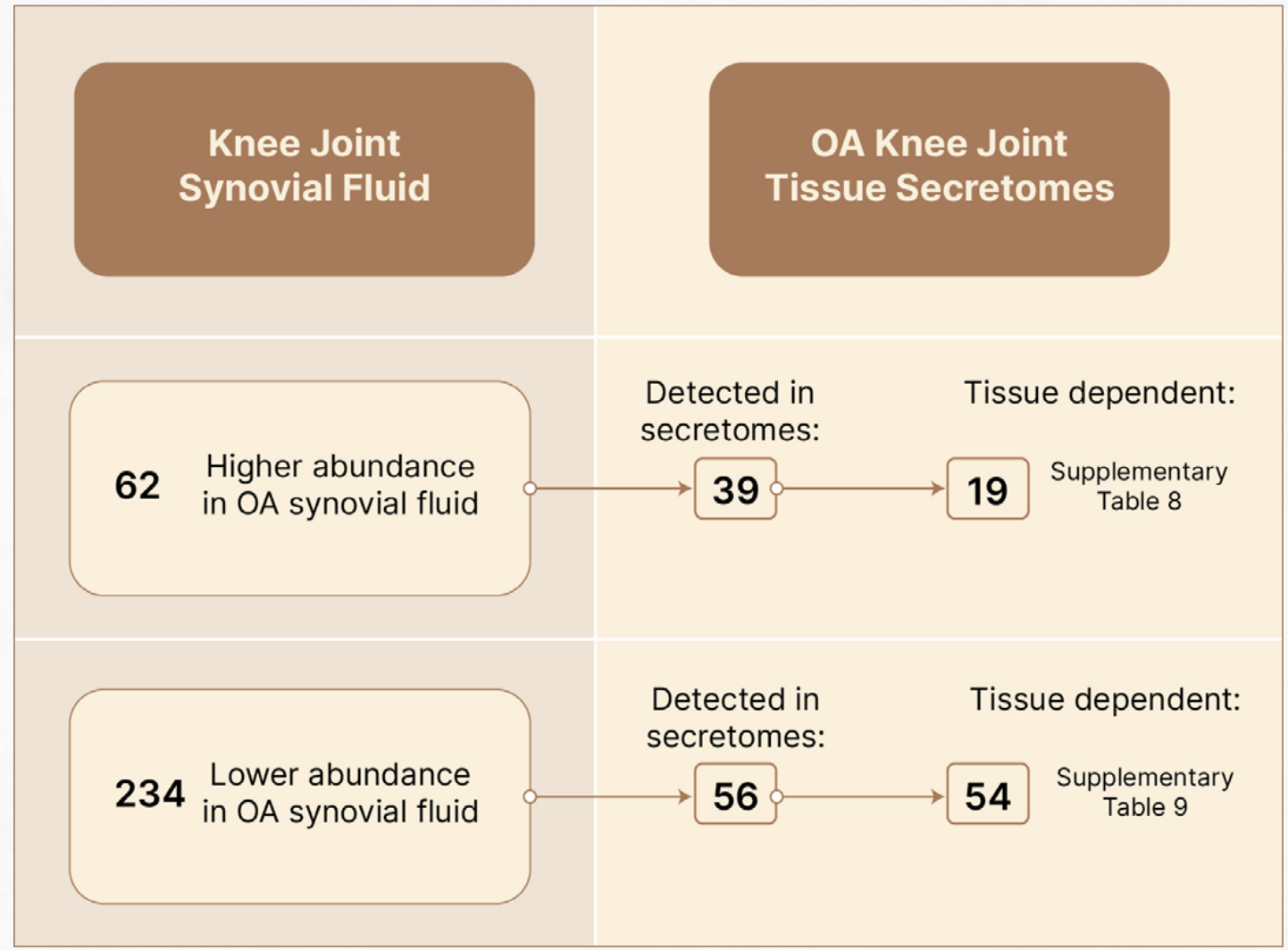

\section{Figure 6: Graphical data summary.}

Numbers of protein species with an OA-specific abundance in knee synovial fluid, the number of protein species from these that were detected in the $O A$ knee joint tissue secretomes, and the number of these with a tissue-dependent release into the $O A$ knee joint tissue secretomes (Supplementary Tables 5, 7, 8, 9). 


\section{Supplementary Data}

Supplementary Table 8: Protein species which are present in higher abundance in $O A$ synovial fluid compared to non-OA synovial fluid and present in the secretomes in a tissuedependent manner

\begin{tabular}{|c|c|}
\hline $\begin{array}{l}\text { PROTEIN ACC. } \\
\text { NUMBER }\end{array}$ & PROTEIN NAME \\
\hline P02751|FINC_HUMAN & Fibronectin OS=Homo sapiens $\mathrm{GN}=\mathrm{FN} 1 \mathrm{PE}=1 \mathrm{SV}=4$ \\
\hline P24821|TENA_HUMAN & Tenascin OS=Homo sapiens GN=TNC PE $=1 \mathrm{SV}=3$ \\
\hline Q92743|HTRA1_HUMAN & Serine protease HTRA1 OS=Homo sapiens $\mathrm{GN}=\mathrm{HTRA} 1 \mathrm{PE}=1 \mathrm{SV}=1$ \\
\hline P02765|FETUA_HUMAN & Alpha-2-HS-glycoprotein OS=Homo sapiens GN=AHSG PE=1 SV=1 \\
\hline P19827|ITIH1_HUMAN & $\begin{array}{l}\text { Inter-alpha-trypsin inhibitor heavy chain } \mathrm{H} 1 \mathrm{OS}=\text { Homo sapiens } \\
\mathrm{GN}=\mathrm{ITIH} 1 \mathrm{PE}=1 \mathrm{SV}=3\end{array}$ \\
\hline P01871|IGHM_HUMAN & Ig mu chain $C$ region $O S=$ Homo sapiens $G N=I G H M P E=1 S V=3$ \\
\hline P07357|CO8A_HUMAN & $\begin{array}{l}\text { Complement component } \mathrm{C} 8 \text { alpha chain } \mathrm{OS}=\text { Homo sapiens } \\
\mathrm{GN}=\mathrm{C} 8 \mathrm{~A} P \mathrm{PE}=1 \mathrm{SV}=2\end{array}$ \\
\hline P02753|RET4_HUMAN & Retinol-binding protein $4 \mathrm{OS}=$ Homo sapiens $\mathrm{GN}=\mathrm{RBP} 4 \mathrm{PE}=1 \mathrm{SV}=3$ \\
\hline P01591|IGJ_HUMAN & $\begin{array}{l}\text { Immunoglobulin J chain OS=Homo sapiens } \mathrm{GN}=\mathrm{JCHAIN} \mathrm{PE}=1 \\
\mathrm{SV}=4\end{array}$ \\
\hline P02768|ALBU_HUMAN & Serum albumin $\mathrm{OS}=$ Homo sapiens $\mathrm{GN}=\mathrm{ALB} P E=1 \mathrm{SV}=2$ \\
\hline Q96PD5|PGRP2_HUMAN & $\begin{array}{l}\text { N-acetylmuramoyl-L-alanine amidase OS=Homo sapiens } \\
\text { GN=PGLYRP2 PE=1 SV=1 }\end{array}$ \\
\hline P04196|HRG_HUMAN & Histidine-rich glycoprotein OS=Homo sapiens $G N=H R G ~ P E=1 S V=1$ \\
\hline P07360|CO8G_HUMAN & $\begin{array}{l}\text { Complement component } \mathrm{C} 8 \text { gamma chain } \mathrm{OS}=\text { Homo sapiens } \\
\mathrm{GN}=\mathrm{C} 8 \mathrm{G} \mathrm{PE}=1 \mathrm{SV}=3\end{array}$ \\
\hline A1L4H1|SRCRL_HUMAN & $\begin{array}{l}\text { Soluble scavenger receptor cysteine-rich domain-containing } \\
\text { protein } S S C 5 D \text { OS=Homo sapiens } G N=S S C 5 D P E=1 S V=3\end{array}$ \\
\hline Q9NQ79|CRAC1_HUMAN & $\begin{array}{l}\text { Cartilage acidic protein } 1 \mathrm{OS}=\text { Homo sapiens } \mathrm{GN}=\mathrm{CRTAC} 1 \mathrm{PE}=1 \\
\mathrm{SV}=2\end{array}$ \\
\hline
\end{tabular}




\begin{tabular}{|c|c|}
\hline $\begin{array}{c}\text { PROTEIN ACC. } \\
\text { NUMBER }\end{array}$ & PROTEIN NAME \\
\hline POCG05|LAC2_HUMAN & $\begin{array}{l}\text { Ig lambda- } 2 \text { chain } C \text { regions } O S=\text { Homo sapiens } G N=I G L C 2 P E=1 \\
S V=1\end{array}$ \\
\hline B9A064|IGLL5_HUMAN & $\begin{array}{l}\text { Immunoglobulin lambda-like polypeptide } 5 \mathrm{OS}=\text { Homo sapiens } \\
\mathrm{GN}=\mid \mathrm{GLL} 5 \mathrm{PE}=2 \mathrm{SV}=2\end{array}$ \\
\hline P17936|IBP3_HUMAN & $\begin{array}{l}\text { Insulin-like growth factor-binding protein } 3 \mathrm{OS}=\text { Homo sapiens } \\
\mathrm{GN}=\mathrm{IGFBP} 3 \mathrm{PE}=1 \mathrm{SV}=2\end{array}$ \\
\hline P01714|LV301_HUMAN & Ig lambda chain V-III region $\mathrm{SH} O S=$ Homo sapiens $\mathrm{PE}=1 \mathrm{SV}=1$ \\
\hline
\end{tabular}

Protein acc. Number $=$ Protein accession Number. 


\section{Chapter 7}

Supplementary Table 9: Protein species which are present in lower amounts in OA synovial fluid compared to non-OA synovial fluid, as well as present in the secretomes in a tissuedependent manner.

\begin{tabular}{|c|c|}
\hline $\begin{array}{l}\text { PROTEIN ACC. } \\
\text { NUMBER }\end{array}$ & PROTEIN NAME \\
\hline O75339|CILP1_HUMAN & $\begin{array}{l}\text { Cartilage intermediate layer protein } 1 \mathrm{OS}=\text { Homo sapiens } \mathrm{GN}=\mathrm{CILP} \\
\mathrm{PE}=1 \mathrm{SV}=4\end{array}$ \\
\hline Q8IUL8|CILP2_HUMAN & $\begin{array}{l}\text { Cartilage intermediate layer protein } 2 \text { OS=Homo sapiens } \\
\mathrm{GN}=\mathrm{CILP} 2 \mathrm{PE}=2 \mathrm{SV}=2\end{array}$ \\
\hline Q14767|LTBP2_HUMAN & $\begin{array}{l}\text { Latent-transforming growth factor beta-binding protein } 2 \\
\mathrm{OS}=\text { Homo sapiens } \mathrm{GN}=\mathrm{LTBP} 2 \mathrm{PE}=1 \mathrm{SV}=3\end{array}$ \\
\hline P05387|RLA2_HUMAN & $\begin{array}{l}60 S \text { acidic ribosomal protein } P 2 \text { OS=Homo sapiens } G N=R P L P 2 \\
P E=1 S V=1\end{array}$ \\
\hline P00325|ADH1B_HUMAN & $\begin{array}{l}\text { Alcohol dehydrogenase } 1 \mathrm{~B} O S=\text { Homo sapiens } \mathrm{GN}=\mathrm{ADH} 1 \mathrm{~B} P E=1 \\
\mathrm{SV}=2\end{array}$ \\
\hline P03973|SLPI_HUMAN & Antileukoproteinase $\mathrm{OS}=\mathrm{H}$ omo sapiens $\mathrm{GN}=\mathrm{SLPI} \mathrm{PE}=1 \mathrm{SV}=2$ \\
\hline P16112|PGCA_HUMAN & Aggrecan core protein $\mathrm{OS}=\mathrm{Homo}$ sapiens $\mathrm{GN}=\mathrm{ACAN} \mathrm{PE}=1 \mathrm{SV}=2$ \\
\hline Q06828|FMOD_HUMAN & Fibromodulin OS=Homo sapiens GN=FMOD PE $=1 \mathrm{SV}=2$ \\
\hline P21333|FLNA_HUMAN & Filamin-A OS=Homo sapiens GN=FLNA PE $=1 \mathrm{SV}=4$ \\
\hline Q13642|FHL1_HUMAN & $\begin{array}{l}\text { Four and a half LIM domains protein } 1 \mathrm{OS}=\text { Homo sapiens } \\
\mathrm{GN}=\mathrm{FHL} 1 \mathrm{PE}=1 \mathrm{SV}=4\end{array}$ \\
\hline P40121|CAPG_HUMAN & $\begin{array}{l}\text { Macrophage-capping protein } \mathrm{OS}=\text { Homo sapiens } \mathrm{GN}=\mathrm{CAPG} \mathrm{PE}=1 \\
\mathrm{SV}=2\end{array}$ \\
\hline P06753|TPM3_HUMAN & $\begin{array}{l}\text { Tropomyosin alpha- } 3 \text { chain } O S=\text { Homo sapiens } G N=T P M 3 P E=1 \\
S V=2\end{array}$ \\
\hline P19971|TYPH_HUMAN & $\begin{array}{l}\text { Thymidine phosphorylase } \mathrm{OS}=\text { Homo sapiens } \mathrm{GN}=\mathrm{TYMP} P E=1 \\
\mathrm{SV}=2\end{array}$ \\
\hline P37802|TAGL2_HUMAN & Transgelin-2 OS=Homo sapiens GN=TAGLN2 PE=1 SV=3 \\
\hline P34096|RNAS4_HUMAN & Ribonuclease $4 \mathrm{OS}=$ Homo sapiens $\mathrm{GN}=\mathrm{RNASE} 4 \mathrm{PE}=1 \mathrm{SV}=3$ \\
\hline P29401|TKT_HUMAN & Transketolase $\mathrm{OS}=$ Homo sapiens $\mathrm{GN}=\mathrm{TKT} \mathrm{PE}=1 \mathrm{SV}=3$ \\
\hline
\end{tabular}




\begin{tabular}{|c|c|}
\hline $\begin{array}{l}\text { PROTEIN ACC. } \\
\text { NUMBER }\end{array}$ & PROTEIN NAME \\
\hline Q05707|COEA1_HUMAN & $\begin{array}{l}\text { Collagen alpha- } 1 \text { (XIV) chain OS=Homo sapiens } G N=C O L 14 A 1 P E=1 \\
S V=3\end{array}$ \\
\hline Q01518|CAP1_HUMAN & $\begin{array}{l}\text { Adenylyl cyclase-associated protein } 1 \mathrm{OS}=\text { Homo sapiens } \mathrm{GN}=\mathrm{CAP} 1 \\
\mathrm{PE}=1 \mathrm{SV}=5\end{array}$ \\
\hline P07585|PGS2_HUMAN & Decorin $\mathrm{OS}=$ Homo sapiens $\mathrm{GN}=\mathrm{DCN} \mathrm{PE}=1 \mathrm{SV}=1$ \\
\hline P13489|RINI_HUMAN & Ribonuclease inhibitor $\mathrm{OS}=$ Homo sapiens $\mathrm{GN}=\mathrm{RNH} 1 \mathrm{PE}=1 \mathrm{SV}=2$ \\
\hline P14555|PA2GA_HUMAN & $\begin{array}{l}\text { Phospholipase } A 2 \text {, membrane associated } O S=\text { Homo sapiens } \\
G N=P L A 2 G 2 A \text { PE }=1 \mathrm{SV}=2\end{array}$ \\
\hline Q14195|DPYL3_HUMAN & $\begin{array}{l}\text { Dihydropyrimidinase-related protein } 3 \mathrm{OS}=\text { Homo sapiens } \\
\mathrm{GN}=\mathrm{DPYSL} 3 \mathrm{PE}=1 \mathrm{SV}=1\end{array}$ \\
\hline P62805|H4_HUMAN & Histone H4 OS=Homo sapiens GN=HIST1H4A PE=1 SV=2 \\
\hline P19338|NUCL_HUMAN & Nucleolin OS=Homo sapiens GN=NCL PE=1 SV=3 \\
\hline P00488|F13A_HUMAN & $\begin{array}{l}\text { Coagulation factor XIII A chain OS=Homo sapiens } \mathrm{GN}=\mathrm{F} 13 \mathrm{~A} 1 \mathrm{PE}=1 \\
\mathrm{SV}=4\end{array}$ \\
\hline P98095|FBLN2_HUMAN & Fibulin-2 OS=Homo sapiens GN=FBLN2 PE=1 SV=2 \\
\hline Q96Q06|PLIN4_HUMAN & Perilipin- 4 OS=Homo sapiens GN=PLIN4 PE $=1$ SV $=2$ \\
\hline P14618|KPYM_HUMAN & Pyruvate kinase $\mathrm{PKM} O S=$ Homo sapiens $\mathrm{GN}=\mathrm{PKM} P E=1 \mathrm{SV}=4$ \\
\hline Q9BXR6|FHR5_HUMAN & $\begin{array}{l}\text { Complement factor } \mathrm{H} \text {-related protein } 5 \mathrm{OS}=\text { Homo sapiens } \\
\mathrm{GN}=\mathrm{CFHR} 5 \mathrm{PE}=1 \mathrm{SV}=1\end{array}$ \\
\hline P08238|HS90B_HUMAN & $\begin{array}{l}\text { Heat shock protein HSP 90-beta OS=Homo sapiens } G N=H S P 90 A B 1 \\
P E=1 S V=4\end{array}$ \\
\hline Q8IUX7|AEBP1_HUMAN & $\begin{array}{l}\text { Adipocyte enhancer-binding protein } 1 \mathrm{OS}=\text { Homo sapiens } \\
\mathrm{GN}=\mathrm{AEBP} 1 \mathrm{PE}=1 \mathrm{SV}=1\end{array}$ \\
\hline Q9ULV4|COR1C_HUMAN & Coronin- $1 \mathrm{C}$ OS=Homo sapiens $\mathrm{GN}=\mathrm{CORO} 1 \mathrm{C} \mathrm{PE}=1 \mathrm{SV}=1$ \\
\hline Q06830|PRDX1_HUMAN & Peroxiredoxin -1 OS=Homo sapiens $\mathrm{GN}=\mathrm{PRDX} 1 \mathrm{PE}=1 \mathrm{SV}=1$ \\
\hline P46940|IQGA1_HUMAN & $\begin{array}{l}\text { Ras GTPase-activating-like protein IQGAP1 OS=Homo sapiens } \\
\mathrm{GN}=\mid \mathrm{Q} \text { GAP1 } \mathrm{PE}=1 \mathrm{SV}=1\end{array}$ \\
\hline
\end{tabular}




\begin{tabular}{|l|l|}
\multicolumn{2}{|c}{ PROTEIN ACC. } \\
NUMBER
\end{tabular}




\begin{tabular}{|c|c|}
\hline $\begin{array}{l}\text { PROTEIN ACC. } \\
\text { NUMBER }\end{array}$ & PROTEIN NAME \\
\hline P07998|RNAS1_HUMAN & $\begin{array}{l}\text { Ribonuclease pancreatic OS=Homo sapiens } G N=\text { RNASE1 } P E=1 \\
S V=4\end{array}$ \\
\hline P21399|ACOC_HUMAN & $\begin{array}{l}\text { Cytoplasmic aconitate hydratase } \mathrm{OS}=\text { Homo sapiens } \mathrm{GN}=\mathrm{ACO} 1 \\
\mathrm{PE}=1 \mathrm{SV}=3\end{array}$ \\
\hline Q9Y279|VSIG4_HUMAN & $\begin{array}{l}\text { V-set and immunoglobulin domain-containing protein } 4 \\
\mathrm{OS}=\text { Homo sapiens } \mathrm{GN}=\mathrm{VSIG} 4 \mathrm{PE}=1 \mathrm{SV}=1\end{array}$ \\
\hline
\end{tabular}

Protein acc. Number $=$ Protein accession Number.

The remaining supplementary data to this article can be found online at https://doi. org/10.1016/j.joca.2020.09.005.

\section{Acknowledgements}

This work was supported by a Wellcome Trust Intermediate Clinical Fellowship (107471/Z/15/Z), a grant from the Dutch Arthritis Society (LLP14), the academic fund of Maastricht University Medical Center, the Annadal Foundation, EU-FP7 HEALTH.2012.2.4.5-2 (D-BOARD, project number 305815) and the START-Program of the Faculty of Medicine of the RWTH Aachen. This work was also supported by the MRC and vs Arthritis as part of the Medical Research Council vs Arthritis Centre for Integrated Research into Musculoskeletal Ageing (CIMA) [MR/R502182/1]. The MRC vs Arthritis Centre for Integrated Research into Musculoskeletal Ageing is a collaboration between the Universities of Liverpool, Sheffield and Newcastle. The authors are grateful to A. Cremers, Dr. P. Feczko and Dr. T. Boymans for their support in collecting the OA patient material. We also thank the University of Liverpool Centre for Proteomic Research for the use of their mass spectrometry facilities. 


\section{References}

1 Hunter D.J., Felson D.T.: Osteoarthritis. BMJ 2006; 332: pp. 639-642.

2 van der Kraan P.M., Blaney Davidson E.N., Blom A., van den Berg W.B.: TGFbeta signaling in chondrocyte terminal differentiation and osteoarthritis: modulation and integration of signaling pathways through receptor-Smads. Osteoarthritis Cartilage 2009; 17: pp. 1539-1545.

3 Petersson I.F., Boegard T., Saxne T., Silman A.J., Svensson B.: Radiographic osteoarthritis of the knee classified by the Ahlback and Kellgren \& Lawrence systems for the tibiofemoral joint in people aged 35-54 years with chronic knee pain. Ann Rheum Dis 1997; 56: pp. 493-496.

4 Glyn-Jones S., Palmer A.J., Agricola R., Price A.J., Vincent T.L., Weinans H., et. al.: Osteoarthritis. Lancet 2015; 386: pp. 376387.

5 Loeser R.F., Goldring S.R., Scanzello C.R., Goldring M.B.: Osteoarthritis: a disease of the joint as an organ. Arthritis Rheum 2012; 64: pp. 1697-1707.

6 Ripmeester E.G.J., Timur U.T., Caron M.M.J., Welting T.J.M.: Recent insights into the contribution of the changing hypertrophic chondrocyte phenotype in the development and progression of osteoarthritis. Front Bioeng Biotechnol 2018; 6: pp. 18.

7 Peffers M.J., Balaskas P., Smagul A.: Osteoarthritis year in review 2017: genetics and epigenetics. Osteoarthritis Cartilage 2018; 26: pp. 304-311.

8 Zhai G.: Alteration of metabolic pathways in osteoarthritis. Metabolites 2019; 9:

9 Nguyen L.T., Sharma A.R., Chakraborty C., Saibaba B., Ahn M.E., Lee S.S.: Review of prospects of biological fluid biomarkers in osteoarthritis. Int J Mol Sci 2017; 18:

10 Ritter S.Y., Subbaiah R., Bebek G., Crish J., Scanzello C.R., Krastins B., et. al.: Proteomic analysis of synovial fluid from the osteoarthritic knee: comparison with transcriptome analyses of joint tissues. Arthritis Rheum 2013; 65: pp. 981-992.

11 Del Rey M.J., Usategui A., Izquierdo E., Canete J.D., Blanco F.J., Criado G., et. al.: Transcriptome analysis reveals specific changes in osteoarthritis synovial fibroblasts. Ann Rheum Dis 2012; 71: pp. 275-280.

12 Carlson A.K., Rawle R.A., Wallace C.W., Brooks E.G., Adams E., Greenwood M.C., 
et. al:: Characterization of synovial fluid metabolomic phenotypes of cartilage morphological changes associated with osteoarthritis. Osteoarthritis Cartilage 2019; 27: pp. 1174-1184.

13 Kosinska M.K., Mastbergen S.C., Liebisch G., Wilhelm J., Dettmeyer R.B., Ishaque B., et. al:: Comparative lipidomic analysis of synovial fluid in human and canine osteoarthritis. Osteoarthritis Cartilage 2016; 24: pp. 1470-1478.

14 Favero M., Belluzzi E., Frallonardo P., Peruzzo L., Tauro L., Oliviero F., et. al.: Synovial fluid fetuin-A levels in patients affected by osteoarthritis with or without evidence of calcium crystals. Rheumatology 2019; 58: pp. 729-730.

15 Dong N., Gao Y.H., Liu B., Zhao C.W., Yang C., Li S.Q., et. al.: Differential expression of adipokines in knee osteoarthritis patients with and without metabolic syndrome. Int Orthop 2018; 42: pp. 1283-1289.

16 Arellano Perez Vertti R.D., Aguilar Muniz L.S., Moran Martinez J., Gonzalez Galarza F.F., Arguello Astorga R.: Cartilage oligomeric matrix protein levels in type 2 diabetes associated with primary knee osteoarthritis patients. Genet Test Mol Biomarkers 2019; 23: pp. 16-22.

17 Clair A.J., Kingery M.T., Anil U., Kenny L., Kirsch T., Strauss E.J.: Alterations in synovial fluid biomarker levels in knees with meniscal injury as compared with asymptomatic contralateral knees. Am J Sports Med 2019; 47: pp. 847-856.

18 Peffers M.J., Beynon R.J., Clegg P.D.: Absolute quantification of selected proteins in the human osteoarthritic secretome. Int J Mol Sci 2013; 14: pp. 20658-20681.

19 Peffers M.J., McDermott B., Clegg P.D., Riggs C.M.: Comprehensive protein profiling of synovial fluid in osteoarthritis following protein equalization.

Osteoarthritis Cartilage 2015; 23: pp. 1204-1213.

20 Anderson J.R., Phelan M.M., RubioMartinez L.M., Fitzgerald M.M., Jones S.W., Clegg P.D., et. al:: Optimization of synovial fluid collection and processing for NMR metabolomics and LC-MS/MS proteomics. J Proteome Res 2020 Jul 2; 19: pp. 25852597..

21 Perez-Riverol Y., Csordas A., Bai J., BernalLlinares M., Hewapathirana S., Kundu D.J., et. al:: The PRIDE database and related tools and resources in 2019: improving support for quantification data. Nucleic Acids Res 2019; 47: pp. D442-D450.

22 Storey J.D.: A direct approach to false discovery rates. J Roy Stat Soc B 2002; 64: pp. 479-498.

23 Benjamini Y., Yekutieli D.: Quantitative trait Loci analysis using the false discovery rate. 
Genetics 2005; 171: pp. 783-790.

24 Storey J.D., Tibshirani R.: Statistical significance for genomewide studies. Proc Natl Acad Sci U S A 2003; 100: pp. 94409445.

25 Core Team: R: A Language and Environment for Statistical Computing.2018.R Foundation for Statistical ComputingVienna, Austria Available online at: https://www.R-project. org/

26 Rohart F., Gautier B., Singh A., Le Cao K.A.: mixOmics: an $\mathrm{R}$ package for 'omics feature selection and multiple data integration. PLoS Comput Biol 2017; 13:

27 Gobezie R., Kho A., Krastins B., Sarracino D.A., Thornhill T.S., Chase M., et. al:: High abundance synovial fluid proteome: distinct profiles in health and osteoarthritis. Arthritis Res Ther 2007; 9: pp. R36

28 Mobasheri A., Henrotin Y.: Biomarkers of (osteo)arthritis. Biomarkers 2015; 20: pp. 513-518.

29 Kraus V., Hsueh M.: Chapter 22 in Genomic and Precision Medicine.3rd edn.2019. Infectious and Inflammatory Diseasepp. 429-444.

30 van Spil W.E., Szilagyi I.A.: Osteoarthritis year in review 2019: biomarkers (biochemical markers). Osteoarthritis
Cartilage 2020; 28: pp. 296-315.

31 Davies D.V.: Synovial membrane and synovial fluid of joints. Lancet 1946; 2: pp. 815-819.

32 Balakrishnan L., Nirujogi R.S., Ahmad S., Bhattacharjee M., Manda S.S., Renuse S., et. al.: Proteomic analysis of human osteoarthritis synovial fluid. Clin Proteonomics 2014; 11: pp. 6.

33 Scanzello C.R., Umoh E., Pessler F., DiazTorne C., Miles T., Dicarlo E., et. al.: Local cytokine profiles in knee osteoarthritis: elevated synovial fluid interleukin-15 differentiates early from end-stage disease. Osteoarthritis Cartilage 2009; 17: pp. 1040-1048.

34 Kamphorst J.J., van der Heijden R., DeGroot J., Lafeber F.P., Reijmers T.H., van El B., et. al.: Profiling of endogenous peptides in human synovial fluid by NanoLC-MS: method validation and peptide identification. J Proteome Res 2007; 6: pp. 4388-4396.

35 Pan X., Huang L., Chen J., Dai Y., Chen X.: Analysis of synovial fluid in knee joint of osteoarthritis:5 proteome patterns of joint inflammation based on matrix-assisted laser desorption/ionization time-of-flight mass spectrometry. Int Orthop 2012; 36: pp. 57-64.

36 Ritter S.Y., Subbaiah R., Bebek G., Crish J., Scanzello C.R., Krastins B., et. al.: 
Proteomic analysis of synovial fluid from the osteoarthritic knee: comparison with transcriptome analyses of joint tissues. Arthritis Rheum 2013; 65: pp. 981-992.

37 Wang Q., Rozelle A.L., Lepus C.M., Scanzello C.R., Song J.J., Larsen D.M., et. al:: Identification of a central role for complement in osteoarthritis. Nat Med 2011; 17: pp. 1674-1679.

38 Bastiaansen-Jenniskens Y.M., Wei W., Feijt C., Waarsing J.H., Verhaar J.A., Zuurmond A.M., et. al:: Stimulation of fibrotic processes by the infrapatellar fat pad in cultured synoviocytes from patients with osteoarthritis: a possible role for prostaglandin f2alpha. Arthritis Rheum 2013; 65: pp. 2070-2080.

39 Chu S.C., Yang S.F., Lue K.H., Hsieh Y.S., Li T.J., Lu K.H.: Naproxen, meloxicam and methylprednisolone inhibit urokinase plasminogen activator and inhibitor and gelatinases expression during the early stage of osteoarthritis. Clin Chim Acta 2008; 387: pp. 90-96.

40 Waarsing J.H., Bierma-Zeinstra S.M., Weinans H.: Distinct subtypes of knee osteoarthritis: data from the Osteoarthritis Initiative. Rheumatology 2015; 54: pp. 1650-1658.

41 Nelson A.E., Fang F., Arbeeva L., Cleveland R.J., Schwartz T.A., Callahan L.F., et. al.: A machine learning approach to knee osteoarthritis phenotyping: data from the FNIH Biomarkers Consortium. Osteoarthritis Cartilage 2019; 27: pp. 9941001. 


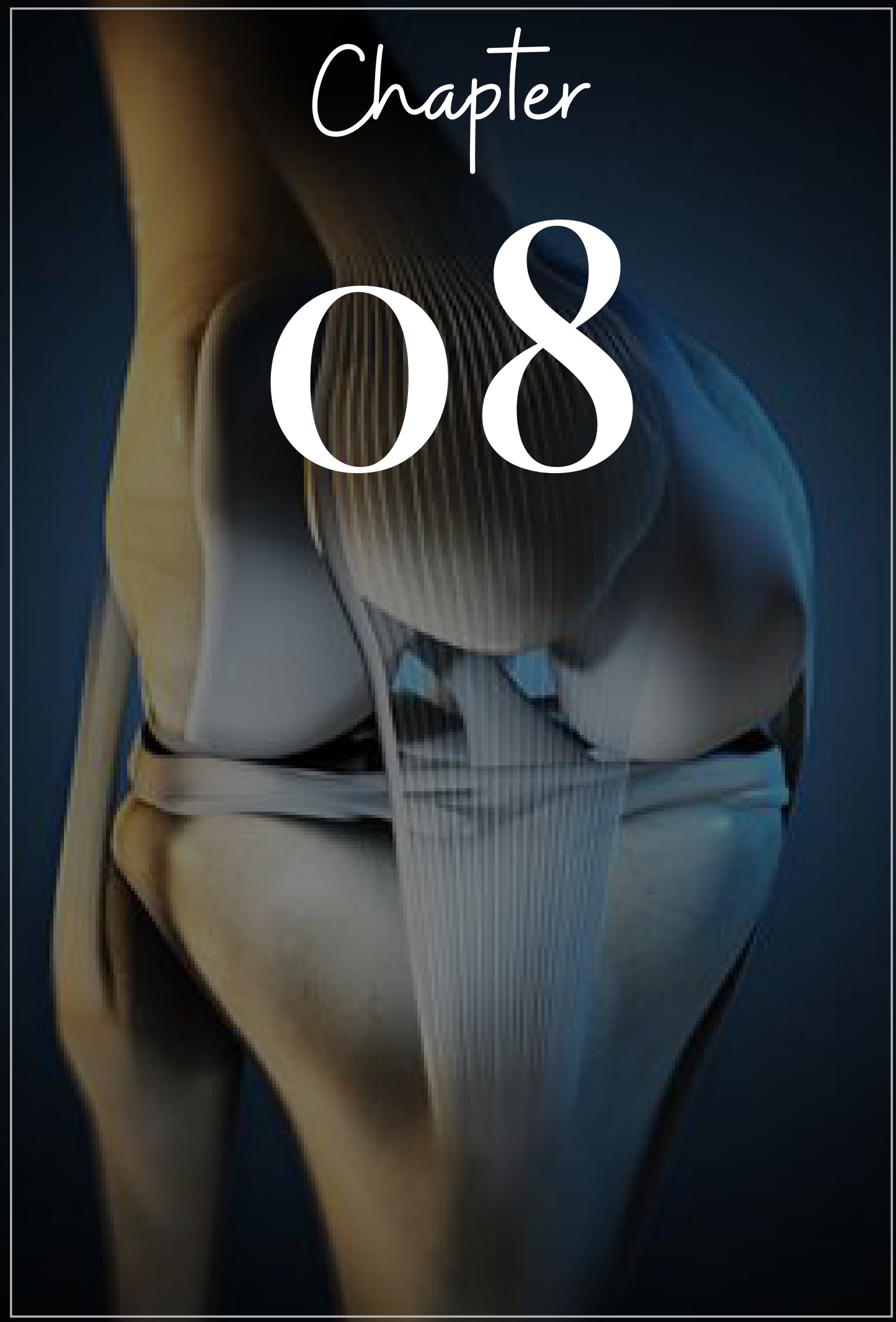


General Discussion, Conclusion and Clinical Perspectives for the Future 
The knee joint is exposed to biomechanical demands and complex interactions exist between its biological composition'. From a micro-environmental point of view, distinct cell types exist within the different intra-articular tissues, which are responsible for a physiological joint functioning. From a macro-environmental point of view, all these distinct cell types and joint tissues form a large functioning unit, the knee joint, which is able to withstand biomechanical forces and support locomotion. External influences on the knee joint can exceed physiological limits, but also internal derangements can lower the capacity for adaptive responses ${ }^{2}$. This will lead to a disruption in knee joint homeostasis leading to an impaired knee joint quality ${ }^{3}$. Knee joint quality depends on the equilibrium between intra-articular tissues such as cartilage, synovium, Hoffa's fat pad (HFP), meniscus, but also extra-articular tissues such as peri-articular muscles ${ }^{2,4}$. Risk factors such as ageing, inflammatory diseases, sex, race, obesity, genetics, joint trauma or loading on a maligned joint are examples of external or internal influences which can induce degenerative changes in joint tissues and cells within the joint ${ }^{3,5,6,7}$. This will consequently lead to a loss of joint tissue quality. If tissue quality is compromised and cells within these tissues cannot compensate by means of tissue remodeling processes, the equilibrium within the knee joint becomes chronically disturbed and even normal daily activity levels may become pathological, leading to inferior 'knee joint quality'. In this thesis, we aimed to gain new insights in novel strategies to improve 'knee joint quality' either on a cellular, tissue or total knee joint level. 


\section{Improving Knee Joint Quality on the Cellular Level}

Cell

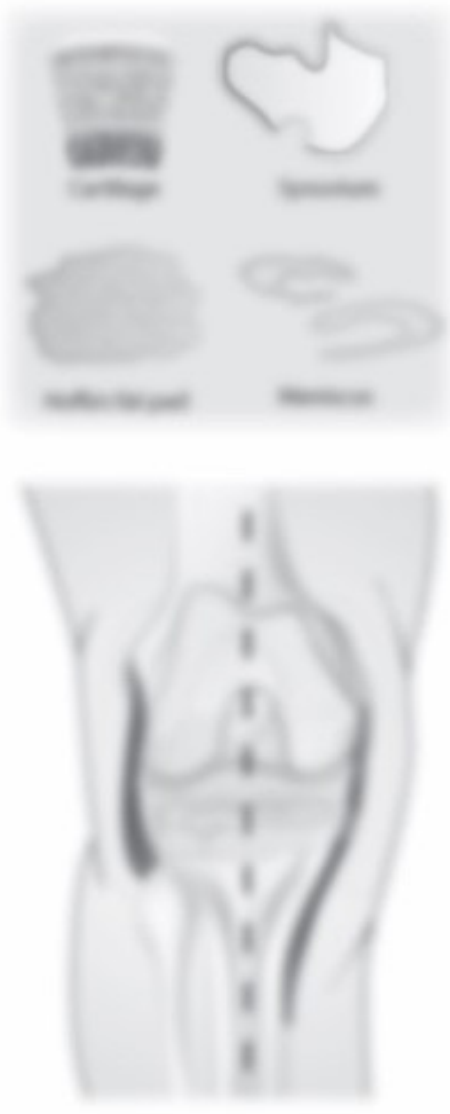




\subsection{Improving the Chondrocyte Phenotype through Culturing Chondrocytes under Conditions Resembling their In Vivo Physiological Environment}

Focal cartilage defects may lead to inferior knee joint quality due to distorted joint biomechanics, an increased inflammatory intra-articular environment, and ultimately lead to osteoarthritis $(\mathrm{OA})^{8}$. Therefore, we have evaluated molecular mechanisms involved in the phenotypic improvement of human articular chondrocytes. This may lead to improvements in cell-based cartilage repair strategies and thereby supporting post-treatment knee joint quality ${ }^{9}$. In Chapter 2, we showed that culturing human articular chondrocytes under oxygen tension closely resembling their physiological in vivo environment, improves collagen type II expression via TGF- $\beta^{10}$. Given the fact that hypoxia has been shown to upregulate mRNA expression of TGF- $\beta$ superfamily members in different cell types ${ }^{11,12,13}$, we hypothesized that TGF- $\beta$ is involved in improving the chondrocyte phenotype in hypoxic cultures. Using specialized bioreactor technology, human articular chondrocytes were cultured under hypoxic $\left(1 \% \mathrm{pO}_{2}\right)$ or normoxic $\left(20 \% \mathrm{pO}_{2}\right)$ conditions. We first confirmed that culturing chondrocytes under hypoxic conditions improves the chondrocyte phenotype. Interestingly, of all three TGF- $\beta$ isoforms, TGF- $\beta 2$ expression was specifically upregulated under hypoxia on both gene and protein level, as were TGF- $\beta$ type I receptors ALK 1 and ALK5. Characterization of the human TGF- $\beta$ isoforms revealed that TGF- $\beta 2$ possesses the longest $5^{\prime}$ untranslated region (UTR), which hints towards a unique post-transcriptional regulation of its protein translation ${ }^{14}$. TGF- $\beta 2$ further differs from the other two isoforms by its binding affinity towards the TGF- $\beta$ type II receptor. In contrast to TGF- $\beta 1$ and TGF- $\beta 3$, its affinity for TGF- $\beta$ type II receptors is weaker and requires the type III receptor betaglycan ${ }^{15}$. While in this study we were not able to show regulation of betaglycan under hypoxic conditions at the mRNA level, post-transcriptional regulation may regulate betaglycan protein levels, which may lead to improved TGF- $\beta 2$ ligand signaling. Indeed, in another study it was found that under hypoxia, endoglin expression was reduced in chondrocytes while faint betaglycan immunoblotting signals appeared increased, hinting towards a role of this assessor receptor in TGF- $\beta$ mediated COL2A 1 expression ${ }^{16}$.

As cartilage is generally considered to be "hypoxic and hyperosmotic"17,18, the involvement of the TGF- $\beta$ pathway in the improvement of the chondrocyte phenotype under hypoxic 
conditions prompted us to also investigate its role under hyperosmotic conditions in Chapter 3. We could confirm an improved chondrocyte phenotype under hyperosmotic conditions. Importantly, we reported earlier that this is not related to accumulation of specific inorganic ions but due to specific osmolarity-mediated effects ${ }^{19}$. Interestingly, hyperosmotic conditions also most prominently increased TGF- $\beta 2$ mRNA expression, which was in concordance with our experiments under hypoxic conditions. This may indicate that of the three TGF- $\beta$ isoforms, TGF- $\beta 2$ has a prominent role in regulating the chondrocyte phenotype under hyperosmotic and hypoxic conditions.

Crosstalk between TGF- $\beta$ superfamily members has been shown to exert synergistic or antagonistic effects on a myriad of events, such as cell proliferation, migration and matrix synthesis in different cell types such as epithelial cells ${ }^{20}$, but also in chondrocytes ${ }^{21}$. Bone morphogenetic proteins (BMPs) are members of the TGF- $\beta$ superfamily ${ }^{22}$. By using the BMP-signaling inhibitor dorsomorphin, we further elucidated the influence of TGF- $\beta$ superfamily members on $C O L 2 A 1$ expression in human articular chondrocytes under TGF- $\beta 2$ knockdown conditions. While COL2A1 expression appeared to be largely BMPsignaling dependent in human articular chondrocytes (HACs), we found higher COL2A1 expression levels under hyperosmotic condition compared to non-hyperosmotic conditions under dorsomorphin treatment. Apparently, hyperosmotic conditions stimulate COL2A1 expression independently of TGF- $\beta$ superfamily signaling. While many of the signaling responses induced by TGF- $\beta$ are mediated by SMAD proteins, evidence is accumulating that TGF- $\beta$ can signal via SMAD-independent pathways, such as MAP kinases ${ }^{23}$. To understand the mechanisms involved in this specific TGF- $\beta$ signalling, it is crucial to unravel the intracellular events that provide a link between activated TGF- $\beta$ on the cell surface and its downstream effects. The mitogen-activated protein kinase (MAPK) pathway consists of several phosphorylation cascades, each of which modulates different signalling events, either alone or in concert with other pathways ${ }^{24}$. Three major subgroups of the MAPK super family, Extracellular signal-regulated kinases (ERK), p38 MAP kinase and c-Jun N-terminal kinase (JNK), have been found to participate in TGF- $\beta$ signalling ${ }^{25,26,27}$. These kinases can be activated by various extracellular stimuli, including environmental stressors such as hypoxia and hyperosmolarity, and they play an essential role in the signal transduction 
cascades that alter cell growth and other key cell functions $\mathbf{s}^{28,29,30}$. In future experiments, it will be of interest to investigate the influence of hyperosmotic and hypoxic conditions on these alternative TGF- $\beta$ signalling components. Targeting downstream kinase targets such as ERK, p38 and JNK in future experiments may give more insights into hypoxia and osmolarity-mediated effects on the chondrocyte phenotype.

Stresses such as osmolarity have been shown to enhance susceptibility to TGF- $\beta$ by increasing TGF- $\beta$ type I receptor protein levels and downregulating the expression of TGF-beta signalling inhibiting SMAD proteins (i.e. SMAD7) ${ }^{31}$. This increased susceptibility to TGF- $\beta$ signalling may be a contributing mechanism and potential explanation for the increased TGF- $\beta$ bioactivity we have demonstrated under hyperosmotic conditions. Furthermore, cytoskeletal changes may activate latent TGF- $\beta$, thereby releasing TGF- $\beta$ from extracellular matrix (ECM) stores ${ }^{32}$. Latent TGF- $\beta$ activation requires a contractile cytoskeleton ${ }^{33}$. In kidney cells, it has been shown that osmotic stress can activate latent TGF- $\beta^{34}$, and this might not be different in other cell types such as the chondrocyte. We speculate that cytoskeletal changes caused by an increase in osmolarity ${ }^{18}$ may lead to contractile forces in the cytoskeleton potentially leading to increased TGF $\beta$ activity. Future experiments have to elucidate the exact mechanisms involved in the osmolarity mediated activation of latent TGF- $\beta$.

Wedoacknowledgethat the hyperosmoticand hypoxicculture conditionswehavedescribed in Chapter $\mathbf{2}$ and Chapter $\mathbf{3}$ can increase the expression of hypertrophic chondrocyte markers such as collagen type $X^{36,37}$. This notion has important clinical implications, since another concern described for cartilage regenerative approaches is the hypertrophic differentiation of the cartilage graft ${ }^{38}$. Hypertrophic differentiation of chondrocytes has been described for $\mathrm{ACl}$, perichondrium transplantation and microfracture ${ }^{39,40}$. Moreover, we have published a review in which we show that OA chondrocytes display features of hypertrophic differentiation showing changes which resemble the process of endochondral ossification ${ }^{41}$. Importantly, targeting chondrocyte hypertrophic processes may aid in improving cartilage-repair strategies and slow down knee OA progression. Our group previously published findings showed that COX-2 inhibition during chondrogenic differentiation of progenitor cells effectively decreased the level of chondrocyte 
hypertrophic differentiation in in vitro, ex vivo and in vivo chondrogenic models ${ }^{42}$. While we showed that TGF- $\beta$ signaling is involved in chondrocyte phenotype improvement, TGF- $\beta$ has also been associated with an induction of COX-2 expression ${ }^{43,44}$. This induction may lead to hypertrophic differentiation of chondrocytes. Therefore, combining hyperosmotic or hypoxic chondrocyte treatment with selective COX-2 inhibitors may be used to prevent hypertrophic differentiation under these environmental conditions.

In conclusion, based on our results and previous literature, our data from Chapter 2 and $\mathbf{3}$ further support existing evidence that TGF- $\beta$ superfamily members are in a tight interplay in regulating the chondrocyte phenotype in environmental conditions relevant for the articular chondrocyte. These environmental conditions describing physiological oxygenation and osmolarity levels in cartilage, could in future research be described as 'physoxia' and 'physosmolarity'. 
Chapter 8

\section{Improving Joint Quality on the Tissue Level}

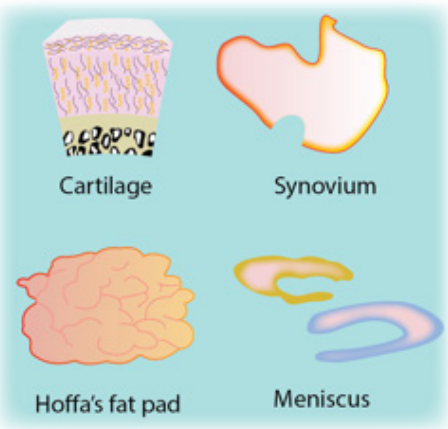

Tissue

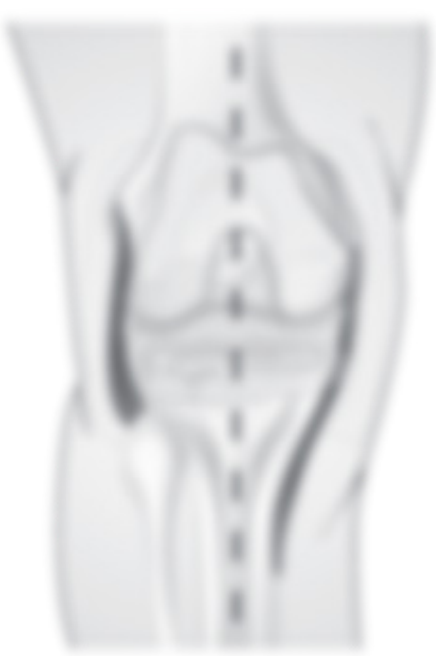




\subsection{Hoffa's Fat Pad: An Important Participant in Determining Knee Joint Quality}

One of the knee joint components which is increasingly being recognized as an important actor in joint pathologies such as knee $\mathrm{OA}^{45}$, is the HFP. In Chapter $\mathbf{4}$ of this thesis, we have focused on this specific knee joint component with a specific focus on inflammatory processes. Inflammation is thought to be a physiological response to a disruption in the homeostatic balance and can be defined as an activation of effector mechanisms in an attempt to restore homeostatic balance and return the system to the status quo ${ }^{46}$. Gaining insights into the role of these inflammatory processes for knee joint quality may yield important clues to develop new treatment strategies to improve knee joint quality.

In Chapter 4, we have compared release of prostaglandins, important molecules involved in inflammation ${ }^{47}$, between HFP from OA and cartilage defect patients. Next to comparing the inflammatory profile between $\mathrm{OA}$ and cartilage defect patients, we also investigated the ability to modulate inflammation in HFP from these patients by means of inhibiting prostaglandin production by celecoxib treatment. Our data support the notion that the HFP is an important contributor to inflammation in joint pathologies such as knee OA but also cartilage defects and should not solely be considered as a shock absorber in the knee joint ${ }^{45}$. The secretion of prostanoid subtypes from the HFP from knee OA patients distributed into $2 \mathrm{OA}$ subgroups. Subgrouping may be related to a different subtype of knee $\mathrm{OA}$, duration of OA development and/or inhomogeneity of HFP tissue with differentially distributed immune cells. Of note, a recent study demonstrated that knee OA patients with hypercholesterolemia have altered expression levels of the downstream $\mathrm{PGE}_{2}$ synthase, mPGES, in HFP ${ }^{48}$. Thus, patient specific characteristics, such as hypercholesterolemia, appear to result in differential expression levels of enzymes involved in inflammation. Our findings in Chapter $\mathbf{4}$ showing variable secretion of prostanoid subtypes distributing to 2 OA subgroups is further in accordance with previous work from Massicotte et al. showing variable secretion of $\mathrm{PGE}_{2}$ by subchondral osteoblasts from knee $\mathrm{OA}$ patients, which distributed to $2 \mathrm{OA}$ subgroups ${ }^{49}$. In our study, in addition to $\mathrm{PGE}_{2^{\prime}}$ release of two other prostanoid subtypes $\mathrm{PGF}_{2 \mathrm{a}}$ and $\mathrm{PGD}_{2^{\prime}}$ but not $\mathrm{TXB}_{2}$, was higher in the high-PGE $\mathrm{P}_{2} \mathrm{OA}$ group than the cartilage defects group, and correlated with increased COX-2 expression. Hence, specific prostanoid subtypes are released from the OA HFP and may participate in the 
inflammatory response in the HFP.

Given the fact that obesity leads to inflammatory changes in adipose tissue ${ }^{50}$, one can hypothesize that similar inflammatory changes may also be present in HFP of obese patients which eventually may lead to articular cartilage pathology. Kisand and colleagues showed prominent associations between OA in the patellofemoral joint in woman, BMI and the adipokine leptin ${ }^{51}$. However, in our study we did not identify a correlation between prostanoid levels released by HFP and BMI in Chapter 4. Also other colleagues in the field do not show an association of BMI and inflammatory changes in HFP ${ }^{52,53}$. Moreover, in contrast to subcutaneous adipose tissue, nor HFP size neither size of the adipocytes in the osteoarthritic HFP is correlated to body mass index ${ }^{52,54,55,56}$. These findings emphasize that the HFP should be considered as a unique adipose tissue, which is distinct from subcutaneous adipose tissue, and suggests that HFP may not be involved in obesity-related joint environmental changes in knee OA.

To evaluate the possibility of improving joint homeostasis via influencing the HFP inflammatory status, we have used the specific COX-2 inhibitor celecoxib to target the inflamed HFP in Chapter 4. Consistent with our data showing a correlation between PTGS2 and $\mathrm{PGE}_{2}$ release in HFP, the COX-2 inhibitor celecoxib was able to effectively reduce $\mathrm{PGE}_{2}$ release by HFP by at least $80 \%$. These data highlight the potential of celecoxib to target the inflamed HFP and reduce release of prostanoids known to be involved in inflammation ${ }^{57}$. We did not evaluate the action of celecoxib on specific cell types present within the HFP, but our experiments in Chapter $\mathbf{4}$ showed that celecoxib treatment of the inflamed HFP modulated expression of factors associated with $\mathrm{M} 1$ and $\mathrm{M} 2$ macrophages. Furthermore, celecoxib was able to skew the expression ratio of $\mathrm{M} 1 / \mathrm{M} 2$ markers towards a more favorable M2 phenotype most effectively in HFP tissue with higher prostanoid release. This indicates that the capacity of celecoxib to skew towards the expression of markers associated with M2 macrophages in HFP tissue is dependent on the amount of inflammation present. Future research should address celecoxib mediated effects on macrophage phenotype in the HFP using flow-cytometry. Furthermore, it will also be interesting to investigate antiinflammatory effects of celecoxib on other immune cells such as lymphocytes and mast cells which have been shown to be present in HFP 45 . 
From Chapter 4 it became evident that the HFP of patients with cartilage defects produce prostanoid subtypes which are involved in inflammation. This supports the theory that the HFP of patients with cartilage defects is an important contributor to inflammatory factors found in synovial fluid of this patient group. The positive association between pro-inflammatory factors in synovial fluid and cartilage degradation is increasingly being recognized ${ }^{46,58,59}$. Considering reports showing that targeting pro-inflammatory cytokines in knee joint synovial fluid may attenuate cartilage degradation in vivo following knee injury ${ }^{58}$, it is likely that an increased inflammatory profile in knee joint synovial fluid negatively affects the outcome of cartilage repair strategies. Therefore, our findings in Chapter 4 demonstrating a difference in prostanoid release profile of HFPs from patients suffering from a cartilage defect may have important therapeutical implications. Specifically, it may implicate that certain patients with an increased inflammatory profile in their HFP may not optimally benefit from cartilage repair approaches. Next to aiding in decision-making for cartilage repair surgery, the level of HFP inflammation may also be used to predict the outcome of cartilage repair surgery.

In conclusion, the HFP is an important actor in determining knee joint quality and by secreting prostanoids and other inflammatory molecules participates in the inflammatory process observed in joint pathologies such as knee OA and cartilage defects. Specific prostanoids secreted by the HFP may serve as biomarkers in synovial fluid to assess the health status of the knee joint, and celecoxib may be used to improve knee joint quality via modulating HFP inflammation.

\subsection{The Influence of other Intra-Articular Tissues on Knee Joint Quality}

Knee joint quality is not attributable to a single joint tissue, but is characterized by the interplay of different intra-articular and extra-articular tissues. Although the work in this thesis has focused on anti-inflammatory modulation of the HFP, we do acknowledge the role of other intra-articular tissues in determining knee joint quality. Next to the HFP other fat pads are present in the knee joint: the posterior fat pad, anterior suprapatellar fat pad and the posterior suprapatellar fat pad $^{45}$. Interestingly, the suprapatellar fat pad together with another fat pad located in the hip joint, the acetabular fat pad, has been shown to 


\section{Chapter 8}

release higher amounts of inflammatory mediators such as IL-7, IL-8 and PGE ${ }_{2}$ compared to subcutaneous adipose tissue ${ }^{60}$. Moreover, stimulation of fibroblast-like synoviocytes with medium conditioned by the HFP and the suprapatellar fat pad from knee OA patients induces an inflammatory response in synoviocytes ${ }^{60}$. This indicates cross-talk between intra-articular adipose tissue and synovium within the joint, which may be involved in joint inflammation. In addition, it has been shown that ACL rupture in sheep results in inflammatory changes in the HFP61, and also inflammatory changes in synovium have been described ${ }^{62}$. Therefore, anti-inflammatory actions of celecoxib on these tissues in vivo may lead to improved joint homeostasis.

The subchondral bone is another functional unit in the knee joint, releasing factors in to the synovial fluid via diffusion through cartilage ${ }^{63}$. The subchondral bone displays a broad range of functional disarrangements in knee OA. At the osteochondral junction of osteoarthritic cartilage, a duplication and sometimes multiplication of the tidemark and vascular channels entering the non-calcified cartilage have been observed ${ }^{64,65}$. The vascular invasion results in advancement of the calcified cartilage layer into the deep zones of the articular cartilage, which leads to thinning of the articular cartilage ${ }^{66,67}$. The subchondral bone in OA cartilage has been shown to display altered biomechanical properties due to bone resorption at the osteochondral junction ${ }^{68,69}$. Moreover, pain in knee OA may be related to the increased osteochondral vascularity which is observed in knee $\mathrm{OA}^{64}$. In addition, bone marrow lesions in the subchondral bone have also been described which may be a cause of pain in $O A$ patients ${ }^{70,71}$. These lesions are characterized by a focally increased signal on fat-suppressed T2-weighted MRI imaging ${ }^{70}$. Histological evaluation of these lesions demonstrate microfractures of the trabecular bone structure, fibrosis, medullary fat necrosis, hypervascularity and poor mineralization ${ }^{72}$. A novel treatment approach to target bone marrow lesions is subchondroplasty ${ }^{73}$. This technique involves the injection of calcium phosphate into the space between trabeculae of cancellous bone in the subchondral bone where the bone marrow lesion is present. It has been suggested to result in pain reduction in knee OA patients ${ }^{73,74}$.

The anterior cruciate ligament $(A C L)$ is another tissue present in the knee joint which plays an important role in knee joint quality. The $A C L$ is essential for knee joint kinematics and 
acts as an anterior/posterior stabilizer but also provides knee joint stability during rotatory movements ${ }^{75}$. An ACL rupture makes the kneejoint more susceptible to damage to important joint structures such as articular cartilage and the meniscus ${ }^{76}$. It is frequently associated with bone bruises in the dorsal lateral tibia plateau and the anterior femoral condyle leading to subchondral fractures, which may lead to future cartilage damage ${ }^{77}$. In addition, altered knee joint kinematics leading to a shift in tibiofemoral cartilage loading has been shown in an ACL-deficient knee ${ }^{78}$. This may on the long-term lead to cartilage deterioration and future OA. Next to alterations in knee joint kinematics, studies have also shown that the ACL is altered at the molecular and cellular level. For instance, neovascularization, leucocyte infiltration, a disorganization of collagen fibers and chondroid metaplasia are well-known features of the $A C L$ that occur during joint pathologies such as knee $O A^{79,80,81}$.

The meniscus plays a major role in knee joint homeostatic processes, both from a mechanical and biochemical point of view. Traditionally, it has been thought that the meniscus plays an important role in maintaining joint homeostasis due to its ability to absorb shocks and to increase joint congruency ${ }^{82}$ and huge scientific efforts have been made in order to develop treatment strategies for meniscal tears, given its association with future OA. However, less focus has been paid on the meniscus as a contributor to molecular mediators in synovial fluid that can compromise joint homeostasis. The meniscus is not merely a bystander in knee OA: it is an active participant in knee OA by secreting mediators involved in inflammatory processes $^{83}$. This is further supported by reports from the literature. For instance, it has been shown that when exposed to impact injury the meniscus releases different mediators involved in inflammation such as $\mathrm{PGE}_{2}$ and IL-1 $\beta^{84}$. In addition, stimulating the meniscus with IL-1 $\beta$ leads to the secretion of proinflammatory and degradative mediators such as $\mathrm{MMPs}^{84}$. Furthermore, in the light of the paracrine interactions that may occur between intraarticular tissues, Favero et al. showed cross-talk between synovial and meniscal explants from knee OA patients and demonstrated induction of different metalloproteases such as MMP3 and MMP-10 involved in OA pathology ${ }^{85}$. Meniscal tissue has been suggested to be more susceptible to adipokine-stimulated catabolism than cartilage ${ }^{86}$. Considering the fact that intra-articular joint tissues such as the HFP release adipokines, this may implicate that joint injury or other factors leading to increased adipokine release in the knee joint may 


\section{Chapter 8}

alter the mechanical integrity of the meniscus, thereby increasing susceptibility to knee OA development.

In conclusion, several intra-articular tissues such as cartilage, synovium, HFP, meniscus, smaller fat pads, the subchondral bone and the $A C L$ are present in the knee joint. These joint tissues can compromise knee joint homeostasis via secretion of catabolic molecules into the synovial fluid. Moreover, paracrine functional interactions which occur between the different joint tissues can further compromise knee joint homeostasis leading to a catabolic joint environment. A catabolic environment in the knee joint may lead to inferior quality of intra-articular tissues such as the cartilage and the meniscus, which fulfill an important biomechanical role ${ }^{82}$. This in turn will lead to a self-perpetuating vicious cycle of tissue damage and biomechanical knee joint failure. Therefore, these joint components are important subjects for future research and to determine whether they can be targeted for the treatment of knee joint pathologies. 
3. Improving Joint Quality on a 'Total Joint' Level

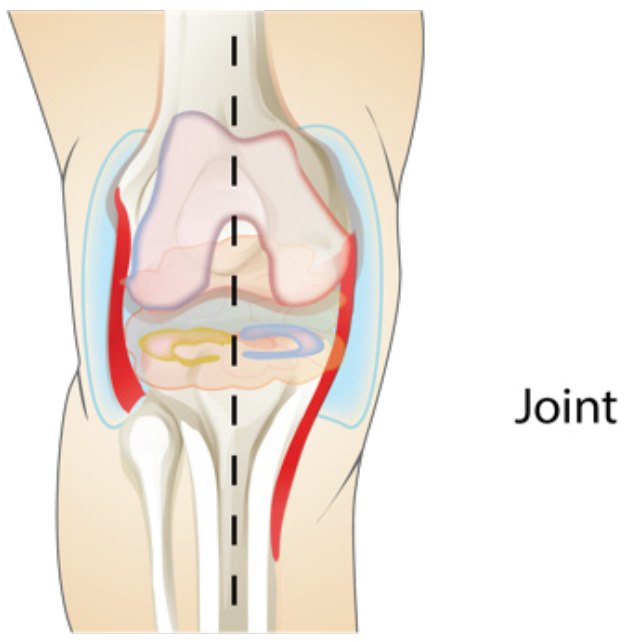




\subsection{Knee Joint Inflammation: Physiologic or Pathologic?}

Knee joint homeostasis can become disturbed and lead to inflammatory changes in intraarticular tissues due to different joint pathologies ${ }^{87}$. One example of a joint pathology that can lead to knee joint inflammation is a focal cartilage defect, as also demonstrated in Chapter $\mathbf{4}^{88}$. These focal cartilage defects are a predisposition for the development of knee OA later in life ${ }^{8}$. The notion that untreated cartilage defects can lead to OA development later in life can be explained from a biomechanical point of view ${ }^{89}$. However, abnormal mechanical loading may, next to purely mechanical damage, also contribute to knee joint inflammation via translation of abnormal mechanical stimuli into inflammatory signaling pathways. This process has been referred to as mechanoinflammation ${ }^{90}$. In concert with this notion, it has been described that subchondral bone changes are associated with early osteoarthritis development ${ }^{91}$. Biomechanical disturbances caused by these changes in subchondral bone architecture can lead to suboptimal biomechanics potentially contributing to a mechanoinflammatory response leading to a self-perpetuating vicious cycle of mechanoinflammation ${ }^{91}$. Given the fact that inflammatory processes may lead to cartilage degradation ${ }^{1}$, it can be hypothesized that a mechanoinflammatory response may potentially cause failure of tissue-engineering strategies to treat cartilage defects. Several reports in literature support the theory that cell-based strategies for cartilage repair are more likely to be successful when implanted into a knee joint with 'normal homeostasis', ${ }^{\prime, 92,93}$. For instance, late treated cartilage defects showed worse outcomes than early treated defects in an in vivo model ${ }^{4}$. This suggests that alterations in joint homeostasis (an increased inflammatory joint environment) specific to the late treated group may have hampered cartilage repair ${ }^{4}$. Moreover, synovial fluid from injured knee joints versus non-injured knee joints negatively affected in vitro chondrogenesis ${ }^{92,93}$. Rodrigo et al. demonstrated that synovial fluid from 'chronically' injured knee joints inhibited the proteoglycan synthesis rate in a chicken limb bud assay ${ }^{93}$. It is tempting to speculate that the synovial fluid of chronically injured knee joints has a specific inflammatory profile inducing catabolic effects on cartilage. However, in the same study it was also shown that the synovial fluid from 'acutely' injured knee joints stimulated proteoglycan synthesis ${ }^{93}$. Thus, it can be concluded that an inflammatory response is not necessarily detrimental for the knee joint 
and is not always related to impaired tissue repair. In fact, inflammation is considered as a normal response of the body to tissue alterations ${ }^{94}$. It has been suggested to be the sum of effector mechanisms activated in response to external or internal noxious stimuli in an endeavor to restore homeostatic balance ${ }^{95}$. Inflammation is a central element of healing processes ${ }^{96}$. As a matter of fact, the transcription factor nuclear factor kappa-light-chainenhancer of activated B cells (NF-KB) is, next to its role in catabolic inflammatory processes, involved in bone fracture repair and has an essential role in chondrogenesis ${ }^{97}$. Lessons we have learned from the role of inflammation in bone fracture healing and the endochondral ossification process have provided important insights in the signaling networks driving cartilage repair processes ${ }^{42}$. Nevertheless, important challenging questions remain within the phenomenon of knee joint inflammation and cartilage repair strategies. When can we consider inflammation as a physiological process attempting to restore homeostatic balance in the knee joint? When should we consider knee joint inflammation as chronic and harmful, leading to knee joint degeneration and inferior knee joint quality? Currently, decision making in treatment for cartilage defects is based on the age of a patient ${ }^{98}$, illustrating the shortcomings in current clinical decision making for this patient group. However, an individual's joint regenerative potential is not necessarily related to age. An individual 35 years of age with multiple comorbidities such as high BMI, diabetes and a mechanically instable knee joint can have a more compromised knee joint homeostasis than an individual 50 years of age with a mechanically stable knee, normal BMI and without diabetes ${ }^{99}$. The future challenge will be to develop a biomarker set for patients with cartilage defects that is able to objectively asses the status of the homeostasis of the joint. Identifying the inflammatory status of the knee joint, for instance by using the prostanoids that we have measured in Chapter $\mathbf{4}$ or inflammatory factors that we have found in the synovial fluid of knee OA patients in Chapter 7, may be part of this set of biomarkers. This identification may lead to better selection of patient groups which will benefit from cartilage repair strategies or alternatively might better be treated using anti-inflammatory strategies to modulate joint homeostasis and to create an environment more permissive for cartilage repair. 
In conclusion, determining the level of knee joint inflammation may aid in patient selection for cartilage repair strategies. A level of knee joint inflammation which does not spontaneously resolve may lead to sustained functional joint problems, which may be treated by means of pharmaceutically active agents that target inflammatory processes. Determining when joint inflammation is not beneficial anymore and investigating factors leading to prolonged and pathologic inflammation will further aid in developing antiinflammatory interventions for joint pathologies.

\subsection{Gaining Control Over Knee Joint Homeostasis}

Joint homeostasis may become disrupted and knee joint quality may become impaired in an inflamed knee joint. To combat this, different methods can be exploited. An intraarticular administration may be an effective means, since this means that the drug will be in direct contact with the different knee joint tissues. In Chapter 5, we have systemically reviewed the evidence for potential in vivo chondroprotective actions of the selective COX2 inhibitors. We reviewed the use of selective COX-2 inhibitors either systemically or intraarticularly. From the systematic review (Chapter 5) it became clear that direct intra-articular administration may be a more effective means to use selective COX-2 inhibitors such as celecoxib to improve joint quality than systemic administration. Importantly, celecoxib is hydrophobic and we speculate that the drug may become entrapped in the Hoffa's fat pad, or other intra-articular adipose tissues which are also present in synovial joints such as the hip and ankle joints ${ }^{100}$. To investigate this possibility, it will be of interest to examine whether these adipose tissues can act as natural drug releasing depots for pharamaceutically active agents, thereby providing anti-inflammatory and chondroprotective effects. While our findings in Chapter 5 suggested superiority of intra-articular injections with selective COX-2 inhibitors over systemic treatment, a drug delivery system may provide additional benefits compared to bolus injections. A drug delivery system may circumvent side effects associated with systemic treatment, allowing a prolonged local drug residence time, increasing patient compliance and preventing frequent intra-articular injections. In this context, the use of a 'smart' drug delivery system in which drug release will be reactive to the disease process, may be an effective means to improve knee joint quality in joint pathologies such as for instance knee OA. In Chapter 6, we have investigated whether celecoxib-loaded 
PEA was chondroprotective. While in Chapter $\mathbf{5}$ chondroprotective effects of celecoxib were suggested, this was not observed in rat knees injected with celecoxib-loaded PEA microspheres. Since we have used a mechanical instability model to induce experimental $O A$, animals mobilizing more may have more severe OA induction. It can therefore be hypothesized that animals which received celecoxib-loaded PEA microspheres loaded the affected joint more compared to animals injected with non-loaded microspheres. This could be attributable to analgesic effects of continuously available celecoxib, and thereby counteracting potential chondroprotective effects of celecoxib.

The auto-regulatory behavior of the drug delivery system we describe in Chapter $\mathbf{6}$ is of particular interest if we consider our results in Chapter 4. In Chapter 4, we identified 2 subgroups of knee OA patients having a high or low inflammatory profile in their HFPs. It will be interesting to investigate whether celecoxib release from our auto regulatory drug delivery system will be more efficient in the patient group with higher inflamed HFPs and whether it will exert its desired anti-inflammatory effect on the HFP and other intraarticular tissues at the moment when inflammation in the tissue flares up.

\subsection{Molecular Diagnostics of Total Knee Joint Homeostasis}

Currently, when assessing joint homeostasis, most techniques focus on only one specific part of the joint. Imaging techniques investigate structural tissue integrity, experimental ex vivo studies focus on articular cartilage specimens, or in vitro studies examine cellular or tissue responses. However, such reductionistic approaches hamper the possibility to fully comprehend the homeostatic nature of a joint and provides a relatively fragmented picture. In Chapter 7, we hypothesized that the synovial fluid, which bathes important intra-articular tissues, represents a promising body fluid to access the homeostatic condition of the knee joint as a whole ${ }^{47,101,102}$. We performed comparative full-proteome analysis of the synovial fluid of OA patients versus non-OA individuals, as well as of the secretomes of Hoffa's fat pad, synovium, meniscus and articular cartilage of osteoarthritic knees. We identified several protein species with a tissue type-dependent release and also demonstrated their OA-specificity. Hence different from hypotheses in literature suggesting that biochemical markers might lack specificity to joint tissues ${ }^{103}$, our findings in Chapter 
7 highlighted the presence of tissue type-dependent release of OA-specific proteins in OA knee joint synovial fluid.

Our findings in Chapter 7 showing a comprehensive insight into the tissue-dependent origin of OA-specific protein species found in knee joint synovial fluid are of particular interest from several points of view. Firstly, considering the current diagnostic limitations in knee $O A$ and given the increasing recognition that several OA subtypes exist ${ }^{103,104,105}$, our findings may aid in the development of molecular diagnostics in sub-/endotyping knee $\mathrm{OA}$. Associations of biochemical markers with severity of knee OA have been shown to correlate to gender, but also even to OA severity in distinct joint compartments such as the tibiofemoral and the patellofemoral joint ${ }^{51}$. The low success rates in clinical trials with new intra-articular treatments to treat joint pathologies such as knee OA may be related to patient heterogeneity and lack of proper patient selection. Therefore, the sub-/endotyping of knee OA holds potential to improve treatment outcomes in clinical trials ${ }^{106}$ (Figure 1). However, it remains to be determined whether biomarkers in synovial fluid can be used as 'stand-alone markers'. Results obtained from measurements of protein biomarkers in the synovial fluid are a snapshot in time, and events such as knee joint trauma might cause important fluctuations in biomarker levels. This will pose specific challenges when using such biomarkers for diagnostics. Nevertheless, these protein biomarkers may aid in clinical decision making in knee OA patients by combining them with other data such as demographical, clinical and imaging data.

Secondly, efficacy studies of novel experimental treatments for knee OA will benefit from biomarkers able to report about the joint's health status on the tissue type level. For instance, cartilage specific biomarkers may aid in evaluating treatments in cartilage repair strategies, while meniscus specific biomarkers may aid in evaluating treatments in meniscus repair strategies. Thirdly, knowledge about the main tissue source of OA-specific proteins present in knee joint synovial fluid is expected to have important implications for understanding knee OA pathophysiology and the tissue type-dependent influence on its progression. 


\section{Knee Osteoarthritis: A Heterogeneous Disease}

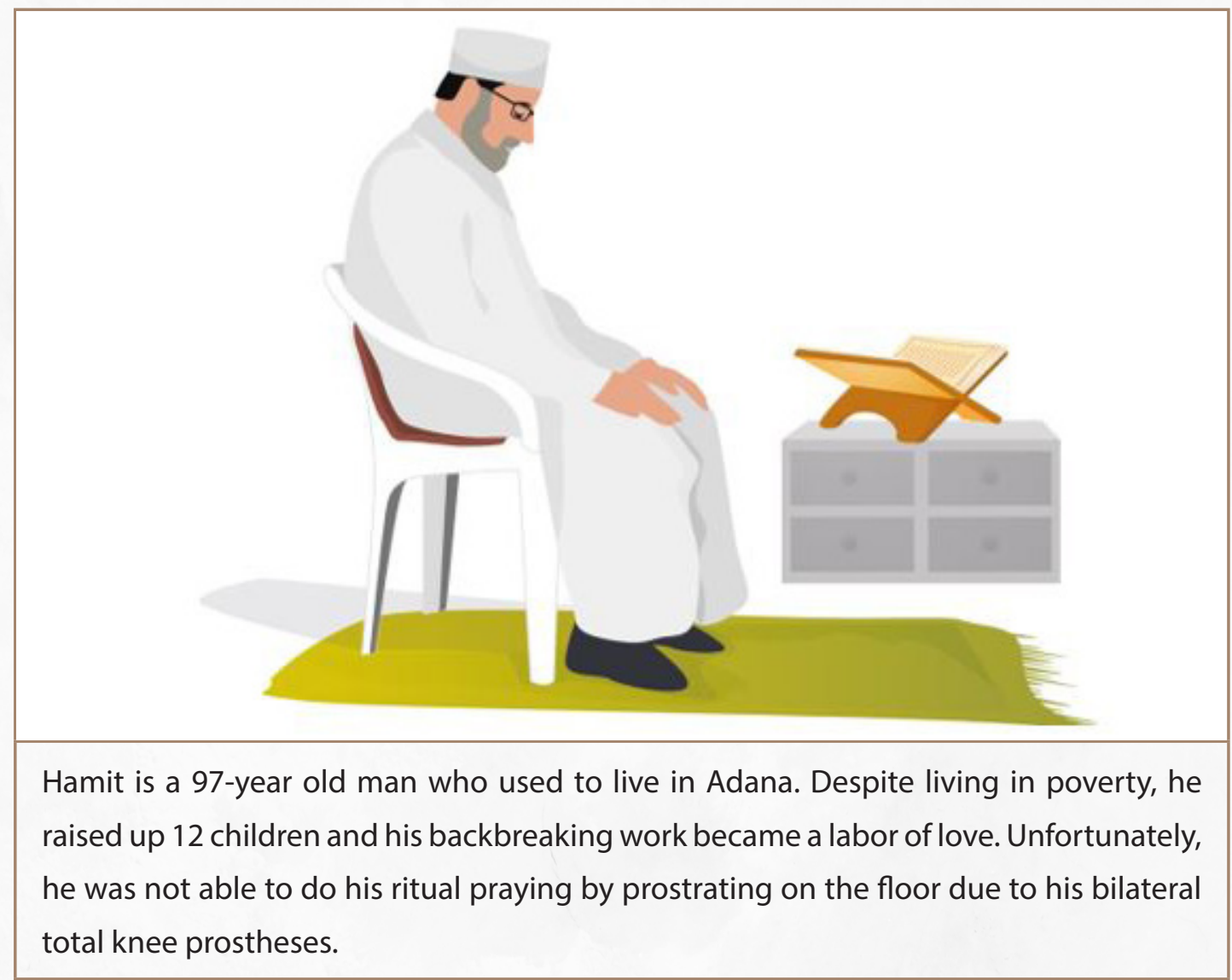



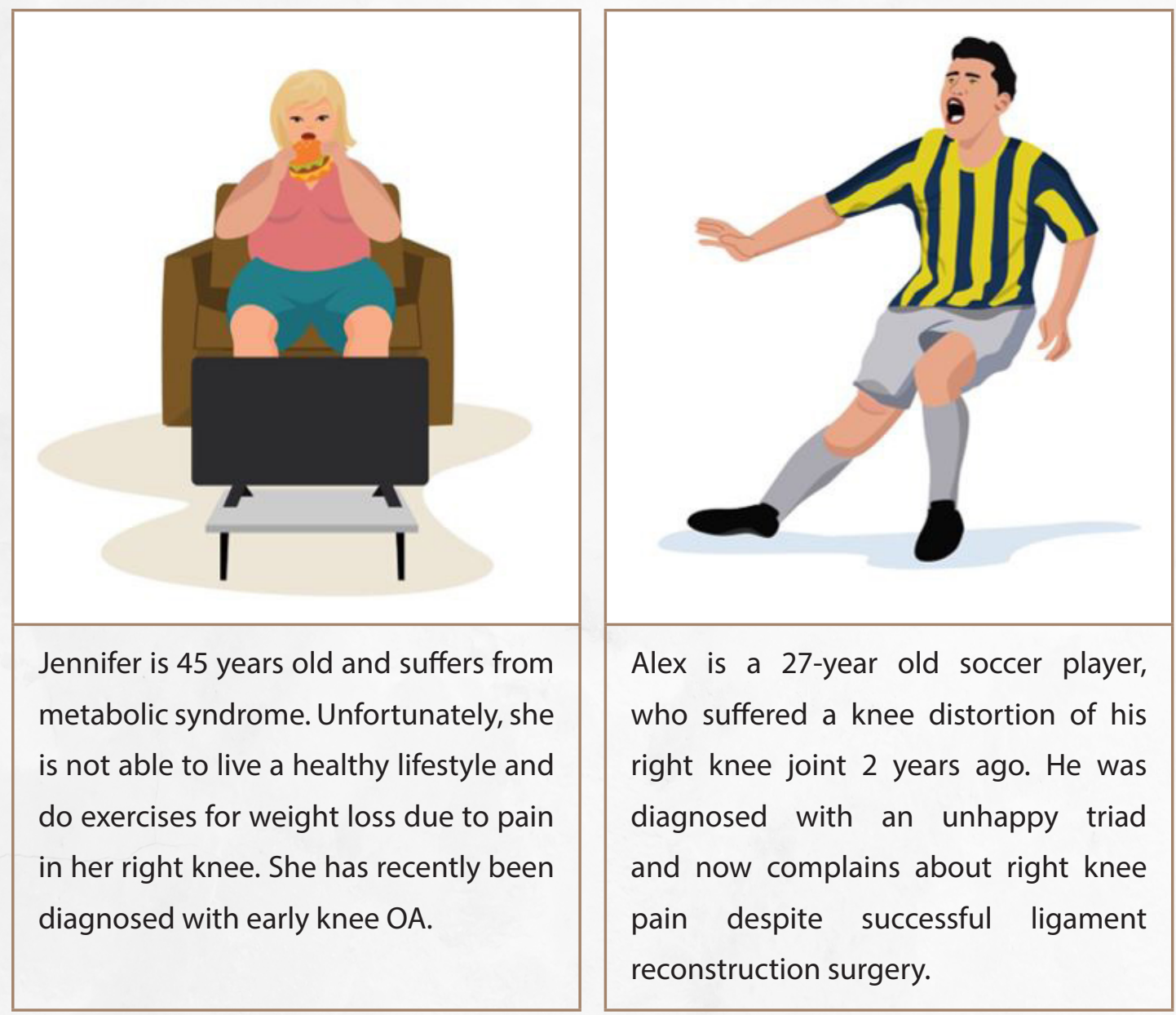


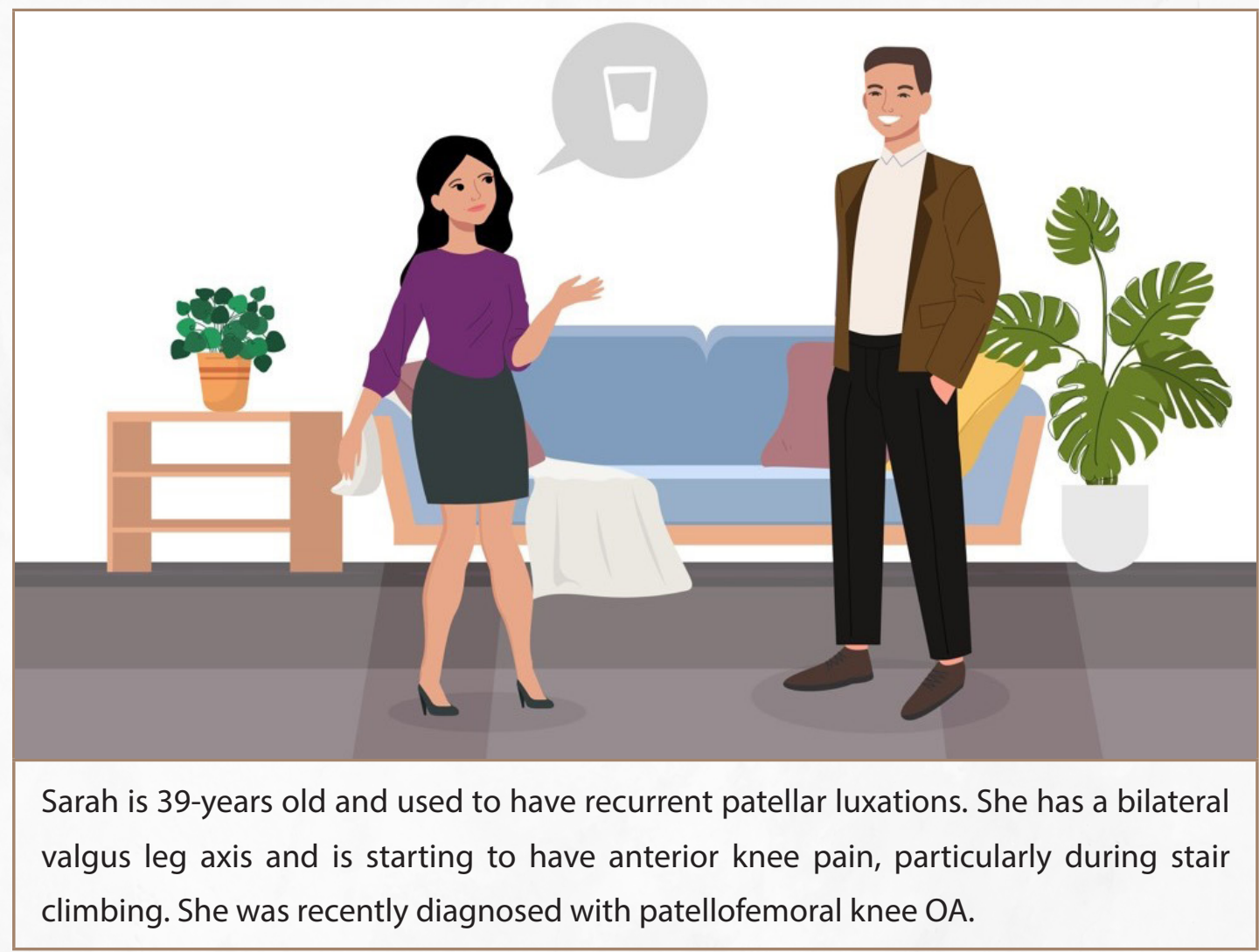




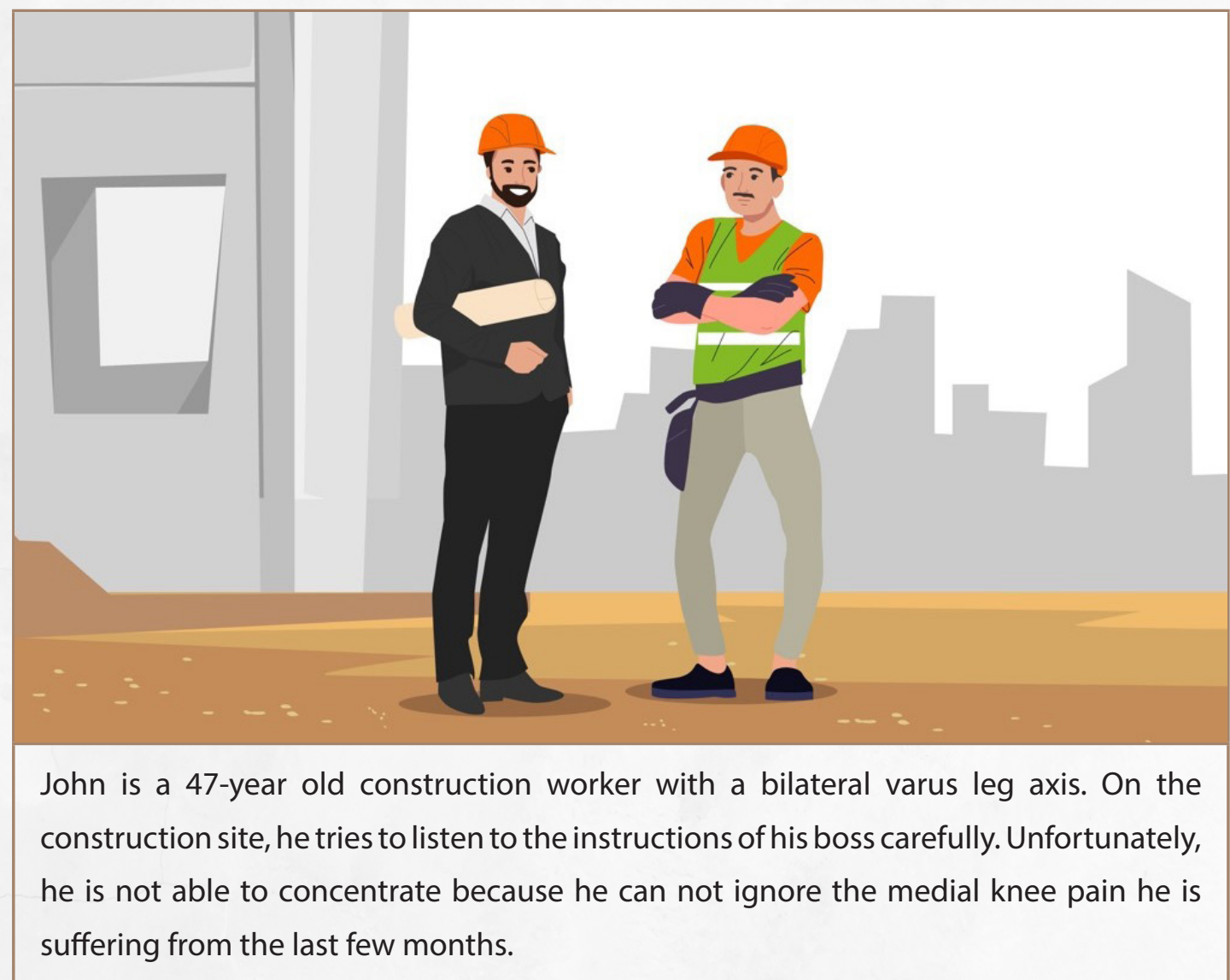

Figure 1: Knee osteoarthritis is a heterogeneous disease.

To date, clinical trials have failed in developing a therapeutic tool which is able to postpone total knee arthroplasty. Clinical trials use a heterogeneous clinical population for whom interventions often are ineffective to modulate $O A$ disease or to relieve pain. Knee osteoarthritis is a final common pathway of cartilage degradation, but should be considered as a total joint disease. In future clinical trials the heterogeneity of the disease should be considered to demonstrate therapeutic effects on disease modification or pain relief. 
Interestingly, TGF- $\beta 2$ was the only cytokine from the TGF- $\beta$ superfamily we detected in our synovial fluid proteomic analysis, as well as in our analyses of the secretomes of cartilage, Hoffa's fat pad, meniscus and synovium. In Chapter $\mathbf{2}$ and Chapter $\mathbf{3}$ we have already demonstrated that this specific TGF- $\beta$ isoform may be of crucial importance for the chondrocyte phenotype. Our protein mass spectrometry results detecting only this specific isoform may point to additional evidence that this specific isoform is important when investigating pathophysiological mechanisms in knee joint pathologies.

Our proteomic analysis of joint tissues in Chapter $\mathbf{7}$ revealed the secretion of several serine proteases such as HTRA, kallikrein and elastase, but also confirmed their presence in synovial fluid. While matrix metalloproteinases are widely believed to be involved in inflammation driven proteolysis in joint pathologies ${ }^{46}$, serine proteases are emerging as important players in degenerative joint pathologies such as osteoarthritis ${ }^{107}$. Therefore, our findings in Chapter 7 highlight the potential of our serine protease-reactive PEA microspheres described in Chapter 6 to be used in joint pathologies and may promise an attractive opportunity to be used as an auto-regulatory drug delivery system with a serine protease activity dependent drug release behavior.

From discovery studies it became clear that the knee joint synovial fluid composition undergoes a great number of detectable biomolecular changes specific for OA and depending on distinct $O A$ subtypes $87,108,109,110,111,112,113,114$. In addition to our proteomic approach, future comparison of release profiles of different joint tissues on the metabolomic, transcriptomic and lipidomic level will provide additional insight in the tissue-type dependent contribution to the development of knee joint pathology.

Taken together, our findings presented in this dissertation demonstrate novel insights in the molecular mechanisms involved in chondrocyte phenotype improvement after hyperosmotic and hypoxic cultures and demonstrate the importance of TGF- $\beta$ signalling in the chondrocyte phenotype. Moreover, the HFP of patients with joint pathologies such as cartilage defects and knee OA has a substantial contribution in the prostanoid content found in synovial fluid. Targeting the knee joint by means of intra-articular injections instead of systemic administration of drugs may be more effective in improving knee joint 


\section{Chapter 8}

homeostasis. Furthermore, celecoxib, either injected as a bolus drug or incorporated in a smart drug release system, such as PEA microspheres, is an attractive novel strategy to improve joint homeostasis. Finally, we uncovered tissue type-dependent release of OAspecific proteins in knee joint synovial fluid. These proteins may be used as biomarkers to aid in developing treatment strategies to improve joint homeostasis for cartilage repair strategies or slowing down knee OA.

In Figure 2, a schematic representation of the main results of this thesis is illustrated. 


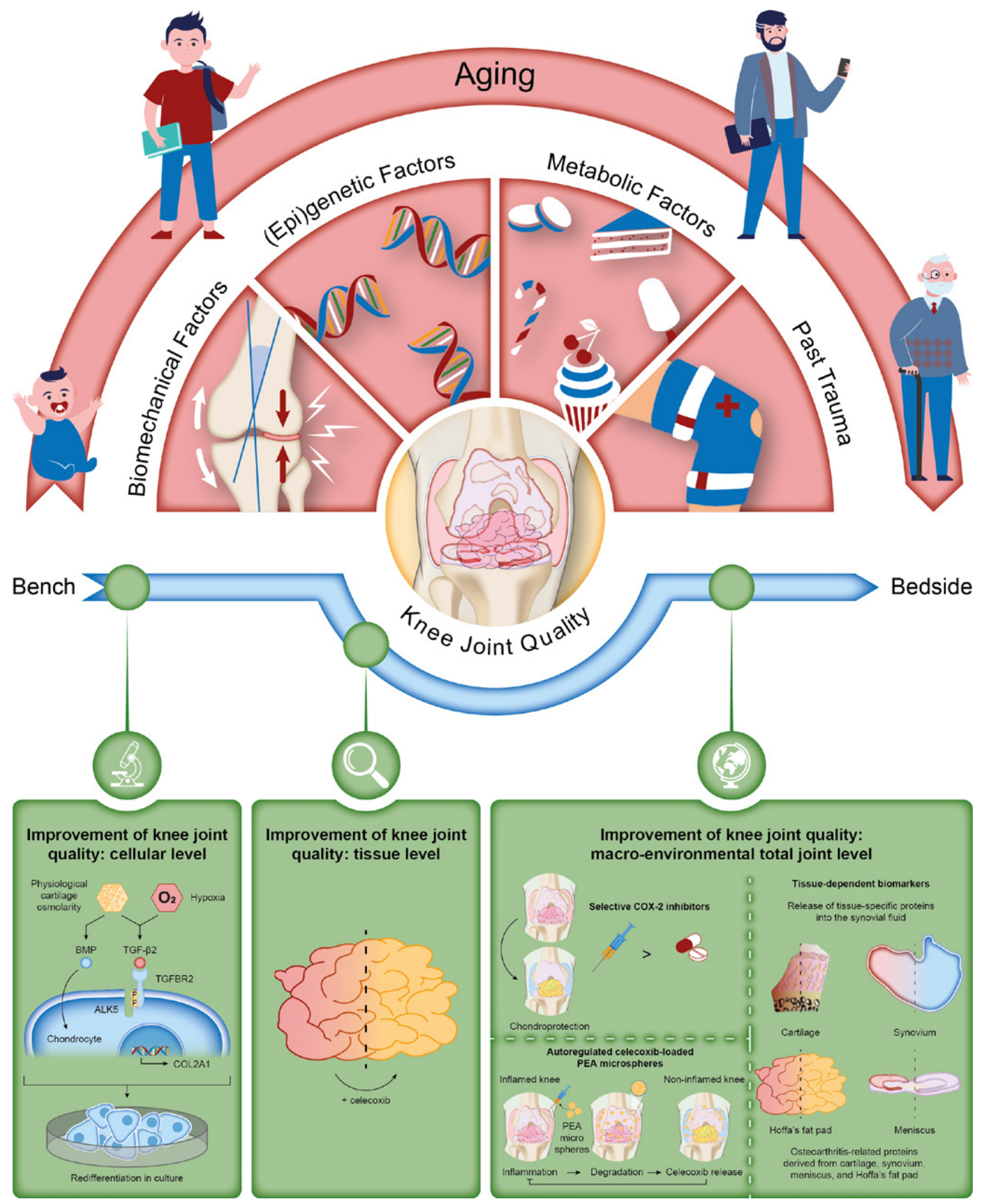


Figure 2: Schematic representation of the main results of this thesis.

Knee joint quality can become compromised due to risk factors such as aging, (epi)genetic factors, metabolic factors, biomechanical factors or past joint trauma. In Chapter $\mathbf{2}$ and $\mathbf{3}$ we have investigated the influence of biophysical environmental factors such as hypoxia and hyperosmolarity on the chondrocyte phenotype. We show that chondrocyte phenotype can be improved when culturing chondrocyte under these conditions and that TGF- $\beta$ superfamily signaling is involved in controlling the chondrocyte phenotype under these conditions. In Chapter 4, we show that the HFP can contribute to the inflammatory mediators found in synovial fluid in joint pathologies such as cartilage defects and generalized knee osteoarthritis and that celecoxib is able to modulate HFP inflammation. The Chapters 5,6 and $\mathbf{7}$ focuses on improving knee joint quality from a more comprehensive macro-environmental point of view. In Chapter 5, our systematic review clarified that direct intra-articular treatment with anti-inflammatory selective COX-2 inhibitor may hold more potential compared to systemic treatment to improve knee joint quality. In Chapter 6, we show that celecoxib loaded PEA microspheres hold potential to be used as an auto regulatory drug release system to improve knee joint quality in inflammatory pathologies such as knee OA. Finally, in Chapter 7 we show tissue type dependent release of OA specific proteins in knee joint synovial fluid which may be used as biomarkers to aid in developing treatment strategies to optimize macroenvironmental joint homeostasis. 


\section{References}

1 Houard X, Goldring MB, Berenbaum F. Homeostatic mechanisms in articular cartilage and role of inflammation in osteoarthritis. Curr Rheumatol Rep. 2013;15(11):375

2 Brandt KD, Radin EL, Dieppe PA, van de Putte L. Yet more evidence that osteoarthritis is not a cartilage disease. Ann Rheum Dis. 2006;65(10):1261-4.

3 Heinegard D, Saxne T. The role of the cartilage matrix in osteoarthritis. Nat Rev Rheumatol. 2011;7(1):50-6.

4 Saris DB, Dhert WJ, Verbout AJ. Joint homeostasis. The discrepancy between old and fresh defects in cartilage repair. J Bone Joint Surg Br. 2003;85(7):1067-76.

5 Sandell LJ. Etiology of osteoarthritis: genetics and synovial joint development. Nat Rev Rheumatol. 2012;8(2):77-89.

6 Zhuo Q, Yang W, Chen J, Wang Y. Metabolic syndrome meets osteoarthritis. Nat Rev Rheumatol. 2012;8(12):729-37.

7 Wluka $A E$, Lombard CB, Cicuttini FM. Tackling obesity in knee osteoarthritis. Nat Rev Rheumatol. 2013;9(4):225-35.

8 Cicuttini F, Ding C, Wluka A, Davis S, Ebeling PR, Jones G. Association of cartilage defects with loss of knee cartilage in healthy, middle-age adults: a prospective study. Arthritis Rheum. 2005;52(7):2033-9.

Hunziker EB, Lippuner K, Keel MJ, Shintani $N$. An educational review of cartilage repair: precepts \& practice--myths \& misconceptions--progress \& prospects. Osteoarthritis Cartilage. 2015;23(3):33450.

10 Pujol JP, Galera P, Redini F, Mauviel A, Loyau G. Role of cytokines in osteoarthritis: comparative effects of interleukin 1 and transforming growth factor-beta on cultured rabbit articular chondrocytes. J Rheumatol Suppl. 1991;27:76-9.

11 Akman $\mathrm{HO}$, Zhang $\mathrm{H}$, Siddiqui MA, Solomon W, Smith EL, Batuman OA. Response to hypoxia involves transforming growth factor-beta2 and Smad proteins in human endothelial cells. Blood. 2001;98(12):3324-31.

12 Falanga V, Qian SW, Danielpour D, Katz $M H$, Roberts AB, Sporn MB. Hypoxia upregulates the synthesis of TGF-beta 1 by human dermal fibroblasts. $J$ Invest Dermatol. 1991;97(4):634-7. 
13 Grimshaw MJ, Mason RM. Modulation of bovine articular chondrocyte gene expression in vitro by oxygen tension. Osteoarthritis Cartilage. 2001;9(4):357-64.

14 Roberts AB, Sporn MB. Differential expression of the TGF-beta isoforms in embryogenesis suggests specific roles in developing and adult tissues. Mol Reprod Dev. 1992;32(2):91-8.

15 Bilandzic M, Stenvers KL. Betaglycan: a multifunctional accessory. Mol Cell Endocrinol. 2011;339(1-2):180-9.

16 Jahr H, Gunes S, Kuhn AR, Nebelung S, Pufe T. Bioreactor-Controlled Physoxia Regulates TGF-beta Signaling to Alter Extracellular Matrix Synthesis by Human Chondrocytes. Int J Mol Sci. 2019;20(7).

17 Zhou S, Cui Z, Urban JP. Factors influencing the oxygen concentration gradient from the synovial surface of articular cartilage to the cartilage-bone interface: a modeling study. Arthritis Rheum. 2004;50(12):3915-24.

18 Urban JP, Hall AC, Gehl KA. Regulation of matrix synthesis rates by the ionic and osmotic environment of articular chondrocytes. J Cell Physiol. 1993;154(2):262-70.

19 van der Windt AE, Haak E, Das RH, Kops N, Welting TJ, Caron MM, et al. Physiological tonicity improves human chondrogenic marker expression through nuclear factor of activated T-cells 5 in vitro. Arthritis Res Ther. 2010;12(3):R100.

20 Guo X, Wang XF. Signaling cross-talk between TGF-beta/BMP and other pathways. Cell Res. 2009;19(1):71-88.

21 Li TF, O'Keefe RJ, Chen D. TGF-beta signaling in chondrocytes. Front Biosci. 2005;10:681-8.

22 Guo X, Wang XF. Signaling cross-talk between TGF-beta/BMP and other pathways. Cell Res. 2009;19(1):71-88.

23 Moustakas A, Heldin CH. Non-Smad TGF-beta signals. J Cell Sci. 2005;118(Pt 16):3573-84.

24 Seger R, Krebs EG. The MAPK signaling cascade. FASEB J. 1995;9(9):726-35.

25 Lee MC, Goomer RS, Takahashi K, Harwood FL, Amiel M, Amiel D. Transforming growth factor beta one (TGF-beta 1) enhancement of the chondrocytic phenotype in aged perichondrial cells: an in vitro study. lowa Orthop J. 2000;20:11-6.

26 Wang W, Zhou G, Hu MC, Yao Z, Tan $\mathrm{TH}$. Activation of the hematopoietic progenitor kinase-1 (HPK1)-dependent, stress-activated c-Jun N-terminal kinase (JNK) pathway by transforming growth factor beta (TGF-beta)-activated kinase (TAK1), a kinase mediator of TGF beta signal transduction. J Biol Chem. 1997;272(36):22771-5. 
27 Simeone DM, Zhang L, Graziano K, Nicke B, Pham T, Schaefer C, et al. Smad4 mediates activation of mitogen-activated protein kinases by TGF-beta in pancreatic acinar cells. Am J Physiol Cell Physiol. 2001;281(1):C311-9.

28 Bokemeyer D, Sorokin A, Dunn MJ. Multiple intracellular MAP kinase signaling cascades. Kidney Int. 1996;49(5):1187-98.

29 Park EC, Rongo C. The p38 MAP kinase pathway modulates the hypoxia response and glutamate receptor trafficking in aging neurons. Elife. 2016;5.

30 Racz B, Reglodi D, Fodor B, Gasz B, Lubics A, Gallyas F, Jr., et al. Hyperosmotic stressinduced apoptotic signaling pathways in chondrocytes. Bone. 2007;40(6):1536-43.

31 Chiang TA, Yang YL, Yang YY, Hu MH, Wu PF, Liu SF, et al. Hyperosmolarity enhanced susceptibility to renal tubular fibrosis by modulating catabolism of type I transforming growth factor-beta receptors. J Cell Biochem. 2010;109(4):66371.

32 Khalil N. TGF-beta: from latent to active. Microbes Infect. 1999;1(15):1255-63.

33 Wipff PJ, Hinz B. Integrins and the activation of latent transforming growth factor beta1 - an intimate relationship. Eur J Cell Biol. 2008;87(8-9):601-15.

34 Sugiura T, Yamauchi A, Kitamura H,
Matusoka Y, Horio M, Imai E, et al. Effects of hypertonic stress on transforming growth factor-beta activity in normal rat kidney cells. Kidney Int. 1998;53(6):165460.

35 Redini F, Galera P, Mauviel A, Loyau G, Pujol JP. Transforming growth factor beta stimulates collagen and glycosaminoglycan biosynthesis in cultured rabbit articular chondrocytes. FEBS Lett. 1988;234(1):172-6.

36 Hirao M, Tamai N, Tsumaki N, Yoshikawa $H$, Myoui A. Oxygen tension regulates chondrocyte differentiation and function during endochondral ossification. J Biol Chem. 2006;281(41):31079-92.

37 van der Windt AE, Haak E, Kops N, Verhaar JA, Weinans $\mathrm{H}$, Jahr $\mathrm{H}$. Inhibiting calcineurin activity under physiologic tonicity elevates anabolic but suppresses catabolic chondrocyte markers. Arthritis Rheum. 2012;64(6):1929-39.

Kreuz PC, Steinwachs M, Erggelet C, Krause SJ, Ossendorf C, Maier D, et al. Classification of graft hypertrophy after autologous chondrocyte implantation of full-thickness chondral defects in the knee. Osteoarthritis Cartilage. 2007;15(12):1339-47.

39 Brittberg $M$, Lindahl A, Nilsson A, Ohlsson C, Isaksson O, Peterson L. Treatment of deep cartilage defects in the knee with 
autologous chondrocyte transplantation.

N Engl J Med. 1994;331(14):889-95.

40 Hayes DW, Jr., Averett RK. Articular cartilage transplantation. Current and future limitations and solutions. Clin Podiatr Med Surg. 2001;18(1):161-76.

41 Ripmeester EGJ, Timur UT, Caron MMJ, Welting TJM. Recent Insights into the Contribution of the Changing Hypertrophic Chondrocyte Phenotype in the Development and Progression of Osteoarthritis. Front Bioeng Biotechnol. 2018;6:18.

42 Welting TJ, Caron MM, Emans PJ, Janssen MP, Sanen K, Coolsen MM, et al. Inhibition of cyclooxygenase- 2 impacts chondrocyte hypertrophic differentiation during endochondral ossification. Eur Cell Mater. 2011;22:420-36; discussion 36-7.

43 Fang L, Chang HM, Cheng JC, Leung PC, Sun YP. TGF-beta1 induces COX-2 expression and PGE2 production in human granulosa cells through Smad signaling pathways. J Clin Endocrinol Metab. 2014;99(7):E1217-26.

44 Harding P, Balasubramanian L, Swegan J, Stevens A, Glass WF, 2nd. Transforming growth factor beta regulates cyclooxygenase- 2 in glomerular mesangial cells. Kidney Int. 2006;69(9):1578-85.

45 Clockaerts S, Bastiaansen-Jenniskens
YM, Runhaar J, Van Osch GJ, Van Offel $J F$, Verhaar JA, et al. The infrapatellar fat pad should be considered as an active osteoarthritic joint tissue: a narrative review. Osteoarthritis Cartilage. 2010;18(7):876-82.

46 Goldring $M B$, Otero $M$, Plumb DA, Dragomir C, Favero M, El Hachem K, et al. Roles of inflammatory and anabolic cytokines in cartilage metabolism: signals and multiple effectors converge upon MMP-13 regulation in osteoarthritis. Eur Cell Mater. 2011;21:202-20.

47 Martel-Pelletier J, Pelletier JP, Fahmi H. Cyclooxygenase-2 and prostaglandins in articular tissues. Semin Arthritis Rheum. 2003;33(3):155-67.

Mukai M, Uchida K, Takano S, Iwase D, Aikawa J, Inoue G, et al. Downregulation of microsomal prostaglandin E2 synthase-1 in the infrapatellar fat pad of osteoarthritis patients with hypercholesterolemia. Lipids Health Dis. 2018;17(1):137.

49 Massicotte F, Lajeunesse D, Benderdour M, Pelletier JP, Hilal G, Duval N, et al. Can altered production of interleukin-1 beta, interleukin-6, transforming growth factorbeta and prostaglandin $\mathrm{E}(2)$ by isolated human subchondral osteoblasts identify two subgroups of osteoarthritic patients. Osteoarthritis Cartilage. 2002;10(6):491500. 
$50 \mathrm{Ni}$ Y, Ni L, Zhuge F, Xu L, Fu Z, Ota T. Adipose Tissue Macrophage Phenotypes and Characteristics: The Key to Insulin Resistance in Obesity and Metabolic Disorders. Obesity (Silver Spring). 2020;28(2):225-34.

51 Kisand K, Tamm AE, Lintrop M, Tamm AO. New insights into the natural course of knee osteoarthritis: early regulation of cytokines and growth factors, with emphasis on sex-dependent angiogenesis and tissue remodeling. A pilot study. Osteoarthritis Cartilage. 2018;26(8):104554.

52 Wei W, Rudjito E, Fahy N, Verhaar JA, Clockaerts S, Bastiaansen-Jenniskens YM, et al. The infrapatellar fat pad from diseased joints inhibits chondrogenesis of mesenchymal stem cells. Eur Cell Mater. 2015;30:303-14.

53 Bastiaansen-Jenniskens YM, Clockaerts S, Feijt C, Zuurmond AM, Stojanovic-Susulic V, Bridts C, et al. Infrapatellar fat pad of patients with end-stage osteoarthritis inhibits catabolic mediators in cartilage. Ann Rheum Dis. 2012;71(2):288-94.

54 Cai J, Xu J, Wang K, Zheng S, He F, Huan S, et al. Association Between Infrapatellar Fat Pad Volume and Knee Structural Changes in Patients with Knee Osteoarthritis. J Rheumatol. 2015;42(10):1878-84.

55 Chuckpaiwong B, Charles HC, Kraus
VB, Guilak F, Nunley JA. Age-associated increases in the size of the infrapatellar fat pad in knee osteoarthritis as measured by 3T MRI. J Orthop Res. 2010;28(9):1149-54.

Duran S, Aksahin E, Kocadal O, Aktekin CN, Hapa O, Gencturk ZB. Effects of body mass index, infrapatellar fat pad volume and age on patellar cartilage defect. Acta Orthop Belg. 2015;81(1):41-6.

57 Ricciotti E, FitzGerald GA. Prostaglandins and inflammation. Arterioscler Thromb Vasc Biol. 2011;31(5):986-1000.

58 Furman BD, Mangiapani DS, Zeitler E, Bailey KN, Horne PH, Huebner JL, et al. Targeting pro-inflammatory cytokines following joint injury: acute intra-articular inhibition of interleukin-1 following knee injury prevents post-traumatic arthritis. Arthritis Res Ther. 2014;16(3):R134.

59 Lieberthal J, Sambamurthy N, Scanzello CR. Inflammation in joint injury and posttraumatic osteoarthritis. Osteoarthritis Cartilage. 2015;23(11):1825-34.

60 Eymard F, Pigenet A, Citadelle D, Tordjman J, Foucher L, Rose C, et al. Knee and hip intra-articular adipose tissues (IAATs) compared with autologous subcutaneous adipose tissue: a specific phenotype for a central player in osteoarthritis. Ann Rheum Dis. 2017;76(6):1142-8.

61 Solbak NM, Heard BJ, Achari Y, Chung M, Shrive NG, Frank CB, et al. 
Alterations in Hoffa's fat pad induced by an inflammatory response following idealized anterior cruciate ligament surgery. Inflamm Res. 2015;64(8):615-26.

62 Tellegen AR, Rudnik-Jansen I, Pouran B, de Visser HM, Weinans HH, Thomas $\mathrm{RE}$, et al. Controlled release of celecoxib inhibits inflammation, bone cysts and osteophyte formation in a preclinical model of osteoarthritis. Drug Deliv. 2018;25(1):1438-47.

63 Findlay DM, Kuliwaba JS. Bonecartilage crosstalk: a conversation for understanding osteoarthritis. Bone Res. 2016;4:16028.

64 Walsh DA, Bonnet CS, Turner EL, Wilson $D$, Situ M, McWilliams DF. Angiogenesis in the synovium and at the osteochondral junction in osteoarthritis. Osteoarthr Cartilage. 2007;15(7):743-51.

65 Pritzker KP, Aigner T. Terminology of osteoarthritis cartilage and bone histopathology - a proposal for a consensus. Osteoarthritis Cartilage. 2010;18 Suppl 3:S7-9.

66 Lane LB, Villacin A, Bullough PG. The vascularity and remodelling of subchondrial bone and calcified cartilage in adult human femoral and humeral heads. An age- and stress-related phenomenon. J Bone Joint Surg Br. 1977;59(3):272-8.
67 Burr DB, Schaffler MB. The involvement of subchondral mineralized tissues in osteoarthrosis: quantitative microscopic evidence. Microsc Res Tech. 1997;37(4):343-57.

68 Fazzalari NL, Parkinson IH. Fractal properties of subchondral cancellous bone in severe osteoarthritis of the hip. J Bone Miner Res. 1997;12(4):632-40.

69 Grynpas MD, Alpert B, Katz I, Lieberman I, Pritzker KP. Subchondral bone in osteoarthritis. Calcif Tissue Int. 1991;49(1):20-6.

70 Roemer FW, Guermazi A, Javaid MK, Lynch JA, Niu J, Zhang Y, et al. Change in MRI-detected subchondral bone marrow lesions is associated with cartilage loss: the MOST Study. A longitudinal multicentre study of knee osteoarthritis. Ann Rheum Dis. 2009;68(9):1461-5.

71 Hunter DJ, Zhang Y, Niu J, Goggins J, Amin $\mathrm{S}$, LaValley MP, et al. Increase in bone marrow lesions associated with cartilage loss: a longitudinal magnetic resonance imaging study of knee osteoarthritis. Arthritis Rheum. 2006;54(5):1529-35.

72 Kazakia GJ, Kuo D, Schooler J, Siddiqui S, Shanbhag S, Bernstein G, et al. Bone and cartilage demonstrate changes localized to bone marrow edema-like lesions within osteoarthritic knees. Osteoarthritis Cartilage. 2013;21(1):94-101. 
73 Chua K, Kang JYB, Ng FDJ, Pang HN, Lie DTT, Silva A, et al. Subchondroplasty for Bone Marrow Lesions in the Arthritic Knee Results in Pain Relief and Improvement in Function. J Knee Surg. 2019.

74 Nairn LN, Subramaniam M, Ekhtiari S, Axelrod DE, Grant JA, Khan M. Safety and early results of Subchondroplasty $(R)$ for the treatment of bone marrow lesions in osteoarthritis: a systematic review. Knee Surg Sports Traumatol Arthrosc. 2020.

75 Woo SL, Livesay GA, Engle C. Biomechanics of the human anterior cruciate ligament. Muscle stabilization and $A C L$ reconstruction. Orthop Rev. 1992;21(8):935-41.

76 Louboutin H, Debarge R, Richou J, Selmi TA, Donell ST, Neyret $P$, et al. Osteoarthritis in patients with anterior cruciate ligament rupture: a review of risk factors. Knee. 2009;16(4):239-44.

77 Patel SA, Hageman J, Quatman CE, Wordeman SC, Hewett TE. Prevalence and location of bone bruises associated with anterior cruciate ligament injury and implications for mechanism of injury: a systematic review. Sports Med. 2014;44(2):281-93.

78 Andriacchi TP, Mundermann A, Smith RL, Alexander EJ, Dyrby CO, Koo S. A framework for the in vivo pathomechanics of osteoarthritis at the knee. Ann Biomed
Eng. 2004;32(3):447-57.

79 Brophy RH, Tycksen ED, Sandell LJ, Rai MF. Changes in Transcriptome-Wide Gene Expression of Anterior Cruciate Ligament Tears Based on Time From Injury. Am J Sports Med. 2016;44(8):2064-75.

80 Mcllwraith CW, Kawcak CE, Frisbie DD, Little CB, Clegg PD, Peffers MJ, et al. Biomarkers for equine joint injury and osteoarthritis. J Orthop Res. 2018;36(3):823-31.

81 Hasegawa A, Otsuki S, Pauli C, Miyaki S, Patil S, Steklov N, et al. Anterior cruciate ligament changes in the human knee joint in aging and osteoarthritis. Arthritis Rheum. 2012;64(3):696-704.

82 Chang PS, Brophy RH. As Goes the Meniscus Goes the Knee: Early, Intermediate, and Late Evidence for the Detrimental Effect of Meniscus Tears. Clin Sports Med. 2020;39(1):29-36.

83 Hsieh YS, Yang SF, Chu SC, Chen PN, Chou MC, Hsu MC, et al. Expression changes of gelatinases in human osteoarthritic knees and arthroscopic debridement. Arthroscopy. 2004;20(5):482-8.

84 Cook AE, Stoker AM, Leary EV, Pfeiffer FM, Cook JL. Metabolic responses of meniscal explants to injury and inflammation ex vivo. J Orthop Res. 2018;36(10):2657-63.

85 Favero M, Belluzzi E, Trisolino G, Goldring 
MB, Goldring SR, Cigolotti A, et al. Inflammatory molecules produced by meniscus and synovium in early and endstage osteoarthritis: a coculture study. J Cell Physiol. 2019;234(7):11176-87.

86 Nishimuta JF, Levenston ME. Meniscus is more susceptible than cartilage to catabolic and anti-anabolic effects of adipokines. Osteoarthritis Cartilage. 2015;23(9):1551-62.

87 Ritter SY, Subbaiah R, Bebek G, Crish J, Scanzello CR, Krastins B, et al. Proteomic analysis of synovial fluid from the osteoarthritic knee: comparison with transcriptome analyses of joint tissues. Arthritis Rheum. 2013;65(4):981-92.

88 Tsuchida Al, Beekhuizen M, t Hart MC, Radstake TR, Dhert WJ, Saris DB, et al. Cytokine profiles in the joint depend on pathology, but are different between synovial fluid, cartilage tissue and cultured chondrocytes. Arthritis research \& therapy. 2014;16(5):441.

89 Guettler JH, Demetropoulos CK, Yang KH, Jurist KA. Osteochondral defects in the human knee: influence of defect size on cartilage rim stress and load redistribution to surrounding cartilage. Am J Sports Med. 2004;32(6):1451-8.

90 Hugle T, Geurts J. What drives osteoarthritis?-synovial versus subchondral bone pathology.
Rheumatology (Oxford). 2017;56(9):146171.

91 Donell S. Subchondral bone remodelling in osteoarthritis. EFORT Open Rev. 2019;4(6):221-9.

92 Yang KG, Saris DB, Verbout AJ, Creemers $L B$, Dhert WJ. The effect of synovial fluid from injured knee joints on in vitro chondrogenesis. Tissue Eng. 2006;12(10):2957-64.

93 Rodrigo JJ, Steadman JR, Syftestad G, Benton $\mathrm{H}$, Silliman J. Effects of human knee synovial fluid on chondrogenesis in vitro. Am J Knee Surg. 1995;8(4):124-9.

94 Eming SA, Krieg T, Davidson JM. Inflammation in wound repair: molecular and cellular mechanisms. J Invest Dermatol. 2007;127(3):514-25.

95 Kotas ME, Medzhitov R. Homeostasis, inflammation, and disease susceptibility. Cell. 2015;160(5):816-27.

96 van der Kraan PM. The Interaction between Joint Inflammation and Cartilage Repair. Tissue Eng Regen Med. 2019;16(4):327-34.

97 Caron MM, Emans PJ, Surtel DA, Cremers A, Voncken JW, Welting TJ, et al. Activation of NF-kappaB/p65 facilitates early chondrogenic differentiation during endochondral ossification. PLoS One. 2012;7(3):e33467. 
98 Martin AR, Patel JM, Zlotnick HM, Carey

$J \mathrm{~L}$, Mauck RL. Emerging therapies for cartilage regeneration in currently excluded 'red knee' populations. NPJ Regen Med. 2019;4:12.

99 Taskiran E, Taskiran D, Duran T, Lok V. Articular cartilage homeostasis after anterior cruciate ligament reconstruction. Knee Surg Sports Traumatol Arthrosc. 1998;6(2):93-8.

100 Davies DV, White JE. The structure and weight of synovial fat pads. J Anat. 1961;95:30-7.

101 Fernandes JC, Martel-Pelletier J, Pelletier $J P$. The role of cytokines in osteoarthritis pathophysiology. Biorheology. 2002;39(12):237-46.

102 Wu CL, Kimmerling KA, Little D, Guilak F. Serum and synovial fluid lipidomic profiles predict obesity-associated osteoarthritis, synovitis, and wound repair. Sci Rep. 2017;7:44315.

103 van Spil WE, Szilagyi IA. Osteoarthritis year in review 2019: biomarkers (biochemical markers). Osteoarthritis Cartilage. 2020;28(3):296-315.

104 Waarsing JH, Bierma-Zeinstra SM, Weinans $H$. Distinct subtypes of knee osteoarthritis: data from the Osteoarthritis Initiative. Rheumatology (Oxford). 2015;54(9):16508.

105 Nelson AE, Fang F, Arbeeva L, Cleveland RJ, Schwartz TA, Callahan LF, et al. A machine learning approach to knee osteoarthritis phenotyping: data from the FNIH Biomarkers Consortium. Osteoarthritis Cartilage. 2019;27(7):9941001.

106 Jones IA, Togashi R, Wilson ML, Heckmann $\mathrm{N}$, Vangsness $C T$, Jr. Intra-articular treatment options for knee osteoarthritis. Nat Rev Rheumatol. 2019;15(2):77-90.

107 Milner JM, Patel A, Rowan AD. Emerging roles of serine proteinases in tissue turnover in arthritis. Arthritis Rheum. 2008;58(12):3644-56.

108 Del Rey MJ, Usategui A, Izquierdo E, Canete JD, Blanco FJ, Criado G, et al. Transcriptome analysis reveals specific changes in osteoarthritis synovial fibroblasts. Ann Rheum Dis. 2012;71(2):275-80.

109 Carlson AK, Rawle RA, Wallace CW, Brooks EG, Adams E, Greenwood MC, et al. Characterization of synovial fluid metabolomic phenotypes of cartilage morphological changes associated with 
osteoarthritis. Osteoarthritis Cartilage.

2019;27(8):1174-84.

110 Kosinska MK, Mastbergen SC, Liebisch G, Wilhelm J, Dettmeyer RB, Ishaque B, et al. Comparative lipidomic analysis of synovial fluid in human and canine osteoarthritis. Osteoarthritis Cartilage. 2016;24(8):14708.

111 Favero M, Belluzzi E, Frallonardo P, Peruzzo L, Tauro L, Oliviero F, et al. Synovial fluid fetuin-A levels in patients affected by osteoarthritis with or without evidence of calcium crystals. Rheumatology (Oxford). 2019;58(4):729-30.

112 Dong N, Gao YH, Liu B, Zhao CW, Yang C, Li SQ, et al. Differential expression of adipokines in knee osteoarthritis patients with and without metabolic syndrome. Int Orthop. 2018;42(6):1283-9.

113 Arellano Perez Vertti RD, Aguilar Muniz LS, Moran Martinez J, Gonzalez Galarza FF, Arguello Astorga R. Cartilage Oligomeric Matrix Protein Levels in Type 2 Diabetes Associated with Primary Knee Osteoarthritis Patients. Genet Test Mol Biomarkers. 2019;23(1):16-22.

114 Clair AJ, Kingery MT, Anil U, Kenny L, Kirsch $T$, Strauss EJ. Alterations in Synovial Fluid Biomarker Levels in Knees With Meniscal Injury as Compared With Asymptomatic Contralateral Knees. Am J Sports Med. 2019;47(4):847-56. 

Impact Paragraph 


\section{Joint Pathologies: A Major Socioeconomic Burden}

Joint pathologies such as knee osteoarthritis $(O A)$ are a major public healthcare problem and cause chronic pain and disability among elderly worldwide' ${ }^{1}$. These pathologies have a huge impact on the health-related quality of life ${ }^{1}$. OA is the single most common cause of disability in older adults ${ }^{2}$. Factors such as population ageing and increasing numbers of obese individuals are examples which explain the increasing prevalence of joint pathologies such as OA worldwide ${ }^{2}$. Current management modalities target symptoms such as pain, and depend on the severity of the symptoms and structural disease, but eventually surgical intervention with joint replacement is inevitable ${ }^{3}$. Pharmaceutical treatments are being investigated to reduce the burden of disease in knee $\mathrm{OA}^{3}$. In addition, drugs are evaluated in their ability to modify the natural course of knee OA by slowing down or stopping the biological processes underlying tissue damage ${ }^{3}$. Currently, no disease modifying $O A$ drug (DMOAD) is available to prevent OA progression. This leads to a major unmet medical need in the treatment of knee $\mathrm{OA}^{4}$. Global health metric data show that the number of disability adjusted life years (DALYs) has increased by 2 -fold due to OA during the past 30 years ${ }^{5}$. Furthermore, $\mathrm{OA}$ is one of the top leading causes of disability in patients aged from 5075 years $^{5}$. Given the fact that a large proportion of patients in this age group represent the working population, disability caused by OA causes a great socioeconomic burden. Therefore, optimizing treatment for joint pathologies such as $\mathrm{OA}$ are of utmost importance.

Unfortunately, the development of treatments to improve knee joint quality and to modify disease progress in joint pathologies such as OA has not made comparable progress with that of many other chronic non-communicable diseases ${ }^{4}$. This may be related to several challenges that exists in joint preserving treatment strategies. In this dissertation, these challenges are described and a scientific basis is provided that can help to impact these challenges. 


\section{Improving Cartilage Repair Strategies to Improve Knee Joint Quality}

In the first part of this thesis (Chapter $\mathbf{2}$ and 3) we have investigated the chondrocyte phenotype in order to improve cell-based cartilage repair strategies in patients with cartilage defects. We have used chondrocyte culture conditions closely resembling the in vivo biophysical environment of the chondrocyte. Our findings published in Chapter 2 and $\mathbf{3}$ may stimulate others in the field to take the biophysical environment of the chondrocyte into account when optimizing cellular therapies. Since focal cartilage defects are wellknown risk factors for knee $\mathrm{OA}^{6,7}$, combatting cartilage defects with cellular therapies may lead to preventing or at least delaying in knee OA progression.

Next to an improvement of the chondrocyte phenotype in vitro, we also expect that our findings will have implications on the intra-articular joint environment in vivo. Knee joint osmolarity is decreased in knee $\mathrm{OA}^{8}$. Considering studies showing an in vitro antiinflammatory action of biophysical medium osmolarity on human OA chondrocytes ${ }^{9,10}$, we expect that increasing intra-articular joint osmolarity to biophysical levels will act anti-inflammatory on the knee joint in vivo. This in turn can lead to improved cellular therapies, but may also delay knee OA progression. Furthermore, a biophysical osmotic environment in the knee joint is expected to protect against iatrogenic injuries to cartilage due to sharp surgical instruments or edges of the arthroscopic sheath during during routine orthopaedic arthroscopic surgery ${ }^{11}$. This is supported by an in vivo study showing that articular chondrocytes are less prone to iatrogenic injury due to surgical instruments when the osmotic pressure of the irrigation fluid used during routine orthopaedic surgery is increased ${ }^{11}$.

In conclusion, our findings published in Chapter $\mathbf{2}$ and $\mathbf{3}$ provide methods to improve the chondrocyte phenotype and this is expected to facilitate others in optimizing cellular therapies for transition of in vitro findings to in vivo patient care. 


\section{Anti-Inflammatory Knee Joint Treatment to Improve Knee Joint Quality}

In knee joint pathologies such as knee OA, joint homeostasis becomes disturbed and pathologic changes can be observed in other joint tissues ${ }^{4}$. Our findings in Chapter 4, showing secretion of prostanoids by HFP from cartilage defect patients, have important implications. Prostanoids are involved in inflammation and cartilage degradation ${ }^{12}$. The increased presence of prostanoids in the knee joint may be a sign of pre-OA, where regenerative cartilage treatment strategies are less likely to succeed ${ }^{13}$. Therefore, our findings can stimulate the field in future research to correlate prostanoid levels produced by joint tissues to clinical outcomes of cartilage repair surgeries. Moreover, we showed that celecoxib can act anti-inflammatory on the HFP of patients with OA and cartilage defects. Given the fact that an inflamed joint environment is associated with cartilage degradation ${ }^{13}$, anti-inflammatory treatment with celecoxib holds potential to create a joint environment more permissive for cartilage repair. Our findings presented in Chapter 4, showing secretion of different prostanoid subtypes, can also have important implications as biomarkers for specific processes such as fibrosis in knee $\mathrm{OA}^{14}$. Prostanoid subtypes are known to be involved in specific pathophysiological processes of the knee joint: for instance, the prostanoid subtype $\mathrm{PGF}_{2 a}$ has been shown to be involved in fibrosis in the knee joint ${ }^{15}$. This specific prostanoid subtype thus holds potential as a target to improve knee joint quality in joint pathologies such as knee OA, where fibrosis has been shown to occur $^{15}$. Furthermore, post-operative fibrosis in the knee joint, i.e. arthrofibrosis, has been described to occur after knee surgeries such as anterior cruciate ligament reconstruction surgeries ${ }^{16}$. Therefore, a modulation of $\mathrm{PGF}_{2 a}$ release in the knee joint holds potential to target post-operative arthrofibrosis.

As earlier mentioned, the development of pharmacological treatments to improve knee joint quality and to modify disease progress in joint pathologies such as OA has not made comparable progress with that of many other chronic non-communicable diseases ${ }^{4}$. This is related to several challenges that exist in developing DMOADs which are inherent 
to the disease. Firstly, OA has a slow and long-term natural course, which requires long follow-up periods for DMOADs to detect OA disease modifying effects'. Secondly, OA is a heterogenous disease characterized by multiple phenotypes, with a substantial variability in its clinical and radiographic presentation ${ }^{17}$. In Chapter 4, we have found a differential inflammatory profile in the HFP from OA patients, which distributed to 2 OA subgroups. It will be interesting to determine whether the different HFP inflammatory states correlate to pain sensation. If this will be the case, then this has a potential impact on the patient specific use of anti-inflammatory treatments for pain relief in knee OA. Considering the fact that also other synovial joints such as for instance the hip, ankle and the elbow joint contain an intra-articular fat pad ${ }^{18}$, it is tempting to speculate that these intra-articular fat depots can be a source of pain in patients that have OA in these specific synovial joints. We hypothesize that these intra-articular fat depots may act as internal homeostatic joint regulators and can become a potential source of pain in joint pathologies such as OA.

In Chapter 4, we described that celecoxib holds potential as an anti-inflammatory drug that can improve knee joint quality via decreasing secretion of inflammatory mediators by the HFP. In Chapter 5, we present a systematic review about the chondroprotective actions of selective COX-2 inhibitors when used systemically or intra-articularly. Our review in Chapter 5 has provided important insights into the chondroprotective actions of selective COX-2 inhibitors: their chondroprotective action may depend on their administration route. This is a possible explanation why clinical trials, which used the systemic administration route ${ }^{19,20}$, failed to show in vivo chondroprotective actions with selective COX-2 inhibitors. The intraarticular administration route may be a more effective means, and this can also hold true for other DMOADs. A disadvantage of the intra-articular administration route is the need of frequent injections, which will increase the risk of bacterial knee joint infection ${ }^{21}$. However, it still remains the question whether frequent injections are needed, or whether drugdelivery systems are paramount to incorporate DMOADs in. Moreover, a DMOAD may only be effective in disease modification for a certain OA subtype. Nevertheless, it is likely that drug delivery systems may become important tools to incorporate DMOADs in, considering the long-term natural course of knee $\mathrm{OA}^{3}$. Therefore, intra-articular drug delivery system are being developed and are under investigation for treatment in joint pathologies such as 
knee $\mathrm{OA}^{22}$. Intra-articular drug delivery has a number of advantages over systemic delivery, including increased local bioavailability, reduced systemic exposure, fewer adverse events and reduced $\operatorname{cost}^{22}$.

In Chapter 6, we have evaluated an auto-regulatory drug delivery system and demonstrated its biocompatibility and auto-regulatory release behavior. Considering the pain-killing effects of selective COX-2 inhibitors such as celecoxib which we have investigated in Chapter $\mathbf{4}$ and 5, one has to consider the delicate balance between the pain-killing and structural disease-modifying effects. The auto-regulatory drug delivery system that we have described in Chapter 6 may provide important advantages compared to a drug delivery system without auto-regulation, especially considering the adverse progression of knee OA that occurred in the clinical trials with for instance anti-NGF ${ }^{23}$. This unwanted adverse progression of $\mathrm{OA}$ was possibly due to the fact that a continuously analgesic effect of the anti-NGF caused patients to increase their physical activity and thereby overloading their joints. The FDA has rejected the introduction of anti-NGF into the clinical practice due to the associated risk for joint destruction and rapidly progressive OA. We expect that an auto-regulatory drug release approach will prevent a continuous suppression of pain sensation. This in turn will likely prevent patients to continuously overload their joints, and avoid adverse effects of the treatment. Thus, an auto-regulatory drug release approach provides an attractive balance between drug release and local knee joint trauma. Before implementation of our investigated drug delivery system into the clinical practice, important challenges remain. Firstly, a DMOAD has to be developed that can be bioactively released from the carrier. As an alternative, an analgesic without adverse effects on knee joint quality may be used. Secondly, sterilization of the system may alter its drug release behavior and few studies pay attention to sterilization of the drug delivery system ${ }^{21}$. Furthermore, contamination with microbial components such as lipopolysaccharides has been described in engineered drug delivery systems and can lead to unwanted toxic side effects $^{24}$. Fourthly, manufacturers of drug delivery systems face regulatory challenges. No uniform definition exists which can classify a certain drug delivery system under a specific category from pharmaceutical science ${ }^{25}$. This prevents the application of a uniform regulation, and certain drug delivery systems may be subject to the European 
Union Medical Device Regulation, introducing specific requirements for medicines with an integral device ${ }^{25}$. Cell therapies, coatings and injectables with drug release behavior are upcoming technologies for which new regulations as well as collaborations between public and private partners are paramount.

\section{Patient Selection and Control of Clinical Outcome in Therapies Targeting Knee Joint Quality}

In this thesis we have described important strategies to improve knee joint quality. Two important considerations regarding these joint-preserving strategies have to be addressed (Figure 1):

1. Selecting patients that will benefit from the joint preserving intervention

2. Measurement of and control over the clinical outcomes of the joint preserving intervention 

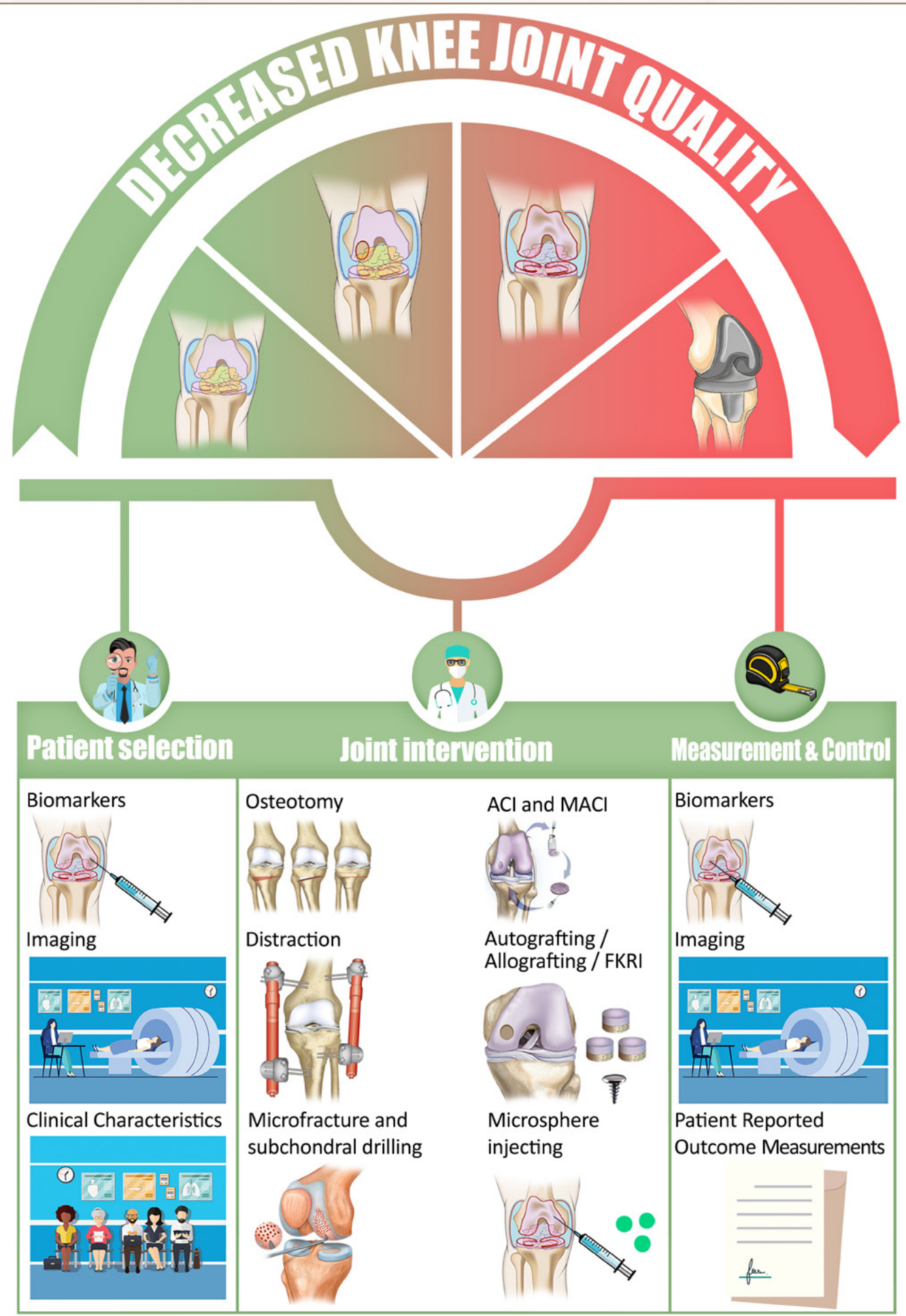


\section{Figure 1: Patient selection, joint intervention and outcome measurement.}

Total knee replacement surgery can be performed when knee joint quality is decreased. To postpone a total knee replacement surgery, it is important to select patients that will benefit from a joint preserving intervention. Clinical characteristics, imaging data and synovial fluid biomarkers are attractive candidates to utilize in patient selection. To evaluate the outcomes of joint preserving interventions, synovial fluid biomarkers, imaging data and patient reported outcome measurements may be combined.

The existence of OA phenotypes has to be considered when selecting patients that can potentially benefit from a specific joint preserving intervention ${ }^{26}$. Currently, it is unclear how the various $\mathrm{OA}$ phenotypes can be applied to predict outcome of the disease or specific response to joint preserving treatments. Post-traumatic OA, for instance OA developing in patients with cartilage defects, is one example of an OA subtype ${ }^{6}$. Since patients with cartilage defects can develop $\mathrm{OA}^{6}$, patient selection for joint preserving interventions such as cartilage repair surgery is important to delay or even prevent OA progression in this patient group. Several prognostic factors have already been described for these patients undergoing cartilage repair surgery. Earlier it was demonstrated that factors such as defect location, patient age, the number of treatments and defect age can predict clinical outcomes after cartilage repair ${ }^{27,28}$. For defect age, it was shown that patients with older defects have decreased improvements on clinical outcome after cartilage repair surgery ${ }^{27}$. This is likely to be related to a more disturbed knee joint homeostasis in this patient group, which is expected to inhibit the reparative response in the knee joint. This disturbed knee joint homeostasis can be evaluated by means of certain biomolecular biomarkers. Biomolecular markers may aid in selecting a specific patient group that will benefit from a joint preserving treatment. To date, no single biomarker has been developed to be sufficient for diagnosis or prognosis of joint pathologies such as cartilage defects or knee $\mathrm{OA}^{17}$. It is unlikely that in joint pathologies such as knee $\mathrm{OA}$, a single biomarker can be used as a stand-alone measurement that will guide therapeutic strategies. However, these biomolecular markers can be used as an additional tool next to clinical, demographical and radiographical data to guide treatment decisions. 
Biomolecular markers can be measured in various body fluids such as blood plasma, urine, serum, lacrimal secretion or synovial fluid. Specifically, the synovial fluid represents a promising body fluid for developing OA biomolecular diagnostics to access the condition of the joint as whole. It is in contact with many of the important intra-articular tissues, and directly represents the status of the knee joint, providing a clear evaluation opportunity of knee joint homeostasis. In Chapter 7 we have identified the intra-articular tissue of origin for many proteins which are known to be increased in synovial fluid from OA patients compared to non-OA patients. Moreover, we found tissue-specific proteins which were increased in OA synovial fluid compared to non-OA synovial fluid. These proteins are potential candidates as biomarkers in efficacy studies of novel experimental treatments for knee OA, and may be able to report about the joint's health status on the tissue level. Cartilage-specific proteins can be used to aid in clinical decision making for patients with a cartilage defect. Furthermore, these tissue specific proteins hold potential to be used as treatment response biomarkers, aiding in the evaluation of outcomes in cartilage and meniscal repair surgery. In addition, our findings published in Chapter $\mathbf{7}$ will fuel the development of novel synovial fluid-based approaches aiming at grading and subtyping knee OA. We expect that grading and subtyping joint pathologies such as knee OA will help to select patients which will benefit from specific treatments such as intra-articular injections with pharmaceuticals or regenerative cartilage repair strategies.

In conclusion, findings published in this thesis hold the potential to limit iatrogenic injuries during routine orthopaedic surgery, and may help to improve cell-based cartilage repair strategies, which can potentially delay knee OA progression. Furthermore, we provided evidence that anti-inflammatory treatment of the inflamed HFP can potentially lead to an improved knee joint quality. Moreover, we reported that the chondroprotective effects of selective COX-2 inhibitors may depend on their administration route. The auto-regulatory drug delivery system that we have described, holds the potential to incorporate analgesics, or DMOADs, to treat pain or improve structural changes in knee OA. Finally, we identified novel potential biomolecular markers that are released from different intra-articular tissues and may be used to assess knee joint quality on a tissue-specific basis. These biomarkers can aid in clinical decision making in joint pathologies such as knee OA and cartilage defects, 
by subtyping knee $O A$ and selecting patients that may benefit from the anti-inflammatory treatment with a drug delivery system. For example, the one that we have described in this thesis. 


\section{References}

1 Glyn-Jones S, Palmer AJ, Agricola

R, Price AJ, Vincent TL, Weinans

$\mathrm{H}$, et al. Osteoarthritis. Lancet.

2015;386(9991):376-87.

2 Peat G, Thomas MJ. Osteoarthritis year in review 2020: epidemiology \& therapy. Osteoarthritis Cartilage. 2021;29(2):180-9.

3 Latourte A, Kloppenburg M, Richette $P$. Emerging pharmaceutical therapies for osteoarthritis. Nat Rev Rheumatol. 2020;16(12):673-88.

4 Hunter DJ, March L, Chew M. Osteoarthritis in 2020 and beyond: a Lancet Commission. Lancet. 2020;396(10264):1711-2.

5 Diseases GBD, Injuries C. Global burden of 369 diseases and injuries in 204 countries and territories, 1990-2019: a systematic analysis for the Global Burden of Disease Study 2019. Lancet. 2020;396(10258):1204-22.

6 Cicuttini F, Ding C, Wluka A, Davis S, Ebeling PR, Jones G. Association of cartilage defects with loss of knee cartilage in healthy, middle-age adults: a prospective study. Arthritis Rheum. 2005;52(7):2033-9.

7 Carey JL, Shea KG, Lindahl A, Vasiliadis
HS, Lindahl C, Peterson L. Autologous Chondrocyte Implantation as Treatment for Unsalvageable Osteochondritis Dissecans: 10- to 25-Year Follow-up. Am J Sports Med. 2020;48(5):1134-40.

Shanfield S, Campbell P, Baumgarten M, Bloebaum R, Sarmiento A. Synovial fluid osmolality in osteoarthritis and rheumatoid arthritis. Clin Orthop Relat Res. 1988(235):289-95.

9 Alinezhad-Bermi S, Kabiri M, Rad I, Irani $\mathrm{S}$, Hanaee-Ahvaz H. Hyperosmolarity benefits cartilage regeneration by enhancing expression of chondrogenic markers and reducing inflammatory markers. In Vitro Cell Dev Biol Anim. 2021;57(3):290-9.

10 Mang T, Lindemann S, Gigout A. Increasing the Medium Osmolarity Reduces the Inflammatory Status of Human OA Chondrocytes and Increases Their Responsiveness to GDF-5. Int J Mol Sci. 2020;21(2).

11 Eltawil NM, Ahmed S, Chan LH, Simpson A, Hall AC. Chondroprotection in Models of Cartilage Injury by Raising the Temperature and Osmolarity of Irrigation Solutions. Cartilage. 2018;9(3):313-20. 
12 Martel-Pelletier J, Pelletier JP, Fahmi H. Cyclooxygenase- 2 and prostaglandins in articular tissues. Semin Arthritis Rheum. 2003;33(3):155-67.

13 van der Kraan PM. The Interaction between Joint Inflammation and Cartilage Repair. Tissue Eng Regen Med. 2019;16(4):327-34.

14 Usher KM, Zhu S, Mavropalias G, Carrino JA, Zhao J, Xu J. Pathological mechanisms and therapeutic outlooks for arthrofibrosis. Bone Res. 2019;7:9.

15 Bastiaansen-Jenniskens YM, Wei W, Feijt C, Waarsing JH, Verhaar JA, Zuurmond $A M$, et al. Stimulation of fibrotic processes by the infrapatellar fat pad in cultured synoviocytes from patients with osteoarthritis: a possible role for prostaglandin f2alpha. Arthritis Rheum. 2013;65(8):2070-80.

16 Shelbourne KD, Wilckens JH, Mollabashy A, DeCarlo M. Arthrofibrosis in acute anterior cruciate ligament reconstruction. The effect of timing of reconstruction and rehabilitation. Am J Sports Med. 1991;19(4):332-6.

17 Deveza LA, Nelson AE, Loeser RF. Phenotypes of osteoarthritis: current state and future implications. Clin Exp Rheumatol. 2019;37 Suppl 120(5):64-72.

18 Labusca L, Zugun-Eloae F. The Unexplored Role of Intra-articular Adipose Tissue in the Homeostasis and Pathology of Articular Joints. Front Vet Sci. 2018;5:35.

19 Tindall EA, Sharp JT, Burr A, Katz TK, Wallemark CB, Verburg $\mathrm{K}$, et al. A 12-month, multicenter, prospective, open-label trial of radiographic analysis of disease progression in osteoarthritis of the knee or hip in patients receiving celecoxib. Clin Ther. 2002;24(12):2051-63.

20 Raynauld JP, Martel-Pelletier J, Beaulieu A, Bessette L, Morin F, Choquette D, et al. An open-label pilot study evaluating by magnetic resonance imaging the potential for a disease-modifying effect of celecoxib compared to a modelized historical control cohort in the treatment of knee osteoarthritis. Semin Arthritis Rheum. 2010;40(3):185-92.

21 Kou L, Xiao S, Sun R, Bao S, Yao Q, Chen R. Biomaterial-engineered intra-articular drug delivery systems for osteoarthritis therapy. Drug Deliv. 2019;26(1):870-85.

22 Jones IA, Togashi R, Wilson ML, Heckmann $\mathrm{N}$, Vangsness $C T$, Jr. Intra-articular treatment options for knee osteoarthritis. Nat Rev Rheumatol. 2019;15(2):77-90.

23 Lane NE, Schnitzer TJ, Birbara CA, Mokhtarani M, Shelton DL, Smith MD, et al. Tanezumab for the treatment of pain from osteoarthritis of the knee. N Engl J Med. 2010;363(16):1521-31. 


\section{Chapter 9}

24 Li Y, Boraschi D. Endotoxin contamination:

a key element in the interpretation of nanosafety studies. Nanomedicine (Lond). 2016;11(3):269-87.

25 Al-Jawadi S, Capasso P, Sharma M.

The road to market implantable drug delivery systems: a review on US FDA's regulatory framework and quality control requirements. Pharm Dev Technol.

2018;23(10):953-63.

26 Yuan C, Pan Z, Zhao K, Li J, Sheng Z, Yao $X$, et al. Classification of four distinct osteoarthritis subtypes with a knee joint tissue transcriptome atlas. Bone Res. 2020;8(1):38.

27 de Windt TS, Bekkers JE, Creemers LB, Dhert WJ, Saris DB. Patient profiling in cartilage regeneration: prognostic factors determining success of treatment for cartilage defects. Am J Sports Med. 2009;37 Suppl 1:58S-62S.

28 Janssen MPF, van der Linden EGM, Boymans T, Welting TJM, van Rhijn LW, Bulstra SK, et al. Twenty-Two-Year Outcome of Cartilage Repair Surgery by Perichondrium Transplantation. Cartilage. 2020:1947603520958146. 
English Summary 
The research that is reported in this dissertation aimed at gaining new insights in novel strategies to improve 'knee joint quality' either on a cellular, tissue or articular joint level.

Focal cartilage defects may lead to inferior knee joint quality due to distorted joint biomechanics, leading to an increased inflammatory intra-articular environment. Ultimately this environment will lead to a joint disease known as osteoarthritis (OA). Therefore, we have evaluated molecular mechanisms involved in the phenotypic improvement of human articular chondrocytes. Generated knowledge is expected to aid in improvements in cell-based cartilage repair strategies and supporting post-treatment knee joint quality. In Chapter 2, we showed that culturing human articular chondrocytes under oxygen tension closely resembling their physiological in vivo environment, improves collagen type II expression via TGF- $\beta$. Besides being hypoxic, cartilage is also generally considered to be hyperosmotic. The involvement of the TGF- $\beta$ pathway in the improvement of the chondrocyte phenotype under hypoxic conditions prompted us to also investigate its role under hyperosmotic conditions in Chapter 3. We could confirm an improved chondrocyte phenotype under hyperosmotic conditions. Interestingly, hyperosmotic conditions also most prominently increased TGF- $\beta 2$ mRNA expression, which was in concordance with our experiments under hypoxic conditions. This may indicate that of the three TGF- $\beta$ isoforms, TGF- $\beta 2$ has a prominent role in regulating the chondrocyte phenotype under hyperosmotic and hypoxic conditions.

Inflammatory processes have been linked to increased articular cartilage deterioration. Gaining insights into the role of such inflammatory processes for knee joint quality may yield important clues to develop new treatment strategies to improve cartilage repair strategies. In Chapter 4, we showed that prostanoid release by HFP from end-stage OA patients was on average higher than prostanoid release by HFP from patients with a cartilage defect. The secretion of prostanoid subtypes from the HFP from knee OA patients distributed into 2 OA subgroups. Furthermore, the COX-2 inhibitor celecoxib was able to effectively reduce prostanoid release by HFP by at least $80 \%$. In addition, celecoxib was able to skew the expression ratio of M1/M2 macrophage markers towards a more favorable M2 phenotype most effectively in HFP tissue with higher prostanoid release. This indicates that the capacity of celecoxib to skew towards the expression of markers associated with 


\section{English Summary}

M2 macrophages in HFP tissue is dependent on the magnitude of inflammation present.

Joint homeostasis may become disrupted and knee joint quality may become impaired in an inflamed knee joint. To combat this, different methods can be exploited. An intra-articular administration may be an effective means, since this means that the drug will be in direct contact with the different knee joint tissues. In Chapter 5, we have systemically reviewed the literature evidence for potential in vivo chondroprotective actions of selective COX-2 inhibitors. We reviewed the use of selective COX-2 inhibitors either systemically or intraarticularly. From this review it became clear that intra-articular administration, either as a bolus drug or incorporated in a drug delivery system (DDS) may be a more effective means to use selective COX-2 inhibitors to improve joint quality than systemic administration.

A DDS may circumvent side effects associated with systemic treatment, allowing a prolonged local drug residence time, increasing patient compliance and preventing frequent intra-articular injections. In this context, the use of a 'smart' drug delivery system from which drug release is reactive to the disease process, may be an effective means to treat joint pathologies such as knee OA. In Chapter 6, we have investigated the use of celecoxib-loaded polyesteramide (PEA) microspheres as a smart intra-articular DDS for OA treatment. PEA microspheres demonstrated good intra-articular biocompatibility and degraded in an in vivo OA model. Degradation of PEA microspheres was significantly higher in an inflammatory environment, while loading the microspheres with celecoxib decreased PEA degradation which may indicate a DDS with an auto regulatory behavior.

In Chapter 7, we hypothesized that knee joint synovial fluid, which is in contact with important intra-articular tissues, represents a promising body fluid to access the homeostatic condition of the knee joint as a whole. We performed comparative full-proteome analysis of the synovial fluid of OA patients versus non-OA individuals, as well as of the protein secretomes of Hoffa's fat pad, synovium, meniscus and articular cartilage of osteoarthritic knees. We identified several protein species with a tissue type-dependent release and also demonstrated their OA-specificity. Our findings demonstrated the presence of tissue typedependent release of OA-specific proteins in OA knee joint synovial fluid. 
Collectively, our findings presented in this dissertation demonstrate novel insights in the molecular mechanisms involved in chondrocyte phenotype improvement after hyperosmotic and hypoxic cultures and demonstrate the importance of TGF- $\beta$ signaling in the context of the chondrocyte phenotype. The HFP of patients with joint pathologies such as cartilage defects and knee OA has a substantial contribution to the prostanoid content found in synovial fluid. Targeting the knee joint by means of intra-articular injections instead of systemic administration of drugs may be more effective in improving knee joint homeostasis. Furthermore, celecoxib, either injected as a bolus drug or incorporated in a smart drug release system is an attractive novel strategy for treatment of joint diseases such as OA. Finally, we uncovered tissue type-dependent release of OA-specific proteins in knee joint synovial fluid. These proteins may be used as biomarkers to aid in developing treatment strategies to improve joint homeostasis for cartilage repair strategies or slowing down knee OA. Taken together, the findings published in this thesis in describing insights in improving knee joint quality on the cellular, tissue of total joint level will contribute to our understanding of joint pathologies such as knee OA and it is expected to aid in developing strategies to treat these joint pathologies. 
Nederlandse Samenvatting 
Het onderzoek dat in dit proefschrift wordt beschreven, is gericht op het verkrijgen van nieuwe inzichten in nieuwe strategieën om de 'kniegewrichtskwaliteit' te verbeteren op cellulair, weefsel- of totaal kniegewrichtsniveau.

Focale kraakbeendefecten kunnen leiden tot een inferieure kwaliteit van het kniegewricht als gevolg van verstoorde gewrichtsbiomechanica. Een verstoring in de gewrichtsbiomechanica kan leiden tot een verhoogde inflammatoire intra-articulaire omgeving, wat uiteindelijk kan leiden tot artrose. Daarom hebben we moleculaire mechanismen geëvalueerd die betrokken zijn bij de fenotypische verbetering van menselijke articulaire chondrocyten. De verkregen wetenschappelijke inizchten kunnen leiden tot verbeteringen in celgebaseerde kraakbeenherstelstrategieën en het verbeteren van de kwaliteit van het kniegewricht. In Hoofdstuk $\mathbf{2}$ hebben we aangetoond dat het kweken van menselijke articulaire chondrocyten onder zuurstofspanning die sterk lijkt op hun fysiologische in vivo omgeving, de expressie van collageen type II via TGF- $\beta$ verhoogt. Behalve dat het hypoxisch is, wordt kraakbeen over het algemeen ook als hyperosmotisch beschouwd. De betrokkenheid van de TGF- $\beta$ pathway bij de verbetering van het chondrocytfenotype onder hypoxische condities heeft ons ertoe aangezet om ook de rol ervan onder hyperosmotische condities te onderzoeken in Hoofdstuk 3. We konden een verbeterd chondrocytfenotype onder hyperosmotische condities bevestigen. Interessant is dat hyperosmotische omstandigheden ook het meest de TGF- $\beta 2$-mRNAexpressie verhoogden, wat in overeenstemming was met onze experimenten onder hypoxische omstandigheden. Dit kan erop wijzen dat van de drie TGF- $\beta$-isovormen, TGF- $\beta 2$ een prominente rol speelt bij het reguleren van het chondrocytfenotype onder hyperosmotische en hypoxische omstandigheden.

Inflammatoire processen zijn in verband gebracht met een verhoogde afbraak van kraakbeen. Het verkrijgen van inzicht in de rol van deze inflammatoire processen voor de kwaliteit van het kniegewricht kan belangrijke aanwijzingen opleveren voor het ontwikkelen van nieuwe behandelingsstrategieën gericht op kraakbeenherstel. In Hoofdstuk 4 hebben we laten zien dat de afgifte van prostanoïden door het Hoffa's vetlichaam (HFP) van artrosepatiënten gemiddeld hoger was dan de afgifte van prostanoïden door HFP van patiënten met een kraakbeendefect. De afscheiding van prostanoïde subtypen uit 
de HFP van patiënten met knieartrose toonde een verdeling over 2 artrose-subgroepen. Bovendien was de COX-2-remmer celecoxib in staat om de PGE $_{2}$-afgifte door HFP met ten minste $80 \%$ te verminderen. Tevens was celecoxib in staat om de expressieverhouding van M1/M2 macrofagenmarkers te veranderen naar een gunstiger M2 fenotype, het meest effectief in HFP-weefsel met hogere prostanoïde-afgifte. Dit geeft aan dat het vermogen van celecoxib om de expressie van markers die zijn geassocieerd met M2-macrofagen in HFP-weefsel te beïnvloeden afhankelijk is van de hoeveelheid aanwezige inflammatie.

De gewrichtshomeostase kan worden verstoord en de kwaliteit van het kniegewricht kan worden aangetast bij een ontstoken kniegewricht. Om dit tegen te gaan, kunnen verschillende methoden worden gebruikt. Een intra-articulaire toediening kan een effectieve methode zijn, aangezien dit betekent dat het medicijn direct in contact komt met de verschillende kniegewrichtsweefsels. In Hoofdstuk $\mathbf{5}$ hebben we het bewijs voor mogelijke in vivo chondroprotectieve acties van ontstekingsremmende selectieve COX-2 remmers onderzocht. We hebben het gebruik van selectieve COX-2 remmers systemisch of intra-articulair beoordeeld. Uit deze review werd duidelijk dat directe intra-articulaire toediening een effectievere manier kan zijn om selectieve COX-2 remmers te gebruiken om de gewrichtskwaliteit te verbeteren in vergelijking met systemische toediening.

Een drug delivery systeem (DDS) kan bijwerkingen als gevolg van een systemische behandeling omzeilen, waardoor een langere lokale verblijftijd van het medicijn mogelijk is, de therapietrouw van de patiënt toeneemt en frequente intra-articulaire injecties worden vermeden. In deze context kan het gebruik van een 'slim' DDS waarin de medicijnafgifte reageert op het ziekteproces, een effectief middel zijn om de kwaliteit van het kniegewricht te verbeteren bij gewrichtspathologieën zoals bijvoorbeeld knieartrose. In Hoofdstuk 6 hebben we het gebruik van celecoxib-geladen polyesteramide (PEA) microsferen onderzocht als een 'slim' intra-articulaire DDS bij artrosebehandeling. PEA-microsferen vertoonden een goede intra-articulaire biocompatibiliteit en werden afgebroken in een in vivo OA-model. De afbraak van PEA-microsferen was significant hoger in een inflammatoire omgeving, terwijl het laden van de microsferen met celecoxib de PEA-afbraak verminderde, wat zou kunnen wijzen op een DDS met auto-regulerend gedrag.

In Hoofdstuk 7 stelden we de hypothese op dat de synoviale vloeistof uit het knie gewricht, 
die in contact is met belangrijke intra-articulaire weefsels, een veelbelovende lichaamsvloeistof vertegenwoordigt om inzichten te verkrijgen in de homeostatische toestand van het hele kniegewricht. We hebben een vergelijkende volledige proteoomanalyse uitgevoerd van de synoviale vloeistof van artrosepatiënten versus niet-artrosepatiënten, evenals van de eiwitsecretomen van HFP, synovium, meniscus en gewrichtskraakbeen van knieën met $O A$. We identificeerden verschillende eiwitsoorten met een weefseltype-afhankelijke afgifte en toonden ook hun OA-specificiteit aan. Onze bevindingen in Hoofdstuk 7 benadrukten de aanwezigheid van weefseltype-afhankelijke afgifte van OA-specifieke eiwitten in synoviaal vocht van het kniegewricht van OApatiënten.

Samenvattend demonstreren onze bevindingen gepresenteerd in dit proefschrift nieuwe inzichten in de moleculaire mechanismen die betrokken zijn bij de verbetering van het chondrocytfenotype na hyperosmotische en hypoxische culturen en demonstreren ze het belang van de TGF- $\beta$ pathway in het chondrocytfenotype. Bovendien levert de HFP van patiënten met gewrichtspathologieën zoals kraakbeendefecten en knieartrose een substantiële bijdrage aan het gehalte aan prostanoïden in gewrichtsvloeistof. Het behandelen van pathologieën in het kniegewricht door middel van intra-articulaire injecties in plaats van systemische toediening van medicijnen kan effectiever zijn bij het verbeteren van de homeostase van het kniegewricht. Celecoxib is, geïnjecteerd als een bolus medicijn of geïncorporeerd in een slim DDS, zoals PEA-microsferen, een aantrekkelijke nieuwe strategie om de gewrichtshomeostase te verbeteren. Tot slot hebben we weefseltypeafhankelijke afgifte van OA-specifieke eiwitten in het synoviale vocht van het kniegewricht aangetoond. Deze eiwitten kunnen worden gebruikt als biomarkers om te helpen bij het ontwikkelen van behandelingsstrategieën om de gewrichtshomeostase te verbeteren voor kraakbeenherstelstrategieën of om knieartrose te vertragen.

Concluderend zullen de bevindingen die in dit proefschrift zijn gepubliceerd over het verkrijgen van inzichten in het verbeteren van de kwaliteit van het kniegewricht op cellulair-, weefsel- en gewrichtsniveau bijdragen aan ons begrip van gewrichtspathologieën zoals knieartrose en zal naar verwachting helpen bij het ontwikkelen van strategieën om deze te behandelen. 
Türkçe Özet 
Bu tezde sunulan araştırmanın amacl; hücresel, doku veya eklem seviyesinde 'diz eklemi kalitesini' geliştirmek için kullanılacak olan yeni stratejiler için yeni öngörüler ve kazanımlar elde etmektir. Fokal kıkırdak defektleri bozulmuş eklem biyomekaniği ve düşük diz eklemi kalitesine neden olabilmekte ve eklem içi artan bir inflamatuar ortama yol açabilmektedir. Bu artan inflamatuar ortam, osteoartrit diye tabir ettiğimiz bir eklem hastalığına neden olmaktadır. Dolayısıyla bu çalışma, insanlardaki kıkırdak hücrelerin fenotipik gelişiminde rol oynayan moleküler mekanizmalar üzerine odaklanmaktadır. Bu üretilen bilginin hücre bazı ı ıkırdak onarım stratejilerinde ve tedavi sonrası diz eklemi kalitesini iyileştirmede yardımcı olması bekleniyor. Tezin İkinci Bölümünde, kıkırdak hücrelerinin, kıkırdağın insan vücudundaki fizyolojik olarak görülen hipoksik oksijen gerilim oranıyla kültüre edilmesiyle ilgili bilgilere yer verilmektedir. Bu araştırmalar neticesinde, kıkırdak hücrelerinde, kıkırdak dokusunda önemli bir protein olan kolajen tip II expresyonunun iyileştiği gözlemlenmiş ve bu iyileştirmede TGF- $\beta$ protein'in önemli bir rol üstlendiği tespit edilmiştir.

Kıkırdak hipoksik olmanın yanı sıra genellikle hiperozmotik olarak değerlendirilir. TGF- $\beta$ protein'in hipoksik gerilim ortamında kıkırdak hücrelerindeki fenotopik gelişimindeki rolu, bizleri Tezin Ücüncü Bölümünde bahsedilen, bu protein'in hiperosmotik ortamlarında kültüre edilmiş kıkırdak hücrelerin fenotipik gelişimindekini rolünü araştırmaya teşvik etmiştir. Bu amaçla öncelikle, hiperosmotik ortamlarında kültüre edilmiş kıkırdak hücrelerindeki fenotipik gelişimi doğrulanmıştır. İlginç bir şekilde, tıpkı hipoksik koşullarda kültüre edilmiş kıkırdak hücrelerinde gözlemlediğimiz gibi, hiperozmotik koşullar da en belirgin şekilde artan TGF- $\beta 2$ mRNA ekspresyonu olduğu gözlemlenmiştir. Bu bulgu, üç TGF- $\beta$ izoformu arasında, TGF- $\beta 2$ izoformunun kıkırdak hücrelerindeki fenotipik gelişiminde önemli bir rol aldığını gösterebilir.

Kıkırdak hasarları inflamatuar bir ortam ile ilişkilendirilmiştir. Bu inflamatuar ortamın diz eklemi kalitesine etkisini araştırmak, yeni kıkırdak onarım tedavileri geliştirmek için önemli ipuçları verebilir. Tezin Dördüncü Bölümünde bahsedildiği üzere, osteoartit hastaların Hoffa yağ yastığı tarafından salgılanan prostanoid oranının, kıkırdak defekt hastaların Hoffa yağ yastığından salgılanan prostanoid oranından, daha yüksek olduğu görülmüştür. Araştırmalarımızda, osteoartrit hastaların Hoffa yağ yastığından salgılanan prostanoid oraninin 2 alt gruba ayrıldığı da gözlemlenmiştir. Ayrıca, COX-2 inhibitörü 
selekoksib, Hoffa yağ yastığı tarafından prostanoid salınımını en az \%80 oranında etkili bir şekilde azaltabilmiştir. Ek olarak, selekoksib M1/M2 makrofaj ekspresyon oranını daha uygun olan M2 fenotipine yönlendirmiştir. Bu M2 fenotipine en etkili yönlendirmenin, prostanoid salınımı yüksek olan Hoffa yağ yastıklarında olduğu gözlemlenmiştir. Bu bulgu, selekoksibin, M2 makrofajları ile ilişkili olan gen expresyonuna yönlendirme kapasitesi, Hoffa yağ yastığında inflamasyon oranına bağlı olduğunu gösterebilir.

Eklem homeostazı bozulabilir ve inflamasyon oranı yüksek olan bir diz ekleminde diz eklem kalitesi düşebilir. Bununla mücadele etmek için farklı yöntemlerden yararlanılabilir. Eklem içi bir enjeksiyon etkili bir araç olabilir, çünkü bu, ilaçın farklı diz eklem dokuları ile doğrudan temas halinde olacağı anlamına gelecektir. Tezin Beşinci Bölümünde, sistematik bir derleme ile selektif COX-2 inhibitörlerin potansiyel in vivo kondroprotektif etkileriyle ilgili araştırma bilgilerine yer verilmektedir. Bu sistematik derlemede selektif COX-2 inhibitörlerin sistemik veya eklem içi kullanımı incelenmiştir. Bu sistematik derlemeden elde edilen bulgular, selektif COX-2 inhibitörlerin sistemik tedaviye nazaran, eklem içi bolus bir ilaç veya bir ilaç dağıtım sistemine dahil edilmiş olarak kullanıldığında, eklem kalitesini geliştirmek için, daha etkili olabileceğini göstermektedir. Eklem hastalıklarında tedavi için, kontrollü bir ilaç salım sistemi daha avantajlı olabilir. Kontrollü ilaç salım sistemi, sistemik tedaviyle ilişkili yan etkilerin üstesinden gelebilir. Ayrıca kontrollü ilaç salım sistemi, ilacın eklem içinde daha uzun kalması, hastanın kullanımından kaynaklı ilaç kaybının engellenmesi ve gerek duyulan eklem içi enjeksiyonları minimum seviyesine indirmesi gibi avantajları vardır. Bu bağlamda, eklem içinde meydana gelen patolojik bulgulara ilaç salımı ile cevap verebilme yeteneği olan'akıllı' bir kontrollü ilaç salım sistemi, osteoartrit gibi bir diz eklem hastalığında, bir avantaj getirebilir. Tezin Altıncı Bölümünde, selekoksib yüklü polyesteramid (PEA) mikrokürelerin osteoartrit tedavisinde eklem içi 'akıllı' bir kontrollü ilaç salım sistemi olarak uygulanabilirliği ile ilgili araştırma bilgilerine yer verilmektedir. Bu PEA mikroküreler, eklem içi biyouyumluluk gösterdi ve in vivo bir osteoartrit laboratuvar hayvan modelinde eklem içi degradasyon göstermiştir. PEA mikrokürelerinin degradasyonu, inflamatuar bir ortamda daha yüksekken, mikroküreleri selekoksib ile yüklemek degradasyonu azaltmıştır. Bu bulgular, PEA mikrokürelerin otoregulasyon davranışı gösterebileceğine dair bir işarettir. 
Tezin Yedinci Bölümünde, diz eklemi içinde bütün dokular ile temas halinde olan sinovyal sıvısı'nın, diz ekleminin homeostatik durumu hakkinda bilgi edinmek için umut verici bir sıvı olduğuna dair bir hipotez geliştirilmiştir. Hem osteoartrit hastaların, hem osteoartrit hastalığı olmayan bireylerin sinovyal sıvılarında proteomik analizlerimizin yanı sıra, Hoffa'nın yağ yastığı, sinovyum, menisküs ve eklem kıkırdağının sekretomlarında proteom analizleri gerçekleştirilmiştir. Analizler de doku-spesifik proteinler bulunmuştur ve bu proteinlerin OA-spesifik özellikleri olduğu gösterilmiştir. Bulgularımız, osteoartrit diz eklemi'nin sinovyal sıvısında doku-spesifik ve osteoartrite özgü proteinlerin varlığını göstermiştir.

Toplu olarak, bu tezde sunulan bulgular, hiperozmotik ve hipoksik kültürlerden sonra kıkırdak hücrelerdeki fenotip gelişiminde rol alan moleküler mekanizmalarda yeni anlayışlar göstermekte ve kıkırdak hücrelerin fenotipinde TGF- $\beta$ 'nin önemli rol oynadığını belirtmektedir. Sinovyal sıvıda bulunan prostanoid içeriğine, kıkırdak defektleri ve osteoartrit gibi eklem patolojileri olan hastaların Hoffa yağ yastığının önemli bir katkısı vardır. İlaçların sistemik uygulanması yerine, eklem içi enjeksiyonlar yoluyla diz ekleminin hedeflenmesi, diz eklemi homeostazını iyileştirmede daha etkili olabilecektir. Ayrıca, bolus ilaç olarak enjekte edilen veya akıllı bir ilaç salım sistemine dahil edilen selekoksib, osteoartrit gibi eklem hastalıklarının tedavisi için çekici bir yeni stratejidir. Son olarak, diz eklemi sinovyal sıvısında osteoartrite özgü proteinlerin doku tipine bağlı salınımı gösterilmiştir. Bu proteinler, kıkırdak onarım stratejileri için eklem homeostazını iyileştirmek veya osteoartriti yavaşlatmak için tedavi stratejileri geliştirmeye yardımcı olmak için biyobelirteçler olarak kullanılabilir.

Birlikte ele alındığında, bu tezde yayınlanan ve hücresel, doku ve total eklem seviyesinde sunulan ve diz eklemi kalitesinin geliştirebilecek yeni bulgular, osteoartrit gibi eklem patolojilerini anlamamıza katkıda bulunacaktır ve bu eklemleri tedavi etmek için stratejilerin geliştirilmesine yardımcı olacaktır. 
List of Publications and Presentations 


\section{List of Publications}

1. Das R, Timur UT, Edip S, Haak E, Wruck C, Weinans H, et al. TGF-beta2 is involved in the preservation of the chondrocyte phenotype under hypoxic conditions. Ann Anat. 2015;198:1-10.

2. Timur UT, van Herwaarden JA, Mihajlovic D, De Jong P, Mali W, Moll FL. (18)F-FDG PET scanning of abdominal aortic aneurysms and correlation with molecular characteristics: a systematic review. EJNMMI Res. 2015;5(1):76.

3. Timur UT, Janssen MPF, Woike N, Welting TJ, Draaisma G, Gijbels M, et al. Celecoxibloaded PEA microspheres as an auto regulatory drug-delivery system after intraarticular injection. J Control Release. 2016;244(Pt A):30-40. (Shared First Author)

4. Timur UT, Ripmeester EGJ, Caron MMJ, Welting TJM. Recent Insights into the Contribution of the Changing Hypertrophic Chondrocyte Phenotype in the Development and Progression of Osteoarthritis. Front Bioeng Biotechnol. 2018;6:18. (Shared First Author)

5. Timur UT, Caron MMJ, Bastiaansen-Jenniskens YM, Welting TJM, van Rhijn LW, van Osch G, et al. Celecoxib-mediated reduction of prostanoid release in Hoffa's fat pad from donors with cartilage pathology results in an attenuated inflammatory phenotype. Osteoarthritis Cartilage. 2018;26(5):697-706.

6. Timur UT, Caron M, van den Akker G, van der Windt A, Visser J, van Rhijn L, et al. Increased TGF-beta and BMP Levels and Improved Chondrocyte-Specific Marker Expression In Vitro under Cartilage-Specific Physiological Osmolarity. Int J Mol Sci. 2019;20(4).

7. Timur UT, Caron MMJ, Jeuken RM, Bastiaansen-Jenniskens YM, Welting TJM, van Rhijn LW, et al. Chondroprotective Actions of Selective COX-2 Inhibitors In Vivo: A Systematic Review. Int J Mol Sci. 2020;21(18). 
8. Timur UT, Jahr H, Anderson J, Green DC, Emans PJ, Smagul A, et al. Identification of tissue-dependent proteins in knee OA synovial fluid. Osteoarthritis Cartilage. 2021;29(1):124-33.

9. Timur UT, Jaspars CCMM, van Baardwijk L. Behandeling van recidiverende hemartros na totale knieprothese. Medisch Journaal MMC, Najaarseditie 2021.

10. Jeuken $R$, v Hugten P, Roth AK, Timur UT, Boymans TAEJ, van Rhijn LW, Bugbee WD, Emans PJ. A Systematic Review of Focal Cartilage Defect Treatments in MiddleAged versus Younger Patients. OJSM 2021.

\section{Conferences with Oral Presentations}

1. Timur UT, van der Windt AE, Caron MC, Haak E, Visser J, Weinans H, Welting TJM, Emans PJ, Jahr $\mathrm{H}$. TGF $\beta 2$ knockdown under physiological osmolarity improves COL2 expression in chondrocytes in vitro. (EORS 2014, Nantes)

2. Timur UT, van der Windt AE, Caron MC, Haak E, Visser J, Weinans $H$, Welting TJM, Emans PJ, Jahr H. TGF $\beta 2$ knockdown under physiological osmolarity improves COL2 expression in chondrocytes in vitro. (NBTE 2014, Lunteren)

3. Timur UT, van der Windt AE, Haak E, Visser J, Caron MC, Weinans H, Welting TJM, Emans PJ, Jahr H. Physiological osmolarity combined with TGF- $\beta 2$ knockdown improves collagen type Il expression in chondrocytes in vitro. (EORS 2015, Bristol, best oral presentation award)

4. Timur UT, van der Windt AE, Caron MC, Weinans $H$, Welting TJM, Emans PJ, Jahr H. TGF- $\beta 2$ knockdown under physiological osmolarity improves COL2 expression in chondrocytes in vitro. (DKOU 2015, Berlin)

5. Timur UT, Janssen M, Berard J, Welting TJM, van Rhijn L, Mihov G, Thies J, Emans PJ. Biocompatibiliteit en afbraak van celecoxib geladen microspheres na intraarticulaire injectie bij osteoartrose. (NOV jaarcongres 2016, Den Bosch, nominated for the prof. dr. ir. Rik Huiskesprijs) 
6. Timur UT, Janssen M, Berard J, Welting TJM, van Rhijn L, Mihov G, Thies J, Emans PJ. Biocompatibiliteit en afbraak van celecoxib geladen microspheres na intraarticulaire injectie bij osteoartrose. (NOV jaarcongres 2016, Den Bosch)

7. Timur UT, Caron MC, Bastiaansen-Jenniskens Y, Welting TJM, van Osch GJVM, Emans PJ. PGE ${ }_{2}$ and $\mathrm{PGF}_{2 \mathrm{a}}$ are secreted by the osteoarthritic infrapatellar fat pad and their release can be modulated by celecoxib. (ICRS 2016, Sorrento)

8. Timur UT, Janssen MPF, Gijbbels M, Draaisma G, Mihov G, Welting T, van Rhijn L, Thies J, Emans PJ. Celecoxib loaded PEA-based microspheres as an auto regulatory drug-delivery system after intra-articular injection. (ICRS 2016, Sorrento)

9. Timur UT, Caron M, van der Windt A, Emans P, Welting T, Jahr H. TGF $\beta$ superfamilydependent and osmolarity-mediated type II collagen expression by chondrocytes in vitro. (ICORS 2016, Xian)

10. Timur UT, van der Windt AE, Caron MC, Weinans H, Welting TJM, Emans PJ, Jahr $\mathrm{H}$. Osmolarity mediated and TGF- $\beta 2$ dependent BMP and COL2 expression in chondrocytes in vitro. (EORS 2016, Bologna)

11. Timur UT, Caron MC, van der Windt AE, Weinans $\mathrm{H}$, Welting TJM, Emans PJ, Jahr H. BMP signalling in human chondrocytes is involved in the expression of COL2 in human chondrocytes. (EORS 2017, Munich)

12. Timur UT, Emans PJ, van Rhijn L, Welting TJM. CART-1: a novel chondrogenic regulator. (EORS 2017, Munich)

13. Timur UT, Caron MC, Welting TJM, van Rhijn L., Emans PJ, Jahr H. BMP signaling in human chondrocytes is involved in the expression of COL2 in human chondrocytes. (EORS 2017, Munich)

14. Timur UT, Caron MC, Bastiaansen-Jenniskens Y, Welting TJM, van Osch GJVM, Emans PJ. Celecoxib vermindert prostanoïde uitscheiding door verschillende intraarticulaire gewrichtsweefsels. (NOV Najaarsvergadering 2017, Veldhoven) 
15. Timur UT, Jahr $H$, van Rhijn L, Emans PJ, Peffers MJ, Welting TJM. Identification of tissue-specific biomarkers in knee OA synovial fluid: a proteomic approach. (OARSI 2018, Liverpool)

\section{Conferences with Poster Presentations}

1. Timur UT, van der Windt AE, Caron MC, Weinans H, Welting TJM, Emans PJ, Jahr $\mathrm{H}$. Improved collagen type II expression in chondrocytes under physiological osmolarity upon TGF- $\beta 2$ knockdown. (ORS 2015, Las Vegas)

2. Timur UT, Caron MC, Bastiaansen-Jenniskens Y, Welting TJM, van Osch GJVM, Emans PJ. PGE 2 and $\mathrm{PGF}_{2 \mathrm{a}}$ are secreted by the osteoarthritic infrapatellar fat pad and their release can be stimulated by celecoxib. (OARSI 2016, Amsterdam)

3. Timur UT, Caron MC, Bastiaansen-Jenniskens Y, Welting TJM, van Osch GJVM, Emans PJ. Synovium, Hoffa's fat pad and meniscus of knee osteoarthritis patiënts release higher levels of prostaglandin subtypes than cartilage and their release can be modulated by celecoxib. (ORS 2017, San Diego)

4. Timur UT, Caron MC, Emans PJ, van Rhijn L, Welting TJM, Jahr H. TAK1 inhibition improves chondrocyte marker expression independent of osmolarity. (EORS 2017, Munich)

5. Timur UT, Caron MC, Bastiaansen-Jenniskens Y, Welting TJM, van Osch GJVM, Emans PJ. Celecoxib modulates release of different prostanoid subtypes by intra-articular tissues: towards celecoxib based intra-articular treatment for OA modulation? (OARSI 2018, Liverpool)

\section{Other Achievements}

Winner of the Mosacell microscopy contest: Mass-spec imaging of a rat knee by Ufuk Tan Timur (Orthopedic Surgery), Nina Ogrinc Potocnik (M4I) and Florian Barré (M4I). 
Dankwoord 


\section{Anneme ve Babama}

Sevgili anne ve baba, bu kitap sizlerin sayesinde mümkün oldu. Benim için ne anlama geldigini ve ne ifade ettiğini anlatmaya kelimeler yetmez ama yine de deneyecegim.

Sevgili annem,

Bana anlattığin bir hikaye ile başlamak istiyorum. Hamileyken anneannemin merdivenlerini silerken dua etmissin, inşallah bir oğlum olur, gözleri yeşil. Oğlan olmasa da gözleri yeşil olsun yeter demissin. Allah sana ikisini birden nasip etmiş. Seni hiç bir zaman üzmedim, ama senin gibi bir anne'yi kim üzebilir ki? Allah herkese senin gibi bir super anne nasip etsin.

Sabahın erken saatlerinde, bazen akşam geç saatlere kadar vardiyelı çalıştığın fulltime bir işe ek olarak, fulltime bir anne olarak benimle ilgilendin. Ilkokul ve ortaokuldayken kendimi geliştirmem için her zaman en iyi şartları sağladın. Türk annelerin klişe bir lafı vardır, oğlum okuyun da bizim gibi olmayın, eskiden anlamiyorduk belki, ama şimdi çok daha iyi anlıyorum. Senin gibi kötü çalışma koşullarında çalışmak zorunda kalmamamız için bana her zaman destek oldun ve iyi bir eğitimin önemini anlattın. Her zaman okulda elimden gelenin en iyisini yapmamı isterdin. Hiç ödev yapmadiğım için sık sık tartışmışolsak da, 'her şey çok güzel olacak medoş' dedig̈imde gerçekten her şeyin yolunda gittigini gördun, bu kitabimi sana ve babama armağan ediyorum, bu kitap sizlerin sayesinde yazıldı. Okuldan iyi bir notla geldiğimde gözlerindeki neşe ve coşkuyu asla unutmayacağım. Kendimi maksimum seviyede geliştirmem gerekme motivasyonun beni olduğum yere getirdi. Çalıştığın fabrikada bir ögrenci olarak bir iş bulduğumda ve geçici olarak meslektaşın olduğumda, nasıl bir süper anne olduğunu gerçekten anladım. Sadece bir süper anne her gün bu işi yapabilir ve aynı zamanda 2 çocuk yetiştirebilir. Rüzgara karşı, yağmur, çamur demeden, beni bisikletle basketbol antrenmanlarıma bıraktın (neyse ki o zamanlar o kadar da kilolu değildim). Benim için en lezzetli yemekleri yaptın. Zor kazanilan paranla bana en güzel Nike Air Max ayakkabılarını aldın. Beni zorlamadan, inancımız hakkında mümkün olduğunca çok şey ögrenebilmem için beni Camiiye gönderdin ama aynı zamanda bana her zaman diğer insanlara, dinlere ve kültürlere saygı duymayı da ögrettin. 


\section{Dankwoord}

Sevgili babam,

35 yıl önce Hollanda'ya misafir işçi olarak geldin. iki küçük çocuk, bir fabrikada fulltime bir iş ve aynı zamanda Fontys'de ögretmenlik eğitimi, pek çok insan seni taklit edemez!

Bir Kürt çocuğu olarak Türk bir ailede damat olmanın senin için kolay olmadığının farkındayım. Azmin harika ve genlerimize kazınmış. Bana bunu verdiğin için teşekkür ederim. Herkese yardimsever yaklaşımın benim için bir gurur kaynağı, seninle gurur duyuyorum. Yaptığım her şeyde beni her zaman destekledin ve hayat derslerin beni bugün oldugum yere getirdi. $\mathrm{Bu}$ yaşıma kadar ne yaptıysam, hatalarımla birlikte, hep arkamda dağ gibi, bir baba gibi durdun. Beni Fenerbahçe taraftarı yaptığın için sana teşekkür ederim. 6 Kasım 2002'de sadece ilk yarısını izlememe izin verdin, ama sonra uyumam gerektiğini söyledin, çünkü ertesi gün okulum olduğu için uyumam gerekiyordu. Yine de o gece beni uyandırıp 6-0 kazandık oğlum dediğini dün gibi hatırlıyorum.

18 yaşıma basıp tıp' kazandığımda beni tatile Türkiye'ye gönderdin. Bu arada, annem ve sen, tatilimden hemen sonra taşınabileceğim Rotterdaridaki daireyi dösuyordunuz! Bir baba figürü olarak hayatım boyunca benim için gerçekten her şeyi nasıl ayarladın, kafamdaki kaosumu düzenlemeyi nasıl sağladın, tüm bunlar olmasaydı, bunu asla başaramazdım. 
Sevgili annem ve babam,

Hayatımda bir olay var, hiç unutamıyorum, size şimdiye kadar hiç bahsetmedim, ama bugüne kısmetmiş. Bir gün hastaydim ve yüzümü yıkamak için banyoya gittim, benim için endişelendiniz, aynaya baktım, săg tarafımda babamın sol eli omuzumda, sol tarafında annemin sağ eli omuzumda, işte bu görüntü sizlerin benim hayatımdaki yeri için bir mecazi.

Gurbet Elde Bir Hal Geldi Başıma,

Ağlama Gözlerim Mevlâ Kerimdir.

Derman Arar iken Derde Düş Oldum,

Ağlama Gözlerim Mevlâ Kerimdir

sizleri çok ama çok seviyorum, iyi ki benim annem ve babamsınız! 


\section{Dankwoord}

Beste collega's, vrienden en familie. Jammer dat u meteen weer het dankwoord opent, in mijn voorwoord had ik al gewaarschuwd, maar het is u vergeven. Het was een lange rit, maar mijn boek is eindelijk af! Dit boek heeft bijgedragen aan mijn wetenschappelijke ontwikkeling, maar ook aan mijn persoonlijke ontwikkeling. Ik wil iedereen bedanken voor hun interesse en hulp in het tot stand komen van dit proefschrift, het is en blijft een team effort. Er zijn een aantal mensen die ik in het bijzonder wil bedanken voor hun bijdrage.

Allereerst natuurlijk mijn fantastische promotieteam. De functionering van mijn promotieteam was eigenlijk wel te vergelijken met een elektrische auto. Ik zie u denken, waar slaat deze vergelijking op Ufuk, maar ik ga het uitleggen.

Mijn Co-Promotor dr. P.J. Emans, beste Pieter, jij was de elektromotor van dit proefschrift, de drijfkracht. Toen ik op 06-03-2014 jouw kamer binnenstapte was ik al gelijk onder de indruk van jouw enthousiasme over wetenschappelijk onderzoek. Je hebt altijd in mij geloofd en hebt me wijze lessen geleerd over onderzoek doen. Je weet altijd overal een praktische oplossing op te bedenken, ook bij tegenslagen:

\section{Promoveren is als trouwen met de universiteit zei je, maar je moet later ook zelf trouwen met een droomvrouw, want achter elk succesvolle man staat een succesvolle vrouw!}

Mijn moeder is nog steeds dankbaar en benieuwd naar wie deze fantastische co-promotor van mij is. Jouw quotes en oneliners zijn inspirerend en ik sta nog steeds versteld van jouw kennis, niet alleen op medisch gebied, maar ook op allerlei andere gebieden zoals de politiek, cultuur of zelfs voetbal. Je kan werkelijk waar over alles meepraten en je bent een lopende encyclopedie. Nadat ik bij jou uit de kamer stapte na een gesprek had ik soms wel kortsluiting in mijn brein, omdat ik veel informatie kreeg en het deels begreep, maar niet alles. Hoe bijzonder en fascinerend is het dat ik werkelijk waar na elke meeting altijd de dingen ben tegengekomen waar jij het over had: 'Oh, dit had Pieter al gezegd, dus dit 
was het wat hij bedoelde'. Woorden schieten te kort om te omschrijven hoeveel je voor mijn carrière hebt betekend en nog steeds betekent. Als ik ergens mee zit bied je altijd een luisterend oor, jouw gesprekken hebben ervoor gezorgd dat ik mezelf ben blijven ontwikkelen en in mezelf ben blijven geloven! Je vervult niet alleen een voorbeeldfunctie voor mij op werk, maar ook een voorbeeldfunctie als mens en vader. Ik zal onze rit in de Tesla over de straten van Bemelen samen met Lotte en Jaap nooit vergeten (Jij sliep al Puk). Ik zou ook Lonneke willen bedanken voor de gezellige etentjes en de effectieve meetings bij jullie thuis, dank voor de gastvrijheid!

Mijn Promotor Prof. dr. T.J.M. Welting, beste Tim, jij was het stuur van dit proefschrift. Ongelofelijk hoe jij tijdens deze rit mij altijd op de juiste weg hebt gehouden. Als ik weer enthousiaste ideeën had over van alles en nog wat, wist jij die goed te bundelen en mij te sturen in de juiste onderzoeksrichting, zodat ik niet weer afdwaalde en van de weg raakte. Ik heb ongelofelijk veel respect voor hoe jij het Orthopedisch Laboratorium hebt getild naar het niveau waar we nu zijn. We begonnen met enkele promovendi en kijk is hoe groot het nu is en wat voor output we hebben! Ik noemde je in 2014 nog dr. Welting, maar inmiddels moet ik je Professor Welting noemen! Hoe jij in 2014 het laboratorium runnende hebt weten te houden in moeilijke privéomstandigheden, heb ik ongelofelijk veel respect voor. Jouw intelligentie en kennis over fundamenteel onderzoek is onvoorstelbaar en bewonderlijk. Ik heb genoten van onze CART-1 kloon experimenten en de chocoladerepen die we uit de automaat gingen halen in het AzM. We kunnen urenlang filosoferen en brainstormen over nieuwe onderzoeksideeën, maar we kunnen ook op een vrijdagmiddag om 16.00 een 'joint in a jar' experiment bedenken waar we een fantastische OA\&Cartilage publicatie mee hebben verdiend die gerekend wordt tot de top 10 Biomarker publicaties van het jaar 2021 ! Dank je wel dat je in de metro in München, weliswaar lachend, als enige mijn verhaal over ribosomen wou aanhoren, dank je wel voor alle leerzame en fijne momenten op het laboratorium!

Mijn Co-Promotor dr. H. Jahr, beste Holger, natuurlijk was jij het gaspedaal. Met jouw creatieve ideeën, enthousiasme en ongelofelijke inspiratie schoten we meteen uit de startblokken, gas erop! Jouw eindeloze, onuitputtende energie is geweldig en inspirerend. Het begon allemaal bij jou. Ik kwam als student geneeskunde op de $16^{\mathrm{e}}$ verdieping in 


\section{Dankwoord}

Rotterdam en ik kreeg meteen een hele tekening overTGF-beta signalling op de whiteboard. Een tekening met SMAD-eiwitten, TGF-beta receptoren, noggin eiwit etc. Ik snapte er niks van. Gelukkig begrijp ik het nu allemaal een stuk beter. Bedankt voor alle leuke momenten op congressen in Berlijn, Nantes en Bristol. Bedankt dat je me wakker hebt gehouden op onze terugrit vanuit Nantes naar Maastricht, waarin je merkte dat ik het toch af en toe moeilijk had richting het einde van de rit. Bedankt voor alle lekkere etentjes in Aachen, waaronder ook in het Turkse restaurant waar niemand Turks kon praten.

Mijn Promotor, Prof. dr. L.W. van Rhijn, beste Lodewijk, jij was het regeneratief remsysteem. Je wist precies op het juiste moment wanneer ik het gaspedaal los moest laten om weer energie bij te tanken zodat ik op mijn opleiding tot Orthopedisch Chirurg kon focussen. Elke keer als ik het gaspedaal losliet ging er bij mij weer een groen balkje omhoog, die ervoor zorgde dat ik weer energie kreeg om op latere momenten effectiever onderzoek te kunnen doen. Ik moet altijd aan je denken als ik de groene balk in mijn auto weer op zie vlammen als ik de gas loslaat in mijn auto. Tijdens onze gesprekken had je altijd een kritische blik en bracht je nieuwe waardevolle inzichten die mij hebben geholpen om dit proefschrift tot stand te brengen. Tijdens deze rit heb jij ervoor gezorgd dat ik precies de goede balans kon vinden tussen onderzoek doen en mij ontwikkelen tot een zo goed mogelijke dokter, daarvoor ben ik jou enorm dankbaar. Bedankt dat je altijd in me hebt geloofd en bedankt dat je altijd een luisterend oor voor mij bent geweest en heel veel succes met jouw nieuwe functie als Afdelingshoofd Orthopedie in het UMCUtrecht!

De leden van de beoordelingscommissie, Prof. dr. M. van Griensven, Prof. dr. S.K. Bulstra, Prof. dr. H.B.J. Karperien, Prof. dr. L.J.C. van Loon en Prof. dr. M. Poeze, veel dank voor uw tijdsinvestering in het kritisch lezen van en beoordelen van mijn proefschrift, alsmede voor de bereidheid zitting te nemen in de beoordelingscommissie.

Ik wil ook alle stafleden Orthopedie van het MUMC+ bedanken voor de leerzame tijd. Beste Lodewijk, Heleen, Pieter, Peter, René, Paul, Jan, Joris, Mark, Adhiambo, Tim en Loek bedankt voor de leerzame tijd in het MUMC+ in de beginfase van mijn vervolgopleiding Orthopedie. Jullie zijn een fantastische opleidingsgroep en het voelt als een voorrecht om door jullie opgeleid te mogen worden. Ik kijk er naar uit om het laatste deel van mijn 
opleiding bij jullie af te ronden. Beste Heleen, als opleider wil ik jou speciaal bedanken. Jouw constructieve feedback heeft ontzettend veel bijgedragen aan mijn ontwikkeling en ik kijk er naar uit om weer met je samen te werken als ik terug ben! Beste Peter, ik wil jou ook in het bijzonder bedanken. Geweldig dat jij plaatsvervangend opleider bent geworden. Ik heb altijd met plezier met je samengewerkt, vanaf de samenwerking bij sport en bewegen al. Dit is tijdens mijn opleiding tot Orthopedisch Chirurg alleen maar gegroeid. Ik kijk er naar uit om nog heel veel van jou te leren en je houdt de derby Fenerbahce-Galatasaray live on site tussen alle fanatieke Fenerbahce supporters nog van me tegoed!

Beste stafleden van Traumachirurgie van het $M U M C+$, bedankt voor de gezellige en leerzame tijd in het MUMC+, tot binnenkort. Beste collega's van de OK, gipskamer, verpleegafdelingen, SEH en polikliniek, dank jullie wel voor de prettige samenwerking.

Beste stafleden van het Maxima Medisch Centrum, beste Rob, Jan, Arnold, Florens, Henk, Hans, Marijn, Willem, Coen, Anouk en Inge. Bedankt voor de fantastische tijd die ik doorbreng in het Maxima Medisch Centrum. Elke AIOS in Nederland zou door zo een fantastische opleidingsgroep opgeleid willen worden. Het voelt als een voorrecht om het perifere deel van mijn opleiding bij jullie te mogen doen. Een dank ook voor alle andere stafleden van het Catharina Ziekenhuis, die onderdeel uitmaken van COGE en ook bijdragen aan onze opleiding tot Orthopedisch Chirurg. De gezellige overdrachten, leerzame momenten op de polikliniek en op de OK, de mogelijkheden die worden geboden om mij te ontwikkelen als Orthopedisch Chirurg zijn oneindig. Ik kijk met tegenzin naar de datum waarop ik jullie helaas moet gaan verlaten. Mijn opleider in het Maxima Medisch Centrum wil ik ook bedanken in het bijzonder. Beste dr. Janssen, beste Rob, bedankt voor alle leerzame momenten. Op de polikliniek, op OK maar ook op persoonlijk vlak. Je hebt mij zoveel geleerd als ANIOS, maar nu ook als AIOS. Als ANIOS heb je me al geleerd:

Waar wrijving is ontstaat warmte. 


\section{Dankwoord}

Als AIOS leer ik nog steeds heel veel van jou. Ik vind het mooi om te zien dat je de AIOS die door jou zijn opgeleid in een oogopslag herkent.

\section{Leuk is voor thuis, interessant is het op werk.}

Jammer dat ik je nog steeds niet kan overtuigen om elektrisch te gaan rijden maar ik ben ervan overtuigd dat ook jij binnenkort elektrisch zal gaan rijden.

Mijn collega arts-assistenten in het Maxima, beste Joost, Bart, Sharmila, Lidewij, Alexandra, Misha, Marieke, Frank, Lonneke, Stephanie, Sander en Wesley, bedankt voor alle mooie momenten en de fijne samenwerking. Ook een dank aan alle collega's van het secretariaat orthopedie, de polikliniek, gipskamer, onderzoeksgroep en natuurlijk de operatiekamer.

Collega's van de Maatschap Chirurgie van het Maxima Medisch Centrum, bedankt voor de fijne samenwerking en de opleidingsmomenten.

Beste ex-collega's en stafleden van de Maatschap Chirurgie van het Catharina Ziekenhuis. Bedankt voor de vooropleiding die ik bij jullie heb mogen volgen en de leerzame tijd! Beste oude huisgenootjes van Villa Zonnedael, beste Martijn, Marijn, Isabelle en Ingrid dank jullie wel voor de gezellige en fantastische tijd die we samen hebben doorgebracht, het was geweldig!

Dan nu een grote dank naar de collega's van het Laboratory of Experimental Orthopedics.

Beste Ralph, rrraaa! Dank je wel voor alle mooie momenten voor het lab. Jouw komst op het laboratorium in 2015 heeft veel veranderd in mijn leven. Jij bent een van de redenen geweest dat ik mezelf ontwikkelde en beter ging presteren. Bedankt voor alle mooie momenten op het laboratorium. Mooi dat we ook een tijdje samen hebben kunnen trainen in UMsport, je hebt me veel technieken bijgebracht voor verschillende oefeningen. Ik zal onze congresbezoeken in München en Sorrento nooit vergeten. De Oktoberfest, dank je wel voor alle lekkere Spezi's waarmee je me weer een booster gaf om het feest tot een goed einde te kunnen brengen. Dank je wel voor alle mooie momenten in Sorrento, met 
als hoogtepunt de club in hartje centrum die we speciaal hebben laten openen op een maandagavond, waar de club normaal gesloten was. Dank je wel voor alle mooie feestjes in Maastricht. Ook een grote dank aan Annemarijn, bedankt voor alle gastvrijheid tijdens onze etentjes bij jullie! Ralph, dank je wel ook voor alle mooie momenten in Cannes, dit was een fantastische vakantie, waarbij we met onze grote maatje Sammie boy, de straten van Cannes onveilig hebben gemaakt! Sammie, jij ook bedankt voor alle mooie momenten in Maastricht, geen dank voor de prettige rit in mijn Toyota Yaris waarin we toch de $210 \mathrm{~km} / \mathrm{h}$ hebben kunnen aantikken bij de afdalingen in België.

Beste Maarten, jij verdient ook een bijzondere plek in mijn dankwoord. Ik heb de eer gehad om je te mogen opvolgen in 2014 op het lab, en wat was het fijn met je samen te werken! Dank je wel voor alle mooie momenten op het dieren lab. Mooi om te zien dat ik precies hetzelfde pad heb bewandeld als jij. Na onze mooie operaties op het CPV, hebben we ook samen mogen opereren in het MUMC+ dit heb ik als bijzonder prettig ervaren. Dank je wel dat je altijd open staat voor een telefoongesprek en je een luisterend oor biedt als ik ergens mee zit.

Beste Marjolein, dank je wel voor alles! Je hebt een ongelofelijke bijdrage geleverd aan de totstandkoming van dit proefschrift. In tijden dat Tim niet op het lab kon zijn was je een direct aanspreekpunt en dat heb ik als prettig ervaren. Ik heb veel bewondering voor jouw probleemoplossend vermogen. Jij zag altijd overal het positieve van in, en bezat het talent om een limitatie in een onderzoek juist om te draaien tot een sterk punt! Bedankt voor de plaatjes die je hebt aangeleverd voor Hoofdstuk 6, en bedankt voor je waardevolle bijdrage in hoofdstuk 3, 4 en 5 van dit proefschrift.

Beste Alex, bedankt voor de gezellige en leerzame tijd op het laboratorium. Jouw kritische blik hebben mij veel bijgebracht en leren nadenken over mijn onderzoek. Je kwam tijdens de ORM-meetings altijd met kritische vragen die ervoor hebben gezorgd dat ik het niveau van mijn onderzoek naar een hoger niveau heb kunnen tillen. Onze trips naar Nantes, Las Vegas, Sorrento en München zal ik nooit meer vergeten. Dank je wel dat je ondanks 1 uur slaap, toch naar mijn oral presentation kwam kijken op de ICRS in Sorrento. Ondanks dat ik je stiller vond toen dan normaal op de ORM-meetings, heb ik dat toch als steun ervaren :P. 


\section{Dankwoord}

Je bent een fantastische persoon, en hebt het hart op de juiste plek.

Beste Marloes, jij ook ontzettend bedankt voor de gezellige tijd. Sorry dat ik je elke dag liet schrikken als je weer achter je computer zat met je oordopjes in. Misschien heb ik je deels kunnen terugbetalen omdat je samen met Alex hebt kunnen oefenen hoe het is om een drukke ADHD-kind op de achterbank te hebben als je door Californië reist :P. Jammer dat ik heb besloten om niet jullie zonnebrandcrème te gebruiken op de stranden van San Diego, gelukkig heeft mijn type 4 huid veel schade voorkomen.

Beste Eva, jouw komst op het laboratorium in 2015 heeft enorm bijgedragen aan mijn ontwikkeling op het laboratorium. Dank je wel hiervoor. Jouw werkethiek, je ambitie en je motivatie is een voorbeeld voor iedereen. Ik heb veel respect hoe hard jij werkt om jouw droom te bereiken. Je bent niet alleen een fijne collega om mee samen te werken in de kliniek, maar ook een fantastische persoon waarmee je de fijnste gesprekken mee kan voeren. Dank je wel voor alles en ik kijk er naar uit om weer met je samen te werken in de kliniek! Oh ja, en je hoeft niet meer te zoeken naar onderzoeksmateriaal in Den Bosch, weet dat je altijd bij mij terecht kan voor schapenwervelkolommen uit het slachthuis in Den Bosch, ik heb mijn connecties!

Beste Tom, heerlijk dat we nu samen AIOS zijn, maar wat was het ook gezellig in onze PhD kamer een aantal jaren terug. Dank je wel dat je begrip toonde voor alle liedjes die ik zong en mijn stopwoordjes die ik soms uitkraamde als ik weer te lang op mijn stoel had gezeten.

Beste Pieter van Hugten, jou wil ik ook in het bijzonder bedanken. We hebben niet lang samen gezeten op het lab, maar we zien elkaar regelmatig in het Maxima Medisch Centrum. Ik kijk er naar uit om met je samen te werken in de kliniek als we samen terugkeren naar het MUMC+. Dank je wel voor onze brainstormsessies over joint preservation en hopelijk kunnen we in de toekomst nog mooie dingen samen publiceren!

Beste Jim, Raymond, Guus, Nina, Mandy, Ellen, Alzbeta, Remco, Bas en Arjan jullie ook ontzettend bedankt voor alle mooie momenten op het lab, tijdens starter of the quarter etentjes, op congressen en natuurlijk Oktoberfest. Bas, fantastisch dat ik coauteur ben op 
jouw fantastische paper over de effecten van synovial fluid op het chondrocytenfenotype, het is bijzonder fijn samenwerken!

Beste Chris, als Provinciegenoot begrijpen wij elkaar heel goed. Bedankt voor alle mooie momenten, met name op congressen. Ik zal de lekkere cocktails in Bristol nooit meer vergeten!

Beste Don, ik heb ontzettend veel bewondering voor jouw geduld en de rust die jij uitstraalt op het laboratorium. Dank je wel voor alle leuke momenten. Ik kon altijd bij je terecht als ik vragen had over labtechnische zaken, waarmee je me altijd goed hebt geholpen. Jouw liedje waarbij je mijn naam nazong, je weet wel, 'Yoeeeefoeeeeek' 'Yoefoeeeek', blijft voor de rest van mijn leven in mijn geheugen.

Beste Andy, als chaoot tot de macht 1000 hebben we wel eens gebotst op het laboratorium. Je hebt mij misschien wel 1000 keer moeten vragen waar wat lag, of wat nu precies waar gelabeld is en waar in mijn labjournaal staat. Wat ben ik blij dat we jou op het laboratorium hebben. Je bent een onmisbare kracht en jouw structuur en drang tot organiseren is van onschatbare waarde! Ondanks dat ik me soms door je opgejaagd voelde, denk ik elke keer als ik weer samples moet opzoeken, gelukkig is Andy er want wat moesten we zonder jou! Dank je wel voor alle mooi momenten op het lab.

Jessica en Laura, onze jonge generatie analisten op het lab, ook jullie bedankt voor al jullie hulp en de mooie tijden op het lab.

Beste Kaj, we hebben niet lang samen gezeten op het laboratorium maar hebben nu de kans om samen te werken op een mooie publicatie. Dank je wel voor jou kritische blik en ik kijk er naar uit om nog veel met je samen te werken in de toekomst. Beste Mirella, mooi dat jij het Hoffa-werk hebt kunnen overnemen van mij en bedankt voor de fijne samenwerking.

Collega's van de afdeling anatomie op UNS40, dank jullie wel voor alle hulp en het beschikbaar stellen van de ruimte zodat ik mijn coupes kon komen snijden. In het bijzonder een grote dank aan Paul, jouw hulp en tips voor het snijden van de Technovit blokjes is van 


\section{Dankwoord}

onmisbare waarde geweest en de kwaliteit van de histologische plaatjes wordt nog altijd geroemd in wetenschappelijke presentaties! Alle collega's van het CPV, bedankt voor jullie hulp bij alle experimenten die ik heb uitgevoerd!

De dames van het trialbureau, Liesbeth, Margareth en Anita bedankt voor de fijne samenwerking. Ook een grote dank aan alle collega's van het secretariaat Orthopedie, Jerney, Chantalle (bedankt voor je geduld als je een meeting met Pieter en mij moet inplannen), Denise, Astrid, Wil, Felice, Helma en Marieke. Denise dank je wel voor alle hulp voor het regelen van alle praktische zaken rondom mijn proefschrift. Bedankt ook dat jullie doen alsof ik goed Limburgs spreek als ik het probeer, want stiekem weten we allemaal dat ik er niks van bak.

Beste collega arts-assistenten van ROGO Zuid, bedankt voor de gezellige ROGOonderwijsdagen, de mooie opleidingsmomenten die we samen hebben doorgemaakt. Beste Martijn, jij verdient een speciale plek. We hebben gezorgd voor een unicum in de historie van het Maxima MC en zijn samen ANIOS geweest. Ik herinner me nog als de dag van vandaag dat we samen tegenover de Matthijsenzaal zaten te wachten op het gesprek met de opleiders. Hoe mooi dat we samen in opleiding zijn en hoe mooi dat we elkaar nooit als concurrenten hebben gezien. Jouw intelligentie en enthousiasme voor het vak is inspirerend en motiverend. Mooi om te zien dat wij bij de snijzaal onderwijsmomenten altijd nog als laatste blijven om nog een operatieve techniek te oefenen. Ik kijk er naar uit om ook in de toekomst nog met je samen te werken!

Beste Bobby, ontzettend bedankt voor het designen van de mooie plaatjes in dit proefschrift en voor de verzorging van de lay-out. Je bijdrage was essentieel voor de totstandkoming van het mooie design van dit proefschrift!

Dear Professor Mandy Peffers, dear Mandy, it has been an honor for me to work with you. Thank you very much for the cooperation that resulted in a wonderful publication published in Chapter 7. You and your colleagues are doing an amazing job in Orthopedic Research and it is a privilege to publish with you. I appreciate your fast responses everytime I had a question and the huge amount of data that was created by your research group. 
Also, a special thanks to Daniel, your help with the statistical analysis in Chapter 7 was amazing and contributed to the acceptance of our paper! James Anderson and Aibek Smagul, I also would like to thank you for your contributions to Chapter 7.

Alle collega's van de $16^{\text {e }}$ verdieping Orthopedie Rotterdam. Bedankt voor alle mooie momenten als student!

Prof. dr. Weinans, beste Harrie. In 2011 kwam ik bij jou op gesprek omdat ik onderzoek wilde gaan doen bij de Orthopedie. Jij gaf mij tijdens dat gesprek al onderwijs over kraakbeen en hoe bijzonder kraakbeen weefsel was. Waarom onderging articulair kraakbeen geen endochondrale ossificatie en kraakbeen in groeischijf bijvoorbeeld wel? Inspirerende vraagstukken en bedankt voor alle onderwijsmomenten!

Prof. dr. G.J.V.M. van Osch, beste Gerjo, bedankt voor je bijdrage aan hoofdstuk 4 en 5 van dit proefschrift. Ik sta nog altijd versneld van hoe snel jij feedback geeft. Als student vond ik het al enorm prettig om met je te brainstormen over fundamenteel onderzoek en dit gevoel is tijdens mijn $\mathrm{PhD}$ alleen maar sterker geworden. Dr. Bastiaansen-Jenniskens, beste Yvonne, ik wil jou ook bedanken voor je waardevolle bijdrage aan hoofdstuk 4 en 5 van dit proefschrift.

Beste Esther, Wendy en Nicole, jullie ben ik natuurlijk niet vergeten. Ik wil jullie ook bedanken voor alle hulp op het laboratorium en het woordenboekshirt wat jullie mij cadeau hebben gedaan ligt nog steeds in mijn kledingkast! Beste Anna, jou wil ik in het bijzonder bedanken. Bedankt voor je hulp bij Hoofdstuk 3. Hoe mooi en toevallig was het dat we behoudens onderzoek ook een jaar hebben kunnen samenwerken in de kliniek, ik heb onze operaties waarin we soms voor uitdagende dilemma's kwamen te staan als heel leerzaam ervaren! Beste Michiel, ook jou wil ik in het bijzonder bedanken. Ik herinner me jouw inspirerende speech nog, waarin je een apart gesprek met me hebt ingepland en mij als student hebt overtuigd dat ik toch echt Orthopedisch Chirurg moest worden.

Dan nu een speciale dank aan mijn vrienden. Ik ga toch een emotionele toespraak geven, jullie weten hoe dat is afgelopen de laatste keer in die café in Amsterdam :p... maar toch.. 


\section{Dankwoord}

Beste Aşkın, we kennen elkaar al 30 jaar. Bedankt voor jouw vriendschap, en bedankt voor je steun, je bent een top gozer. Ayhan, onze BraboTurk, ik moet nog elke keer lachen als ik jouw Helmondse accent hoor, je bent altijd overal op tijd en jouw huis staat altijd voor ons open. Bilal oftewel Bilel, wij kennen elkaar ook al 30 jaar, vroeger gingen we naar het voetbal kijken bij onze papa's, we hebben ook een tijdje samen in hetzelfde voetbalteam gezeten, mooie tijden. Bedankt voor alle mooie tijden en bedankt dat je mijn Paranimf wilt zijn! Fatih oftwel Fatex, ook een speciale dank aan jou. Je staat altijd open voor een gesprek als ik ergens mee zit en hebt een hart van goud. Heybet oftewel Bets, jouw vriendschap betekent veel voor me. Jouw gevoel voor humor is geweldig, maar je bent ook een hele betrouwbare vriend in alle opzichten, bedankt voor alle mooie vakanties en momenten. Mehmet, oftewel Mem(s), ook een speciale dank aan jou. Er is geen eerlijker persoon dan jij op aarde denk ik, jouw gevoel voor humor, jou oprecht- en eerlijkheid, het is een voorrecht om jou als vriend te hebben, dank je wel! Ik kijk uit naar de vele kulis boys Derby's die gaan volgen! Rıza, oftewel RizRiz, eee saçmaa, moet ik dit nu in het Nederlands of Turks schrijven. Nederlands heb ik je nooit horen praten, maar ik ben er zeker van dat je het kan spreken, alsmede ook Frans. Bedankt voor jouw vriendschap. Şenol, oftewel Şeeeeeensssss, op basketbal plaagde ik je altijd en nu nog steeds, maar gelukkig kan je het nu beter verdragen. Jouw nuchterheid is een voorbeeld voor iedereen, bedankt. Umut, oftewel Umsje onze superstar. Ongeacht het feit dat niemand naar jouw liedjes wil luisteren, luister ik met plezier naar jou superhits, dank je wel voor alle gezelligheid!

Beste vrienden van mijn basketbalteam, wat is het geweldig om met jullie af en toe op een feestje weer Tarkan te kunnen zingen, bedankt voor alle gezelligheid!

Mijn paranimf Dalibor, a.k.a. DADO. We kennen elkaar sinds het eerste jaar van geneeskunde. Het begon allemaal met een papieren propje die ik als jongetje van 18 jaar in de collegezaal naar beneden gooide en die op jouw hoofd kwam. Jij stapte naar mij toe, ik stapte naar jou toe. Wat doe je stoer? Wat doe jij stoer? Verhitte discussie, maar de grootste vriendschappen beginnen met vijandigheid, is een Turkse gezegde. Dat hebben we geweten ook! Wat een vriendschap hebben wij opgebouwd in al die jaren. Wat heb ik ongelofelijk veel respect voor wat jij hebt bereikt in je leven. Je komt als asielzoeker uit Joegoslavië naar Nederland en bent nu inmiddels Neuroloog! Ik kan niet met woorden 
omschrijven hoeveel je voor mij betekent. Jouw hart van goud is onvoorstelbaar. Je staat altijd voor iedereen klaar ongeacht geloof en cultuur. Hoe mooi symboliserend was jouw bruiloft met 20-30 verschillende nationaliteiten en culturen? Dit heb jij in Servië aan iedereen laten zien, je bent zelfs op het nieuws gekomen, fantastisch. Onze discussies over politiek, religie maar ook medische zaken zijn altijd verhit, maar heerlijk om jou uit de tent te lokken. Jouw intelligentie en kennis over van alles en nog wat is onvoorstelbaar. We gaan naar Frankrijk en je spreekt vloeiend Frans. We gaan naar Spanje en je spreekt vloeiend Spaans. Je werkt een half jaar in Duitsland en je spreekt vloeiend Duits. Je bent een alleskunner en een harde werker. Hoe mooi is het dat we rond dezelfde periode, na al onze harde werken, samen onze eerste mooie auto's hebben gekocht? Je bent de enige persoon die even lang aan de eettafel blijft zitten als ik, want wat kunnen we allebei eten zeg. Bedankt voor alle mooie momenten in ons leven en ik kijk nu al uit naar de mooie momenten die komen gaan. Bedankt dat je mijn paranimf wilt zijn! Marija, hvala vam na gostoprimstvu!

Mijn Bratski's. Nemo, je bent als een broertje voor mij. Dank je wel dat je altijd voor mij klaarstaat, ook als ik mijn rijbewijs kwijt ben. Razzo, dank je wel voor je vriendschap en alle mooie momenten ook op vakanties in Joego. Ik vergeet nooit meer hoe je de deur van onze huurauto open kreeg toen we onszelf hadden buitengesloten. Aladdin, Dano, Dino, Leon, Petar, Rhommik, Andrej en Tigran bedankt voor alle mooie momenten en jullie vriendschap.

Kevin en Mirjana bedankt voor alle gastvrijheid en de mooie momenten, in het bijzonder op jullie bruiloft!

Sevgili Timmy, Ulaş ve Su. Büyüdüğünüzde bu kitabı okuduğunuzda sizleri ne kadar çok sevdiğimi anlarsınız. Sevgili ablam Didem, üç çoçuk büyütmek kolay bir iş değil ve bunun farkındayım, sana da teşekkür ederim. 
Sevgili anneannem, babaannem, rahmetli buyukbabam ve dedem, amcalarım, halalarım, dayılarım, teyzelerim, kuzenlerim. Hepinize hayatımdaki yaptığınız yardımlar için teşekkür ederim. Metin Amca ve Suna Yenge, Rotterdamda okurken kapınız herzaman bana açıktı, sizi seviyorum.

Mijn schoonfamilie. Sevgili Fatma annem ve Ali Ihsan babam, sizinle tanıştığım ilk günden beri kapınız herzaman bana açık. Beni her geldiğimde kendi evimdeymişim gibi hissetmemi sağladığınız için sizlere ne kadar teşekkür etsem azdır, sizi seviyorum iyi ki benim ikinci annem ve babamsınız!

Mijn allerliefste schoonzusje Rabia, oftewel Rabbs. Wat ben ik blij dat ik een schoonzusje zoals jij erbij heb gekregen. Je bent het pareltje van onze familie. We kunnen allebei niet tegen ons verlies, dus hopelijk zitten we voortaan altijd in hetzelfde team, enişte-baldiz Power! Sevgili Efe, senin için özel bir yer ayırdım, kalbimdesin, ilk günden beri aramızda güçlü bir bağ oluştu, iyiki benim kuzenim oldun!

Mijn andere allerliefste schoonzusje Leyla en mijn BACANAKI Hamdi. Ik kan niet met woorden omschrijven hoe blij ik met jullie ben. Jullie deur op de Zijderupsvlinderlaan stond altijd voor mij open. Dank voor alle mooie momenten op vakanties in Turkije en Griekenland. We kunnen altijd zoveel lachen met elkaar en hoe mooi is het dat we binnenkort overburen zijn. Ik kan niet wachten tot we kunnen intrekken in onze huizen en alle mooie momenten die gaan komen! Leyla, je toont altijd respect voor mij en maakt altijd de lekkerste maaltijden klaar, dat er nog maar vele liters şalgam suyu en mooie vakanties mogen volgen. Bacanaki Hamdi, je bacanaki kan je niet kiezen, maar als ik zou moeten kiezen had ik jou gekozen als bacanaki! We hadden meteen al een klik op onze eerste vakantie. De rust die jij uitstraalt en jouw constructieve kijk op zaken is een voorbeeld voor mij. Hopelijk kunnen we na de Corona Maatregelen weer samen trainen zodat we weer kasten worden. 
Het beste bewaar ik voor het laatste. Lieve, lieve, sevgili El Professore, lieve Eslem, sevgili Eslemim. Ik kan niet met woorden omschrijven hoeveel jij voor me betekent, maar ik ga het toch proberen. Sinds het moment dat je in mijn leven bent gekomen maak je me elke dag weer de gelukkigste man op aarde. Jouw intelligentie is wonderbaarlijk en jouw warme liefdevolle karakter is geweldig. Bedankt voor jouw kritische blik op het design van dit proefschrift. Bedankt voor jouw liefde en respect die je toont voor onze familie, mijn ouders konden geen betere schoondochter wensen! Bedankt voor je steun en toeverlaat die je was en bent voor mij in moeilijke tijden. Bedankt dat je altijd achter me staat en bedankt dat je mijn beschermende engel bent. Bedankt voor alle mooie momenten die we samen hebben. Bedankt dat je altijd in me gelooft. Ik kan niet wachten op onze bruiloft volgend jaar en om in te trekken in onze eerste nieuwe huis. Seni seviyorum, iyiki varsın ve herşeyimsin! 
About the Author 


\section{CURRICULUM VITAE}

Ufuk Tan Timur was born on the $9^{\text {th }}$ of May 1989 in Waalwijk, The Netherlands. After graduating cum laude from high school (Gymnasium, Willem van Oranje College, Waalwijk) in 2007, he started with his Medical School Training at the Erasmus University Rotterdam in the Netherlands. During his Medical School Training he was selected for the Erasmus MC Molecular Medicine programme, which is a Master of Science programme which focuses on developments

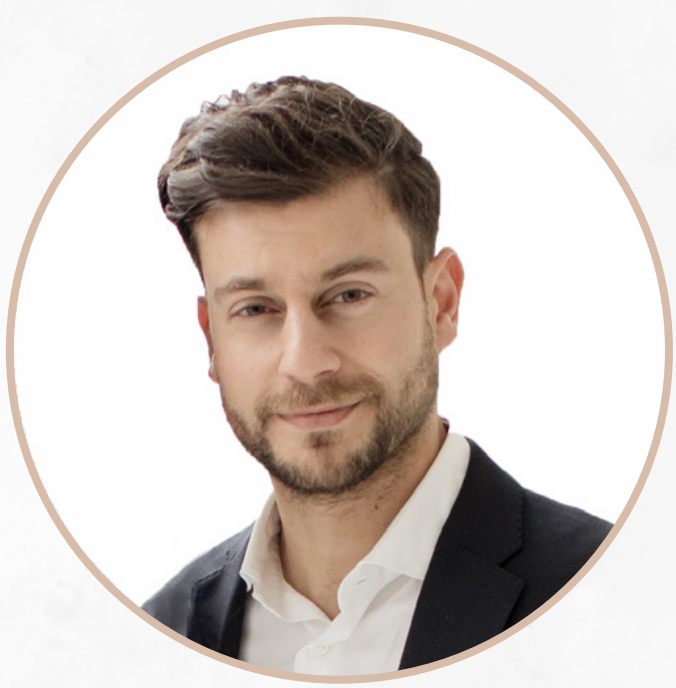
in biomedical science.

As part of his Medical School Training, he started with Orthopaedic Research at the Department of Orthopaedic surgery in Rotterdam, under supervision of prof. dr. ir. H.H. Weinans and dr. H. Jahr. After graduating cum laude from medical school at the Erasmus University in Rotterdam in 2014, he has continued with a research year at the Department of Orthopaedic Surgery in Maastricht to finish his last year of the Molecular Medicine Master of Science Programme. The research he has conducted in Rotterdam and Maastricht led to the start of his PhD training Programme in 2015 at the Department of Orthopaedic Surgery in Maastricht (under supervision of prof. dr. L.W. Van Rhijn, prof. dr. T.J.M. Welting and dr. P.J. Emans) and Uniklinik RWTH in Aachen (under supervision of dr. H. Jahr). To gain clinical experience, he has interrupted his PhD training in 2016 to work as a resident-notin-training at the Department of Orthopaedic Surgery, Maxima Medical Center Veldhoven under supervision of dr. R.P.A. Janssen. In 2017, Ufuk Tan Timur was accepted for the Orthopaedic Surgery Residence Programme in ROGO Zuid. In January 2018, he started his general surgical training at the Catharina Hospital in Eindhoven (under supervision of $d r$. S.W. Nienhuijs). 
He continued his Orthopaedic Surgery Training at the MUMC+ (under supervision of prof dr. L.W. Van Rhijn and dr. H.M. Staal) and currently prolonged his residency at the Maxima Medical Center in Veldhoven (under supervision of dr. R.P.A. Janssen). He is expected to finish his Orthopaedic Training in 2024.

Ufuk Tan Timur has Turkish and Kurdish Roots. He is engaged to Eslem Coban and the wedding is planned in September 2022. 
Welcome to the incredible world of Orthopedic Surgery. Joint pathologies such as knee osteoarthritis are a major public healthcare problem and cause chronic pain and disability worldwide. These pathologies have a huge impact on the health-related quality of life.

In this thesis, author Ufuk Tan Timur offers an insightful look into methods to improve knee joint quality on a micro- and macro-environmental level to combat knee joint pathologies such as cartilage defects and knee osteoarthritis. This thesis will learn you about new insights in improving knee joint quality on the cellular, tissue or total joint level. These insights will contribute to our understanding of joint pathologies and it is expected to aid in developing strategies to treat these joint pathologies. 